Florida International University FIU Digital Commons

6-29-2018

\title{
Spatial and Temporal Patterns of Arctic Nearshore Fish Community and Food Web Structures
}

Mark B. Barton

Florida International University, mbart034@fiu.edu

DOI: $10.25148 /$ etd.FIDC006901

Follow this and additional works at: https://digitalcommons.fiu.edu/etd

Part of the Aquaculture and Fisheries Commons, Biology Commons, Laboratory and Basic Science Research Commons, Marine Biology Commons, Other Ecology and Evolutionary Biology Commons, and the Terrestrial and Aquatic Ecology Commons

\section{Recommended Citation}

Barton, Mark B., "Spatial and Temporal Patterns of Arctic Nearshore Fish Community and Food Web Structures" (2018). FIU Electronic Theses and Dissertations. 3735.

https://digitalcommons.fiu.edu/etd/3735 


\title{
FLORIDA INERNATIONAL UNIVERSITY
}

\author{
Miami, Florida
}

\section{SPATIAL AND TEMPORAL PATTERNS OF ARCTIC NEARSHORE FISH COMMUNITY AND FOOD WEB STRUCTURES}

A dissertation submitted in partial fulfillment of

the requirements for the degree of

DOCTOR OF PHILOSOPHY

in

BIOLOGY

by

Mark B. Barton 
To: Dean Michael R. Heithaus

College of Arts, Sciences and Education

This dissertation, written by Mark B. Barton, and entitled Spatial and Temporal Patterns of Arctic Nearshore Fish Community and Food Web Structures, having been approved in respect to style and intellectual content, is referred to you for judgement.

We have read this dissertation and recommend that it be approved.

$\begin{array}{r}\hline \text { Joel C. Trexler } \\ \hline \text { William T. Anderson } \\ \hline \text { Alastair R. Harborne } \\ \hline \text { Alexei I. Pinchuk } \\ \hline \text { Kevin M. Boswell, Major Professor }\end{array}$

Date of Defense: June 29, 2018

The dissertation of Mark B. Barton is approved.

Dean Michael R. Heithaus

College of Arts, Sciences and Education

Andrés G. Gil

Vice President of Research and Economic Development and Dean of the University Graduate School

Florida International University, 2018 


\section{COPYRIGHT PAGE}

The chapter listed below are published, submitted, or in prep for peer-reviewed journals. The journal "Polar Biology" published by Spinger International Publishing allow use of published articles for educational use at the home institution, Florida International University. Chapters II, IV, V and VI have been formatted for publication in the journals where they are submitted in prep. Chapter III is currently in review at the "Journal of Experimental Marine Biology and Ecology", and has been formatted according to the publication guidelines of the respective journal.

CHAPTER II: Barton MB, Heintz RA, Norcross BL, Vollenweider JJ, and Boswell KM. Spatiotemporal variation of environmental conditions and prey availability that drive Arctic nearshore fish beta diversity in the Point Barrow, AK region. In Prep, Deep Sea Research II: Topical Studies in Oceanography.

CHAPTER III: Barton MB, SY Litvin, KM Boswell, JJ Vollenweider, RA Heintz, BL Norcross, C Li. Experimental determination of isotope tissue turnover rates and trophic discrimination factors for Arctic sculpin (Myoxocephalus scorpioides): a common Arctic nearshore fish. In Review. Journal of Experimental Marine Biology and Ecology.

CHAPTER IV: Barton MB, KM Boswell, RA Heintz, JJ Vollenweider, BL Norcross, L Sousa. Investigating seasonal variation in prey resources usage using tissue-specific stable isotope analysis in nearshore sculpin species. In Prep. Canadian Journal of Fisheries and Aquatic Sciences.

CHAPTER V: Barton MB, KM Boswell, JJ Vollenweider, RA Heintz, JR Moran. Latitudinal dependence of body condition, growth rate, and stable isotopes of juvenile capelin (Mallotus villosus) in the Bering and Chukchi Seas. Polar Biology; October 2016. doi: $10.1007 / \mathrm{s} 00300-016-2041-8$

CHAPTER VI: Barton MB, KM Boswell, JJ Vollenweider, RA Heintz, BL Norcross, L Sousa. Implications of trophic discrimination factor selection for stable isotope food web models of low trophic levels in the Arctic nearshore. In Review. Ecology Letters.

CHAPTER VII: Barton MB, KM Boswell, JJ Vollenweider, RA Heintz, BL Norcross, L Sousa. Food web dynamics of trophic niche space and basal resource dependence in Arctic nearshore fish communities. In Prep. Deep Sea Research II: Topical Studies in Oceanography.

All other materials () Copyright 2018 by Mark B. Barton

All rights reserved. 


\section{DEDICATION}

For my family, friends, and loved ones, and everyone who helped me along the way. 


\section{ACKNOWLEDGMENTS}

When I was nearing the end of my undergraduate degree, I really didn't know what

I wanted to do. I knew I loved science and research, and like most bright-eyed senior undergraduates, I knew I wanted to make a difference in the world. There were a few individuals that I owe thanks to for directing me down the road to graduate school, even though there were tougher and more challenging times during which I would have cursed them for it... but all in all I am grateful! A few professors that really excited me about the field include Mike Parsons, Greg Tolley, Serge Thomas, and Michael Savarese at Florida Gulf Coast University. The Parsons Lab gave me experience in the field and allowed me to develop my own research project, which really motivated me to continue in the field of ecology. However, it wasn't until my good friend Alex Leynse and I were having a heartfelt (and slurred) conversation, under the stars at the Florida Key's Marine Lab, about the current state of scientific knowledge, that it occurred to me what my next chapter would be, so thanks for that buddy!

I also want to thank my advisor, Kevin Boswell, for somewhat blindly taking me under his wing without really know what he was getting into. We had similar interests, and I guess he saw something in me... or maybe he just needed to fill up his relatively new lab... regardless of how this relationship started, I think we are both proud and excited about what came out of it in the end. I didn't even know what project I would be working on when he sponsored my application to FIU, but we said we would figure it out. When he told me that I would work in the Arctic, I was ecstatic! I never thought I would get to see the Arctic circle, let alone spend months of my life there. 
I got so much more out of my work in Utqiagivik than just this dissertation, I found a new family. The ARFies, as we call ourselves, made life exciting in a relatively drab city with very little to do. Movie night (every night) at the ARF kept me sane during those long field seasons. Thank you, Ann Robertson for being the biggest pain-in-the-behind I have ever had the pleasure of working with. Our different strengths, opinions, approaches, and our 'old married couple' style bickering ended up making us an effective team, and we really got a lot done together. Thank you, Sam George a.k.a. RatchetLad for being the best field tech anyone could ever ask for. Even after you had worked way more than the hours we were paying you for, you were always eager to help, and always eager to celebrate a job well done any chance we got. RatchetMan couldn't be prouder of his disciple! And that brings me to Yosty Storms a.k.a. RatchetLass... what a truly wonderful human being you are! I have never met anyone so positive and happy as you. Living with you in the ARF and having you volunteer with us in the field was always a joy. And Bree Zenone, what can I say about you... I think the best way to describe our relationship is a sibling rivalry. You have given me as much grief as you have joy. I am sorry, I almost killed you when you ate my steak... hopefully a lifelong lesson for you: never eat a fat man's steak! Especially when it's purchased in a remote place like Utqiagvik for a ridiculously inflated price. But thanks for all your help out there, I know it wasn't even your project and you came just to help out the lab, and I am truly grateful for that! And of course, the parents of the ARFie family, Raphaela Stimmelmayr and Maureen Sullivan. Raphi, you are one of the best scientists I know! As accomplished as you are, you always remain humble, and are never too busy to talk about science with up and coming scientists. It may not have meant much to you, but your constant interest in our work, and asking me questions about 
fish, made me feel like I was doing something that mattered. And Maureen, you weren't in the ARF with us for long, but you remain a part of the family, and your fun-loving attitude always brightens my day! I look forward to another get together in Naples!

I also need to thank all of the people in Utqiagivik that supported us. North Slope Borough played a huge part in our efforts and we could not have done all this work without their assistance. Thank you, Craig George, for always being upbeat and supporting our project, and for letting me play your guitars every time I visited your house (you may not have known I was doing that... so now you know... that custom one with the star inlays is amazing!). Leandra Sousa and Todd Sformo thank you for sharing data and collaborating with us. Bobby the ARF manager, thanks for letting me make a mess in the garage and use your tools while fixing our four-wheelers that were somehow always breaking, and for putting up with my messiness. I would also like to thank the Tuzzy Consortium Library for working together with us on several outreach events! And a special thanks to Craig Tweedie's and Vanessa Lougheed's labs from University of Texas El Paso for collaborating with us and helping any way that they could. Don't worry guys, we will keep trying on that proposal, we will get it sooner or later!

Jumping back to Florida, I want to thank all of the Boswell Lab for their support, especially the undergraduate interns that put in countless hours (mostly for free) to process samples and even develop some of their own side projects. Robert Darcy, Mark Kleese, Alex Brownstein, Andrea Nodal, David Block, Katrina Abel, and Daniel Correia, thank you for all of your hard work. Thanks to all of the amazing people I have had the pleasure of getting to know over the years, and the FamBam (Ben Binder, Monica Castillo, and 
Katrina Abel) for all of the amazing adventures and good times. This is not the end of the Fantastic Four FamBam Feets, let's get another trip on the books! Thanks, Danny Perez, for showing me the way in the woods! Having an excuse to think about terrestrial ecosystems instead of marine ecosystems provided some much-needed balance in my life. I am sure the deer are thinking about us as much as we think about them! All of my brothers from another mother back home in The Netherlands, thanks for always being supportive and letting me chase my dream! And thanks to my band for being understanding when I left you guys to move to the states and become a marine biologist. "I always promised myself to try and be all that I can be. I'm always searching and never satisfied." You know you all mean the world to me...SFD for life! My true biological family back in Europe, thanks for all of your love and support! Thanks, Mom and Dad for bailing me out on numerous occasions when my luxurious graduate student salary wasn't quite cutting it. I can't wait to see you all for graduation!

I can't forget all of my co-authors and PI's on the project. Thank you all for editing and teaching me a thing or two about how to be a better writer. I hope some of those lessons come through in this dissertation. Thanks to my graduate committee for helping me develop my ideas over the years, and jumping through the paperwork hoops with me. I also want to thank the FIU SERC stable isotope lab and John Harris for always doing their best to get our sample data back in time, even though we sometimes had unrealistic deadlines. And finally, our funding sources; this work was supported by the North Pacific Research Board (grant number 1229, 2012); Bureau of Ocean Energy Management (BOEM), Cooperative Agreement Contract Nos. M12PG00024 (ACES), and M12PG00018 (Arctic EIS) of the U.S. Department of the Interior (Cooperative Agreement Contract 
\#M12PG00024, \#M12PG00018). Furthermore, I would like to thank FIU for providing funding from the Dissertation Year Fellowship, allowing me to write my dissertation in peace.

There are so many people to acknowledge, and I have undoubtedly forgotten someone. However, if you have helped me, you know who you are, and I appreciate all of your efforts! 


\begin{abstract}
OF THE DISSERTATION
SPATIAL AND TEMPORAL PATTERNS OF ARCTIC NEARSHORE FISH

COMMUNITY AND FOOD WEB STRUCTURES

by
\end{abstract}

Mark B. Barton

Florida International University, 2018

Miami, Florida

Professor Kevin M. Boswell, Major Professor

Climate change and increasing anthropogenic activities are causing rapid changes to environmental and ecological processes in the Arctic Ocean. To better understand these changes, scientists have increased research efforts in these regions, but to date the number of studies on Arctic nearshore habitats are lacking. My dissertation responds to the paucity of information and investigates patterns in Arctic nearshore fish communities and food webs to gain insight to how these ecosystems may shift as these changes continue. I used multivariate statistical analysis to examine patterns in community structure and composition to determine that Arctic nearshore fish communities are largely driven by prey availability, salinity and temperature; and that species that are more abundant in warmer conditions are likely to increase in abundance as climatic conditions in the Arctic continue to warm. I improved the ability to apply stable isotope methods to Arctic food web studies by determining more appropriate model parameters using a laboratory-based isotope study on a common Arctic nearshore fish, and discuss its potential as a biological monitor 
species. These new parameters are used to confirm that a shift in prey resource dependence occurs across the seasonal shift from ice-covered winter to open-water summer conditions. Changes in basal resource dependence also occur later in the season across a latitudinal gradient where a shift to dependence on allochtonous inputs from nearby rivers increased trophic diversity. Using isotopic niche space theory, it was determined that the Arctic nearshore has a diverse prey base but that niche spaces of Arctic warm-water and coldwater species do overlap, and if numbers of warm-water fish continue to increase it will likely increase competition for resources for potentially less-adaptable, well-established, cold-water forage fish. On the other hand, if pelagic productivity is expected to increase and support larger fish biomasses, then there will be more than enough resources for warmwater and cold-water species to coexist, thus creating a more diverse prey base for piscivores in the Arctic. 


\section{TABLE OF CONTENTS}

CHAPTER

PAGE

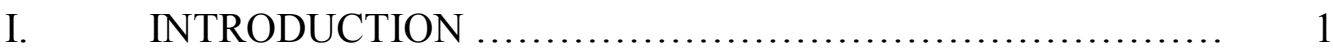

References ......................................... 7

II. SPATIOTEMPORAL VARIATION OF ENVIRONMENTAL CONDITIONS AND PREY AVAILABILITY THAT DRIVE ARCTIC NEARSHORE FISH COMMUNITY STRUCTURE IN THE POINT BARROW, AK REGION ...................... 9

Abstract ................................................ 10

Introduction ........................................ 10

Methods ................................................ 13

Results ............................................... 22

Discussion ............................................. 28

References ........................................... 35

III. EXPERIMENTAL DETERMINATION OF TISSUE TURNOVER RATES AND TROPHIC DISCRIMINATION FACTORS FOR STABLE CARBON AND NITROGEN ISOTOPE RATIOS FOR ARCTIC SCULPIN (MYOXOCEPHALUS SCORPIOIDES): A COMMON ARCTIC NEARSHORE FISH ................................ 50

Abstract .......................................... 51

1. Introduction ..................................... 51

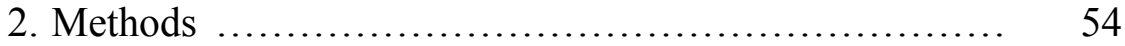

3. Results ................................................ 64

4. Discussion ........................................... 67

5. Bibliography .................................... 75

IV. IDENTIFYING A SHIFT IN BASAL RESOURCE DEPENDENCE USING TISSUE-DEPENDENT CARBON AND NITROGEN ISOTOPES IN SCULPINS FROM ARCTIC NEARSHORE SURROUNDING POINT BARROW, AK ...... 85

Abstract .................................................... 86

Introduction ........................................... 86

Methods .................................................. 89

Results ............................................... 92

Discussion ............................................ 93

References .......................................... 99 
V. LATITUDINAL DEPENDENCE OF BODY CONDITION, GROWTH RATE, AND STABLE ISOTOPES OF JUVENILE CAPELIN (MALLOTUS VILLOSUS) IN THE BERING AND CHUKCHI SEAS (PUBLISHED)

Abstract ................................................... 110

Introduction .......................................... 110

Materials and Methods ....................................... 114

Results ................................................... 118

Discussion ............................................ 121

References ........................................... 132

VI. IMPLICATIONS OF TROPHIC DISCRIMINATION FACTOR SELECTION FOR STABLE ISOTOPE FOOD WEB MODELS OF LOW TROPHIC LEVELS IN THE ARCTIC NEARSHORE Abstract ................................................ 148

Introduction ........................................... 148

Methods ................................................. 151

Results .................................................. 155

Discussion ................................................ 156

References ............................................ 160

VII. FOOD WEB DYNAMICS OF TROPHIC NICHE SPACE AND BASAL RESOURCE DEPENDENCE IN ARCTIC NEARSHORE FISH COMMUNITIES ........................ 167 Abstract ............................................ 168

Introduction ............................................. 168

Methods .................................................... 173

Results ............................................. 178

Discussion ........................................ 181

References ................................................ 187

VIII. CONCLUSIONS ........................................... 199

References ............................................... 204

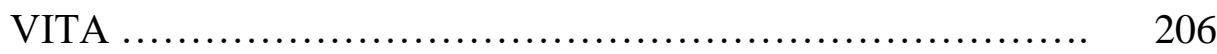


2.1 A summary of fish species and abundances used in CCA analyses. The Centroid Label column refers to the label used in CCA ordination plots for each of the species centroids. ..................

2.2 A summary of all variables included in the study. The variables highlighted in color are those which were selected as the most explanatory significant variables for each variable type (environmental, spatial, and temporal) using the forward selection process outlined by Blanchet et al. (2008). Only those variables which were selected were assigned labels, which are used as shorthand in subsequent CCA ordination plots as well as discussion of those variables. The Explanatory Matrix column indicates the fundamental explanatory matrix in which each variable was included, and the highlighter color corresponds to the same colored

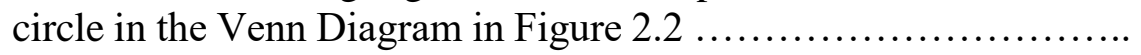

3.1 Exponential growth model parameters for all 12 models fit to isotopic ratios of carbon and nitrogen in tissues of Arctic Sculpin (Myoxocephalus scorpioides) fed the high-lipid fish (HLF) and low-lipid krill (LLK) diets. For $\delta^{13} \mathrm{C}$ in fin tissues on the HLF diet, the model did not fit the data properly (indicated by the negative $\lambda$ value) and thus further parameters were not calculated. a is the difference in \%o between $\delta_{0}$ and the steady-state final isotope ratio, and $\mathrm{c}$ is the steady-state final isotope ratio of the subject tissue (equation 3.4). $\mathrm{t}_{0.5}(\mathrm{k}+\mathrm{m})$, and $\mathrm{t}_{0.1}(\mathrm{k}+\mathrm{m})$ are the number of days taken to reach $50 \%$ and $90 \%$ isotopic turnover, respectively (equation 3.5). TDF is the trophic discrimination factor derived using equation $3.11 \mathrm{k}$ is the overall growth rate constant derived using equation 3.8, and $\mathrm{m}$ is the metabolic rate constant or the difference between $\lambda$ and $\mathrm{k} . \mathrm{P}_{\mathrm{g}}$ and $\mathrm{P}_{\mathrm{m}}$ are the proportion of isotopic turnover driven by growth and metabolism, respectively (equation 3.9 and 3.10). Finally, $\mathrm{t}_{0.1} \mathrm{k}$ and $\mathrm{t}_{0.1} \mathrm{~m}$ are the estimated number of days it would take to reach $90 \%$ isotopic turnover if turnover was solely driven by metabolism.

*LLK-fed sculpin experienced a diet switch 36 days before the start of the experiment (from wild food to the low-lipid krill diet). Therefore, the parameters estimated from those models are only used for discussion of influence of growth vs. metabolism..........

4.1 A summary of isotopic signatures in muscle and liver tissues of the five species of Arctic nearshore sculpin included in this study....... 
5.1 Details of sample sizes and regional group differentiation. Throughout this paper, "regional group" refers to the 7 groups differentiated by symbols.

6.1 Results from the literature searches on Google Scholar@ and Research Gate (O). "Field Isotopes" experiment type refers to the deduction of TDFs from isotope ratios of species collected in a field study. These deductions require the assumption that the consumer species is a specialist feeding only on the prey species. "Lab based" experiment type refers to controlled experiments where the isotopic ratio of food was known and controlled. $\Delta^{15} \mathrm{~N}$ and $\Delta \Delta^{13} \mathrm{C}$ are the differences in $\delta^{15} \mathrm{~N}$ and $\delta^{13} \mathrm{C}$ between prey and consumer. TDS is the Trophic Discrimination Slope, calculated from the TDFs from each study $\left(\Delta^{15} \mathrm{~N} / \Delta^{13} \mathrm{C}\right)$

7.1 A summary of the stable isotope data, lipid content, length, mass, and estimated trophic positions. Errors represent standard deviation, except for $\delta^{15} \mathrm{~N}$ and $\delta^{13} \mathrm{C}$, where it represents standard error. The top section comprises fish, middle section is benthic crustaceans, and the bottom is zooplankton. ' $n$ ' represents the number of samples that were analyzed. ' $\% \mathrm{~N}$ ', ' $\% \mathrm{C}$ ', and ' $\mathrm{C} / \mathrm{N}$ ' are the percentages of nitrogen and carbon in the samples, and the ratio of the two. $\%$ Lipid' is an estimate of lipid content based on the $\mathrm{C} / \mathrm{N}$ ratios as described in equation 3. Each column of trophic positions are the trophic positions calculated for each species using the baseline $\delta^{15} \mathrm{~N}$ values from each of the three basal resources (TERA $=$ Terrestrial Material, PRIM = Pelagic Primary Producers, ICEA = Ice Algae). .

7.2 A summary of isotopic signatures by year for the six species for which samples were available from all three sampling years. Values in parentheses are standard deviations. 
FIGURE

\section{LIST OF FIGURES}

2.1 A map of the study area and relevant geographic and oceanographic features. Sampling stations are depicted by circles: blue (Chukchi Sea), green (Beaufort Sea), and red (Elson Lagoon). The prevalent flow of the Alaska Coastal Current (ACC) is depicted by red arrows traveling along the Alaskan coast north past Point Barrow through the Barrow Canyon. The Beaufort Gyre moved water in a clockwise direction (westward) along the Beaufort Sea continental shelf (yellow arrows). The prevalent wind driven flow along the Beaufort coast and through the Elson Lagoon out Eluitkak Pass is depicted

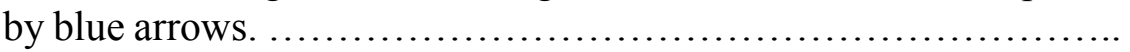

2.2 A modification of Anderson and Cribble's (1998) representation of variance in species abundance (yellow circle) explained by three fundamental variable matrices: ENV in Green, SPT in Brown, and TMP in Blue. The Model Equation column indicates which variable matrix was used to constrain the model, and which matrices were conditioned out (represented by subtraction). The Diagram Compartments column represents the variance compartments in the Venn Diagram explained by each model. The following three columns (Constrained, Conditioned, and Unconstrained Inertia) represent the portion of the total inertia (5.038) that is constrained, conditioned or unconstrained in each model.

2.3 Beach Oriented Wind Direction (BOWD) was derived for each survey station. The red arrows represent the structure of the BOWD variable. During an onshore wind the beach is exposed to waves and thus these winds are scored higher (up to $90^{\circ}$ ), an offshore wind renders the beach sheltered and thus this has the lower scores (down to $-90^{\circ}$ ), and a longshore wind is ranked neutrally at $0^{\circ}$. The yellow and purple arrows and compasses show how a North wind $\left(360^{\circ}\right)$ can have opposite angles to two beaches on either side of a barrier island. In Yellow, the compass indicates that the beach is oriented in a Northeasterly direction, such as our Beaufort Sea stations. In this case, a North wind $\left(360^{\circ}\right)$ would result in an onshore wind at a $45^{\circ}$ angle to the beach. However, if sampling from Southwesterly facing beach such as the Elson Lagoon stations on the inside of the Eluitkak Pass, this same North wind would result in an offshore wind at $45^{\circ}$. This exemplifies the importance of accounting for beach orientation when considering wind direction. 
2.4 A CCA ordination plot constrained by all three explanatory matrices (ENV, SPT, and TMP). Ellipses represent standard deviation from the waterbody centroids: Blue is Chukchi Sea, Green is Beaufort Sea, and Red is Elson Lagoon. Black labels are species centroids: ACOD (Arctic Cod), SALA (Arctic Sand Lance), SHAN (Arctic Shanny), ARSM (Arctic Smelt), BESC (Belligerent Sculpin), FHSC (Fourhorn Sculpin), UNSC (Larval Sculpin), CAPE (Pacific Capelin), SCOD (Saffron Cod), SLEB (Slender Eelblenny), CISC (Ciscos), FLAF (Flatfishes), ASHS (Arctic/Shorthorn Sculpin), POAC (Poachers), SNFI (Snailfishes). Purple vectors represent variable axes, the length of the vector represents the strength of that variables influence on species centroid position in ordination space. Years were used as categorical variables, and thus 2013, 2014, and 2015 are displayed as centroid centers. .............................................

2.5 A CCA ordination plot constrained only by ENV. Ellipses represent standard deviation from the waterbody centroids: Blue is Chukchi Sea, Green is Beaufort Sea, and Red is Elson Lagoon. Black labels are species centroids: ACOD (Arctic Cod), SALA (Arctic Sand Lance), SHAN (Arctic Shanny), ARSM (Arctic Smelt), BESC (Belligerent Sculpin), FHSC (Fourhorn Sculpin), UNSC (Larval Sculpin), CAPE (Pacific Capelin), SCOD (Saffron Cod), SLEB (Slender Eelblenny), CISC (Ciscos), FLAF (Flatfishes), ASHS (Arctic/Shorthorn Sculpin), POAC (Poachers), SNFI (Snailfishes). Purple vectors represent variable axes, the length of the vector represents the strength of that variables influence on species centroid position in ordination space. .............................

2.6 A CCA ordination plot constrained only by SPT. Ellipses represent standard deviation from the waterbody centroids: Blue is Chukchi Sea, Green is Beaufort Sea, and Red is Elson Lagoon. Black labels are species centroids: ACOD (Arctic Cod), SALA (Arctic Sand Lance), SHAN (Arctic Shanny), ARSM (Arctic Smelt), BESC (Belligerent Sculpin), FHSC (Fourhorn Sculpin), UNSC (Larval Sculpin), CAPE (Pacific Capelin), SCOD (Saffron Cod), SLEB (Slender Eelblenny), CISC (Ciscos), FLAF (Flatfishes), ASHS (Arctic/Shorthorn Sculpin), POAC (Poachers), SNFI (Snailfishes). Purple vectors represent variable axes, the length of the vector represents the strength of that variables influence on species centroid position in ordination space ............................. 
2.7 A CCA ordination plot constrained only by TMP. Ellipses represent standard deviation from the waterbody centroids: Blue is Chukchi Sea, Green is Beaufort Sea, and Red is Elson Lagoon. Black labels are species centroids: ACOD (Arctic Cod), SALA (Arctic Sand Lance), SHAN (Arctic Shanny), ARSM (Arctic Smelt), BESC (Belligerent Sculpin), FHSC (Fourhorn Sculpin), UNSC (Larval Sculpin), CAPE (Pacific Capelin), SCOD (Saffron Cod), SLEB (Slender Eelblenny), CISC (Ciscos), FLAF (Flatfishes), ASHS (Arctic/Shorthorn Sculpin), POAC (Poachers), SNFI (Snailfishes). Purple vectors represent variable axes, the length of the vector represents the strength of that variables influence on species centroid position in ordination space. Years were used as categorical variables, and thus 2013, 2014, and 2015 are displayed as centroid centers.

2.8 A CCA ordination plot constrained only by ZOOP. Ellipses represent standard deviation from the waterbody centroids: Blue is Chukchi Sea, Green is Beaufort Sea, and Red is Elson Lagoon. Black labels are species centroids: ACOD (Arctic Cod), SALA (Arctic Sand Lance), SHAN (Arctic Shanny), ARSM (Arctic Smelt), BESC (Belligerent Sculpin), FHSC (Fourhorn Sculpin), UNSC (Larval Sculpin), CAPE (Pacific Capelin), SCOD (Saffron Cod), SLEB (Slender Eelblenny), CISC (Ciscos), FLAF (Flatfishes), ASHS (Arctic/Shorthorn Sculpin), POAC (Poachers), SNFI (Snailfishes). Purple vectors represent variable axes, the length of the vector represents the strength of that variables influence on species centroid position in ordination space. ...........

2.9 A CCA ordination plot constrained by ZOOP, with partial contributions from $\mathrm{ENV}_{\text {zoop }}+\mathrm{SPT}_{\text {zoop }}+\mathrm{TMP}_{\text {zoop }}$ conditioned out. Ellipses represent standard deviation from the waterbody centroids: Blue is Chukchi Sea, Green is Beaufort Sea, and Red is Elson Lagoon. Black labels are species centroids: ACOD (Arctic Cod), SALA (Arctic Sand Lance), SHAN (Arctic Shanny), ARSM (Arctic Smelt), BESC (Belligerent Sculpin), FHSC (Fourhorn Sculpin), UNSC (Larval Sculpin), CAPE (Pacific Capelin), SCOD (Saffron Cod), SLEB (Slender Eelblenny), CISC (Ciscos), FLAF (Flatfishes), ASHS (Arctic/Shorthorn Sculpin), POAC (Poachers), SNFI (Snailfishes). Purple vectors represent variable axes, the length of the vector represents the strength of that variables influence on species centroid position in ordination space. ........... 
3.1 Exponential growth models (Equation 3 ) fit to the isotopic ratios of nitrogen $\left(\delta^{15} \mathrm{~N}\right.$; A and C) and carbon $\left(\delta^{13} \mathrm{C}\right.$; B and D) for Arctic Sculpins (Myoxocephalus scorpioides) on the High-Lipid Fish diet (A and B) and Low-Lipid Krill diet (C and D) across the 147-day study period. Gray points and lines represent isotope ratios in fin tissue, black represents liver, open black circles and dashed lines represent muscle. Arctic Sculpin on the LLK diet (solid circles and lines) did not have a diet switch on day 0. Further model parameters are displayed in table 1 . The exponential growth model either had poor fits or could not be fit to carbon isotope ratios for sculpin on the HLF diet.

3.2 Linear regressions of bulk $\delta^{13} \mathrm{C}$ vs. lipid corrected $\delta^{13} \mathrm{C}$ (protein) of liver (black; $\mathrm{R}^{2}=0.59$ ) than those of fin (gray) and muscle (open

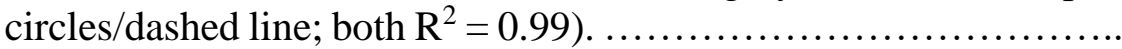

3.3 Individual growth rate constants (k') plotted for individuals across the 147 days of experimentation. Open circles represent high-lipid fish fed sculpin and solid circles represent low-lipid krill fed sculpin.

4.1 A map of Point Barrow showing the geography of the three waterbodies from which fish were collected. Stations marked by a circle $(\bullet)$ were those in the Chukchi Sea waterbody, triangles $(\boldsymbol{\Delta})$ were those in the Beaufort Sea, and squares ( $\mathbf{(})$ in the Elson Lagoon.

4.2 A biplot of average carbon and nitrogen isotope signatures in muscle (white) and liver (black). Error bars represent standard error. Averages and standard errors were calculated from muscle and liver tissues from 35 Arctic Sculpin (Myoxocephalus scorpioides), 7 Belligerent Sculpin (Megalocottus platycephalus), 9 Fourhorn Sculpin (Myoxocephalus quadricornis), 7 Plain Sculpin (Myoxocephalus jaok), 4 Shorthorn Sculpin (Myoxocephalus scorpius). The arrows show the isotopic shift from muscle to liver tissues, representing the shift in dietary carbon and nitrogen between ice-covered winter and open-water summer, respectively. 
4.3 A scatter plot representing the difference in carbon isotope ratios in muscle (white) and liver (black) for each species. Error bars represent standard error. Averages and standard errors were calculated from muscle and liver tissues from 35 Arctic Sculpin (Myoxocephalus scorpioides), 7 Belligerent Sculpin (Megalocottus platycephalus), 9 Fourhorn Sculpin (Myoxocephalus quadricornis), 7 Plain Sculpin (Myoxocephalus jaok), 4 Shorthorn Sculpin (Myoxocephalus scorpius). The difference between the white and black points represent the isotopic shift $\left(\delta^{13} \mathrm{C}\right)$ from muscle to liver tissues, respectively, which represents the shift in dietary carbon between ice-covered winter and open-water summer. ..............

4.4 A scatter plot representing the difference in nitrogen isotope ratios in muscle (white) and liver (black) for each species. Error bars represent standard error. Averages and standard errors were calculated from muscle and liver tissues from 35 Arctic Sculpin (Myoxocephalus scorpioides), 7 Belligerent Sculpin (Megalocottus platycephalus), 9 Fourhorn Sculpin (Myoxocephalus quadricornis), 7 Plain Sculpin (Myoxocephalus jaok), 4 Shorthorn Sculpin (Myoxocephalus scorpius). The difference between the white and black points represent the isotopic shift $\left(\delta^{15} \mathrm{~N}\right)$ from muscle to liver tissues, respectively, which represents the shift in dietary nitrogen between ice-covered winter and open-water summer.

5.1 Map of Alaskan waters showing sampling locations of juvenile capelin collected. Filled shapes represent the Chukchi Sea stations, open shapes represent Bering Sea stations. Like symbols represent regional groups of fish at similar latitudes. The numbers in parentheses after each river represent the individual annual discharge $\left(\mathrm{km}^{3} \mathrm{yr}^{-1}\right)$ of each river (Benke and Cushing, 2006; Nemeth et al., 2014). This map was produced with the CRAN-R package "Rgooglemaps" (Loecher and Ropkins, 2015).

5.2 Linear regression between energy density and RNA/DNA ratios were strongly correlated $\left(A ; R^{2}=0.3163, p<0.0001\right)$. A linear regression between $\delta^{13} \mathrm{C}$ and $\delta^{15} \mathrm{~N}$ shows a strong negative

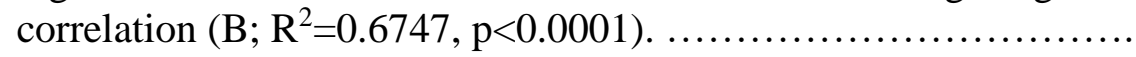


5.3 General Additive Models for energy density (A), RNA/DNA Ratios (B), $\delta^{13} \mathrm{C}(\mathrm{C})$ and $\delta^{15} \mathrm{~N}(\mathrm{D})$ for all juvenile capelin with a smoothing function on latitude. All models were created using cubic splines were used with 5 knots $($ edf $=4)$ for Energy Density and RNA/DNA ratios, and 4 knots (edf $=3$ ) for $\delta^{13} \mathrm{C}$ and $\delta^{15} \mathrm{~N}$. The dashed lines represent the $95 \%$ confidence interval. Each model was significant with varying levels of deviance explained $\left(A: R^{2}=0.34, p<0.0001\right.$; $\mathrm{B}: \mathrm{R}^{2}=0.14, \mathrm{p}=0.01 ; \mathrm{C}: \mathrm{R}^{2}=0.54, \mathrm{p}<0.0001 ; \mathrm{D}: \mathrm{R}^{2}=0.67$, $\mathrm{p}<0.0001)$. The bold tick marks above the $\mathrm{x}$-axis represent latitudes at which fish samples were collected. .............................

5.4 Linear regressions of energy density (A), RNA/DNA Ratios (B), $\delta^{13} \mathrm{C}(\mathrm{C})$ and $\delta^{15} \mathrm{~N}$ (D) with latitude. The northern-most sampling stations (Point Barrow group: $\mathbf{\square})$ and the southern-most sampling stations (Bristol Bay group: $\diamond$ ) were removed as outliers for the analysis. Energy density was strongly correlated $\left(\mathrm{R}^{2}=0.36\right.$, $\mathrm{p}<0.0001)$ with latitude, but RNA/DNA ratios were not $\left(\mathrm{R}^{2}=0.06\right.$, $\mathrm{p}=0.05) . \quad \delta^{13} \mathrm{C}$ is negatively correlated and $\delta^{15} \mathrm{~N}$ is positively correlated with latitude $\left(\mathrm{R}^{2}=0.55, \mathrm{p}<0.0001 ; \mathrm{R}^{2}=0.75, \mathrm{p}<0.0001\right.$; respectively). Station symbology: Wainwright inlet $(\bullet)$, Point Hope $(\boldsymbol{\Delta})$, Kotzebue Sound $(\bullet)$, Norton Sound $(\nabla)$, and Nunivak Island (口).

5.5 General Additive Models for energy density (A), RNA/DNA Ratios (B), $\delta^{13} \mathrm{C}(\mathrm{C})$ and $\delta^{15} \mathrm{~N}$ (D) for all juvenile capelin with a smoothing function on temperature. All models were created using cubic splines were used with 5 knots $($ edf $=4)$ for Energy Density, and 4 knots (edf $=3$ ) for RNA/DNA ratios, $\delta^{13} \mathrm{C}$ and $\delta^{15} \mathrm{~N}$. The dashed lines represent the $95 \%$ confidence interval. All models were significant with varying levels of deviance explained $\left(A: R^{2}=0.15\right.$, $\mathrm{p}<0.0001 ; \mathrm{B}: \mathrm{R}^{2}=0.28, \mathrm{p}<0.0001 ; \mathrm{C}: \mathrm{R}^{2}=0.31, \mathrm{p}<0.0001 ; \mathrm{D}: \mathrm{R}^{2}=$ $0.30, \mathrm{p}<0.0001)$. The bold tick marks above the $\mathrm{x}$-axis represent latitudes at which fish samples were collected.

5.6 GAM of surface temperature with a smoothing function on latitude. The non-linear relationship shows that there is no discernable trend between surface temperature and latitude. The dashed lines represent the $95 \%$ confidence intervals. Cubic splines were used with 5 knots (edf $=4)$, the GAM explains $28.8 \%$ of the deviance and the relationship was found to be significant $(\mathrm{p}<0.0001)$. The bold tick marks above the $\mathrm{x}$-axis represent latitudes at which fish samples were collected. 
5.7 Average contributions by weight of prey type in the stomach contents of the analyzed capelin for 6 of the 7 regional groups identified in Table 1. Cal = Calanus spp. copepod. No stomach contents data was available for the Norton Sound Group.

6.1 A map of the study area and relevant geographic and oceanographic features. Sampling stations are depicted by circles: blue (Chukchi Sea), green (Beaufort Sea), and red (Elson Lagoon). The prevalent flow of the Alaska Coastal Current (ACC) is depicted by red arrows traveling along the Alaskan coast north past Point Barrow through the Barrow Canyon. The prevalent wind driven flow along the Beaufort coast and through the Elson Lagoon out Eluitkak Pass is depicted by blue arrows.

164

6.2 Graphical representations of trophic level niche spaces estimated from published trophic discrimination factors (TDF) of four Arctic species; Polar Bears (Ursus maritimus; A), Harp Seals (Pagophilus groenlandicus; B), Amphipods (Ampelisca macrocephala; C), Chaetognaths (Parasagitta elegans; D). The data points are measured carbon and nitrogen isotope values of fish and zooplankton collected from the Arctic nearshore in 2013 and 2014. The blue ellipses represent the measured trophic niche space of all fish, and the green, yellow, and red ellipses represent the estimated trophic niche space of their prey resources at 1,2, and 3 trophic levels below the fish, respectively. ..............................

6.3 Graphical representations of trophic level niche spaces estimated from the trophic discrimination factors (TDF) of Arctic Sculpin (Myoxocephalus scorpioides; Chapter III). The data points are measured carbon and nitrogen isotope values of fish and zooplankton collected from the Arctic nearshore in 2013 and 2014. The blue ellipse represents the measured trophic niche space of all fish, and the green, yellow, and red ellipses represent the estimated trophic niche space of their prey resources at 1,2, and 3 trophic levels below the fish, respectively. ..............................

7.1 A map of the study area and relevant geographic and oceanographic features. Sampling stations are depicted by circles: blue (Chukchi Sea), green (Beaufort Sea), and red (Elson Lagoon). The prevalent flow of the Alaska Coastal Current (ACC) is depicted by red arrows traveling along the Alaskan coast north past Point Barrow through the Barrow Canyon. The prevalent wind driven flow along the Beaufort coast and through the Elson Lagoon out Eluitkak Pass is depicted by blue arrows. ....................................... 
7.2 The average trophic niche spaces occupied by each species. Error bars represent standard error. Colors are grouped by groups functional species groups identified by in Chapter II: Red (anadromous and estuarine fish), green (Arctic cold-water fish), blue (Arctic warm-water fish), gray (benthic crustaceans), brown (zooplankton). Ellipses represent the trophic groups for which niche space was investigated separately. ..............................

7.3 Isotope ratios for all individuals in Trophic Group 1-4, BCRU, and ZOOP in $\delta^{13} \mathrm{C}-\delta^{15} \mathrm{~N}$ space in relation to estimated trophic niche space of trophic pathways that depend on Terrestrial Materials (TERA), Pelagic Primary Producers (PRIM), and Ice Algae (ICEA). Data point shape and color match throughout Figures 7.2, 7.3, and 7.5. Color represents functional species groups derived in Chapter II: red (anadromous and estuarine fish), green (Arctic coldwater fish), blue (Arctic warm-water fish), gray (benthic crustaceans), brown (zooplankton). ................................

7.4 Isotope ratios for all individuals in $\delta^{13} \mathrm{C}-\delta^{15} \mathrm{~N}$ of the two species that exhibit significant difference between trophic niche space between 2013, 2014, and 2015 samples. Color represents different sampling years: gray (2013), white (2014), black (2015)...................

7.5 A summary of estimated trophic positions for each species. Points represent average trophic position; error bars represent standard deviation. The color of points represents functional species groups derived in Chapter II: red (anadromous and estuarine fish), green (Arctic cold-water fish), blue (Arctic warm-water fish) The colors of the error bars indicate the baseline $\delta^{15} \mathrm{~N}$ values used to estimate the average trophic position that they originate from: red (TERA), yellow (PRIM), blue (ICEA). ................................ 
CHAPTER I

INTRODUCTION 
Polar regions have become of interest because of the rapid rate of climate change in these extreme environments and subsequent vulnerability to increased anthropogenic activities (Johannesson et al., 2004; McMahon et al., 2009; Moline et al., 2008). The rapid decrease in sea ice cover has drawn the attention of oil and gas, shipping, and tourism industries looking to capitalize on previously unavailable resources (AMAP, 2008; Jones, 2012). Though these new opportunities may benefit the world economy, they have equal potential to have detrimental impacts on nearby ecosystems. In response to these potential threats, scientists have focused on understanding ecosystems of the Arctic Ocean to establish baselines and predict how these ecosystems may respond to imminent environmental changes.

Bluhm and Gradinger (2008) predicted that shifting timing of ice melt could restructure primary and secondary production cycles in the Arctic. Under current conditions, Arctic waters are covered by a thick layer of ice in the winter, and the photoperiod is limited to less than a few hours a day, thus very little light penetrates the water column for primary production to occur. In this scenario, nutrient concentrations increase as they are not being used. As summer conditions return, photoperiod increases, ice begins to melt, and light penetrates the ice allowing algae to start proliferating in the bottom layer of the ice and directly under the ice. As the ice melts, this algae is released from the lattice structure, and without turbulence caused by wave action it begins to sink to the benthos. During this time, surface waters are cold due to sea ice cover, and zooplankton grazers are less abundant allowing much of this primary production to be deposited at the benthos (Bluhm and Gradinger, 2008). Benthic-pelagic coupling leads to high biomass in benthic communities of the Arctic Ocean, and is considered an important 
process in maintaining Arctic marine food webs (Gorbatenko et al., 2009; Grebmeier et al., 1988; Iken et al., 2010). As ice cover diminishes, and the shift from ice cover to open water occurs earlier and faster with increasing Arctic temperatures; Bluhm and Gradinger (2008) predicted three large-scale biotic changes in Arctic production cycles: (1) higher primary and secondary production as unused nutrients from under the ice become available; (2) a reduction in benthic-pelagic coupling leading to decreased biomass in benthic food webs; and (3) increased pelagic grazing will recycle nutrients during open water conditions, thus maintaining higher biomass in pelagic zones of the water column. These predicted changes, especially the latter, are expected to increase pelagic biomass and thus support larger populations of fish in the Arctic Ocean.

Simultaneously, warming conditions in the Arctic are extending the ranges of tolerable temperatures for lower-latitude species (Grebmeier, 2012). The majority of flow through the Bering Strait carries larval organisms from low latitudes to the Arctic Ocean, providing a vector for these species to colonize Arctic habitats (Eisner et al., 2013; Grebmeier, 2012; Woodgate et al., 2012). As climate change continues, it is expected that lower-latitude species associated with warmer conditions will become more prevalent in Arctic ecosystems, and these newcomers present new competition for space and resources for the well-established Arctic forage fish that prefer colder conditions. Since species distributions and behaviors are sensitive to climatic conditions, competition, and external resource availability, changes in community and food web structure are likely to follow environmental changes (Legendre et al., 2005; Logue et al., 2011). Understanding responses to variable scales of spatial and temporal patterns may offer insight to how these communities and food webs may fare in the long term as the effects of climate change 
become more pervasive. Furthermore, it is important to understand the magnitude of natural variation in community composition, so that we may detect significant environmental impacts from climate change and potential oil spills if they should arise in the future.

Despite an increase in effort to gain a better understanding of Arctic marine ecosystems, only a fraction of this research effort has been focused on coastal regions (Bluhm and Gradinger, 2008; Iken et al., 2010; Norcross et al., 2004), and an even smaller portion of that has focused on the very nearshore (shallower than $15 \mathrm{~m}$; Craig et al. 1982; Craig et al. 1985; Dunton et al. 2006; Dunton et al. 2012). The Arctic nearshore is largely comprised of estuarine lagoon and barrier island systems. On the basis of knowledge of well-studied lower-latitude systems, these estuaries have the potential to be highly productive and important habitats for the rearing of juvenile fish, foraging grounds for a multitude of protected and endangered marine mammals and birds (Beck et al., 2001; Dunton et al., 2012; Elliott et al., 1990; Fry et al., 2003), as well as an important resource for nearby subsistence villages. As a consequence of their shallow nature and potential to host sensitive juveniles and forage species, these habitats may be especially susceptible to the impacts of oil spills and climate change (Gundlach and Hayes, 1978). Though we presume that these Arctic estuaries function and respond to disturbances in similar ways as their low-latitude counterparts, we cannot make these assumptions without the necessary empirical information.

In my dissertation, I explore spatial and temporal ecological patterns of Arctic nearshore fish communities and food webs to assess the reality of these predicted changes to Arctic marine production and community composition, and discuss the potential impacts 
that they may have in the future. In Chapter II, I use a multivariate statistical approach to identify spatial, temporal, and environmental drivers in species composition across three common nearshore habitats in the Arctic Ocean. The difference in responses to environmental stimuli for warm-water and cold-water species and their potential long-term implications on food web structure are discussed.

Recognizing the potential changes to food web structure in the Arctic, the next step is to investigate food web structures and trophic niche space. Because the Arctic is covered by ice for most of the year, it is difficult to sample fish year-round as needed to understand energy flows in Arctic marine food webs. However, stable isotope analysis (SIA) offers insight to feeding habits and trophic niche space over extended periods of time before sampling occurred, but to use this method effectively, a thorough understanding of isotope assimilation processes is needed. In Chapter III, I respond to the paucity of available parameters to model trophic dynamics in the Arctic with an experiment on Arctic Sculpin (Myoxocephalus scorpioides) to determine isotopic tissue turnover rates for three tissues that represent different time scales of prey resource consumption and identify appropriate trophic discrimination factors (TDF) used to represent the difference in isotopic signatures between consumer and prey.

In Chapters IV and V, I investigate the ability of SIA to recognize changes in prey resource usage across known gradients of environmental conditions. In Chapter IV, I use tissue-dependent SIA in five sculpin species to identify a temporal shift in basal resource dependence from ice-algae to pelagic primary producers that occurs during the shift from ice-covered winter conditions to open-water summer conditions. In Chapter V, stable isotopes in a fish species that has a large latitudinal range from the North Pacific Ocean to 
the Arctic Ocean, Pacific Capelin (Mallotus catervarius; formerly known as Mallotus villosus) is used to investigate prey resource usage and energy allocation strategies across an array of environmental conditions extending from the Southern Bering Sea to Point Barrow, AK.

In Chapter VI, I review the available TDFs derived from Arctic marine species from published peer-reviewed journal articles and the experiment in Chapter III, and discuss the implications of selecting appropriate TDFs for the species in a food web model. The accuracy of isotope models derived from TDFs from the experiment in Chapter III and models from TDFs of other Arctic marine species are compared using their predictions of the trophic niche space of prey resources on which Arctic nearshore fish depend, to select the most appropriate TDFs to model trophic dynamics in lower trophic levels in the Arctic nearshore. In Chapter VII, the selected TDFs are used to investigate the basal resource dependence of fish species in the Arctic nearshore. Furthermore, isotopic space of species are compared, including a comparison of warm-water species to cold-water species, and the potential implications are discussed.

In conclusions, my dissertation advances our knowledge of Arctic nearshore fish communities and food webs. I expand our knowledge of isotope assimilation processes in Arctic fish species and offer better parameters for modeling trophodynamics in lower trophic levels of the Arctic nearshore. I show that predictions of increasing abundance of warm-water associated species are likely to continue, and that these new introductions are likely to change the structure of Arctic nearshore food webs. 


\section{References}

AMAP, 2008. Arctic oil and Gas. Arctic Monitoring and Assessment Programme, Oslo, Norway.

Beck, M., Jr, K.H., Able, K., 2001. The identification, conservation, and management of estuarine and marine nurseries for fish and invertebrates. Bioscience 51, 633-641.

Bluhm, B., Gradinger, R., 2008. Regional variability in food availability for Arctic marine mammals. Ecol. Appl. 18, S77-S96. https://doi.org/http://dx.doi.org/10.1890/06-0562.1

Craig, P., Griffiths, W., Haldorson, L., McElderry, H., 1985. Distributional patterns of fishes in an Alaskan arctic lagoon. Polar Biol. 4, 9-18.

Craig, P.C., Griffiths, B., Griffiths, W.B., Ffiths, W.B.G.R., 1982. Ecological studies of Arctic Cod (Boreogadus saida) in Beaufort Sea coastal waters, Alaska. Can. Bull. Fish. Aquat. Sci. 39, 395-406. https://doi.org/10.1139/f82-057

Dunton, K.H., Schonberg, S. V., Cooper, L.W., 2012. Food web structure of the Alaskan nearshore shelf and estuarine lagoons of the Beaufort Sea. Estuaries and Coasts 35, 416435. https://doi.org/10.1007/s12237-012-9475-1

Dunton, K.H., Weingartner, T., Carmack, E.C., 2006. The nearshore western Beaufort Sea ecosystem: Circulation and importance of terrestrial carbon in arctic coastal food webs. Prog. Oceanogr. 71, 362-378. https://doi.org/10.1016/j.pocean.2006.09.011

Eisner, L., Hillgruber, N., Martinson, E., Maselko, J., 2013. Pelagic fish and zooplankton species assemblages in relation to water mass characteristics in the northern Bering and southeast Chukchi seas. Polar Biol. 36, 87-113. https://doi.org/10.1007/s00300-012-12410

Elliott, M., O’Reilly, M.G., Taylor, C.J.L., 1990. The forth estuary: a nursery and overwintering area for North Sea fishes. Hydrobiologia 195, 89-103. https://doi.org/10.1007/BF00026816

Fry, B., Baltz, D., Benfield, M., Fleeger, J., Gace, A., Haas, H., Quinones-Rivera, Z., 2003. Stable Isotope Indicators of Movement and Residency for Brown Shrimp (Farfantepenaeus aztecus) in Coastal Louisiana Marshscapes. Estuaries 26, 82-97.

Gorbatenko, K.M., Kiyashko, S.I., Lazhentsev, A. Y., Nadtochii, V. a., Savin, a. B., 2009. Benthic-pelagic trophic interactions within the fish assemblage in the western Bering Sea shelf area according to stomach content analysis and ratios of $\mathrm{C}$ and $\mathrm{N}$ stable isotopes. Russ. J. Mar. Biol. 34, 497-506. https://doi.org/10.1134/S1063074008070092

Grebmeier, J.M., 2012. Shifting patterns of life in the Pacific Arctic and sub-Arctic seas. Ann. Rev. Mar. Sci. 4, 63-78. https://doi.org/10.1146/annurev-marine-120710-100926 
Grebmeier, J.M., Mcroy, C.P., Feder, H.M., 1988. Pelagic-benthic coupling on the shelf of the northern Bering and Chukchi Seas. I. Food supply source and benthic biomass. Mar. Ecol. 48, 57-67.

Gundlach, E., Hayes, M., 1978. Vulnerability of coastal environments to oil spill impacts. Mar. Technol. Soc. J. 12, 18-27.

Iken, K., Bluhm, B., Dunton, K., 2010. Benthic food-web structure under differing water mass properties in the southern Chukchi Sea. Deep. Res. Part II Top. Stud. Oceanogr. 57, 71-85. https://doi.org/10.1016/j.dsr2.2009.08.007

Johannesson, O.M., Bengtsson, L., Miles, M.W., Kuzmina, S.I., Semenov, V.A., Alekseev, G. V, Nagurnyi, A.P., Zakharov, V.F., Bobylev, L.P., Pettersson, L.H., Hasselmann, K., Cattle, H.P., 2004. Arctic climate change: observed and modelled temperature and sea-ice variability. Tellus 56, 328-341.

Jones, N., 2012. Oil exploration ramps up in US Arctic.

Legendre, P., Borcard, D., Peres-Neto, P.R., 2005. Analyzing beta diversity: partitioning the spatial variation of community composition data. Ecol. Monogr. 75, 435-450. https://doi.org/10.1890/05-0549

Logue, J.B., Mouquet, N., Peter, H., Hillebrand, H., 2011. Empirical approaches to metacommunities: A review and comparison with theory. Trends Ecol. Evol. 26, 482-491. https://doi.org/10.1016/j.tree.2011.04.009

McMahon, C.R., Bester, M.N., Hindell, M. A., Brook, B.W., Bradshaw, C.J. a, 2009. Shifting trends: Detecting environmentally mediated regulation in long-lived marine vertebrates using time-series data. Oecologia 159, 69-82. https://doi.org/10.1007/s00442008-1205-9

Moline, M. A, Karnovsky, N.J., Brown, Z., Divoky, G.J., Frazer, T.K., Jacoby, C.A., Torres, J.J., Fraser, W.R., 2008. High latitude changes in ice dynamics and their impact on polar marine ecosystems. Ann. N. Y. Acad. Sci. 1134, 267-319. https://doi.org/10.1196/annals.1439.010

Norcross, B.L., Holladay, B.A., Busby, M.S., Mier, K., 2004. RUSALCA - Fisheries Ecology and Oceanography.

Woodgate, R. A., Weingartner, T.J., Lindsay, R., 2012. Observed increases in Bering Strait oceanic fluxes from the Pacific to the Arctic from 2001 to 2011 and their impacts on the Arctic Ocean water column. Geophys. Res. Lett. 39, 2-7. https://doi.org/10.1029/2012GL054092 
CHAPTER II

SPATIOTEMPORAL VARIATION OF ENVIRONMENTAL CONDITIONS AND PREY AVAILABILITY THAT DRIVE ARCTIC NEARSHORE FISH COMMUNITY STRUCTURE IN THE POINT BARROW, AK REGION 


\begin{abstract}
The Arctic nearshore surrounding Point Barrow is a dynamic system with complex oceanographic and meteorological processes that drive community composition to change rapidly in space and time. Spatial, temporal, environmental, and biological drivers of fish community structure in the Arctic nearshore surrounding Point Barrow were investigated using multivariate Canonical Correspondence Analysis (CCA). A CCA model using the 13 most explanatory variables (3 environmental, 1 spatial, 4 temporal, and 5 zooplankton abundances) explained $73 \%$ of the variance in community structure in this region. Distinct fish communities were identified within the three waterbodies that were studied (Chukchi Sea, Beaufort Sea, and Elson Lagoon), and these distinctions were largely driven by salinity. Species moved into the nearshore at various times after landfast ice breaks up, creating an annual succession of species that can be found in nearshore habitats. Species that tend to become more abundant later in the open-water season, were also most abundant in warmer years, suggesting that warmer conditions may be more favorable for them. Other species were more abundant early in the open-water season, and in colder years, suggesting that colder conditions are more favorable for them. The differential responses of species to warm and cold conditions in the Arctic nearshore may have serious implications for these ecosystems as climate change continues.
\end{abstract}

\title{
Introduction
}

Many environmental scientists have shifted attention to polar regions where the effects of climate change occur most rapidly (Johannesson et al., 2004). In addition to 
environmental changes, decreasing sea ice cover is providing opportunities for oil and gas exploration, tourism, and the shipping industry (Berkman and Young, 2009). In response to these imminent threats, a considerable amount of research has been focused on understanding Arctic marine systems and establishing baselines from which we can assess changes associated with these impacts. However, to date, most of this effort has overlooked the lagoons and barrier island systems that span much of the Arctic Ocean's coastlines. Analogous estuarine habitats play vital roles as nurseries and foraging grounds for many important species in well-studied lower latitude systems (Dunton et al., 2006; Elliott et al., 1990; Kneib, 1997; Nuraini et al., 2007); and we assume that their Arctic counterparts are of similar importance and play similar roles for their inhabitants. Furthermore, these habitats are home to several endangered and protected marine mammals and seabirds, and provide important resources for subsistence fisherman and hunters in local villages (Brewster et al., 2010). A thorough understanding of these nearshore ecosystems and the communities that inhabit them is needed to predict how they will respond to changes associated with climate variation and anthropogenic activities.

Spatiotemporal changes in community composition may be the best indicator of ecosystem changes (Legendre and Gauthier, 2014). The Arctic nearshore is subject to extreme environmental fluctuations that can range from interannual to seasonal scales (i.e., transitioning between ice covered winters and open water summers) to hourly scales (i.e., erratic weather patterns). Consequently, nekton communities can display complex responses to environmental variables that generate heterogeneity in species distributions in space and time (Legendre and Gauthier, 2014; Logue et al., 2011; Ter Braak, 1987), and it is important to understand these responses so that we may interpret how and why 
communities change in the future. The best approach is to first identify the most important factors that drive changes in community composition (Blanchet et al., 2008). This approach not only provides crucial information to understand spatial and temporal changes in community structure, but also streamlines future monitoring efforts to improve the efficiency in data collection programs. Given that the nekton communities consist of an array of species with varying life history characteristics, we expect that community composition will be shaped simultaneously by multiple environmental factors, therefore a multivariate approach that incorporates multiple independent variables as well as multiple response variables is appropriate (Legendre and Gauthier, 2014).

Environmental explanatory variables are important to identify spatiotemporal community structure, but these variables are often structured by or covariate with space and time between sampling events. To understand the response of communities to environmental factors, we must also understand their response to spatial and temporal factors. Anderson and Cribble (1998) used twelve different combinations of explanatory variable matrices in Canonical Correspondence Analysis (CCA) to partition the variance in community composition explained by environmental, spatial and temporal variables to identify the most explanatory variables in community structure. We apply this method to identify important drivers of change in community structure in Arctic nearshore fish communities at lagoon, barrier island, and beach habitats in the Chukchi and Beaufort Sea near Point Barrow, Alaska, and use a series of CCA ordinations to identify patterns in community composition and discuss possible driving mechanisms. The main objectives of the study are to examine nearshore fish community dynamics to test the hypothesis that a variety of environmental variables and oceanographic or ecological processes are 
simultaneously important in structuring nearshore nekton communities in the Arctic Ocean at varying spatial and temporal scales.

\section{Methods}

\section{Study Area}

Point Barrow, Alaska is a unique area where multiple Arctic nearshore habitat types are found in close proximity to each other. Point Barrow is bordered on the West by the Chukchi Sea (CHS), and to the East by the Beaufort Sea (BFS), with the large estuarine Elson Lagoon (ESL) opening into the Beaufort Sea just $5 \mathrm{~km}$ Southeast of Point Barrow (Figure 1). Ecosystems surrounding Point Barrow region are highly dynamic due to complex oceanographic processes that have been shown to create stark differences in community structure of offshore fish species from one side of the point to the other (Norcross et al., 2004). The Chukchi Sea is a relatively shallow sea with an extensive continental shelf, and is in general highly productive in comparison to the Beaufort Sea due to strong benthic-pelagic coupling (Dunton et al., 2012, 2005; Iken et al., 2010). The eastern Chukchi Sea is fed by three main northbound currents that originate from the Bering Strait that transport nutrient rich waters along the Alaskan Chukchi coast: (1) Anadyr Water, (2) Bering Shelf Water, and (3) The Alaska Coastal Current (ACC; Danielson et al., 2014; Stabeno et al., 1995). The ACC flows along the Alaskan coastline and extends on average $30 \mathrm{~km}$ from shore, the Anadyr Water and Bering Shelf Water are further from shore and probably play minimal roles in the community structure of the nearshore as defined in this article. The ACC flows northward toward Point Barrow and 
continues northeast off the point in a narrow but deep trench known as Barrow Canyon, and continues east along the Beaufort Continental shelf.

The Beaufort Sea on the other hand has a short continental shelf and is relatively deep in comparison to the Chukchi Sea. The Beaufort Sea Gyre moves water clockwise in deeper waters, but in the nearshore currents are driven by wind. Easterly winds are prevalent in this region, so currents along the Western Beaufort coast tend to flow west toward Point Barrow (Danielson et al., 2014). This sea is generally less productive relative to the Chukchi Sea due to poor benthic-pelagic coupling (Dunton et al., 2005), and as a result, its coastal food webs have high dependence on nutrients and materials transported out of numerous lagoon systems along its coast (Dunton et al., 2006).

Finally, the third waterbody within the study area, Elson Lagoon, is a large shallow lagoon system that connects to the Beaufort Sea on the West side of the lagoon by the narrow and deep Eluitkak Pass, and to the east by a series of wider and shallower inlets. During prevailing Easterly winds (the most common scenario) water flows into the lagoon through eastern inlets and flows out the west through Eluitkak Pass (Li et al. pers. comm.). The lagoon also receives tremendous terrestrial runoff from meltwater by several rivers and creeks on the East, and a myriad of ephemeral tundra streams and melting permafrost (Carothers, 2013; Johnson et al., 2010; Okkonen, 2008), which can cause rapid fluctuations in salinity.

\section{Sample Collection}

The communities were sampled using a beach seine at 12 stations (5 CHS, 3 BFS, and 4 ESL) at weekly intervals from July $14^{\text {th }}-$ August $25^{\text {th }}$ for three consecutive years 
(2013-15). The seine was $37 \mathrm{~m}$ long with variable mesh sizes (10 $\mathrm{m}$ of $32 \mathrm{~mm}$ outer panels, $4 \mathrm{~m}$ of $6 \mathrm{~mm}$ middle panels, and $9 \mathrm{~m}$ of $3.2 \mathrm{~mm}$ blunt panel). Each set was round-haul style, paid out of a $3 \mathrm{~m}$ inflatable zodiac following methods used by Johnson et al. (2010). All collections occurred during daylight hours. The entire catch was put in a Ziploc ${ }^{\circledR}$ bag and placed on ice to be processed in the lab. In the case of very large catches (> 1000 fish), fish larger than $40 \mathrm{~mm}$ were set aside, the remainder of the catch was weighed in the field, and a $1 \mathrm{~L}$ subsample was placed in a Ziploc $®$ bag to be processed in the lab. Once in the lab, all fish were sorted by species and enumerated. In the case of a subsample, the numbers of each species were multiplied proportionally by the weight of the entire sample to estimate their abundances. Temperature, salinity, turbidity (NTU), and Dissolved Oxygen (DO) were recorded using a YSI EXO2 data sonde at each sampling event. Wind speed, direction and air temperature for each sampling time were obtained from the NOAA Earth Systems Research Laboratory weather station located at Wiley Post-Will Rogers Memorial Airport in Utqiagivik, AK.

Zooplankton samples were collected intermittently during the 2014 and 2015 beach seine surveys. A $50 \mathrm{~cm}$ diameter, $333 \mu \mathrm{m}$ plankton net was towed under the surface behind a $3 \mathrm{~m}$ rigid hull inflatable at 3 knots for approximately 3 minutes. Samples were reduced volumetrically to approximately $50 \mathrm{~mL}$ using a Folsom Splitter. Plankton were then sorted by major taxa and enumerated. Larger taxa (krill, mysids, amphipods, ichtyoplankton, etc.) were sorted first, and then smaller taxa (copepods, small larvae) were sorted under a dissecting microscope. 


\section{Canonical Correspondence Analysis}

Several constrained ordination methods exist, with Canonical Correspondence Analysis (CCA) and Canonical Redundancy Analysis (RDA) being the most popular for abundance data, but CCA was selected for this analysis for two reasons. The first, CCA assumes that the response variables (community composition) have a unimodal distribution in relation to the explanatory variables, whereas RDA assumes a linear relationship between response and explanatory variables (Anderson and Cribble, 1998). These linear functions are more appropriate when the gradient of explanatory variables is short, but given that environmental patterns in the Arctic are highly variable, a CCA seems more suitable than a RDA. Furthermore, CCA also has a linear face and thus is also capable of handling short gradient variables (Palmer, 1993). Secondly, beach seines are notoriously susceptible to bias toward small sedentary species and thus the data collected from them should be used as relative abundance, not absolute abundance. A CCA uses data as relative abundance but a RDA does not, and thus the CCA is the most appropriate model for our analysis (Palmer, 1993).

\section{Variance Partitioning}

Changes in community structure are driven by environmental, spatial, and temporal variables, but to understand these relationships we must also understand the covariance among explanatory variables. We partition the variance in species abundance explained by environmental, spatial, and temporal variables using four fundamental matrices: environmental variables (ENV), spatial variables (SPT), temporal variables (TMP), and species abundance. For each of the twelve steps of variance partitioning outlined by 
Anderson and Cribble (1998), a combination of one or more of these three explanatory variable matrices was used to constrain the CCA models of species abundance. The sum of eigenvalues generated by a CCA (constrained inertia) over the sum of all eigenvalues generated by an unconstrained correspondence analysis (CA; total inertia) yields the proportion of variance in the response matrix (species abundance) explained by the constraining variables (ENV, SPT, TMP, etc.). Because the explanatory variables in ENV, SPT, and TMP often overlap with each other, we can include them as covariables so that the partial contribution (overlap in variance explained) of each explanatory matrix is conditioned out of the model (conditioned inertia). The remaining variability in species abundance that is not explained is termed "unconstrained inertia". Using variance partitioning, we may identify the true proportion of variance explained by each matrix of variables, and gain a better understanding of how these variables influence community structure.

We present a modified version of Anderson and Cribble's (1998) representation of the variance in species abundance and the proportion explained by ENV, SPT, and TMP (Figure 2.2). To find the variance explained by each of the variable matrices, a model is simply constrained by only one of the fundamental matrices ([1], [2], or [3] in Figure 2.2); but these models have redundant explanatory power (represented by the overlapping segments of the Venn Diagram) that need to be accounted for in order to find the true variance explained by all variables. For example, a CCA model constrained by ENV represents variance in species abundance explained by ENV with partial contributions from ENV+SPT, ENV+TMP, and ENV+SPT+TMP. By conditioning the CCA model constrained by ENV, SPT, or TMP with one of the remaining matrices, the model 
represents the explained variance by the chosen matrix and the partial contribution of the matrix that was not conditioned from the model ([4], [5], [7], [8], [10], or [11] in Figure 2.2). For example, a model constrained by ENV and conditioned by SPT, would represent the variance explained by ENV and the partial contribution of variance explained by ENV+SPT. Finally, the variance explained purely by variables from one explanatory matrix can be represented in a CCA model if both of the remaining matrices are conditioned from the model ([6] or [9] or [12] in Figure 2.2). For example, A CCA model constrained by ENV with SPT and TMP conditioned out will represent variance explained only by ENV. Once the values corresponding to all sections of the Venn diagram are known, the total variance explained by all variables can be calculated using one of three equations: [1] $+[7]+[12]$, or $[2]+[4]+[12]$, or $[3]+[5]+[9]$.

\section{Variables}

Several variables were included in the modeling process. The following is an account of all variables that were included in the forward selection process outlined by Blanchet et al. (2008). A summary of all variables can be found in Table 2.2.

\section{Species Abundance}

During the three summers of sampling, the 150 beach seine hauls included in the analysis caught 37 species, but CCA ordinations with that many species centroids become cluttered and difficult to interpret. Since many of these species were rare, the species list used for this analysis was truncated by removing species that were caught in less than 5 hauls $(2.8 \%)$, or less than $5 \%$ of the hauls in each sampled year. Additionally, species that 
were always caught together were grouped to minimize the number of species centroids in each plot. Table 2.1 summarizes the species that were included in CCA analyses, and the centroid label to which they were assigned for CCA ordinations. For the remainder of this article, species will be referred to by their common names.

\section{Environmental Variables}

Wind effects on water can take time to manifest, and we accounted for the potential lag effects of wind by examining responses across multiple temporal scales of average wind speed and direction from $0,1,3,6,12,24,72$, and 168 hours prior to the sampling event. Given that our sampling stations comprise a range of orientations, with respect to cardinal directions, these nearshore areas will be differentially affected by prevailing wind conditions. We accounted for the effect of wind direction relative to beach orientation (BOWD) so that a direct onshore wind scored 90, an along shore wind scored 0 , and a direct offshore wind scored -90 (Figure 2.3). Thus, wind variables selected for the analysis included wind direction (degrees; coerced to a circular variable using CRAN-R package “circular"), wind speed (m/s), beach oriented wind direction (BOWD), the easterly component of wind speed $(\mathrm{m} / \mathrm{s})$, and the southerly component of wind speed $(\mathrm{m} / \mathrm{s})$, air temperature at $2 m$ above sea level. Forward selection was performed on these variables, and the selected variables made up an explanatory variable matrix henceforth referred to as ENV. 


\section{Spatial Variables}

Since CCA is capable of using both categorical variables and numerical variables (Ter Braak, 1987), it is tempting to use categorical variables such as sampling stations or waterbodies (Chukchi Sea, Beaufort Sea, and Elson Lagoon). However, the effects of spatial autocorrelation cannot be accounted for with categorical variables. Thus, we included Distance-Based Moran's Eigenvector Maps (dbMEMs) to represent the autocorrelation associated with Euclidean distance (Dray et al., 2012; Legendre et al., 2005; Legendre and Gauthier, 2014). Originally, the dbMEMs methodology was not intended for use with CCA because CCA uses row weights. Therefore, we performed an unconstrained correspondence analysis (CA) on abundance data and created the dbMEM variables using the row weights obtained from the CA. Because our water bodies are separated by a landmass, we could not use Latitude and Longitude to create a spatial matrix, instead the distance between each station was manually measured and used to generate a spatial matrix. Forward selection was performed on these variables, and the selected variables made up an explanatory variable matrix henceforth referred to as SPT.

\section{Temporal Variables}

Similar to the spatial variables, temporal variables can be represented as both categorical variables and Euclidean distance variables, and both were used in the analysis. Year was entered as a categorical variable. Time of day was entered as a continuous numeric variable (decimal hours; i.e. 13:30 = 13.5). Temporal autocorrelation was represented by dbMEMs using time (days) between each sampling event, the same method 
described for spatial dbMEMs was used. To avoid confusion, temporal MEMs will be referred to as tbMEMs (time-based MEMs)

A variable was created for days since ice break-up in the Elson lagoon. The Elson Lagoon is always the first to become ice free at the onset of summer, therefore the variable was created to identify seasonal patterns such as the succession of emigration to newly available habitat after winter conditions subside.

Additionally, we recognize a potential bias in our sampling methods where favorable wind conditions were often selected to facilitate efficient sampling along exposed coastlines. Sampling stations for each day were selected using weather predictions, and stations where wave action was expected to be too great (wind exceeding $28 \mathrm{~km} / \mathrm{h}$ with a BOWD of at least $45^{\circ}$ ) were avoided. The variable, "Days since a significant wind event" was counted from the last day during which the threshold was surpassed, allowing us to account for the effects of strong winds on community composition without being able to sample during the wind event. Forward selection was performed on these variables, and the selected variables made up an explanatory variable matrix henceforth referred to as TMP.

\section{Zooplankton Abundance}

Zooplankton samples were collected intermittently during 2014 and 2015 beach seine surveys. To explain more of the variance in fish species abundance, zooplankton abundance was used to parameterize an explanatory variable matrix. Zooplankton were categorized into 13 major taxonomic groups: Chaetognaths, Copepods, Amphipods, Ctenophores, Decapod Larvae, Ichthyoplankton, Euphausids, Isopods, Polychaete 
Larvae, Mysids, Barnacle Larvae, and Pteropods. These collections resulted in a much smaller sample size $(\mathrm{n}=44)$, and thus in order to constrain CCA models by zooplankton abundance, the fish species abundance, environmental, spatial and temporal variable matrices were truncated to match the sampling events of zooplankton collections, this truncation was only done for models including zooplankton abundance as an explanatory variable matrix, all other models used the matrices with sample size $n=150$.

Environmental, spatial and temporal variables were kept constant with those that were forward selected for the previously mentioned ENV, SPT, and TMP; in their truncated form will be referred to as $\mathrm{ENV}_{\text {zoop }}, \mathrm{SPT}_{\text {zoop }}$, and $\mathrm{TMP}_{\text {zoop }}$. The truncated fish species abundance matrix will be referred to as $\mathrm{SPA}_{\text {zoop. }}$ Zooplankton counts were normalized for each collection, and each taxa was treated as a variable in forward selection, resulting in an explanatory matrix henceforth referred to as ZOOP.

\section{Results}

\section{Sampled Abundance}

A total of 150 beach seine hauls collected over the three consecutive summers were included in this analysis (Table 1). In these 150 hauls, 33,874 individuals of the species included in the Species Abundance matrix were caught. In the Chukchi Sea, 52 seines were hauled totaling 24,295 fish with a Catch Per Seine Haul (CPUE) of 467; in the Beaufort Sea 31 seines were hauled totaling 5,093 fish, with an average CPUE of 162.5; and in the Elson Lagoon we pulled 67 seines totaling 4,486 fish with a CPUE of 65.0. Catch was also broken down by year: 2013 had the highest abundance of fish by CPUE with 42 beach seine hauls and a total catch of 19,057 (CPUE $=453.7), 2015$ was the second most 
productive with 56 beach seine hauls, total catch of 9,544 (CPUE $=170.4)$, and 2014 was the least productive with 52 beach seine hauls, total catch of $5273(\mathrm{CPUE}=101.4)$.

\section{Forward Selection of Variables}

The lag time after which wind variables became most explanatory was determined by comparing the $\mathrm{R}^{2}$ of global models containing all environmental variables, where only the wind variables differed by lag time between models. All wind variables with a 3-day lag time had the highest $\mathrm{R}^{2}(0.32)$. The forward selection process outlined by Blanchet et al. (2008) was used on all environmental variables including the 3-day wind variables. The following were selected as the most explanatory variables and made up the environmental variables matrix (ENV) for the CCA modelling and variance partitioning portion of the analysis: Salinity, Easterly wind speed, and Dissolved Oxygen $\left(\mathrm{R}^{2}=0.18\right)$.

The dbMEM method created six principal components representing positive spatial autocorrelation. Forward selection of these principal components selected only the first principle component (dbMEM.1) as a significant explanatory variable $\left(\mathrm{R}^{2}=0.08\right)$, and made up the spatial variables matrix (SPT) for the CCA modelling and variance partitioning portion of the analysis.

The tbMEM method created four principal components representing positive temporal autocorrelation, and forward selection selected the second principle component (tbMEM.2), as well as year (categorical), time of day, and days since ice break-up in Elson lagoon (Daysicefree) as the most significant explanatory variables $\left(R^{2}=0.25\right)$. These four variables made up the temporal variables matrix (TMP) for the CCA modelling and 
variance partitioning portion of the analysis. All selected and unselected variables are summarized in Table 2.2.

Forward selection of plankton relative abundance selected five zooplankton taxa as important explanatory variables. The following were selected as the most explanatory variables and made up the environmental variables matrix (ZOOP) for the CCA modelling and variance partitioning portion of the analysis: Copepods, Mysids, Chaetognaths, Amphipods, and Ctenophores.

\section{Variance Partitioning}

The total inertia in the ASP matrix was 5.038; the global CCA model of all forward selected constraining variables (ENV+SPT+TMP) explained $38.5 \%$ of the variance in species abundance. The CCA models constrained by individual explanatory matrices explained $18 \%(\mathrm{ENV}), 8 \%$ (SPT), and 26\% (TMP) of the total variance in species abundance (Figure 2.4). The partial contribution of SPT to ENV was 4\%, the partial contribution of TMP to ENV was 9\%, and the partial contribution of SPT+TMP to ENV was $11 \%$, leaving $7 \%$ of the variance in species abundance explained by purely ENV variables. Partial contributions of ENV, TMP, and ENV+TMP to SPT were 4\%, 3\%, and $5 \%$, respectively, leaving $3 \%$ of variance in species abundance explained purely by SPT variables. Finally, partial contributions of ENV, SPT, and ENV+SPT to TMP were 8\%, $3 \%$, and $8 \%$, respectively, leaving $17 \%$ of variance in species abundance explained by purely TMP variables.

The CCA models of $\mathrm{SPA}_{\text {zoop }}$ constrained by individual explanatory variable matrices $\mathrm{ENV}_{\text {zoop }}, \mathrm{SPT}_{\text {zoop }}$, were not significant $(\mathrm{p}=0.115$ and 0.370 , respectively), but the 
models constrained by $\mathrm{TMP}_{\text {zoop }}$ and ZOOP were significant $(\mathrm{p}=0.042$ and 0.001$)$. Using these truncated matrices, the percentage of variance explained were higher for $\mathrm{ENV}_{\mathrm{zoop}}$,

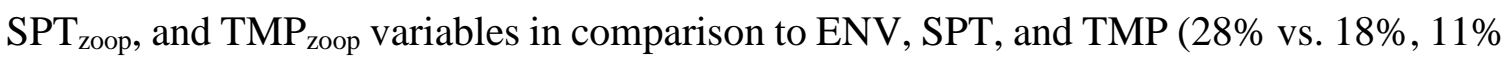
vs. $8 \%$, and $35 \%$ vs. $26 \%$, respectively), however the variance explained by the ZOOP matrix is substantially higher $(52 \%)$. Partial contributions of $\mathrm{ENV}_{\text {zoop }}+\mathrm{SPT}_{\text {zoop }}+\mathrm{TMP}_{\text {zoop }}$ to ZOOP was $33 \%$ leaving $19 \%$ of variance in fish species abundance explained by purely zooplankton abundance. However, partial contributions of $\mathrm{ZOOP}+\mathrm{SPT}_{\mathrm{zoop}}+\mathrm{TMP}_{\mathrm{zoop}}$ to $\mathrm{ENV}_{\text {zoop }}, \mathrm{ENV}_{\text {zoop }}+\mathrm{ZOOP}+\mathrm{TMP}_{\text {zoop }}$ to $\mathrm{SPT}_{\text {zoop }}$, and $\mathrm{ENV}_{\text {zoop }}+\mathrm{SPT}_{\text {zoop }}+\mathrm{ZOOP}$ to $\mathrm{TMP}_{\text {zoop }}$ left little variance explained by purely $\mathrm{ENV}_{\text {zoop, }} \mathrm{SPT}_{\text {zoop}}$, or $\mathrm{TMP}_{\text {zoop }}(5 \%, 2 \%$, and 6\%). The model constrained by $\mathrm{ENV}_{\text {zoop }}+\mathrm{SPT}_{\text {zoop }}+\mathrm{TMP}_{\text {zoop }}+\mathrm{ZOOP}$ explains $73 \%$ of the variance in $\mathrm{SPA}_{\text {zoop. }}$.

\section{CCA Ordinations}

The ordination of the global forward selected model (ENV+SPT+TMP) showed high variance in community structure along the $2^{\text {nd }}$ CCA Axis (Y-axis in Figure 2.4) which coincided with salinity and the dbMEM.1. Along the same axis, there was clear separation between communities sampled among the three waterbodies, indicating that these waterbodies cover a range of salinities with the Elson Lagoon at the lower end of the spectrum and the Chukchi Sea at the upper end. The separation between communities sampled in each water body also indicates that dbMEM.1 represented a spatial scale similar to the distance between the waterbodies.

The constraints of the model resulted in three distinct species groups that are likely to be associated with each water body: (1) Ciscos, Pacific Rainbow Smelt, Fourhorn 
Sculpin, and Flatfishes were most common in the Elson Lagoon sampling stations; (2) Arctic/Shorthorn Sculpin, Snailfishes, Arctic Cod, Belligerent Sculpin, and Larval Sculpin were most common in the Beaufort Sea and Elson Lagoon stations; and (3) Pacific Capelin, Slender Eelblenny, Saffron Cod, Poachers, and Pacific Sand Lance were most common in Chukchi Sea and Beaufort Sea stations.

Furthermore, the CCA ordination gives clear indications of the variables that were covariates, and thus made partial contributions of variance explained by the three fundamental explanatory matrices. Salinity and $d b M E M .1$ were covariates and are likely to the responsible for the partial contributions between ENV and SPT. Time.of.day and 3day.East.Wind were covariates, as well as tbMEM.2 and DO, and together are probably responsible for the large partial contributions of variance explained between TMP and ENV. Other variables may have smaller degrees of covariance that account for further partial contributions between ENV, SPT, and TMP.

When CCA ordination plots are made using only one fundamental matrix of constraining variables, the relationships between species abundance and the explanatory variables become easier to interpret. For the ENV constrained model (Figure 2.5), most variation in species composition coincided with changes in salinity; along the salinity axis species were grouped similar to the global forward selected model, suggesting salinity and dbMEM.1 were covaried significantly. Less variation in species abundance occurred with changes in DO or 3 day.East. Wind, however it is notable that Pacific Sand Lance appeared to respond to one of these variables, or perhaps a combination of both. It is also notable that $D O$ tended to increase with proximity to the Elson Lagoon. 
For the SPT model (Figure 2.6), species group in similar ways as the previous models, and waterbody ellipses also separated similarly. However, there is clearly variation in species composition orthogonally to $A b M E M .1$, indicating that there is much variation that is not explained by distance alone.

When the model is only constrained by the TMP matrix (Fig 1.7), the waterbody ellipses have more overlap, as their species composition do not correlate to any of the temporal variables. The species groups that were distinct in the previous models are no longer associated with waterbody. Rather, there is clear separation of species abundance that has positive correlation with Daysicefree. The centroids for years indicate that years 2013 and 2015 have abundance of species that are more abundant as Daysicefree increases. Pacific Sand Lance abundance is strongly correlated with Time.of.Day, suggesting they may be more common in beach seine range later in the day.

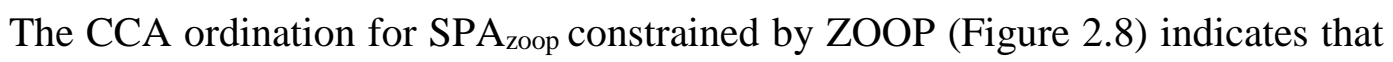
the most variation in species abundance coincides with abundance of Copepods and Mysids, and that Ciscos, Fourhorn Sculpin, Belligerent Sculpin, and Slender Eelblennies were most abundant at high copepod densities. Arctic/Shorthorn Sculpin, Arctic Smelt, Poachers, Larval Sculpin, Arctic Shanny, Saffron Cod, and Arctic Cod were all positively correlated to Copepods and Mysids abundance as well, but to a lesser degree. Furthermore, Arctic Sand Lance and Snailfishes abundance coincide with abundance of Amphipods, and Capelin were most abundant when Ctenophores were in high abundance. However, there exists a clear separation in waterbody ellipses that corresponded to copepod and mysids abundance, suggesting that these zooplankton taxa are most abundance in closer proximity to the Elson Lagoon. 
When the partial contributions of variance explained by $\mathrm{ENV}_{\mathrm{zoop}}+\mathrm{SPT}_{\mathrm{zoop}}+\mathrm{TMP}_{\mathrm{zoop}}$ to ZOOP were conditioned out (Figure 2.9), the remaining $19 \%$ of variance explained by ZOOP indicated minimal response in the abundance of most species to zooplankton abundance, and only Mysids and Chaetognaths had a strong influence on the position of species centroids. Only four fish species stand out: Slender Eelblenny, Ciscos are abundant when Mysids and Chaetognath abundance was high, respectively. The centroids for Arctic Smelt and Belligerent Sculpin are far from the plot origin, however they are in between the axes of Mysids and Chaetognaths, indicating that they are either respond to a combination of Mysids and Chaetognaths, or their abundance is not explained by zooplankton abundance.

\section{Discussion}

Arctic nearshore fish communities were largely structured by habitat type. The community compositions associated with the three waterbodies (BFS, CHS, and ESL) in the study area show separation in CCA ordination plots that are constrained by SPT or ENV, however this is not the case when the models are constrained by TMP. The ellipses are always in the same order with BFS in the center, and corresponds to the physical orientation of each waterbody. Each station was sampled each week, and thus TMP constrained ordination plots should not show as much separation between the waterbody ellipses as in the other cases. However, there is still some differentiation between waterbodies for the TMP constrained model, and this is likely because each waterbody not always being sampled on every single day, and thus the smaller scale variance within TMP (Time.of.day and tbMEM.2) may still show differences between waterbody. ENV 
constrained ordination plots show similar differentiation between waterbodies, suggesting that these spatially separated waterbodies differ in environmental conditions.

Species abundances are likely to respond to differences in environmental conditions and thus it is important to consider the difference between each of the waterbodies that were sampled. Oceanographic processes in the three waterbodies led to large differences in environmental conditions, and are likely to be the reason why different species are abundant. Specifically, salinity was lowest in the Elson Lagoon (avg $\pm \mathrm{sd}=23.45 \pm 5.67$ ppt), highest in the Chukchi Sea $(31.00 \pm 3.42 \mathrm{ppt})$, and the Beaufort Sea was in between these two $(28.00 \pm 3.77 \mathrm{ppt})$. The salinity gradient between water bodies is strongly associated with geographic location of the water bodies as the lagoon gets a tremendous input of freshwater, which flows out of Eluitkak Pass and is entrained and mixed with the westward flow of oceanic water in the Beaufort Sea towards the BFS sampling stations that lie between Eluitkak Pass and Point Barrow. The Chukchi Sea coast does have lagoons but none in as close proximity to our sampling stations as the Elson Lagoon and thus its waters are generally going to be more saline. Anadromous Ciscos, Arctic Smelt, and estuarine Fourhorn Sculpin and flatfishes (Craig, 1984) became abundant in the lagoon in summer as meltwater mixed in the lagoons, presumably to take advantage of prolific prey availability associated with ice break-up (Bluhm and Gradinger, 2008; Gradinger and Bluhm, 2010). However, these fish seemed to be limited by the salinity gradient as they were rarely caught outside of the Elson Lagoon.

The other waterbodies also had associated species that coincide with changes in salinity, however, when SPT is not used to constrain the model, and only ENV is used, the groups of species associated with each waterbody are closer together suggesting that 
salinity may not have been the most important factor, but rather space (or waterbody) was. Considering that the majority of species sampled were juvenile and larval fish, it is reasonable to assume that most have been advected to the area by coastal currents. By this logic, species that are most abundant on the east side of Point Barrow, the Beaufort Sea (Arctic/Shorthorn Sculpin, Arctic Cod, Snailfishes, Belligerent Sculpin, and larval sculpin) and Elson Lagoon (Cisco, Arctic Smelt, Fourhorn Sculpin, and Flatfishes), are likely to be advected from the Beaufort Sea and Arctic Ocean through the Beaufort Gyre and wind driven currents (Figure 1, Danielson et al., 2014). Furthermore, species that are most abundant to the west of Point Barrow, the Chukchi Sea (Pacific Capelin, Slender Eelblenny, Saffron Cod, Arctic Shanny, Poachers, and Pacific Sand Lance), are likely to be advected north by the ACC. The lower abundance of each group of species on the opposite sides of Point Barrow may also be explained by the dominant currents, as it is difficult for a juvenile or larval fish to travel against the current, thus concentrating distributions to the side of Point Barrow from which they were advected.

In the TMP constrained ordination plot, waterbody is less important, and most variation coincides with Daysicefree, indicating that there is a succession of species becoming abundant in the nearshore as ice breaks apart, moves offshore and the nearshore warms as the summer progresses. According to this succession, Belligerent Sculpin, snailfishes, and larval sculpin were most abundant immediately after the ice breaks up, which suggests that these species had been present under the ice. The fact that larval sculpin were abundant at this time also indicates that sculpin spawn near the end of the ice covered season, probably so that larvae will be present at the time of summer blooms allowing rapid growth (Gradinger and Bluhm, 2010). Next, anadromous and estuarine fish (Pacific 
Rainbow Smelt, Flatfishes, Fourhorn Sculpin and Ciscos) became more abundant. Then Arctic Cod and Arctic/Shorthorn Sculpin increased in abundance, and finally, Arctic Shanny, Slender Eelblenny, Saffron Cod, Poachers, Arctic Sand Lance and Pacific Capelin became abundant. This pattern may indicate that the abundance of species in the Arctic nearshore changes as conditions change later in the open-water season.

In addition, this same succession of species coincides with the difference between the centroids for 2014 which is located near the earlier species, and 2013 and 2015 which are located near the later species. 2014 was a relatively cold year $(\operatorname{avg} \pm \mathrm{sd}=3.66 \pm 2.58$ $\left.{ }^{\circ} \mathrm{C}\right)$ in comparison to $2013\left(6.49 \pm 3.08{ }^{\circ} \mathrm{C}\right)$ and $2015\left(5.84 \pm 2.02{ }^{\circ} \mathrm{C}\right)$. This means that some species in the Arctic nearshore are favored by colder or warmer conditions, and can be separated into three major groups: Estuarine Fish (Cisco, Arctic Smelt, Fourhorn Sculpin, flatfishes), Arctic Cold-water Fish (Belligerent Sculpin, Arctic Cod, Larval Sculpin, snailfishes, Arctic/Shorthorn Sculpin), and Arctic Warm-water fish (Arctic Sand Lance, Arctic Shanny, Slender Eelblenny, Pacific Capelin, and Saffron Cod). Arctic warmwater fish are most abundant in the Chukchi Sea, and appear later in summer but are also more abundant in warmer years, suggesting that they have are favored by warmer temperatures that may become prevalent as Arctic temperatures continue to rise and sea ice cover diminishes. Arctic cold-water fish and estuarine fish are more abundant in the Beaufort Sea and Elson Lagoon, respectively, and are favored by colder conditions that may become less prevalent in the future. Though the potential increase in abundance of warm-water fish may provide more prey resources for Arctic piscivores, it may also increase competition for resources with well-established species that prefer colder conditions. 
The CCA model constrained by ENV+SPT+TMP explained a substantial amount of the variance in species abundance, but there is still $62 \%$ of variance that remains unexplained by the selected variables. Given that most of the fish caught in this survey were larval or young-of-the-year (YOY), and that theoretically the most important thing to a YOY fish is growth, it comes as no surprise that prey resource availability was highly explanatory in fish species abundance. The inclusion of the ZOOP matrix as explanatory variables increased the variance explained by the global forward selected model from 53\% to $73 \%$. However, many of the zooplankton species are far too large to be prey to the majority of the fish that were collected, and thus the relationships between fish and the larger zooplankton abundances are not likely to describe predator-prey relationships.

For instance, juvenile Arctic Sand Lance and Capelin have small gape sizes, and mostly eat copepods and similar sized prey items (Purcell and Sturdevant, 2001; Vesin et al., 1981), yet the CCA ordination indicates that they were in high abundance along with Amphipods and Ctenophores, respectively. It is possible that these plankton prefer similar conditions or prey items as the fish species. However, these fish prefer to eat copepods, and the clear separation of waterbodies along the axis of Copepods suggests that Copepods are not highly abundant in the Chukchi Sea where Arctic Sand Lance and Capelin were most abundant. The plankton abundance variables were relative abundances (percentage), and thus a high abundance of Amphipods or Ctenophores in the Chukchi Sea, may simply be the result of a lack of other plankton taxa that are more abundant in the Elson Lagoon and the Beaufort Sea. Amphipods and Ctenophores are present in small numbers throughout all waterbodies, and the lack of Copepods in comparison to Elson Lagoon 
suggests that Arctic Sand Lance and Capelin are responding to the presence of Amphipods and Ctenophores, whereas, they may also be responding to non-plankton related variables.

However, all species other than Capelin and Arctic Sand Lance increase in abundance along with Copepods and Mysids, which increase in abundance with proximity to the Elson Lagoon. Copepods are an energy rich prey resource that is favored by many species of fish and Mysids (Campbell et al., 2009; Michaud et al., 1996; Theilacker and Kimball, 1984), and thus it is expected that fish and Mysids will congregate in areas where copepods are abundant. Furthermore, plankton tow surveys done in 2014 and 2015 around Point Barrow (Pinchuk pers. comm.) indicate that the Elson Lagoon is a hotspot for small neritic copepods that are an excellent prey item for juvenile or larger fish. This supports the findings of Dunton et al. (2006) which indicated that nearshore fish communities in the Beaufort Sea are highly dependent on nutrients provided by lagoons as the Beaufort Sea is relatively unproductive in comparison to the Chukchi Sea.

When the influence of environmental conditions, space, and time $\left(\mathrm{ENV}_{\text {zoop }}\right.$, $\mathrm{SPT}_{\text {zoop }}$, and $\mathrm{TMP}_{\text {zoop }}$ ) are removed, most species of fish are collapsed at the center of the ordination. The zooplankton taxa that were most explanatory change, in this case Mysids and Chaetognaths become the most important. Slender Eelblennies were abundant along with Mysids which are generally about the same size as the Slender Eelblennies that were caught, and thus is unlikely that this is due to a predator-prey relationship. Instead, it seems more likely that Mysids and Slender Eelblennies share similar prey resources, and this is supported by the similar trophic niche space that they share (Chapter VII). Ciscos are most abundant coincident with Chaetognaths, and stomach contents of Ciscos and Chaetognaths indicates that they both prey on small sized zooplankton (Dunton et al., 2012; Norcross et 
al. pers. comm.). It is notable, that Pacific Capelin and Arctic Sand Lance, which stood out in the model constrained by all explanatory variable matrices, no longer stand out when the partial contributions of environmental conditions, space and time are removed, suggesting that their coincidence with Amphipods and Ctenophores is related to environment, space, or time rather than the abundance of these plankton taxa as suggested above.

\section{Conclusions}

Changes in community composition in the Arctic nearshore in the Point Barrow region is strongly dependent on habitat type, as indicated by the clear separation of species groups in relation to waterbodies. This relationship is largely driven by salinity. The abundance of Copepods covaried with salinity and distance between waterbodies, and most species of fish sampled tend to increase along with copepods, suggesting that the Arctic nearshore is dependent on copepod production in these lagoon systems.

Biogeographic affinities of the dominant species collected in each waterbody indicate that species that are abundant in Beaufort Sea and Elson Lagoon are likely to originate in the Arctic (in freshwater or the Arctic Ocean), and these all tend to be favored by colder conditions. Whereas species that are most abundant in the Chukchi Sea are associated with warmer condition and are likely to be advected to the region by the ACC. As the climate continues to warm in the Arctic, and ice coverage continues to decrease, it can be expected that these Arctic warm-water species will become more prevalent as their range expands and increase in abundance in the Arctic. Further evidence of this imminent shift in species abundance in the Arctic is apparent as these Arctic warm-water species 
become more abundant later in the summer months as temperatures increase, as well as in warmer years.

The implications that changing species abundances may have on Arctic food webs and ecosystems is unclear, though it is possible that changing conditions of the Arctic nearshore and increasing competition from Arctic warm-water species will have detrimental or deleterious effects on populations of Arctic cold-water fish species. On a more positive note, these warm-associated fish species such as Pacific Capelin and Arctic Sand Lance are a high energy prey resource and are often present in extremely high abundances, thus offering a new high-quality prey and perhaps a glimmer of hope for piscivores that are also challenged by changing Arctic conditions.

\section{References}

Anderson, M.J., Cribble, N.A., 1998. Partitioning the variation among spatial, temporal and environmental component in a multivariate data set. Aust. J. Ecol. 23, 158-167.

Berkman, P., Young, O., 2009. Governance and environmental change in the Arctic Ocean. Science (80). 324, 339-340.

Blanchet, G., Legendre, P., Borcard, D., 2008. Forward selection of spatial explanatory variables. Ecology 89, 2623-2632. https://doi.org/10.1890/07-0986.1

Bluhm, B., Gradinger, R., 2008. Regional variability in food availability for Arctic marine mammals. Ecol. Appl. 18, S77-S96. https://doi.org/http://dx.doi.org/10.1890/06-0562.1

Brewster, K., Program, O.H., Aiken, M., Brower, A., Itta, M., Itta, N., Leavitt, M. Lou, Leavitt, O., Matumeak, W., 2010. Iñupiat knowledge of selected subsistence fish near Barrow, Alaska. Wildlife Management Barrow Elders.

Campbell, R.G., Sherr, E.B., Ashjian, C.J., Plourde, S., Sherr, B.F., Hill, V., Stockwell, D. A., 2009. Mesozooplankton prey preference and grazing impact in the western Arctic Ocean. Deep. Res. Part II Top. Stud. Oceanogr. 56, 1274-1289. https://doi.org/10.1016/j.dsr2.2008.10.027 
Carothers, C., 2013. Coastal Marine Institute Subsistence Use and Knowledge of salmon in Barrow and Nuiqsut, Alaska. https://doi.org/2013-0015

Craig, P., 1984. Fish use of coastal waters of the Alaskan Beaufort Sea: a review. Trans. Am. Fish. Soc. 113, 37-41.

Danielson, S.L., Weingartner, T.J., Hedstrom, K.S., Aagaard, K., Woodgate, R., Curchitser, E., Stabeno, P.J., 2014. Coupled wind-forced controls of the Bering-Chukchi shelf circulation and the Bering Strait throughflow: Ekman transport, continental shelf waves, and variations of the Pacific-Arctic sea surface height gradient. Prog. Oceanogr. 125, 40-61. https://doi.org/10.1016/j.pocean.2014.04.006

Dray, S., Pélissier, R., Couteron, P., Fortin, M.J., Legendre, P., Peres-Neto, P.R., Bellier, E., Bivand, R., Blanchet, F.G., De Cáceres, M., Dufour, A.B., Heegaard, E., Jombart, T., Munoz, F., Oksanen, J., Thioulouse, J., Wagner, H.H., 2012. Community ecology in the age of multivariate spatial analysis. Ecol. Monogr. 82, 257-275. https://doi.org/10.1890/11-1183.1

Dunton, K.H., Goodall, J.L., Schonberg, S. V., Grebmeier, J.M., Maidment, D.R., 2005. Multi-decadal synthesis of benthic-pelagic coupling in the western Arctic: Role of crossshelf advective processes. Deep. Res. Part II Top. Stud. Oceanogr. 52, 3462-3477. https://doi.org/10.1016/j.dsr2.2005.09.007

Dunton, K.H., Schonberg, S. V., Cooper, L.W., 2012. Food web structure of the Alaskan nearshore shelf and estuarine lagoons of the Beaufort Sea. Estuaries and Coasts 35, 416435. https://doi.org/10.1007/s12237-012-9475-1

Dunton, K.H., Weingartner, T., Carmack, E.C., 2006a. The nearshore western Beaufort Sea ecosystem: Circulation and importance of terrestrial carbon in arctic coastal food webs. Prog. Oceanogr. 71, 362-378. https://doi.org/10.1016/j.pocean.2006.09.011

Dunton, K.H., Weingartner, T., Carmack, E.C., 2006b. The nearshore western Beaufort Sea ecosystem: Circulation and importance of terrestrial carbon in arctic coastal food webs. Prog. Oceanogr. 71, 362-378. https://doi.org/10.1016/j.pocean.2006.09.011

Elliott, M., O’Reilly, M.G., Taylor, C.J.L., 1990. The forth estuary: a nursery and overwintering area for North Sea fishes. Hydrobiologia 195, 89-103. https://doi.org/10.1007/BF00026816

Gradinger, R., Bluhm, B., 2010. Timing of ice algal grazing by the Arctic nearshore benthic amphipod Onisimus litoralis. Arctic 63, 355-358.

Iken, K., Bluhm, B., Dunton, K., 2010. Benthic food-web structure under differing water mass properties in the southern Chukchi Sea. Deep. Res. Part II Top. Stud. Oceanogr. 57, 71-85. https://doi.org/10.1016/j.dsr2.2009.08.007 
Johannesson, O.M., Bengtsson, L., Miles, M.W., Kuzmina, S.I., Semenov, V.A., Alekseev, G. V, Nagurnyi, A.P., Zakharov, V.F., Bobylev, L.P., Pettersson, L.H., Hasselmann, K., Cattle, H.P., 2004. Arctic climate change: observed and modelled temperature and sea-ice variability. Tellus 56, 328-341.

Johnson, S.W., Thedinga, J.F., Neff, A.D., Hoffman, C.A., 2010. Fish Fauna in Nearshore Waters of a Barrier Island in the Western Beaufort Sea, Alaska.

Kneib, R., 1997. The role of tidal marshes in the ecology of estuarine nekton. Oceanogr. Mar. Biol. 35, 163-220.

Legendre, P., Borcard, D., Peres-Neto, P.R., 2005. Analyzing beta diversity: partitioning the spatial variation of community composition data. Ecol. Monogr. 75, 435-450. https://doi.org/10.1890/05-0549

Legendre, P., Gauthier, O., 2014. Statistical methods for temporal and space - time analysis of community composition data Statistical methods for temporal and space - time analysis of community composition data $\uparrow$.

Logue, J.B., Mouquet, N., Peter, H., Hillebrand, H., 2011. Empirical approaches to metacommunities: A review and comparison with theory. Trends Ecol. Evol. 26, 482-491. https://doi.org/10.1016/j.tree.2011.04.009

Michaud, J., Fortier, L., Rowe, P., Ramseier, R., 1996. Feeding success and survivorship of Arctic cod larvae, Boreogadus saida, in the northeast Water polynya (Greenland Sea). Fish. Oceanogr. 5, 120-135.

Norcross, B.L., Holladay, B.A., Busby, M.S., Mier, K., 2004. RUSALCA - Fisheries Ecology and Oceanography.

Nuraini, S., Carballo, E.C., Van Densen, W.L.T., Machiels, M.A.M., Lindeboom, H.J., Nagelkerke, L.A.J., 2007. Utilization of seagrass habitats by juvenile groupers and snappers in Banten Bay, Banten Province, Indonesia. Hydrobiologia 591, 85-98. https://doi.org/10.1007/s10750-007-0786-3

Okkonen, S., 2008. Exchange between Elson Lagoon and the nearshore Beaufort Sea and its role in the aggregation of zooplankton 18.

Palmer, M.W., 1993. Putting thing in event better order: The advantages of Canonical Correspondence Analysis. Ecology 74, 2215-2230.

Purcell, J.E., Sturdevant, M. V., 2001. Prey selection and dietary overlap among zooplanktivorous jellyfish and juvenile fishes in Prince William Sound, Alaska. Mar. Ecol. Prog. Ser. 210, 67-83. 
Stabeno, P.J., Reed, R.K., Schumacher, J.D., 1995. The Alaska coastal current: Continuity of transport and forcing. J. Geophys. Res. 100, 2477-2485.

Ter Braak, C.J.F., 1987. The analysis of vegetation-environment relationships by canonical correspondence analysis. Vegetation 69, 69-77.

Theilacker, G.H., Kimball, A.M.Y.S., 1984. Comparative quality rotifers and copepods as foods for larval fishes. Calif. Coop. Ocean. Fish. Investig. XXV, 80-86.

Vesin, J., Legget, W., Able, K., 1981. Feeding ecology of capelin (Mallotus villosus) in the estuary and Western Gulf of St. Lawrance and its multispecies implications. Can. J. Fish. Aquat. Sci. 38, 257-267. 


\section{Tables}

Table 2.1 A summary of fish species and abundances used in CCA analyses. The Centroid Label column refers to the label used in CCA ordination plots for each of the species centroids.

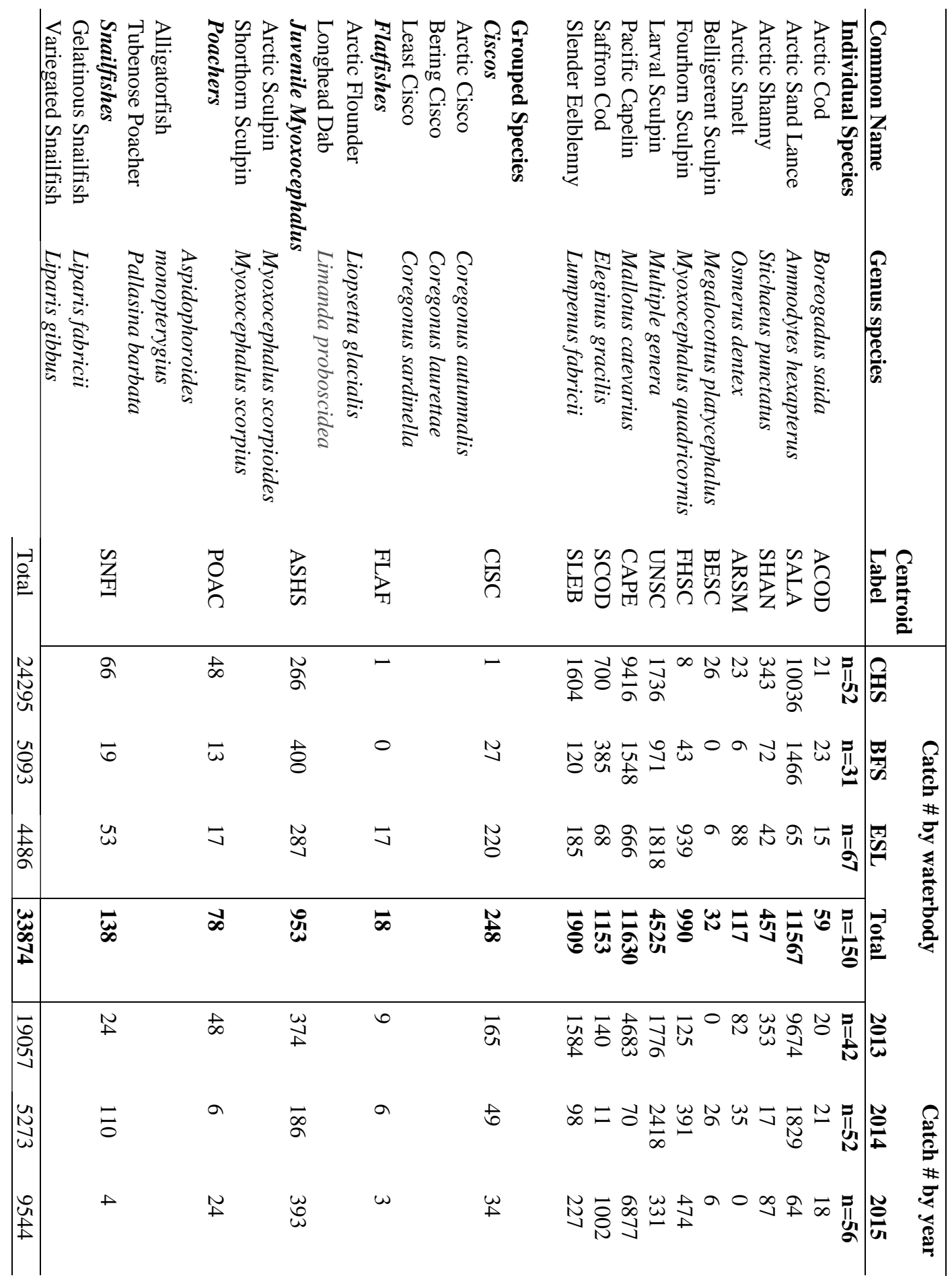


Table 2.2 A summary of all variables included in the study. The variables highlighted in color are those which were selected as the most explanatory significant variables for each variable type (environmental, spatial, and temporal) using the forward selection process outlined by Blanchet et al. (2008). Only those variables which were selected were assigned labels, which are used as shorthand in subsequent CCA ordination plots as well as discussion of those variables. The Explanatory Matrix column indicates the fundamental explanatory matrix in which each variable was included, and the highlighter color corresponds to the same colored circle in the Venn Diagram in Figure 2.2.

\begin{tabular}{|c|c|c|}
\hline Variable & Label & $\begin{array}{l}\text { Explanatory } \\
\text { Matrix }\end{array}$ \\
\hline \multicolumn{3}{|l|}{ Environmental Variables } \\
\hline Surface Salinity & Salinity & ENV \\
\hline Dissolved Oxygen & DO & ENV \\
\hline 3hr Easterly Component of Wind Speed & 3hr.East.Wind & ENV \\
\hline $\begin{array}{l}\text { Surface Temperature } \\
\text { Air Temperature ( } 2 \mathrm{~m} \text { asl) } \\
3 \mathrm{hr} \text { Wind Direction } \\
3 \mathrm{hr} \text { Beach Oriented Wind Direction } \\
3 \mathrm{hr} \text { Wind Speed } \\
3 \mathrm{hr} \text { Southerly Component of Wind } \\
\text { Speed }\end{array}$ & & \\
\hline \multicolumn{3}{|l|}{ Spatial Variables } \\
\hline distance-based MEM.1 & dbMEM.1 & SPT \\
\hline $\begin{array}{l}\text { distance-based MEM.2 } \\
\text { distance-based MEM.3 } \\
\text { distance-based MEM.4 }\end{array}$ & & \\
\hline \multicolumn{3}{|l|}{ Temporal Variables } \\
\hline time-based MEM.2 & tbMEM.2 & TMP \\
\hline Days since ice break up in Elson Lagoon & Daysicefree & TMP \\
\hline Time of day & Time.of.Day & TMP \\
\hline Year (Categorical) & 2013,2014 , and 2015 & TMP \\
\hline $\begin{array}{l}\text { time-based MEM.1 } \\
\text { time-based MEM. } 3 \\
\text { time-based MEM.4 } \\
\text { time-based MEM.5 } \\
\text { time-based MEM. } 6 \\
\text { Davs since sionificant wind event }\end{array}$ & & \\
\hline
\end{tabular}




\section{Figures}

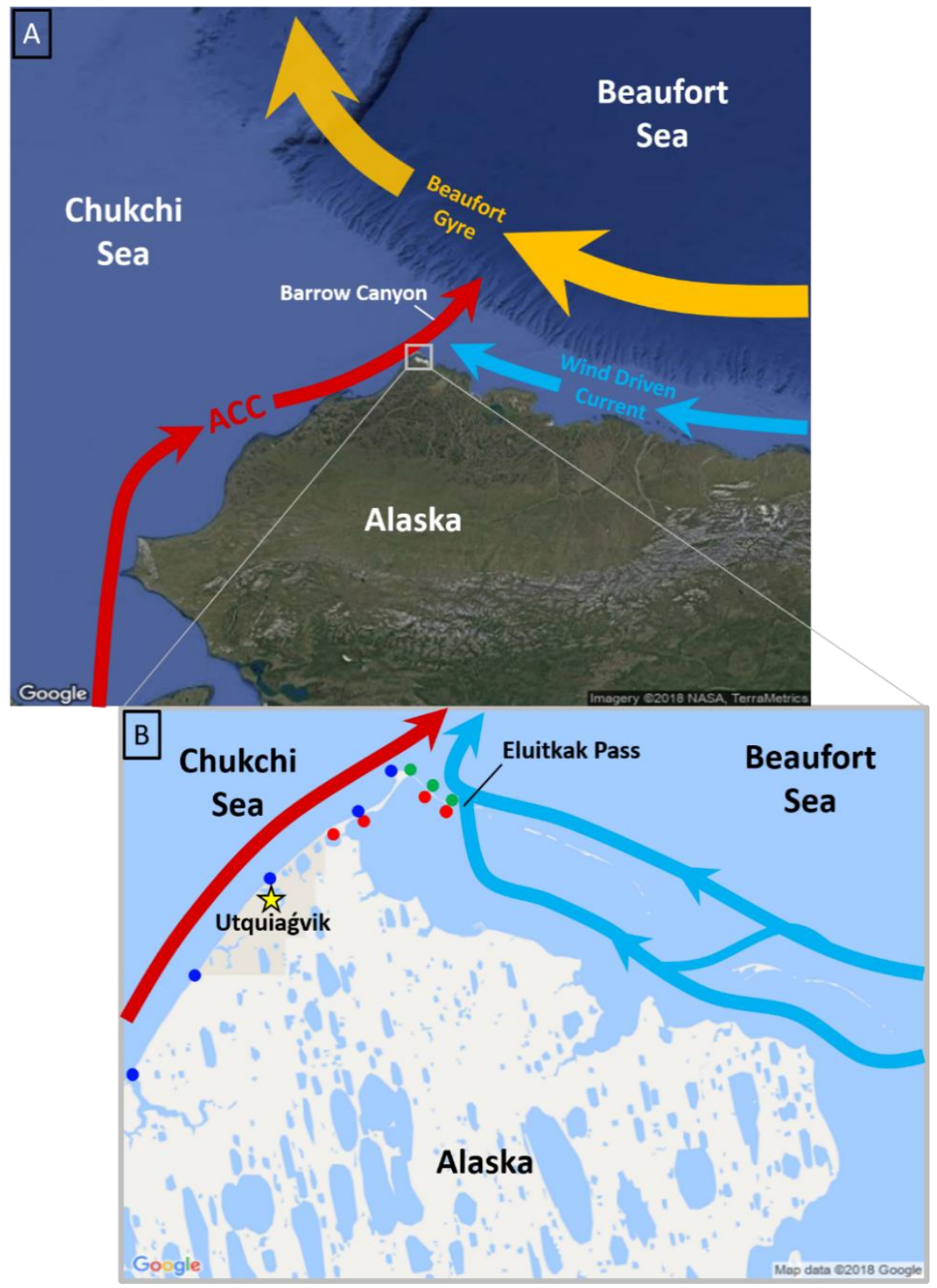

Figure 2.1 A map of the study area and relevant geographic and oceanographic features. Sampling stations are depicted by circles: blue (Chukchi Sea), green (Beaufort Sea), and red (Elson Lagoon). The prevalent flow of the Alaska Coastal Current (ACC) is depicted by red arrows traveling along the Alaskan coast north past Point Barrow through the Barrow Canyon. The Beaufort Gyre moved water in a clockwise direction (westward) along the Beaufort Sea continental shelf (yellow arrows). The prevalent wind driven flow along the Beaufort coast and through the Elson Lagoon out Eluitkak Pass is depicted by blue arrows. 


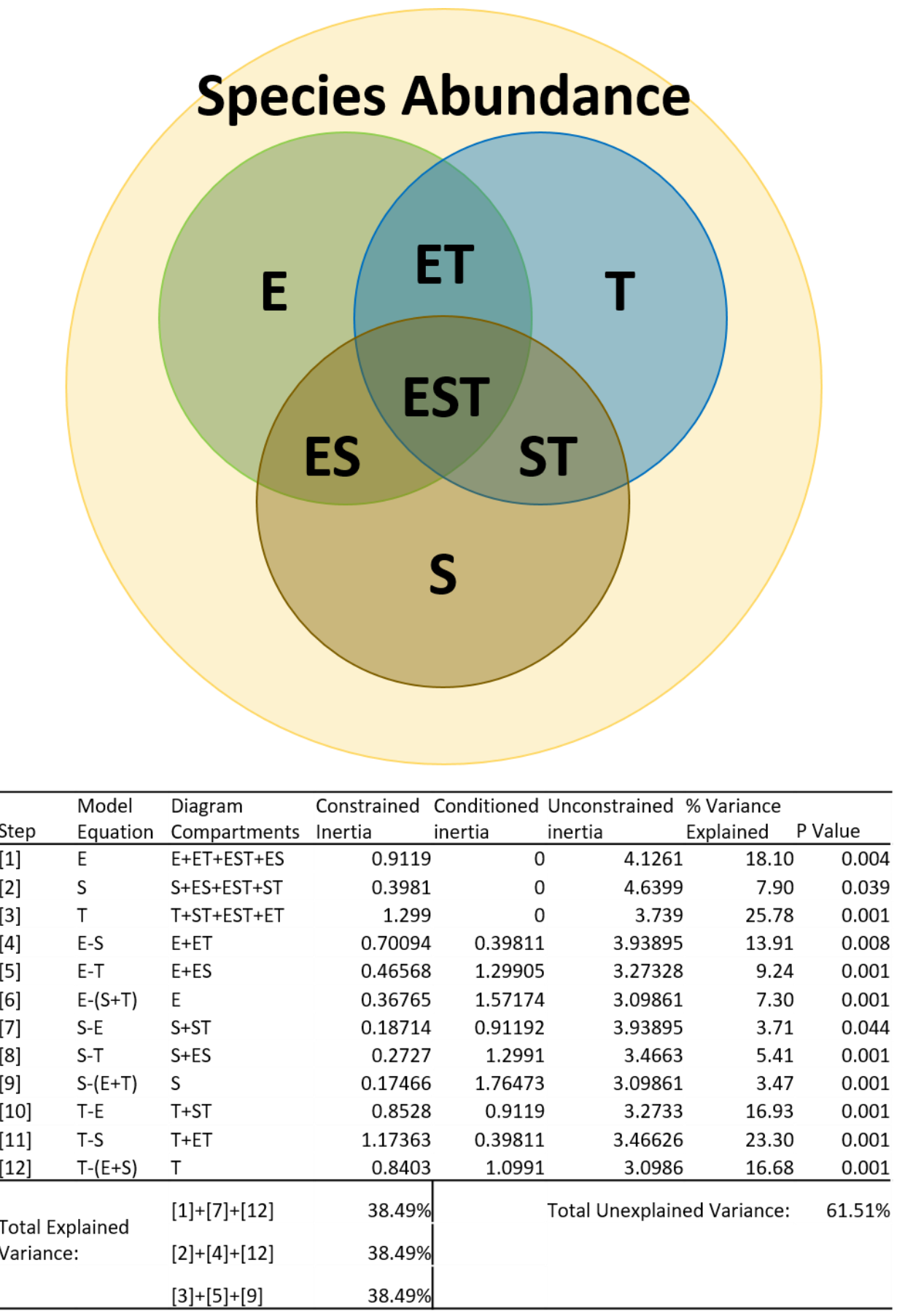

Figure 2.2 A modification of Anderson and Cribble's (1998) representation of variance in species abundance (yellow circle) explained by three fundamental variable matrices: ENV in Green, SPT in Brown, and TMP in Blue. The Model Equation column indicates which variable matrix was used to constrain the model, and which matrices were conditioned out (represented by subtraction). The Diagram Compartments column represents the variance compartments in the Venn Diagram explained by each model. The following three columns (Constrained, Conditioned, and Unconstrained Inertia) represent the portion of the total inertia (5.038) that is constrained, conditioned or unconstrained in each model. 


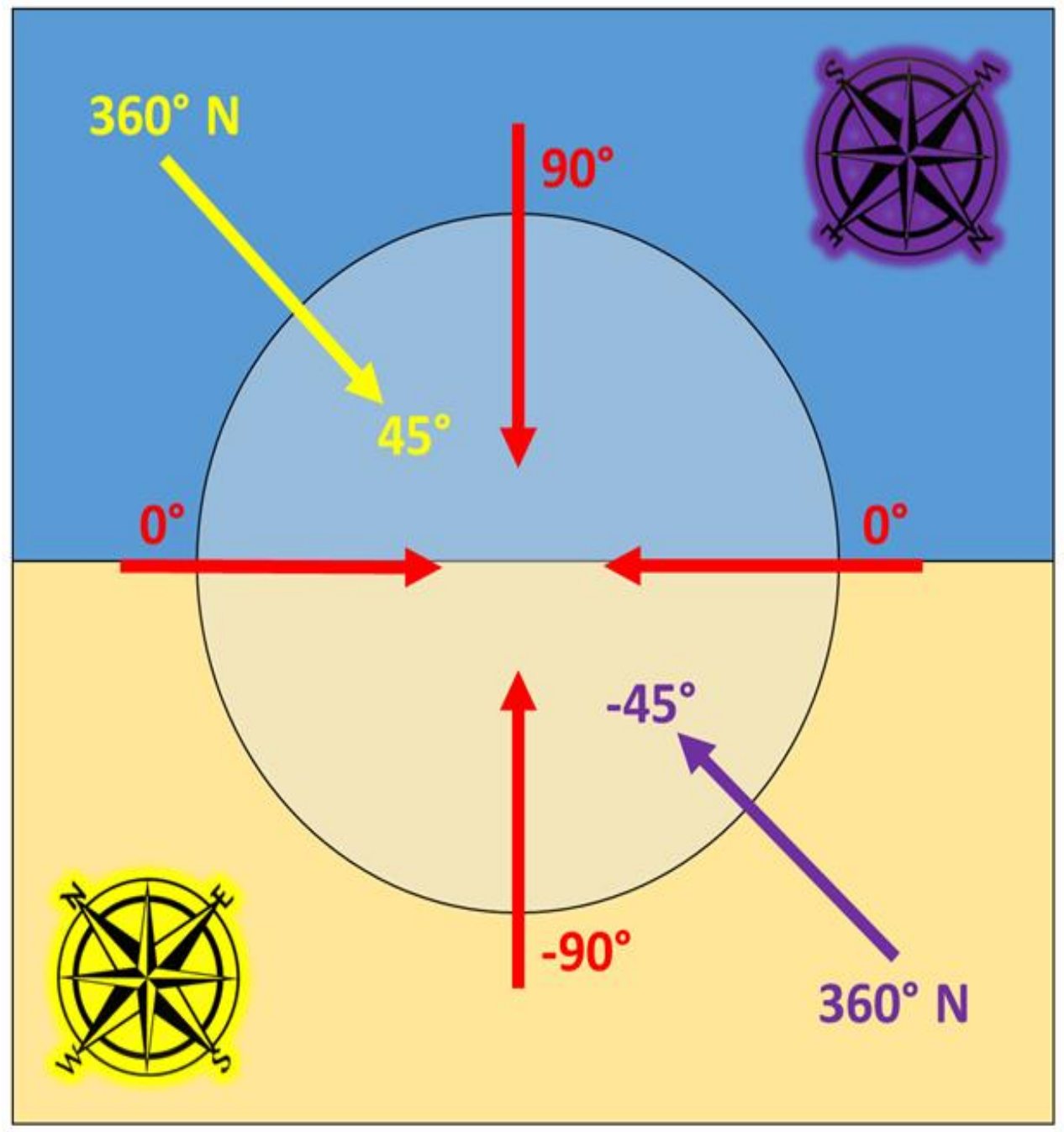

Figure 2.3 Beach Oriented Wind Direction (BOWD) was derived for each survey station. The red arrows represent the structure of the BOWD variable. During an onshore wind the beach is exposed to waves and thus these winds are scored higher (up to $90^{\circ}$ ), an offshore wind renders the beach sheltered and thus this has the lower scores (down to $-90^{\circ}$ ), and a longshore wind is ranked neutrally at $0^{\circ}$. The yellow and purple arrows and compasses show how a North wind $\left(360^{\circ}\right)$ can have opposite angles to two beaches on either side of a barrier island. In Yellow, the compass indicates that the beach is oriented in a Northeasterly direction, such as our Beaufort Sea stations. In this case, a North wind $\left(360^{\circ}\right)$ would result in an onshore wind at a $45^{\circ}$ angle to the beach. However, if sampling from Southwesterly facing beach such as the Elson Lagoon stations on the inside of the Eluitkak Pass, this same North wind would result in an offshore wind at $45^{\circ}$. This exemplifies the importance of accounting for beach orientation when considering wind direction. 


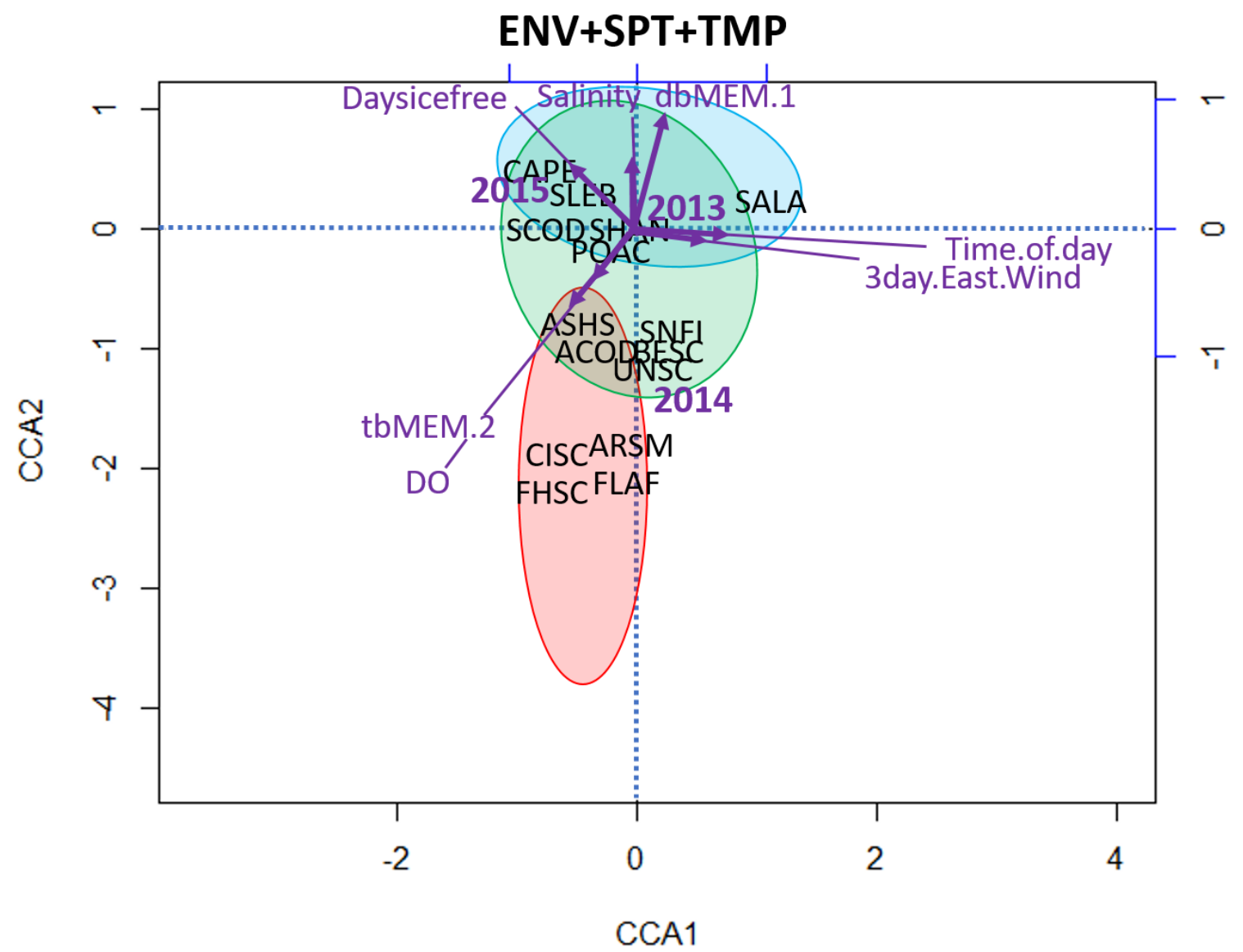

Figure 2.4 A CCA ordination plot constrained by all three explanatory matrices (ENV, SPT, and TMP). Ellipses represent standard deviation from the waterbody centroids: Blue is Chukchi Sea, Green is Beaufort Sea, and Red is Elson Lagoon. Black labels are species centroids: ACOD (Arctic Cod), SALA (Arctic Sand Lance), SHAN (Arctic Shanny), ARSM (Arctic Smelt), BESC (Belligerent Sculpin), FHSC (Fourhorn Sculpin), UNSC (Larval Sculpin), CAPE (Pacific Capelin), SCOD (Saffron Cod), SLEB (Slender Eelblenny), CISC (Ciscos), FLAF (Flatfishes), ASHS (Arctic/Shorthorn Sculpin), POAC (Poachers), SNFI (Snailfishes). Purple vectors represent variable axes, the length of the vector represents the strength of that variables influence on species centroid position in ordination space. Years were used as categorical variables, and thus 2013, 2014, and 2015 are displayed as centroid centers. 


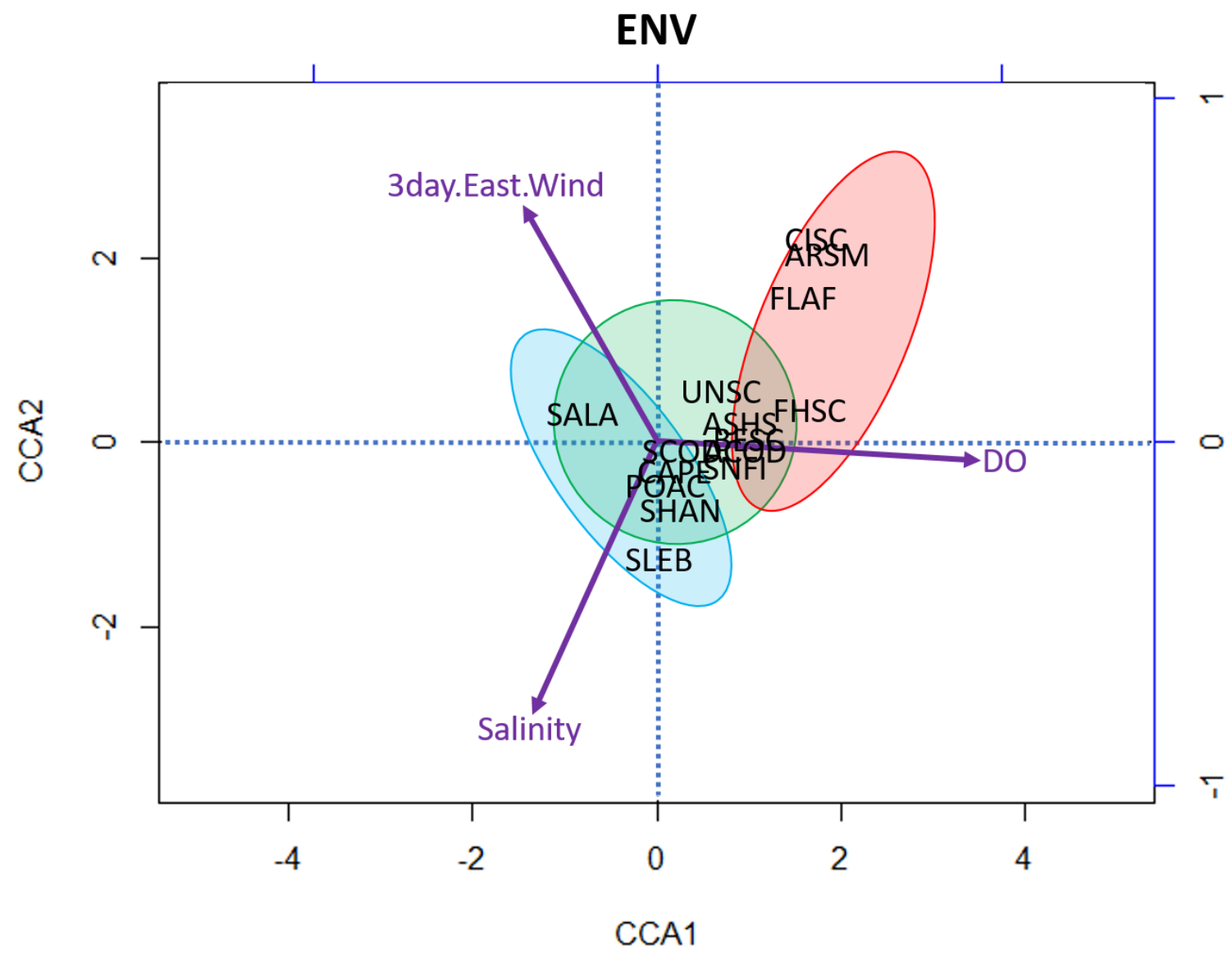

Figure 2.5 A CCA ordination plot constrained only by ENV. Ellipses represent standard deviation from the waterbody centroids: Blue is Chukchi Sea, Green is Beaufort Sea, and Red is Elson Lagoon. Black labels are species centroids: ACOD (Arctic Cod), SALA (Arctic Sand Lance), SHAN (Arctic Shanny), ARSM (Arctic Smelt), BESC (Belligerent Sculpin), FHSC (Fourhorn Sculpin), UNSC (Larval Sculpin), CAPE (Pacific Capelin), SCOD (Saffron Cod), SLEB (Slender Eelblenny), CISC (Ciscos), FLAF (Flatfishes), ASHS (Arctic/Shorthorn Sculpin), POAC (Poachers), SNFI (Snailfishes). Purple vectors represent variable axes, the length of the vector represents the strength of that variables influence on species centroid position in ordination space. 


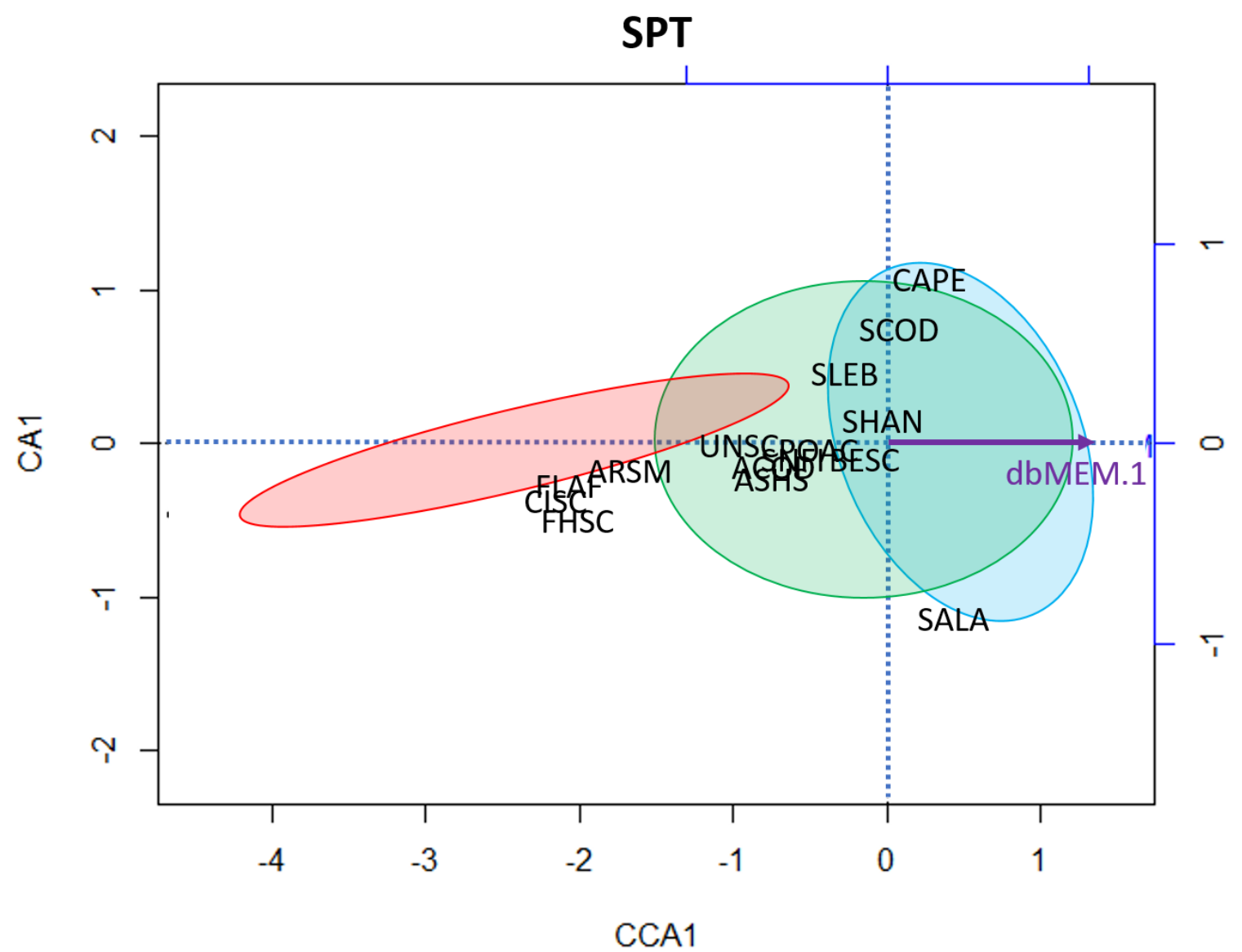

Figure 2.6 A CCA ordination plot constrained only by SPT. Ellipses represent standard deviation from the waterbody centroids: Blue is Chukchi Sea, Green is Beaufort Sea, and Red is Elson Lagoon. Black labels are species centroids: ACOD (Arctic Cod), SALA (Arctic Sand Lance), SHAN (Arctic Shanny), ARSM (Arctic Smelt), BESC (Belligerent Sculpin), FHSC (Fourhorn Sculpin), UNSC (Larval Sculpin), CAPE (Pacific Capelin), SCOD (Saffron Cod), SLEB (Slender Eelblenny), CISC (Ciscos), FLAF (Flatfishes), ASHS (Arctic/Shorthorn Sculpin), POAC (Poachers), SNFI (Snailfishes). Purple vectors represent variable axes, the length of the vector represents the strength of that variables influence on species centroid position in ordination space. 


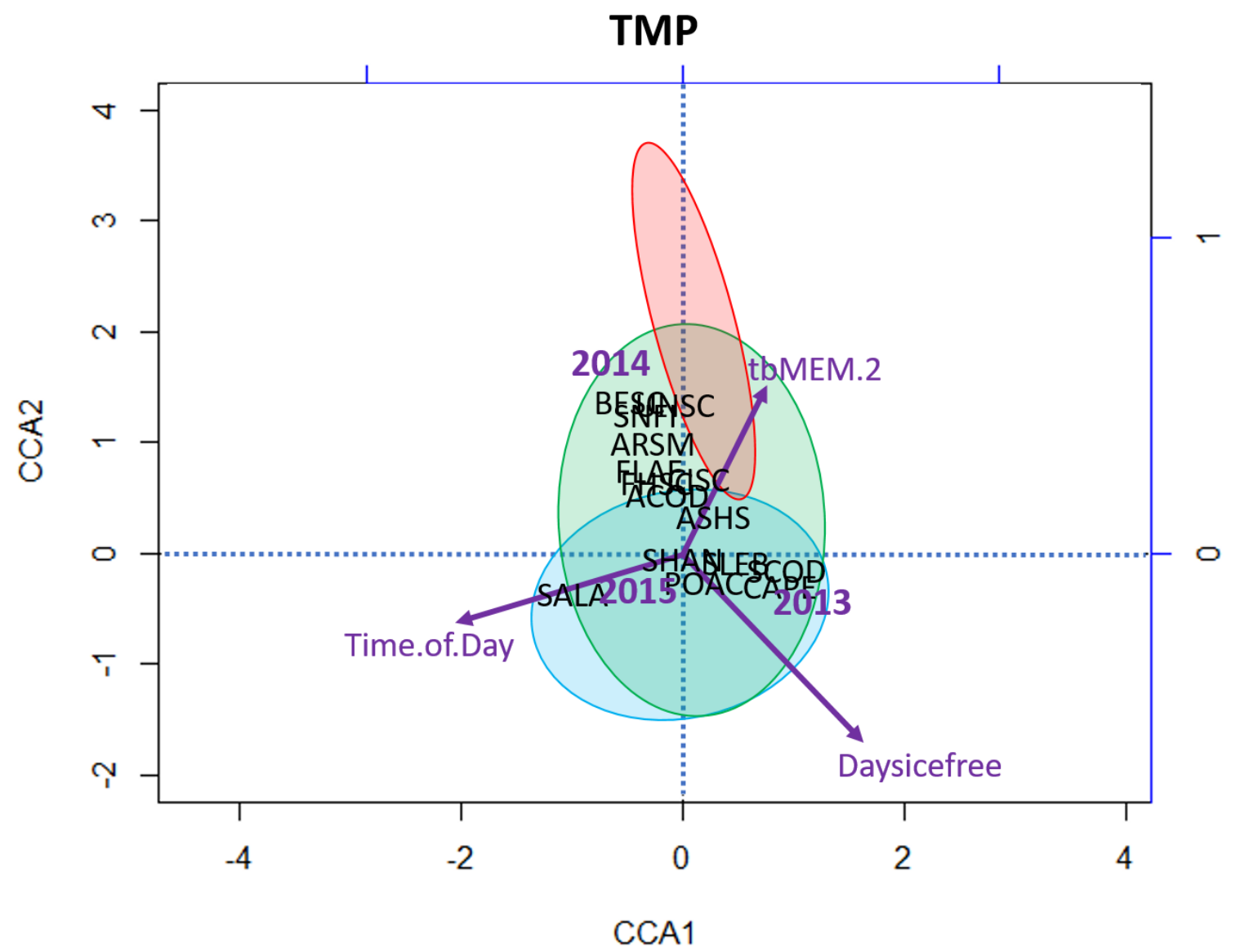

Figure 2.7 A CCA ordination plot constrained only by TMP. Ellipses represent standard deviation from the waterbody centroids: Blue is Chukchi Sea, Green is Beaufort Sea, and Red is Elson Lagoon. Black labels are species centroids: ACOD (Arctic Cod), SALA (Arctic Sand Lance), SHAN (Arctic Shanny), ARSM (Arctic Smelt), BESC (Belligerent Sculpin), FHSC (Fourhorn Sculpin), UNSC (Larval Sculpin), CAPE (Pacific Capelin), SCOD (Saffron Cod), SLEB (Slender Eelblenny), CISC (Ciscos), FLAF (Flatfishes), ASHS (Arctic/Shorthorn Sculpin), POAC (Poachers), SNFI (Snailfishes). Purple vectors represent variable axes, the length of the vector represents the strength of that variables influence on species centroid position in ordination space. Years were used as categorical variables, and thus 2013, 2014, and 2015 are displayed as centroid centers. 


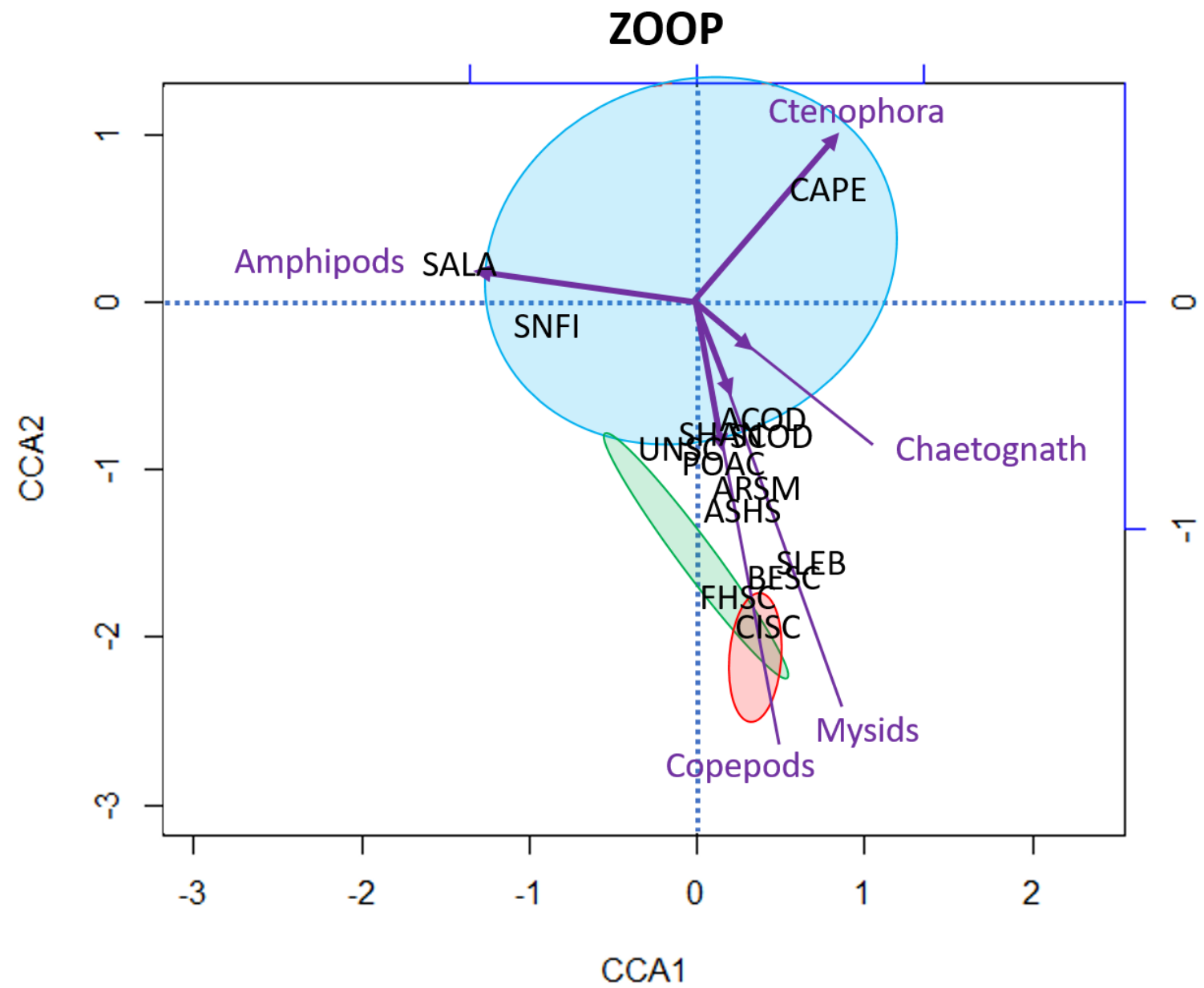

Figure 2.8 A CCA ordination plot constrained only by ZOOP. Ellipses represent standard deviation from the waterbody centroids: Blue is Chukchi Sea, Green is Beaufort Sea, and Red is Elson Lagoon. Black labels are species centroids: ACOD (Arctic Cod), SALA (Arctic Sand Lance), SHAN (Arctic Shanny), ARSM (Arctic Smelt), BESC (Belligerent Sculpin), FHSC (Fourhorn Sculpin), UNSC (Larval Sculpin), CAPE (Pacific Capelin), SCOD (Saffron Cod), SLEB (Slender Eelblenny), CISC (Ciscos), FLAF (Flatfishes), ASHS (Arctic/Shorthorn Sculpin), POAC (Poachers), SNFI (Snailfishes). Purple vectors represent variable axes, the length of the vector represents the strength of that variables influence on species centroid position in ordination space. 


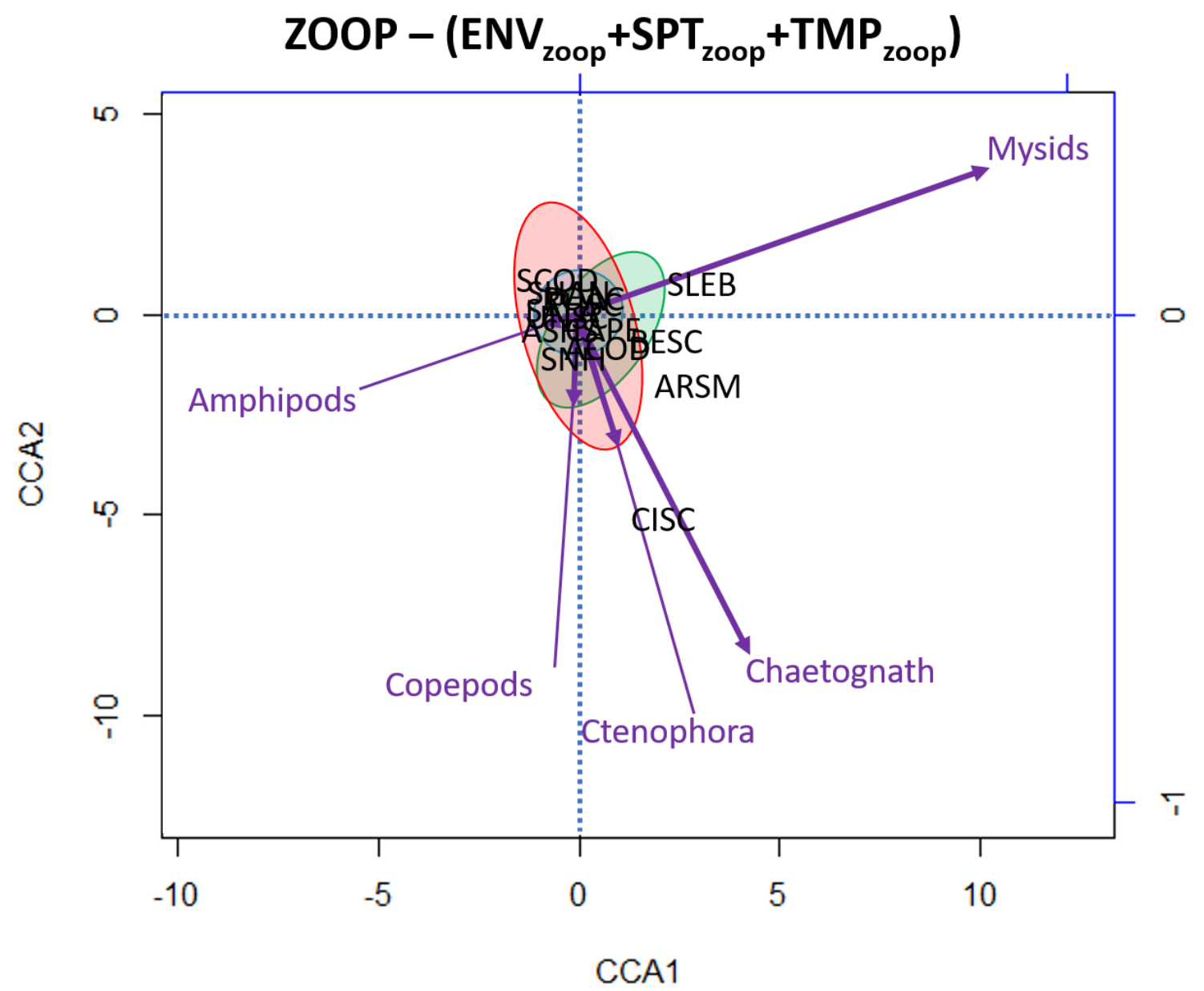

Figure 2.9 A CCA ordination plot constrained by ZOOP, with partial contributions from $\mathrm{ENV}_{\text {zoop }}+\mathrm{SPT}_{\text {zoop }}+\mathrm{TMP}_{\text {zoop }}$ conditioned out. Ellipses represent standard deviation from the waterbody centroids: Blue is Chukchi Sea, Green is Beaufort Sea, and Red is Elson Lagoon. Black labels are species centroids: ACOD (Arctic Cod), SALA (Arctic Sand Lance), SHAN (Arctic Shanny), ARSM (Arctic Smelt), BESC (Belligerent Sculpin), FHSC (Fourhorn Sculpin), UNSC (Larval Sculpin), CAPE (Pacific Capelin), SCOD (Saffron Cod), SLEB (Slender Eelblenny), CISC (Ciscos), FLAF (Flatfishes), ASHS (Arctic/Shorthorn Sculpin), POAC (Poachers), SNFI (Snailfishes). Purple vectors represent variable axes, the length of the vector represents the strength of that variables influence on species centroid position in ordination space. 


\section{CHAPTER III}

EXPERIMENTAL DETERMINATION OF TISSUE TURNOVER RATES AND TROPHIC DISCRIMINATION FACTORS FOR STABLE CARBON AND NITROGEN ISOTOPE RATIOS FOR ARCTIC SCULPIN (MYOXOCEPHALUS

SCORPIOIDES): A COMMON ARCTIC NEARSHORE FISH 


\section{Abstract}

Rapid environmental changes occurring in the Arctic nearshore are expected to have significant effects on food web structures. Landfast ice cover limits the effectiveness of monitoring methods during winter months, precluding understanding of how seasonal Arctic nearshore food webs operate. Tissue-dependent stable isotope analysis (SIA) offers an efficient and cost-effective approach to monitoring changes in food webs during icecovered months, but requires controlled laboratory experiments to determine isotopic turnover rates and trophic discrimination factors (TDFs) of different tissues. We propose that Arctic Sculpin (Myoxocephalus scorpioides) be used to investigate Arctic nearshore trophodynamics given its opportunistic feeding habits and consistent residence within nearshore Arctic habitats. We present the first tissue-dependent SIA experiment on an Arctic marine fish species and show that nitrogen isotope ratios of fin (or liver) and muscle of Arctic Sculpin may be used to identify shifts in low-trophic-level resource availability between 56 and 122 days before sacrifice. Furthermore, TDFs were determined for carbon isotopes $(1.87 \%$ ), but results for nitrogen (1.23\%o to $3.23 \%$ ) suggest that TDFs in Arctic fish may be highly dependent on lipid content of their diet. We observed similar turnover rates between liver and fin tissues (56 and 58 days, respectively), and suggest it may not be necessary to sample both, making it possible to use Arctic Sculpin for tissue dependent analyses with potentially non-lethal sampling of fin and muscle tissues.

\section{Introduction}

Climate change and associated repercussions such as decreasing sea ice cover, storm-driven marine mixing, and changes in freshwater input to marine environments will 
likely affect Arctic marine food webs (AMAP, 2008; Berkman and Young, 2009; Divoky et al., 2015; Grebmeier, 2012). In response to these imminent threats, much work has been done to better understand the ecology of Arctic marine ecosystems, but until recently the very nearshore ( $<15 \mathrm{~m}$ depth) has been largely excluded from these efforts despite the known vulnerability of these habitats (Dunton et al., 2014, 2012, 2006; Gundlach and Hayes, 1978; McTigue and Dunton, 2014). These ecosystems are inhabited by multiple endangered and protected marine mammals and sea birds that are important resources for subsistence hunters and fishermen in the Arctic. It is expected that these environmental changes will cause shifts in nearshore food web structure and basal resources that are likely to cascade through all trophic levels (Gradinger and Bluhm, 2010; Grebmeier et al., 2006). It is unclear how these changes will impact nearshore wildlife, but previous research has shown that even the smallest perturbations in food web structure can have drastic cascading effects on ecosystems (Fortin et al., 2005; Mumby et al., 2012; Pace et al., 1999); thus, it is imperative to monitor changes to make predictions of future conditions and provide protection for relatively pristine Arctic ecosystems.

To quantify and understand changes, it is helpful to first recognize the annual variability in trophic dynamics in nearshore Arctic habitats under current climatic conditions. Landfast ice cover limits sample collection from October to June in the Arctic nearshore and consequently, little is known about the variability in trophodynamics outside of the open-water summer period. However, stable isotope analysis (SIA) of carbon and nitrogen isotope ratios $\left(\delta^{13} \mathrm{C}\right.$ and $\delta^{15} \mathrm{~N}$, respectively) is a great tool to investigate feeding during the ice-covered period because it is dependent on the assumption that an organism's tissues are derived of the material they ingest over time, and thus represents feeding that 
occurred days to years before the organism is collected (Fry, 2006; Hobson and Clark, 1992; Madigan et al., 2012). Therefore, SIA is useful to gain significant insight to the level of trophic variation in nearshore food webs during periods when sampling is hindered; that may lead to a better understanding of future changes in structure and function of these ecosystems.

The interpretation of stable isotope ratios is dependent on a thorough understanding of metabolic and growth processes that incorporate isotopes into consumer tissues. Controlled lab experiments can measure isotopic tissue turnover rates (TTRs) and trophic discrimination factors (TDFs) for a species to provide temporal context of isotopic ratios among tissue types and investigate trophic structure, respectively (Hobson and Clark, 1992; Madigan et al., 2012; Tieszen et al., 1983). Previous controlled isotope experiments on fish have reported TTRs ranging from a few days (Bosley et al., 2002) to over a year (Gaston and Suthers, 2004) depending on tissue type and life-stage. Often, TDFs for nitrogen and carbon of $3.4 \%$ and $1 \%$ are used across marine species and ecosystems (Post, 2002). However, a large array of environmental conditions can impact metabolic rates and thus TTRs and TDFs (Vander Zanden and Rasmussen, 2001), making it important to investigate these parameters for species in extreme environments. Furthermore, differential assimilation of macromolecules from dietary materials into different tissues can cause unexpected variability in trophic discrimination among species, environmental conditions, or diet types (Gannes et al., 1997; Vander Zanden and Rasmussen, 2001). Many studies have been conducted on the topic of tissue turnover and trophic discrimination, but few have focused on Arctic marine organisms, and none of them have focused on Arctic marine fish. To address this gap in knowledge, we conducted a controlled experiment to determine 
TTRs and TDFs in fin, liver, and muscle tissues of Arctic Sculpin (Myoxocephalus scorpioides).

Arctic Sculpin is well suited to investigate trophodynamics of Arctic nearshore habitats for several reasons. (1) Arctic Sculpin are commonly observed in a variety of Arctic nearshore habitats and can be sampled easily and cost effectively from shore with beach seines or fish traps (Mecklenburg et al. 2010). (2) Sculpins are opportunistic feeders (Gray et al., 2017; Link and Almeida, 2002) and are expected to assimilate materials from all available prey resources into their own tissues. (3) Their high site fidelity suggests that their tissues would be representative of the habitat in which they are sampled (Gray et al., 2004).

We present the first experimental data to examine the incorporation of stable isotopes in Arctic marine fish tissues, and establish the Arctic Sculpin as a useful tool in assessing changes in trophodynamics of nearshore Arctic habitats. We hope that the experiment prompts further development of this useful bioindicator species as it can potentially be used to investigate any biological responses to ecological change that manifest themselves within tissue composition.

\section{Methods}

\subsection{Husbandry}

Juvenile Arctic Sculpin $(<50 \mathrm{~mm} ; \mathrm{n}=86)$, were collected by beach seines from nearshore Arctic lagoons and barrier island shores near Point Barrow, Alaska during July and August 2014, and transported alive to climate controlled holding tanks at Florida International University, Miami, FL. Throughout the duration of the experiment, fish were 
maintained in $51 \mathrm{~L}$ tanks with a bottom surface area of $0.25 \mathrm{~m}^{2}$. Water temperatures were maintained at $8^{\circ} \mathrm{C}$ to mimic summer conditions in the Arctic nearshore ( $<15 \mathrm{~m}$ depth) when fish growth is expected to be maximized (Fonds et al., 1992; Vollenweider et al., 2016). No more than 5 individual fish were kept in each of 22 tanks at any given time during the experiment. Fish were fed a diet of homogenized Antarctic Krill (Euphausia superba; $\delta^{13} \mathrm{C}=-23.72 \pm 0.09 \%, \delta^{15} \mathrm{~N}=4.92 \pm 0.21 \%$, CSan Francisco Bay Brand fish foods) during a 36-day quarantine and acclimation period. Since the fast growth of juveniles incorporates new isotopes rapidly (Bosley et al., 2002; Fry and Arnold, 1982), feeding was minimized to 2 times per week during this period to prevent significant growth, so that the isotope incorporation could be documented during the experiment.

To track individual growth rates throughout the experiment, each specimen was assigned to a holding tank, tagged using a subcutaneous Visible Implant Elastomer Tag (Northwest Marine Technology, Inc.) in one of four colors on the left or right side of the anal fin. Every 7 days following the start of the experiment each fish was weighed to the nearest $\mathrm{mg}$, and length was measured to the nearest $0.01 \mathrm{~mm}$ (TL). Fish that developed ailments that might affect growth or metabolic rates were culled from the experiment $(n=10)$ and their data were not used in subsequent analyses.

Our approach to quantifying isotopic turnover in Arctic Sculpin tissues was adapted from Tieszen et al. (1983). After the acclimation period (day 0), half $(n=43)$ of the fishes' diets were switched from Antarctic Krill to a homogenized fish diet $\left(\delta^{13} \mathrm{C}=-21.72 \pm 0.27\right.$ $\%$ o, $\delta^{15} \mathrm{~N}=15.36 \pm 0.16 \%$ ) consisting of Pacific Capelin (Mallotus catervarius) and Arctic Sand Lance (Ammodytes hexapterus) collected by beach seine in Point Barrow, AK during July and August 2014. All diets were homogenized in one single batch, frozen, and used 
through the entire experiment to ensure consistent isotopic composition. Both diets had similar protein content (Krill: 70\%, Fish: $72 \%$ dry weight) but lipid content was different (Krill: 6\%, Fish: 24\% dry weight). Thus, these diets will be referred to as LLK (Low Lipid Krill) and HLF (High Lipid Fish). The HLF diet was derived from fish collected in the natural habitat of Arctic Sculpin, and thus is naturally available to them. The LLK diet is derived solely of Antarctic Krill. While there are numerous krill species available as prey in the Arctic nearshore, they have similar protein and lipid content as the LLK diet (Vollenweider et al., 2016), and thus both krill and fish experimental diets are comparable to naturally available prey resources.

Arctic Sculpin were fed ad libitum for the duration of the experiment. Ten randomly selected individuals were sacrificed on day 0 before the start of the experiment, and five randomly selected individuals were sacrificed from each diet treatment using MS-222 (as directed by Florida International University Institutional Animal Care and Use Committee) at $2,5,10,21,42,81$, and 147 days after the start of the experiment and were frozen whole at $-80^{\circ} \mathrm{C}$ prior to further processing (Logan et al., 2006; Madigan et al., 2012; Tieszen et al., 1983). All tissues and rays from the caudal and pectoral fins, the entire left side fillet with the skin and bones removed, and whole livers were collected for fin, muscle, and liver tissue samples, respectively.

\subsection{Stable Isotope Analysis}

Tissues were dried at $50^{\circ} \mathrm{C}$ for at least 7 days, weighting the vial every 2 days until a consistent weight was obtained, indicating that all moisture was removed. Samples were then homogenized to a uniform consistency using a mortar and pestle. Samples were 
weighed (0.4-0.7 mg of dry homogenate), rolled into a tin capsule, and sent to the Florida International University Southeast Environmental Research Center Stable Isotope Laboratory. The samples were analyzed using Elemental Analysis - Isotope Ratio Mass Spectrometry (EA-IRMS), with a Delta C Finnagen (Thermo Fisher Scientific) and Conflo II dilution interface (Thermo Fisher Scientific) coupled to a NA-1500 NC Carlo ERBA elemental analyzer (Fisons Instruments). Precision and accuracy of the instruments were controlled with NIST standard IAEA-CH-6 for $\delta^{13} \mathrm{C}$, and IAEA-N1 for $\delta^{15} \mathrm{~N}$. Three inhouse standards were also used: Bovine Liver, Citrus Leaves, and Glycine. Error based on standard deviations of internal glycine standards ranged $0.09-0.21 \%$ for $\delta^{15} \mathrm{~N}$ and $0.07-$ $0.10 \%$ for $\delta^{13} \mathrm{C}$. Isotope ratios are expressed in delta-notation $(\delta)$ as per mil (\%o) relative to the standard Vienna Peedee Belemnite (VPDB; $\left.{ }^{13} \mathrm{C}\right)$ and atmospheric nitrogen $\left({ }^{15} \mathrm{~N}\right)$ as shown below:

$$
\delta^{q} X=\left(\frac{R_{\text {sample }}}{R_{\text {standard }}}-1\right) \times 1000
$$

where $q$ is the mass number of the isotope, $X$ is the element of the isotope, and $R$ represents the ratio of heavy to light stable isotopes for carbon $\left({ }^{13} \mathrm{C} /{ }^{12} \mathrm{C}\right)$ and nitrogen $\left({ }^{15} \mathrm{~N} /{ }^{14} \mathrm{~N}\right)$ within the sample and standards.

Carbon isotope ratios were corrected for the effects of lipid content in sample tissues (Sweeting et al., 2006). 


$$
\delta^{13} C_{\text {protein }}=\delta^{13} C_{\text {sample }}+\left(6 \% 0 \times\left(\frac{\% \text { lipid }}{100}\right)\right),
$$

where $\delta^{13} C_{\text {protein }}$ is the isotope ratio of lipid-free sample tissue, and $\delta^{13} C_{\text {sample }}$ is the isotope ratio of bulk sample tissue (Sweeting et al. 2006). This correction method makes two assumptions: (1) lipid $\delta^{13} \mathrm{C}$ is $6 \%$ depleted compared to protein, and (2) the lipid-extracted tissue and pure protein are isotopically identical (Logan et al., 2008; McConnaughey and McRoy, 1979; Sweeting et al., 2006). Lipid corrections were not applied to diet samples because the fish consumed the diet materials in bulk state and we cannot assume that carbon from dietary lipids is not incorporated into the consumers proteins (Martinez del Rio et al., 2009; Mohan et al., 2016). Furthermore, carbonate corrections also were not applied to food sources despite them consisting of ground whole organisms because previous works found no significant effect of acidification on samples of fish or crustaceans (Bosley and Wainright, 1999; Pomerleau et al., 2014).

Because \% lipid was not determined for all samples (see 2.3 Lipid Content) because of limited sample size, a linear model was fit between \% lipid content and C:N ratios $\left(\mathrm{R}^{2}\right.$ $=0.70, \mathrm{p}<0.001)$ for the samples in which both measures were available (Fin: $\mathrm{n}=3$, Liver: $\mathrm{n}=28$, Muscle: $\mathrm{n}=26$ ). The resulting model equation was used to predict $\%$ lipid content from C:N ratios for all the samples for which lipid content data was not available:

$$
\text { Predicted \% lipid }=\frac{C}{N} * 2.04-3.01,
$$




\subsection{Lipid Content}

Lipid analysis was conducted using the microcolorimetric sulfophosphovanillan method on fish diet samples and Arctic Sculpin tissues (Lu et al., 2008; van Handel, 1985). For each sample, 10-20 mg of homogenized dry tissue was placed into a glass vial to which $2 \mathrm{ml}$ of 2:1 (v/v) chloroform-methanol solution was added. Vials were capped and sonicated in a Branson 3510-DTH Ultrasonic Cleaner for 30 minutes. A 1:10 dilution of each sample was made and three $100 \mu 1$ aliquots of the diluted sample were transferred to a glass 96-well plate. Solvent was evaporated on a hot plate at $100{ }^{\circ} \mathrm{C}$ for 10 minutes. 20 $\mu l$ of concentrated sulfuric acid was added to each well and the samples were incubated at $100{ }^{\circ} \mathrm{C}$ for 10 minutes, after which time the plate was cooled to room temperature. $280 \mu \mathrm{l}$ of vanillin-phosphoric acid reagent $(6.8 \mathrm{mM}$ vanillin, 2.6 $\mathrm{M}$ phosphoric acid) was added to each sample and incubated at room temperature $\left(23^{\circ} \mathrm{C}\right)$ with gentle shaking for 30 minutes. The absorbance at $490 \mathrm{~nm}$ was recorded for each well using a Perkin Elmer Victor3 1420 Multilabel Counter spectrophotometer. With each batch of samples, a solvent blank was run through the entire procedure to assess interference $(<0.30 \mathrm{mg})$ and 2 samples of dried walleye pollock (Gadus chalcogrammus) reference material with known lipid content were analyzed to ensure accuracy (average 5.7\% error). Total lipid was calculated by comparison of the absorbance values to a lipid:absorbance 10-point calibration curve generated using Menhaden oil (Sigma-Aldrich). Percent lipid values were reported as the averages of the triplicate samples. 


\subsection{Protein Content of Diet}

Protein content of the Arctic Sculpin diets was measured following the Dumas method using a $\mathrm{LECO}^{1}$ nitrogen determinator TruSpec CHN[1] (Association of Official Analytical Chemists, 2002). Replicate aliquots of $>0.07 \mathrm{~g}$ dried homogenate were dropped into a hot furnace $\left(950^{\circ} \mathrm{C}\right)$ and flushed with oxygen for rapid and complete combustion. Expelled nitrogen was quantified and protein content was estimated by multiplying total nitrogen by a conversion factor of 6.06 (Leco Instruction Manual 2001). Quality assurance samples included one EDTA and two atmospheric blanks for every 10 sample analysis. Additionally, a replicate sample and Meat1546 (National Institute of Standards) was included with each batch of 17 samples. If quality assurance samples exceeded prescribed limits (15\% variation for reference samples, $0.1 \%$ protein for blanks, and 1.5 standard deviation for replicates), samples were re-analyzed. Protein values of replicates were averaged.

\subsection{Tissue Specific Isotopic Turnover Rates}

The TTRs were derived from exponential models fit to isotope ratios for each isotope, tissue, and diet type (Hobson and Clark, 1992; Madigan et al., 2012; Rosenblatt and Heithaus, 2013; Tieszen et al., 1983):

$$
\delta_{t}=a e^{-\lambda t}+c,
$$

where $\delta_{t}$ is the isotope ratio at time $t, \lambda$ is a rate constant derived from the fitted model, $a$ is the difference in \%o between the initial isotope ratio $\left(\delta_{\mathrm{i}}\right)$ and the steady-state final isotope 
ratio $(c)$. These models were fit to estimate $a, \lambda$ and $c$ using nonlinear least square with the CRAN-R 'stats' package, function 'nls' (R Team 2013). Time needed to achieve a percentage $(\alpha)$ of isotopic turnover was estimated for each tissue:

$$
t_{\alpha / 100}=\frac{\ln \left(1-\frac{\alpha}{100}\right)}{\lambda}
$$

where $\alpha$, the percentage of isotopic turnover was set to 50 (half-life) and 90 , and $\lambda$ is a rate constant derived from the fitted model as in Equation 3.4.

Equations 3.4 and 3.5 were applied separately to the $\delta^{13} \mathrm{C}$ and $\delta^{15} \mathrm{~N}$ values of the three tissues (fin, liver, and muscle) of Artic Sculpin from both diet treatments (HLF and LLK). Model parameters $a, \lambda$, and $c$ are reported, as well as the number of days needed to achieve turnover half-life and $90 \%$ turnover (Table 1).

The turnover rate of an isotope can be separated into the proportion attributable to the addition of new biomass through growth and the replacement of tissues caused by metabolic processes. The proportion of turnover driven by growth versus metabolism was estimated using measured weights with a modification of Equation 3.4 (Madigan et al., 2012):

$$
\delta_{t}=a e^{-\left(k^{\prime}+m\right) t}+c,(3.6)
$$

where $a$ is the difference in \%o between the initial isotope ratio and the steady-state final isotope ratio $(c)$, and $k^{\prime}$ is the growth rate constant for each fish for the duration of the 
experiment. These models were fit for each tissue-isotope combination using nonlinear least squares with the CRAN-R 'stats' package, function 'nls' (R Team 2013), to determine $m$, the metabolic rate constant. $\left(\delta_{i}-\delta_{f}\right)$ is analogous to $a$ in Equation 3.4, and $\delta_{f}$ is analogous to $c$; thus, these values were derived from model fits described for Equation 3.4. $k$ ' was estimated for each fish using the following equation:

$$
k^{\prime}=\frac{\ln \left(\frac{W_{f}}{W_{i}}\right)}{t},
$$

where $W_{f}$ is the final weight of the fish and $W_{i}$ is the initial weight of the fish. The following model was fit to estimate the overall growth rate constant for all fish, $k$ :

$$
W_{f}=e^{(k * t)},
$$

Lastly, isotopic turnover is driven by a combination of catabolic and metabolic processes as well as growth (Carleton and Martinez Del Rio, 2010), and the contribution of each varies across life stages (Madigan et al., 2012). To increase the scope of age classes to which the results can be applied, we estimate the relative contribution of growth and metabolism to isotope turnover in tissues:

$$
\begin{gathered}
P_{g}=k / \lambda, \\
P_{m}=m / \lambda,
\end{gathered}
$$


where $P_{g}$ and $P_{m}$ are the proportion of isotope turnover caused by growth and metabolism, respectively. This equation makes the assumption that the isotopic turnover driven by metabolism $(m)$ is the proportion of $\lambda$ that is not driven by growth $(k)$. Thus, any observed differences in the contributions of growth to isotopic turnover are expected to be driven by metabolism.

\subsection{Trophic Discrimination Factors (TDFs)}

The TDFs were estimated as the difference between the final steady-state isotope ratios of each tissue type and the mean isotope ratios of the dietary materials that they were fed during the experiment.

$$
\Delta_{T I S S U E}=c-\delta_{F O O D},
$$

where $\Delta_{\text {TISSUE }}$ is the TDF for the tissue of interest, $c$ is the final steady-state isotope ratio determined from Equation 3.1, and $\delta_{F O O D}$ is the mean isotope ratio of the food type that was fed.

Equations 3.6, 3.7, 3.9-3.11 (Madigan et al., 2012) were applied separately to the $\delta^{13} \mathrm{C}$ and $\delta^{15} \mathrm{~N}$ values of the three tissues (fin, liver, and muscle tissues) of Arctic Sculpin from both diet treatments (HLF and LLK). Equation 3.8 was applied to all individual relative weights. Model parameters $m$ and $k$ are reported, as well as the half-life (50\%) and 90\% isotopic turnover times $\left(\mathrm{t}_{0.5}, \mathrm{t}_{0.1} ;\right.$ Table 3.1$)$. Additionally, the estimated $90 \%$ turnover time solely driven by growth or metabolism are reported as $\mathrm{t}_{0.1} \mathrm{k}$ and $\mathrm{t}_{0.1} \mathrm{~m}$, respectively. 
Furthermore, the relative contribution of growth and metabolism are reported as proportions of the rate constant $\lambda$, derived from Equation 3.4.

\subsection{Ethics Statement}

All methods and procedures used in these experiments were approved and in compliance with guidelines set by Florida International University Institutional Animal Care and Use Committee (protocol \#: IACUC-13-013-CR01).

\section{$\underline{\text { 3. Results }}$}

Nitrogen isotope values of all tissues (fin, liver, and muscle) reached a steady-state within the 147 days of the diet switch from LLK to HLF, facilitating estimation of timedependent and growth-dependent turnover rates, as well as TDFs for $\delta^{15} \mathrm{~N}$ (Fig 3.1A). However, the initial carbon isotope ratios of Arctic Sculpin were more similar to those of the HLF diet than expected making steady-state and initial isotope ratios indistinguishable (c and $a$ in Equation 3.3, respectively; $\mathrm{p}=0.55$ for fin, $\mathrm{p}=0.56$ for muscle). Consequently, sub-optimal model fits make it difficult to determine carbon isotope turnover rates for all tissues (Fig 3.1B). Steady-state isotope ratios of fish feeding on LLK were also observed (c, in Table 3.1), permitting for accurate calculation of TDFs.

\subsection{Time-Dependent Isotopic Turnover}

The dietary switch from LLK to HLF is used to trace the isotopic turnover rates for each tissue, thus all results referring to turnover use isotope ratios from Arctic Sculpin that were switched from the LLK to the HLF diet at the start of the experiment, unless the LLK 
diet is explicitly stated. Lipid corrections were applied to all $\delta^{13} \mathrm{C}$ values of Arctic Sculpin tissues. Average lipid content in fin and muscle were relatively low (3.7\% and 5.2\%, respectively), but in liver was much higher (21.2\%). Linear regressions of bulk $\delta^{13} \mathrm{C}$ and lipid-corrected $\delta^{13} \mathrm{C}$ showed strong correlations in both fin and muscle $\left(\mathrm{R}^{2}=0.99\right)$ but not in liver $\left(\mathrm{R}^{2}=0.59\right.$; Fig 3.2). Following the dietary switch at the start of the experiment, all tissues of Arctic Sculpin on the HLF diet reached 90\% turnover of nitrogen isotopes within the 147 days of the experiment (Fig 3.1A). Fin and liver tissues reached 90\% turnover within 56 and 58 days $\left(\mathrm{R}^{2}=0.85\right.$ and 0.96 ), respectively (Table 1 ). Muscle was much slower reaching $90 \%$ turnover within 122 days $\left(\mathrm{R}^{2}=0.80\right)$.

The exponential growth model (Equation 3.1) could not be fit or had poor fits to $\delta^{13} \mathrm{C}$ data for fin, liver, and muscle tissues (Fig 3.1B), and thus TTRs could not be calculated. For fin tissues, the data never reached an isotopic steady state (Fig 3.1B). Liver tissues show an unusual pattern with $\delta^{13} \mathrm{C}$ being more enriched in the early part of the experiment, reaching an asymptote like that of the model for muscle tissue after 42 days, and then becoming significantly depleted toward the end of the experiment (Fig 3.1B). Though this pattern warrants further discussion, we were unable to estimate turnover rates for liver tissue. The exponential growth model was fit to $\delta^{13} \mathrm{C}$ data for muscle, and the $90 \%$ carbon isotope turnover rate for muscle tissues was predicted to be 37 days. However, the model fit was poor $\left(\mathrm{R}^{2}=0.008\right)$ and thus this prediction is not reliable (Fig 3.1B).

\subsection{Growth- and Metabolic-Dependent Isotopic Turnover}

Conditions in the holding tanks were regulated and potential confounding factors were monitored. Temperature $\left(8^{\circ} \mathrm{C}\right)$ and salinity $(30 \mathrm{ppt})$, were kept constant to minimize 
their effect on metabolic and growth rates. A Student's T-test comparing the growth rate $\left(k^{\prime}\right)$ for each Arctic Sculpin indicated that diet did not affect growth rates $(\mathrm{p}=0.59)$. Density dependent effects were not significant based on a linear regression between growth by weight during the week before sacrifice and the number of fish in the tank during that week $\left(R^{2}=0.01, p=0.75\right)$.

Arctic Sculpin sacrificed at the end of the experiment increased 3.9 to 6.1 times their initial weight, with an average daily growth rate of $1.2 \%$ (wet wt.; $k^{\prime}=0.012$ ). Growth

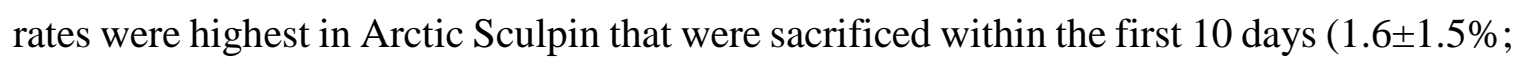
$k^{\prime}=0.16 \pm 0.15$ ) and gradually decreased to a steady growth rate constant of $3 \%$ (wet wt.; $k^{\prime}=0.03$ ) for fish that were sacrificed near the end of the 147 days of the experiment (Fig 3.3). Accordingly, growth rates decreased with increasing weight of Arctic Sculpin.

For the $\delta^{15} \mathrm{~N}$ values, diet type influenced the proportion of isotopic turnover driven by metabolism and growth $\left(\mathrm{P}_{\mathrm{m}}\right.$ and $\mathrm{P}_{\mathrm{g}}$ in Equations 3.9 and 3.10, respectively; Table 3.1). Across all three tissues, metabolism had greater average influence on turnover in HLF-fed sculpins than in LLK-fed sculpins ( $\mathrm{P}_{\mathrm{m}}$ mean \pm SD: $63 \pm 15 \%$ and $18 \pm 25 \%$, respectively, $\mathrm{p}$ $=0.02)$. In HLF-fed sculpin, the majority of turnover in liver and fin was driven by metabolism (73\% each), and to a lesser degree in muscle tissue (42\%). However, turnover in fin and muscle of LLK-fed sculpins was solely driven by growth (100\%), but turnover in livers had a greater influence from metabolism (54\%). The TTRs for nitrogen isotopes based on metabolism alone were also calculated from the HLF models, and would be approximately 77 days for fin, 79 days for liver, and 287 days for muscle.

As a result of poor model fits, we cannot comment on the role of metabolism and growth in carbon turnover in HLF-fed fish. However, for LLK-fed fish, carbon turnover 
was mostly driven by metabolism in fin tissue $(64 \%)$, and by growth in muscle $(61 \%)$. Again, because of poor model fits, these estimates of TTRs based on metabolism alone could not be made for carbon.

\subsection{Trophic Discrimination Factors (TDF's)}

The TDFs were found to be variable between diets for nitrogen isotopes, but consistent for carbon. The TDFs for nitrogen were determined to be different between diet types as HLFfed sculpin ranged from $0.62 \%$ to $2.06 \%$, and LLK-fed sculpin ranged from $2.7 \%$ to 3.5 $\%$ o $(\mathrm{p}<0.01)$. As for $\delta^{13} \mathrm{C}$ TDFs, LLK-fed sculpin ranged between $1.7 \%$ and $2.2 \%$. Muscle tissues of HLF-fed sculpin had the same value of $1.7 \%$ (Table 1). When lipid corrections are applied to carbon isotope ratios of food sources, the range of calculated $\delta^{13} \mathrm{C}$ TDFs change slightly for LLK-fed sculpin (1.3\%o to $1.8 \%$ ), and greatly for HLF-fed sculpin ($0.3 \%$ to $0.02 \%$ ).

\section{Discussion}

The estimates of TTRs in Arctic Sculpin measured in three different tissue have the potential to identify trophic shifts that occur on monthly (fin, liver) and seasonal/annual (muscle) timescales in nearshore Arctic systems. The TTRs determined from this experiment agree with previous experiments on lower-latitude species as liver and fin are fast-turnover tissues relative to muscle. Half-life values of $\delta^{15} \mathrm{~N}$ in Arctic Sculpin (17 days for liver, 37 days for muscle; Table 3.1) resemble those of juvenile mid-trophic level

consumers from lower latitudes. Mohan et al. (2016) reported $\delta^{15} \mathrm{~N}$ half-lives of 9-18 days for liver, and 27-54 days for muscle in juvenile Atlantic Croakers (Micropogonias 
undulates). Similarly, Suzuki et al. (2005) reported $\delta^{15} \mathrm{~N}$ half-lives of 14.4 days for liver, and 19.3-25.7 days for muscle in Japanese Temperate Bass (Lates japonicus).

Because model fits for $\delta^{13} \mathrm{C}$ values were poor in comparison to $\delta^{15} \mathrm{~N}$ values for Arctic Sculpin tissues on the HLF diet, we were unable to determine the TTRs for carbon. This is likely the result of $\delta^{13} \mathrm{C}$ in the fish collected for food (Pacific Capelin and Arctic Sand Lance) being indistinguishable to $\delta^{13} \mathrm{C}$ in Arctic Sculpin, which was not expected. Consequently, the difference between the average initial isotope ratio and the final steadystate isotope ratio is less than the overall variation observed in initial isotope ratios, leading to poor model fits. Average LLK-diet $\delta^{13} \mathrm{C}$ values were approximately 2 per mil enriched from the average initial isotope ratios of Arctic Sculpin, which resulted in better model fits than on the HLF diet.

The models from Arctic Sculpin on the LLK-diet cannot be used to determine turnover rates, however they are still used to determine TDFs and the influence of metabolism and growth in isotopic turnover. If the LLK-fed sculpin were also fed $\mathrm{ad}$ libitum during the acclimation period, we could have simply added 36 days (quarantine period) to the estimated TTRs from these models to arrive at the true TTRs. However, because the dietary switch from wild prey to LLK occurred before growth was being measured, and because feeding rate was different during the quarantine period, we cannot assume that growth and metabolic rates were the same as during the experiment. However, these models are still eligible to determine TDFs because it only requires the isotope ratios in diet and the isotopic steady-state values of tissues. The influence of metabolism and growth can still be determined because they are proportional values determined from measured growth and the rate constant $(\lambda)$ estimated from the model. 
The incorporation of isotopes from diet to assimilated tissues is dependent on two major factors, metabolic rate and growth rate (Carleton and Martinez Del Rio, 2010; Hesslein et al., 1993; Madigan et al., 2012). In juvenile fish, such as the Arctic Sculpin used in this experiment, isotope turnover is expected to be dominated by growth (Bosley et al., 2002; Logan et al., 2006); however, this was only found to be the case in muscle tissues. Liver tissues usually have rapid catabolism and metabolism on top of similar growth rates as muscle, and therefore turn over faster than muscle (Heady and Moore, 2013; Logan et al., 2006; Madigan et al., 2012; Tieszen et al., 1983). This is confirmed as 90\% isotopic turnover for nitrogen in HLF-fed sculpin was achieved at 58 days for liver versus 122 days for muscle, and on both diets metabolism contributed more to isotopic turnover in liver than in muscle. In this experiment, fin tissues turned over at similar rates as liver for $\delta^{15} \mathrm{~N}$ values, but in previous studies fin tissues have had variable turnover rates in different species, making it important to determine TTRs before using this tissue (Heady and Moore, 2013; Suzuki et al., 2005).

In the past, many studies have used SIA of liver and muscle to identify shifts in diet between short-term and long-term temporal scales; however, the fatty composition of liver often increases variability in carbon isotope values, complicating this identification and thus may not be the best choice as a fast turnover tissue (Logan et al., 2008; Mohan et al., 2016; Sweeting et al., 2006). In Arctic Sculpin, livers were also found to be fatty in comparison to fin and muscle (21\%, $4 \%$ and 5\%, respectively; Table 3.1). Arithmetic lipid corrections can account for the effects of lipids on carbon isotope ratios but there is often isotopic variability in the isotope values of high lipid tissues that is not explained by lipid content alone (Logan et al., 2008; Post et al., 2007; Sweeting et al., 2006). The higher error 
in lipid corrections of liver tissues, shown by the lower $\mathrm{R}^{2}(0.59$; Fig 3.3$)$ for the linear regression between bulk and lipid-corrected $\delta^{13} \mathrm{C}$, suggest that fin tissues may be more appropriate than liver to investigate short term shifts in the diet of Arctic Sculpin. Fin tissues can be harvested non-lethally, and muscle plugs have been taken non-lethally with 14 gauge biopsy needles (Baker et al., 2004); suggesting that it may be possible to use nonlethal sampling of high-turnover rate and low-turnover rate tissues to capture different time windows of a system. However, this method has not been attempted on sculpins, and should be tested before employment in the field.

When using derived TTRs to provide temporal context to isotope values in sculpins, one caveat that may arise is changing metabolic rate through ontogeny. The fish in our experiment were juveniles, thus the isotopic turnover is largely driven by growth; however, in adult fish turnover may be almost exclusively driven by metabolism as growth rates reduce (Fonds et al., 1992; Harvey et al., 2002). For this reason, 90\% TTRs that are derived solely on metabolic turnover were reported. These values may give a more appropriate estimate of temporal context to tissue isotopes of adult fish that have reduced growth rates. However, it is unclear how much metabolic rates decrease in sculpin as they reach maturity, thus these turnover rates may not be applicable until this relationship is further investigated.

The TDFs determined from this experiment may be used to represent isotopic fractionation in food webs. The TDFs estimated for carbon isotopes had minor variation among each of the models and suggests that $1.87 \%$ may be an appropriate TDF to represent carbon fractionation in Arctic Sculpin. However, fractionation of nitrogen isotopes was diet dependent, with TDFs in HLF-fed sculpin (1.23 $\pm 0.61 \%$ ) being lower than in LLK-fed sculpin (3.23 $\pm 0.39 \%$ ). The commonly used $\delta^{15} \mathrm{~N}$ TDF is $3.4 \%$, however 
TDFs ranging from 0.5 to $5.5 \%$ have been reported, and the commonly used $\delta^{13} \mathrm{C}$ TDF is $0.39 \%$ (Post 2002). Based on data presented by Post (2002), the $\delta^{15} \mathrm{~N}$ TDF determined from the HLF-fed sculpin (1.23\%) is in the lower $9^{\text {th }}$ percentile and thus is uncommonly low. However, given that sculpin are generalists that feed mostly on benthic invertebrates, it is also unlikely that wild Arctic Sculpin have such a lipid-rich diet (Gray et al., 2017). The $\delta^{15} \mathrm{~N}$ TDF for LLK (3.23) is within the most commonly reported $\delta^{15} \mathrm{~N}$ TDF values, and may be more appropriate than the $\delta^{15} \mathrm{~N}$ TDF for HLF (1.23) based on lipid content of benthic invertebrates in the Point Barrow region (Vollenweider et al., 2016). The $\delta^{13} \mathrm{C}$ TDF reported for Arctic Sculpin (1.87) is in the upper $35^{\text {th }}$ percentile based on data presented by Post (2002) and is thus relatively uncommon. The combination of different nitrogen and carbon TDFs will impact the conclusions drawn from food web models, and thus it is important to choose appropriate TDFs when building such a model.

The results of contributions of metabolism and growth to isotopic turnover indicated that metabolism contributes to turnover rates more when high-lipid diet was fed, suggesting that high quality diets increase metabolic rates, which may explain the observed differences in trophic discrimination. These results may suggest that the appropriate $\delta^{15} \mathrm{~N}$ TDF to accurately determine the diet of sculpin ranges between 1.22 and 3.23, and is dependent on the prey quality (lipid content) in the habitat where they are being sampled. Though there are no published data on the feeding ecology of Arctic Sculpin, the congeneric Shorthorn Sculpin (Myoxocephalus scorpius) has a similar body shape and gape, but is more abundant further from shore. Shorthorn Sculpin is considered a generalist that mostly feeds on benthic crustaceans and worms, but fish can also be a common prey source depending on the region (Gray et al., 2017). With this diet data in mind, it may be 
helpful to determine the lipid content of common prey species within a sampling area to determine the correct TDFs for parameterizing food web models.

Mohan et al. (2016) described similar effects of lipid content on TDFs of Atlantic Croakers (Micropogonias undulatus) and suggested that this was likely because routing of macromolecules from dietary lipid into assimilated proteins. This idea is supported by the fact that TDFs for carbon calculated for Arctic Sculpin, using isotope ratios of lipid-free dietary materials (protein; HLF $=-20.3 \%$, LLK $=-23.4 \%$ ), suggests that there is no fractionation between the proteins of the HLF diet and assimilated proteins (avg $\Delta_{\mathrm{FOOD}} \pm$ sd: $\mathrm{HLF}=0.10 \pm 0.14 \%$ ). It is highly unlikely that no trophic fractionation is occurring and this suggests that much of the assimilated carbon in proteins may be derived of dietary lipids, and because the routing of lipids in protein synthesis is poorly understood one should not perform lipid corrections on dietary materials. Furthermore, lipid corrections may be inappropriate when reconstructing food web dynamics from whole fish isotopes using stable isotopes and TDFs in polar habitats where survival is often dependent on the ability to ingest and store lipid-rich prey (Mohan et al. 2016).

Another confounding factor that remains unclear is the effect of different temperatures on isotope incorporation rates in Arctic Sculpin. The constant temperature of $8{ }^{\circ} \mathrm{C}$ used in the experiment was based on the average temperature during the ice-free season (July-September) in which the test subjects were collected, but the Arctic nearshore undergoes extreme temperature changes between ice covered and open water seasons. Temperature has been known to have direct effects on metabolic rate, and could affect consumer isotope assimilation rates and TDFs (Bosley et al., 2002; Fonds et al., 1992). Until the effects of temperature on TTRs and TDFs are better understood, the results of 
this experiment may only be applicable to fish collected during summer months when temperatures are similar to those in the experiment. However, isotope ratios in tissues of Arctic Sculpin collected at the beginning of the open-water season should represent their diet through ice-covered months (prior to July) despite not knowing the exact turnover time of those tissues; when compared to Arctic Sculpin collected well into the open-water season (August) it should offer new insight to seasonal variability in trophodynamics of Arctic nearshore fish.

In the past, Arctic marine food web ecologists were forced to rely on less appropriate TDF values determined from species in different taxa (Hobson and Welch, 1992). Determining TDFs in an Arctic marine fish will allow for better parameterization of future food web models, leading to a better understanding of energy flow, resource and prey dependence within Arctic marine food webs.

With known TTRs, Arctic Sculpin can be used as a biological indicator to monitor changes in trophodynamics in the Arctic nearshore. Previous studies have shown that Arctic warming is melting ice faster, thus decreasing the time period when ice algae can bloom (Arrigo et al., 2008; Bluhm and Gradinger, 2008; Gradinger and Bluhm, 2010; Iken et al., 2010). Ice algae production is a crucial basal resource during ice covered months, and much of this production is transported to the benthos to support highly productive benthic communities in the Arctic. As ice continues to melt faster, it is expected that the degree of benthic-pelagic coupling will decrease, causing a major shift from a benthic invertebrate dominated food web to a pelagic fish dominated food web. Using tissuedependent SIA, the timing and magnitude of such a shift in basal resources can be determined. Tissue-dependent SIA could be applied to monitor any scenario in which a 
shift in trophodynamics is expected, such as increasing inputs of terrestrial organic material from melting permafrost or increasing riverine discharge (Barton et al., 2016; Dunton et al., 2012; Schuur et al., 2008; Strauss et al., 2011). There may also be potential to identify shifts in resource utilization by Arctic Sculpin resulting from anthropogenic impacts to lower trophic levels such as those from oil spills or other anthropogenic stressors (Aguilar et al., 2008; Gundlach and Hayes, 1978; Moreno et al., 2013). In conjunction with SIA, other tissue dependent analyses could be used to investigate an array of biological responses of Arctic Sculpin, in parallel with changes in resources utilization, to ecological changes associated with climate change including condition (Vollenweider et al. 2016), hydrocarbon contamination (Aas et al., 2000), and stress responses (Pickering and Pottinger, 1989).

\section{Conclusions}

Our results demonstrate that tissue dependent $\delta^{15} \mathrm{~N}$ values of Arctic Sculpin can be used to identify shifts in prey resource use between approximately 56 and 122 days using fin and muscle tissues, respectively. Liver has a turnover rate similar to fin, and given the higher variance in isotopic ratios of liver tissues, fin is a better choice to identify short-term dietary shifts. Furthermore, non-lethal tissue sampling of Arctic Sculpin for SIA could be a viable way to monitor changes in food web structure, basal resource use, or potential impacts of anthropogenic activities.

As previous studies have also shown, there is an apparent influence of diet quality/lipid content on the isotopic TTRs (Mohan et al., 2016). It is likely that these effects relate to the response of metabolic processes to dietary compositions, but little is known 
about the specific influence of diet on metabolism of specific isotopes. Furthermore, the effect of temperature on TTRs and TDFs of isotopes in Arctic Sculpin requires more research.

Differences in TDFs were likely driven by metabolic changes caused by diet quality/lipid content, and thus it is important to consider the quality of available prey in a food web when reconstructing its structure using SIA. Another explanation is that dietary carbon and nitrogen of lipids and proteins are being rerouted to different tissue types in the consumer. This is supported by the fact that the TDFs between dietary protein and assimilated protein is near zero, and thus it is likely that dietary lipid is being incorporated into consumer proteins; however, the data provided by this experiment cannot adequately address this issue and further investigation is needed.

Given the generalist diet, high site-fidelity, and abundance of Arctic Sculpin, they are a viable biological indicator. This study outlines how tissue-dependent SIA can be used to investigate seasonal changes in trophic structure and resource dependence, which will help elucidate the effects that climate change and adverse anthropogenic impacts will have on Arctic nearshore food webs, but the utility of this bioindicator may exceed trophodynamics and its tissues could be used to approach a vast array of questions related to climate changes and further anthropogenic impacts.

\section{Bibliography}

Aas, E., Beyer, J., Goksoyr, A., 2000. Fixed wavelength fluorescence (FF) of bile as a monitoring tool for polyaromatic hydrocarbon exposure in fish: an evaluation of compound specificity, inner filter effect and signal interpretation. Biomarkers 5, 9-23.

Aguilar, C., González-Sansón, G., Faloh, I., Allen Curry, R., 2008. Spatial variation in stable isotopes $\left(\delta^{13} \mathrm{C}\right.$ and $\left.\delta^{15} \mathrm{~N}\right)$ in marine fish along the coast of Havana City: Evidence of 
human impacts from harbor and river waters. J. Coast. Res. 245, 1281-1288. https://doi.org/10.2112/07-0832.1

AMAP, 2008. Arctic oil and Gas. Arctic Monitoring and Assessment Programme, Oslo, Norway.

Arrigo, K.R., van Dijken, G., Pabi, S., 2008. Impact of a shrinking Arctic ice cover on marine primary production. Geophys. Res. Lett. 35, 1-6. https://doi.org/10.1029/2008GL035028

Baker, R.F., Blanchfield, P.J., Paterson, M.J., Flett, R.J., Wesson, L., 2004. Evaluation of Nonlethal Methods for the Analysis of Mercury in Fish Tissue. Trans. Am. Fish. Soc. 133, $568-576$.

Barton, M.B., Moran, J.R., Vollenweider, J.J., Heintz, R.A., Boswell, K.M., 2016. Latitudinal dependence of body condition, growth rate, and stable isotopes of juvenile capelin (Mallotus villosus) in the Bering and Chukchi Seas. Polar Biol. 1-13. https://doi.org/10.1007/s00300-016-2041-8

Berkman, P., Young, O., 2009. Governance and environmental change in the Arctic Ocean. Science (80). 324, 339-340.

Bluhm, B., Gradinger, R., 2008. Regional variability in food availability For Arctic marine mammals. Ecol. Appl. 18, S77-S96. https://doi.org/http://dx.doi.org/10.1890/06-0562.1

Bosley, K., Witting, D., Chambers, R., Wainright, S., 2002. Estimating turnover rates of carbon and nitrogen in recently metamorphosed winter flounder Pseudopleuronectes americanus with stable isotopes. Mar. Ecol. Prog. Ser. 236, 233-240. https://doi.org/10.3354/meps236233

Bosley, K.L., Wainright, S.C., 1999. Effects of preservatives and acidification on the stable isotope ratios $\left({ }^{15} \mathrm{~N}:{ }^{14} \mathrm{~N},{ }^{13} \mathrm{C}:{ }^{12} \mathrm{C}\right)$ of two species of marine animals. Can. J. Fish. Aquat. Sci. 56, 2181-2185. https://doi.org/10.1139/f99-153

Carleton, S.A., Martinez Del Rio, C., 2010. Growth and catabolism in isotopic incorporation: a new formulation and experimental data. Funct. Ecol. 24, 805-812. https://doi.org/10.1111/j.1365-2435.2010.01700.x

Divoky, G.J., Lukacs, P.M., Druckenmiller, M.L., 2015. Effects of recent decreases in arctic sea ice on an ice-associated marine bird. Prog. Oceanogr. 136, 151-161. https://doi.org/10.1016/j.pocean.2015.05.010

Dunton, K.H., Grebmeier, J.M., Trefry, J.H., 2014. The benthic ecosystem of the northeastern Chukchi Sea: An overview of its unique biogeochemical and biological characteristics. Deep. Res. Part II Top. Stud. Oceanogr. 102, 1-8. https://doi.org/10.1016/j.dsr2.2014.01.001 
Dunton, K.H., Schonberg, S. V., Cooper, L.W., 2012. Food Web Structure of the Alaskan Nearshore Shelf and Estuarine Lagoons of the Beaufort Sea. Estuaries and Coasts 35, 416435. https://doi.org/10.1007/s12237-012-9475-1

Dunton, K.H., Weingartner, T., Carmack, E.C., 2006. The nearshore western Beaufort Sea ecosystem: Circulation and importance of terrestrial carbon in arctic coastal food webs. Prog. Oceanogr. 71, 362-378. https://doi.org/10.1016/j.pocean.2006.09.011

Fonds, M., Cronie, R., Vethaak, A., Puyl, P., 1992. Metabolism, food consumption and growth of Plaice (Pleuronectes platessa) and Flounder (Platichthys flesus) in relation to fish size and temperature. Netherlands J. Sea Res. 29, 127-143.

Fortin, D., Beyer, H.L., Boyce, M.S., Smith, D.W., Duchesne, T., Mao, J.S., 2005. Wolves influence elk movements: Behavior shapes a trophic cascade in Yellowstone National Park. Ecology 86, 1320-1330. https://doi.org/10.1890/04-0953

Fry, B., 2006. Stable Isotope Ecology, Third. ed. Springer, Baton Rouge, LA.

Fry, B., Arnold, C., 1982. Rapid ${ }^{13} \mathrm{C} /{ }^{12} \mathrm{C}$ Turnover During Growth of Brown Shrimp (Penaeus aztecus). Oecologia 54, 200-204. https://doi.org/10.1007/BF00378393

Gannes, L.Z., Brien, D.M.O., Martínez, C., Jun, N., 1997. Stable Isotopes in Animal Ecology: Assumptions, Caveats, and a Call for More Laboratory Experiments. Ecology 78, 1271-1276.

Gaston, T.F., Suthers, I.M., 2004. Spatial variation in $\delta^{13} \mathrm{C}$ and $\delta^{15} \mathrm{~N}$ of liver, muscle and bone in a rocky reef planktivorous fish: The relative contribution of sewage. J. Exp. Mar. Bio. Ecol. 304, 17-33. https://doi.org/10.1016/j.jembe.2003.11.022

Gradinger, R., Bluhm, B., 2010. Timing of ice algal grazing by the Arctic nearshore benthic amphipod Onisimus litoralis. Arctic 63, 355-358.

Gray, B.P., Norcross, B.L., Beaudreau, A.H., Blanchard, A.L., Seitz, A.C., 2017. Food habits of Arctic staghorn sculpin (Gymnocanthus tricuspis) and shorthorn sculpin (Myoxocephalus scorpius) in the northeastern Chukchi and western Beaufort Seas. Deep. Res. Part II Top. Stud. Oceanogr. 135, 111-123. https://doi.org/10.1016/j.dsr2.2016.05.013

Gray, M.A., Cunjak, R.A., Munkittrick, K.R., 2004. Site fidelity of slimy sculpin (Cottus cognatus): Insights from stable carbon and nitrogen analysis. Can. J. Fish. Aquat. Sci. 61, 1717-1722. https://doi.org/10.1139/f04-108

Grebmeier, J.M., 2012. Shifting patterns of life in the Pacific Arctic and sub-Arctic seas. Ann. Rev. Mar. Sci. 4, 63-78. https://doi.org/10.1146/annurev-marine-120710-100926 
Grebmeier, J.M., Overland, J.E., Moore, S.E., Farley, E. V, Carmack, E.C., Cooper, L.W., Frey, K.E., Helle, J.H., McLaughlin, F.A., McNutt, S.L., 2006. A major ecosystem shift in the northern Bering Sea. Science 311, 1461-4. https://doi.org/10.1126/science.1121365

Gundlach, E., Hayes, M., 1978. Vulnerability of coastal environments to oil spill impacts. Mar. Technol. Soc. J. 12, 18-27.

Harvey, C.J., Hanson, P.C., Essington, T.E., Brown, P.B., Kitchell, J.F., 2002. Using bioenergetics models to predict stable isotope ratios in fishes. Can. J. Fish. Aquat. Sci. 59, 115-124. https://doi.org/10.1139/f01-203

Heady, W.N., Moore, J.W., 2013. Tissue turnover and stable isotope clocks to quantify resource shifts in anadromous rainbow trout. Oecologia 172, 21-34. https://doi.org/10.1007/s00442-012-2483-9

Hesslein, R.H., Hallard, K.A., Ramlal, P., 1993. Replacement of sulfur, carbon, and nitrogen in tissue of growing Broad Whitefish (Coregonus nasus) in response to a change in diet traced by $\delta^{34} \mathrm{~S}, \delta^{13} \mathrm{C}$, and $\delta^{15} \mathrm{~N}$. Can. J. Fish. Aquat. Sci. 50, 2071-2076. https://doi.org/10.1139/f93-230

Hobson, K., Clark, R., 1992. Assessing avian diets using stable isotopes I: turnover of ${ }^{13} \mathrm{C}$ in tissues. Condor 94, 181-188.

Hobson, K., Welch, H., 1992. Determination of trophic relationships within a high arctic marine food web using $\delta^{13} \mathrm{C}$ and $\delta^{15} \mathrm{~N}$ analysis. Mar. Ecol. Prog. Ser. 84, 9-18.

Iken, K., Bluhm, B., Dunton, K., 2010. Benthic food-web structure under differing water mass properties in the southern Chukchi Sea. Deep. Res. Part II Top. Stud. Oceanogr. 57, 71-85. https://doi.org/10.1016/j.dsr2.2009.08.007

Link, J.S., Almeida, F.P., 2002. Opportunistic feeding of longhorn sculpin (Myoxocephalus octodecemspinosus): Are scallop fishery discards an important food subsidy for scavengers on Georges Bank? Fish. Bull. 385, 381-385.

Logan, J., Haas, H., Deegan, L., Gaines, E., 2006. Turnover rates of nitrogen stable isotopes in the salt marsh mummichog, Fundulus heteroclitus, following a laboratory diet switch. Oecologia 147, 391-5. https://doi.org/10.1007/s00442-005-0277-z

Logan, J.M., Jardine, T.D., Miller, T.J., Bunn, S.E., Cunjak, R.A., Lutcavage, M.E., 2008. Lipid corrections in carbon and nitrogen stable isotope analyses: Comparison of chemical extraction and modelling methods. J. Anim. Ecol. 77, 838-846. https://doi.org/10.1111/j.1365-2656.2008.01394.X

Lu, Y., Ludsin, S.A., Fanslow, D.L., Pothoven, S.A., 2008. Comparison of three microquantity techniques for measuring total lipids in fish. Can. J. Fish. Aquat. Sci. 65, 2233-2241. https://doi.org/10.1139/F08-135 
Madigan, D.J., Litvin, S.Y., Popp, B.N., Carlisle, A.B., Farwell, C.J., Block, B.A., 2012. Tissue turnover rates and isotopic trophic discrimination factors in the endothermic teleost, pacific bluefin tuna (Thunnus orientalis). PLoS One 7, e49220. https://doi.org/10.1371/journal.pone.0049220

Martínez del Rio, C., Wolf, N., Carleton, S., Gannes, L., 2009. Isotopic ecology ten years after a call for more laboratory experiments. Biol. Rev. Camb. Philos. Soc. 84, 91-111. https://doi.org/10.1111/j.1469-185X.2008.00064.X

McConnaughey, T., McRoy, C.P., 1979. Food-Web structure and the fractionation of carbon isotopes in the Bering Sea. Mar. Biol. 53, 257-262. https://doi.org/10.1007/BF00952434

McTigue, N.D., Dunton, K.H., 2014. Trophodynamics and organic matter assimilation pathways in the northeast Chukchi Sea, Alaska. Deep Sea Res. Part II Top. Stud. Oceanogr. 102, 84-96. https://doi.org/10.1016/j.dsr2.2013.07.016

Mecklenburg, C.W., Møller, P.R., Steinke, D., 2010. Biodiversity of Arctic marine fishes: taxonomy and zoogeography. Mar. Biodivers. 41, 109-140. https://doi.org/10.1007/s12526-010-0070-z

Mohan, J.A., Smith, S.D., Connelly, T.L., Attwood, E.T., McClelland, J.W., Herzka, S.Z., Walther, B.D., 2016. Tissue-specific isotope turnover and discrimination factors are affected by diet quality and lipid content in an omnivorous consumer. J. Exp. Mar. Bio. Ecol. 479, 35-45. https://doi.org/10.1016/j.jembe.2016.03.002

Moreno, R., Jover, L., Diez, C., Sardà, F., Sanpera, C., 2013. Ten Years after the Prestige Oil Spill: Seabird Trophic Ecology as Indicator of Long-Term Effects on the Coastal Marine Ecosystem. PLoS One 8, 1-10. https://doi.org/10.1371/journal.pone.0077360

Mumby, P.J., Steneck, R.S., Edwards, A.J., Ferrari, R., Coleman, R., Harborne, A.R., Gibson, J.P., 2012. Fishing down a Caribbean food web relaxes trophic cascades. Mar. Ecol. Prog. Ser. 445, 13-24. https://doi.org/10.3354/meps09450

Pace, M.L., Cole, J.J., Carpenter, S.R., Kitchell, J.F., 1999. Trophic cascades revealed in diverse ecosystems. Trends Ecol. Evol. 14, 483-488. https://doi.org/10.1016/S01695347(99)01723-1

Pickering, A., Pottinger, T., 1989. Stress responses and disease resistance in salmonid fish: Effects of chronic elevation of plasma cortisol. Fish Physiol Biochem 7, 253-8. https://doi.org/10.1007/BF00004714

Pomerleau, C., Winkler, G., Sastri, A., Nelson, R.J., Williams, W.J., 2014. The effect of acidification and the combined effects of acidification/lipid extraction on carbon stable isotope ratios for sub-arctic and arctic marine zooplankton species. Polar Biol. 37, 15411548. https://doi.org/10.1007/s00300-014-1540-8 
Post, D.M., 2002. Using stable isotopes to estimate trophic position: Models, methods, and assumptions. Ecol. Soc. Am. 83, 703-718.

Post, D.M., Layman, C.A., Arrington, D.A., Takimoto, G., Quattrochi, J., Montan, C.G., 2007. Getting to the fat of the matter: models, methods and assumptions for dealing with lipids in stable isotope analyses. Oecologia 152, 179-189. https://doi.org/10.1007/s00442006-0630-x

Rosenblatt, A.E., Heithaus, M.R., 2013. Slow isotope turnover rates and low discrimination values in the American alligator: implications for interpretation of ectotherm stable isotope data. Physiol. Biochem. Zool. 86, 137-48. https://doi.org/10.1086/668295

Schuur, E.A.G., Bockheim, J., Canadell, J.G., Euskirchen, E., Field, C.B., Goryachkin, S. V, Hagemann, S., Kuhry, P., Lafleur, P.M., Lee, H., Mazhitova, G., Nelson, F., Rinke, A., Romanovsky, V.E., Shiklomanov, N., Tarnocai, C., Venevky, S., Vogel, J.G., Zimov, S.A., 2008. Vulnerability of permafrost carbon to climate change: Implications for the global carbon cycle. Bioscience 58, 701-714. https://doi.org/10.1641/B580807

Strauss, J., Schirrmeister, L., Wetterich, S., Mangelsdorf, K., 2011. Old Organic Matter in Siberian Permafrost Deposits and it's Degradation Features 571-572.

Suzuki, K.W., Kasai, A., Nakayama, K., Tanaka, M., 2005. Differential isotopic enrichment and half-life among tissues in Japanese temperate bass (Lateolabrax japonicus) juveniles: implications for analyzing migration. Can. J. Fish. Aquat. Sci. 62, 671-678. https://doi.org/10.1139/f04-231

Sweeting, C.J., Polunin, N.V.C., Jennings, S., 2006. Effects of chemical lipid extraction and arithmetic lipid correction on stable isotope ratios of fish tissues. Rapid Commun. Mass Spectrom. 20, 595-601. https://doi.org/10.1002/rcm.2347

Team, R.C., 2013. R: A language and environment for statistical computing.

Tieszen, L.L., Boutton, T.W., Tesdahl, K.G., Slade, N.A., 1983. Fractionation and turnover of stable carbon isotopes in animal tissues: Implications for $\delta^{13} \mathrm{C}$ analysis of diet. Oecologia $57,32-37$.

van Handel, E., 1985. Rapid determination of glycogen and sugars in mosquitoes. J. Am. Mosq. Control Assoc. 1, 299-301.

Vander Zanden, M., Rasmussen, J., 2001. Variation in ${ }^{15} \mathrm{~N}$ and ${ }^{13} \mathrm{C}$ trophic fractionation: Implications for aquatic food web studies. Limnol. Oceanogr. 46, 2061-2066.

Vollenweider, J.J., Heintz, R.A., Boswell, K.M., Norcross, B.L., Li, C., Barton, M.B., Sousa, L., George, J.C., 2016. Distribution and habitat use of fish in the nearshore ecosystem in the Beaufort and Chukchi Seas. 


\section{Figure and Tables}

Table 3.1. Exponential growth model parameters for all 12 models fit to isotopic ratios of carbon and nitrogen in tissues of Arctic Sculpin (Myoxocephalus scorpioides) fed the highlipid fish (HLF) and low-lipid krill (LLK) diets. For $\delta^{13} \mathrm{C}$ in fin tissues on the HLF diet, the model did not fit the data properly (indicated by the negative $\lambda$ value) and thus further parameters were not calculated. $a$ is the difference in \%o between $\delta_{0}$ and the steady-state final isotope ratio, and $c$ is the steady-state final isotope ratio of the subject tissue (equation 3.4). $t_{0.5}(k+m)$, and $t_{0.1}(k+m)$ are the number of days taken to reach $50 \%$ and $90 \%$ isotopic turnover, respectively (equation 3.5). TDF is the trophic discrimination factor derived using equation 3.11. $k$ is the overall growth rate constant derived using equation 3.8 , and $m$ is the metabolic rate constant or the difference between $\lambda$ and $k . P_{g}$ and $P_{m}$ are the proportion of isotopic turnover driven by growth and metabolism, respectively (equation 3.9 and 3.10). Finally, $t_{0.1} k$ and $t_{0.1} \mathrm{~m}$ are the estimated number of days it would take to reach $90 \%$ isotopic turnover if turnover was solely driven by metabolism.

*LLK-fed sculpin experienced a diet switch 36 days before the start of the experiment (from wild food to the low-lipid krill diet). Therefore, the parameters estimated from those models are only used for discussion of influence of growth vs. metabolism.

\begin{tabular}{|c|c|c|c|c|c|c|c|c|c|c|c|c|c|c|c|c|}
\hline Tissue & Food & Isotope & $a$ & $\lambda$ & $c$ & $R^{2}$ & $\begin{array}{c}t_{0.5} \\
(\mathbf{k}+\mathbf{m})\end{array}$ & $\begin{array}{c}t_{0.1} \\
(\mathbf{k}+\mathbf{m})\end{array}$ & $\begin{array}{c}\delta \text { food } \\
(\%)\end{array}$ & $\begin{array}{l}\text { TDF } \\
(\%)\end{array}$ & $k$ & $m$ & $P_{g}$ & $\boldsymbol{P}_{\boldsymbol{m}}$ & $\mathbf{t}_{0.1} \mathrm{k}$ & $\mathbf{t}_{0.1} \mathrm{~m}$ \\
\hline Fin & HLF & $\mathrm{N}$ & -4.82 & 0.041 & 16.35 & 0.85 & 17 & 56 & 15.36 & 1.0 & 0.011 & 0.030 & 0.27 & 0.73 & 209 & 77 \\
\hline Liver & HLF & $\mathrm{N}$ & -5.87 & 0.040 & 15.98 & 0.96 & 17 & 58 & 15.36 & 0.6 & 0.011 & 0.029 & 0.28 & 0.73 & 209 & 79 \\
\hline Muscle & HLF & $\mathrm{N}$ & -4.53 & 0.019 & 17.42 & 0.80 & 37 & 122 & 15.36 & 2.1 & 0.011 & 0.008 & 0.58 & 0.42 & 209 & 287 \\
\hline Fin & LLK & $\mathrm{N}$ & 2.91 & 0.011 & 8.44 & 0.38 & 65 & 214 & 4.92 & 3.5 & $0.011^{*}$ & $0.000 *$ & $1.00^{*}$ & $0.00^{*}$ & & \\
\hline Liver & LLK & $\mathrm{N}$ & 1.60 & 0.024 & 7.62 & 0.37 & 29 & 98 & 4.92 & 2.7 & $0.011^{*}$ & $0.013 *$ & $0.46^{*}$ & $0.54 *$ & & \\
\hline Muscle & LLK & $\mathrm{N}$ & 4.00 & 0.009 & 8.45 & 0.55 & 74 & 246 & 4.92 & 3.5 & $0.011^{*}$ & $0.000 *$ & $1.00^{*}$ & $0.00^{*}$ & & \\
\hline Fin & HLF & $\mathrm{C}$ & 0.21 & -0.008 & -20.37 & -0.02 & & & -21.72 & & & & & & & \\
\hline Liver & HLF & $\mathrm{C}$ & & & & & & & -21.72 & & & & & & & \\
\hline Muscle & HLF & $\mathrm{C}$ & 0.26 & 0.064 & -20.02 & 0.01 & & & -21.72 & 1.7 & & & & & & \\
\hline Fin & LLK & $\mathrm{C}$ & 1.16 & 0.025 & -21.55 & 0.42 & 28 & 91 & -23.72 & 2.2 & $0.011^{*}$ & $0.014 *$ & $0.44 *$ & $0.64^{*}$ & & \\
\hline Liver & LLK & $\mathrm{C}$ & 0.44 & 0.020 & -22.05 & 0.03 & & & -23.72 & 1.7 & & & & & & \\
\hline Muscle & LLK & $\mathrm{C}$ & 1.82 & 0.018 & -21.77 & 0.72 & 39 & 129 & -23.72 & 2.0 & $0.011^{*}$ & $0.007 *$ & $0.61^{*}$ & $0.39^{*}$ & & \\
\hline
\end{tabular}




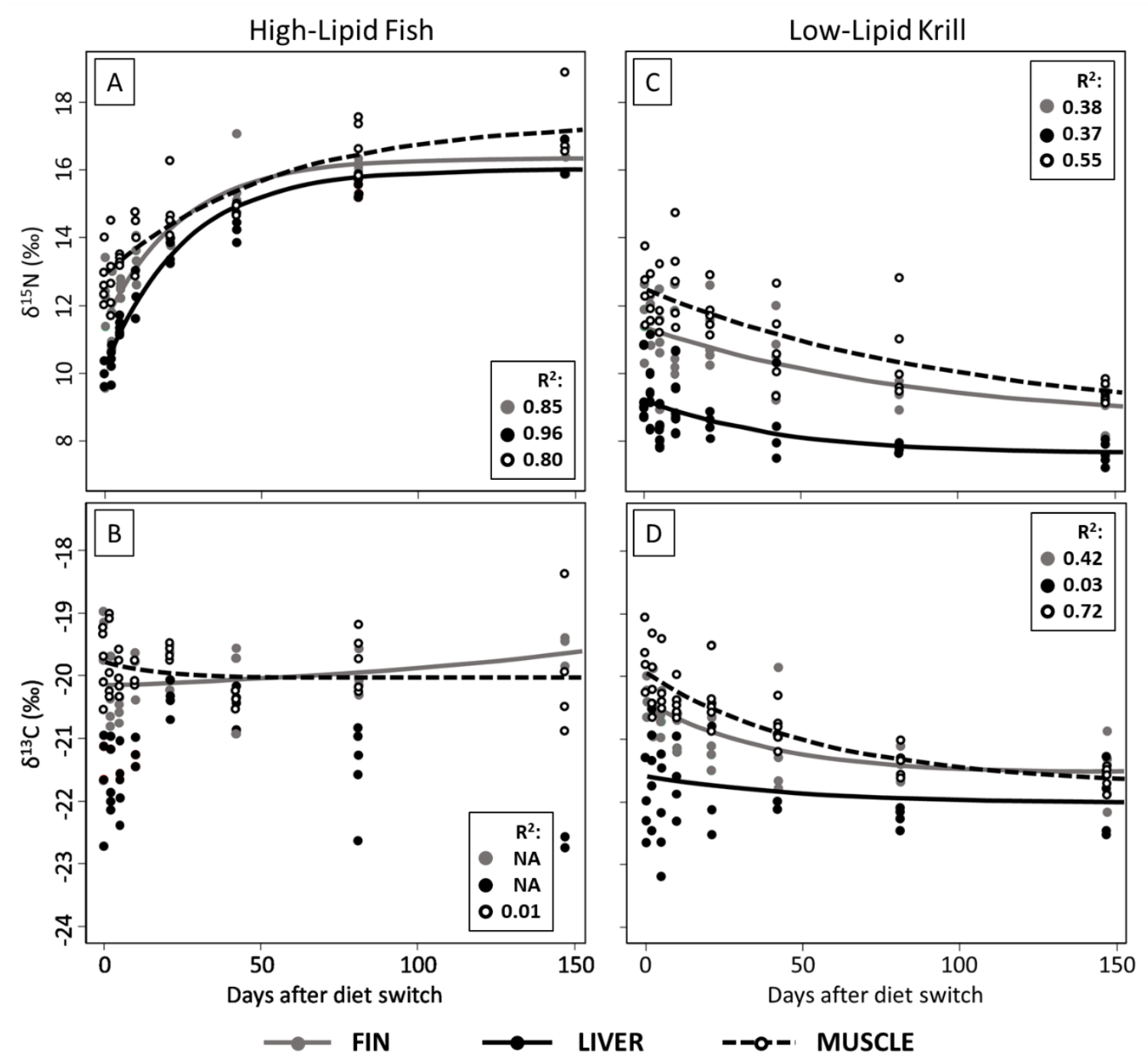

Figure 3.1. Exponential growth models (Equation 3.3) fit to the isotopic ratios of nitrogen $\left(\delta^{15} \mathrm{~N}\right.$; A and C) and carbon $\left(\delta^{13} \mathrm{C}\right.$; B and D) for Arctic Sculpins (Myoxocephalus scorpioides) on the High-Lipid Fish diet (A and B) and Low-Lipid Krill diet (C and D) across the 147-day study period. Gray points and lines represent isotope ratios in fin tissue, black represents liver, open black circles and dashed lines represent muscle. Arctic Sculpin on the LLK diet (solid circles and lines) did not have a diet switch on day 0. Further model parameters are displayed in Table 3.1. The exponential growth model either had poor fits or could not be fit to carbon isotope ratios for sculpin on the HLF diet. 


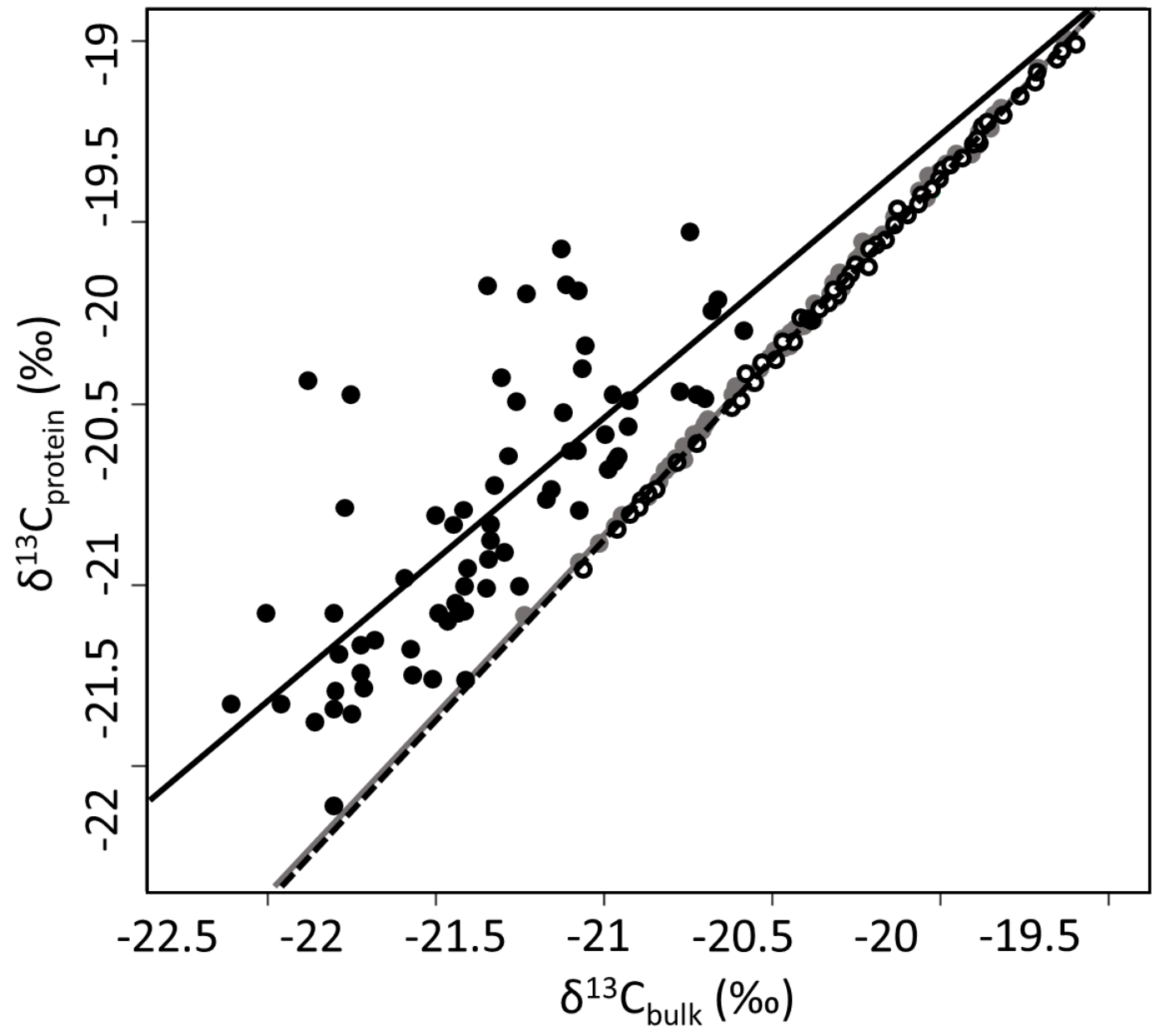

Figure 3.2. Linear regressions of bulk $\delta^{13} \mathrm{C}$ vs. lipid corrected $\delta^{13} \mathrm{C}$ (protein) of liver (black; $\mathrm{R}^{2}=0.59$ ) than those of fin (gray) and muscle (open circles/dashed line; both $\mathrm{R}^{2}=0.99$ ). 


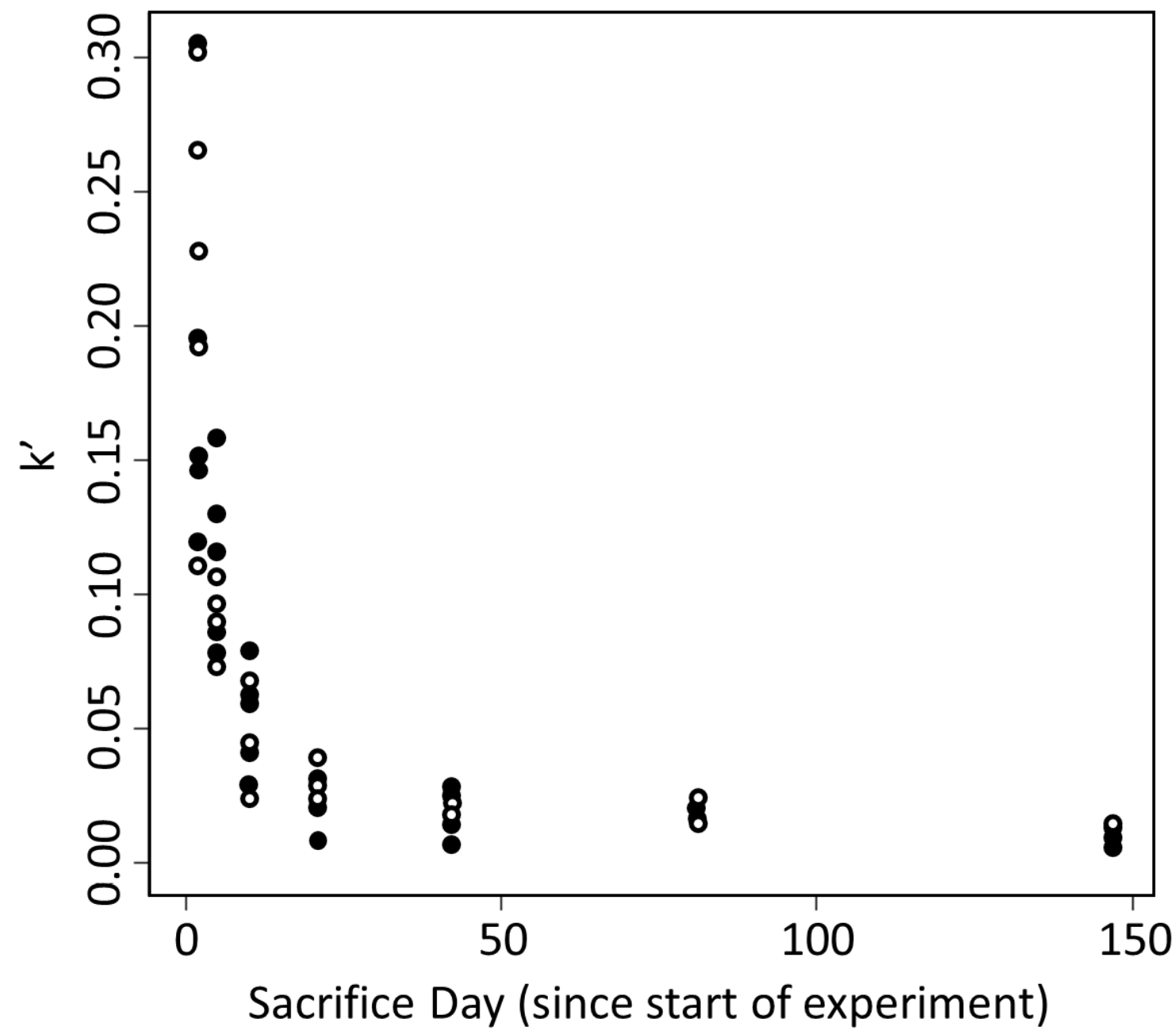

Figure 3.3 Individual growth rate constants (k') plotted for individuals across the 147 days of experimentation. Open circles represent high-lipid fish fed sculpin and solid circles represent low-lipid krill fed sculpin. 
CHAPTER IV

IDENTIFYING A SHIFT IN BASAL RESOURCE DEPENDENCE USING TISSUE-

DEPENDENT CARBON AND NITROGEN ISOTOPES IN SCULPINS FROM

ARCTIC NEARSHORE SURROUNDING POINT BARROW, AK 


\begin{abstract}
Arctic nearshore habitats can be highly productive as nutrients from terrestrial runoff and permafrost melt are concentrated there. Arctic coastal food webs have been shown to have strong dependence on nearshore production during open-water summer months. While ice algae serve as an integral basal resource for offshore food webs during winter months, landfast ice has made it difficult to investigate the important basal resources within the nearshore. Tissue-dependent stable isotopes of muscle and liver in five species of sculpin collected in nearshore habitats surrounding Point Barrow, AK were used to investigate dietary resource dependence across the shift from ice-covered winter to open-water summer. Differences between muscle and liver in carbon and nitrogen isotopes suggest that a distinct shift in basal resource dependence from ice algae to phytoplankton occurs during the onset of summer conditions. Differences between fish species are expected to be driven by the incorporation of terrestrial nutrients that are associated with proximity to lagoon systems. Changes in the magnitude of the difference between muscle and liver tissues may be helpful to track a shift in resource dependence as climate change continues to impact Arctic nearshore food webs.
\end{abstract}

\title{
Introduction
}

Potential impacts of climate change on Arctic ecosystems have raised interests in trophodynamics, with particular concern for understanding of how food webs may shift in response to changing conditions. Though much is known about trophic structures and prey resource dependence in Arctic marine systems (Bluhm and Gradinger, 2008; Dunton et al., 2006, 2005; Gray et al., 2017; Iken et al., 2010), little is known about nearshore systems 
as landfast ice limits access for collecting biological samples. The Arctic nearshore is inhabited by a diverse community of fish, invertebrates, and multiple protected or endangered mammals and seabirds, and provides important resources for subsistent hunters and fishermen in nearby villages (Brewster et al., 2010). Analogous nearshore habitats in well-studied lower-latitude systems are known to be highly productive, providing important nurseries and feeding grounds for a multitude of species (Deegan, 1993; Elliott et al., 1990), and play an important role in adjacent food webs. Though it is expected that Arctic nearshore habitats have a similar role, this cannot be assumed. Understanding Arctic nearshore food webs may offer insight to how species will fair in the face of climate change as habitat conditions and prey resources shift.

The ability of fish to take advantage of prolific prey resources during the relatively short open-water season may be crucial for survival and successful spawning. The long, cold winters of the Arctic are energetically costly for fish as prey availability tends to be low and much of their energy is derived of fat stores that were created during the summer (Barton et al., 2016; Vollenweider et al., 2011). Furthermore, fecundity and age at maturity in many cold water species can be highly dependent on fat stored prior to spawning (Hansen et al., 2001; Karlsen et al., 1995; Rijnsdorp, 1990). During winter, sea ice in the nearshore can occupy most or all of the water column, displacing nearshore organisms into deeper waters (Dunton et al., 2006). During these ice-covered months, benthic materials and ice algae released from melting sea ice are some of the few available basal resources for species below the ice (Gradinger, 2009). However, the open-water season in the Arctic has been shown to be highly productive as sea ice melt or breakup exposes waters to more sunlight, and terrestrial melt water causes a massive influx of nutrients to the nearshore, 
which is either incorporated into food webs directly or broken down and released into the water column allowing phytoplankton to bloom (Bluhm and Gradinger, 2008; Gradinger and Bluhm, 2010). These terrestrial materials and nutrients are often deposited or concentrated in lagoon systems, respectively, and Arctic coastal fishes have a high dependence on lagoon-associated basal resources during summer months (Dunton et al., 2005); therefore, it is expected that the trophic pathways that support fish will shift from ice algal dependence to lagoon-associated resources (terrestrial resource or pelagic primary producers) at the onset of open-water season. However, due to the difficulty of collecting fish from under landfast ice, this dietary shift is not well documented.

Stable isotope analysis (SIA) of carbon and nitrogen can offer insight to food web structures and resource dependence, and is based on the assumption that the carbon and nitrogen in tissues are derived of food ingested over time, and thus represent dietary resources that were utilized before a tissue sample was collected (Fry and Arnold, 1982). Stable isotopes in different tissues within the same organism turnover at variable rates, therefore tissues from a single specimen can be used to identify shifts in prey resources that occurred between the difference in tissue turnover rates (Carlisle et al., 2012; Madigan et al., 2012; Tieszen et al., 1983). Recent work has shown that turnover rates of nitrogen isotopes of muscle and liver in Arctic Sculpin (Myoxocephalus scorpioides) differ by approximately 64 days (58 vs. 122 days, respectively; Chapter III). Sculpins are opportunistic feeders with high site fidelity and thus the stable isotopes in their muscle and liver tissues sampled during the first 64 days of the open-water season should be indicative of the dietary resources that are available during ice-covered winter and open-water summer, respectively (Gray B. et al., 2017, Gray M. et al. 2004). 
Given that the three most common basal resources found in the Arctic nearshore (ice algae, pelagic primary producers, and terrestrial resources) have significantly different isotope signatures, a shift in resource dependence in a consumer can be traced through time using tissue-dependent stable isotopes. We investigate the isotopic ratios of carbon and nitrogen in muscle and liver tissues in five species of sculpin collected in the first six weeks of open water season to investigate whether a dietary shift occurred between ice-covered and open-water conditions.

\section{Methods}

\section{Sample Collection}

Fish were sampled using a beach seine at 12 stations on the Chukchi and Beaufort Sea, and Elson Lagoon in the Point Barrow, AK region (Figure 4.1) from July 14 - August 25 (Week 1-6) for two consecutive years (2013-14). The seine was $37 \mathrm{~m}$ long with variable mesh sizes (10 m of $32 \mathrm{~mm}$ outer panels, $4 \mathrm{~m}$ of $6 \mathrm{~mm}$ middle panels, and $9 \mathrm{~m}$ of $3.2 \mathrm{~mm}$ blunt panel). Each set was round-haul style, paid out of a $3 \mathrm{~m}$ inflatable Zodiac following methods used by Barton et al. (2016). Fishes were sorted by species and frozen whole at $80^{\circ} \mathrm{C}$ prior to further processing. The entire left side fillet with the skin and bones removed was dissected for the muscle tissue samples, and whole livers were collected for the liver tissue samples.

\section{Stable Isotope Analysis}

Tissues were dried to a consistent weight at $50^{\circ} \mathrm{C}$ for at least 7 days, and homogenized to a uniform consistency using a mortar and pestle. Samples were weighed 
(0.4-0.7 mg of dry homogenate), rolled into a tin pellet, and sent to the Florida International University Southeast Environmental Research Center Stable Isotope Laboratory. The samples were analyzed using Elemental Analysis - Isotope Ratio Mass Spectrometry (EAIRMS), with a Delta C Finnagen (Thermo Fisher Scientific) and Conflo II dilution interface (Thermo Fisher Scientific) coupled to a NA-1500 NC Carlo ERBA elemental analyzer (Fisons Instruments). Precision and accuracy of the instruments were controlled with NIST standard IAEA-CH-6 for $\delta^{13} \mathrm{C}$, and IAEA-N1 for $\delta^{15} \mathrm{~N}$. Three in-house standards were also used: Bovine Liver, Citrus Leaves, and Glycine. Isotope ratios are expressed in $\delta$-notation as per mil (\%o) difference to the standard Vienna Peedee Belemnite (VPDB) for carbon isotopes and atmospheric nitrogen ( $\mathrm{AN}$ ) for nitrogen isotopes as shown below:

$$
\delta^{q} X=\left(\frac{R_{\text {sample }}}{R_{\text {standard }}}-1\right) \times 1000
$$

where $q$ is the mass number of the isotope, $X$ is the element of the isotope, and $R$ represents the ratio of heavy to light isotopes within the sample or the standards PDB and $\mathrm{AN}\left({ }^{13} \mathrm{C} /{ }^{12} \mathrm{C}\right.$ for carbon; ${ }^{15} \mathrm{~N} /{ }^{14} \mathrm{~N}$ for nitrogen).

Carbon isotope ratios were corrected for the effects of lipid content in sample tissues (Sweeting et al., 2006).

$$
\delta^{13} C_{\text {protein }}=\delta^{13} C_{\text {sample }}+\left(6 \% \times\left(\frac{\% \text { lipid }}{100}\right)\right)
$$


where $\delta^{13} C_{\text {protein }}$ is the isotope ratio of lipid-free sample tissue, and $\delta^{13} C_{\text {sample }}$ is the isotope ratio of bulk sample tissue (Sweeting et al. 2006). This method makes two assumptions: (1) lipid $\delta^{13} \mathrm{C}$ is $6 \%$ depleted compared to protein, and (2) the lipid-extracted tissue and pure protein are isotopically identical (Logan et al., 2008; McConnaughey and McRoy, 1979; Sweeting et al., 2006). \%lipid was estimated from C:N ratios using a linear model created from C:N ratios and lipid content in Arctic Sculpins (Chapter III).

$$
\text { Predicted \% lipid }=\frac{C}{N} * 2.04-3.01 \text {, }
$$

\section{Statistical Analysis}

The isotopic carbon and isotope ratios of muscle and liver tissues in five species of sculpin collected in the Arctic nearshore were compared using paired Student's T-tests to identify differences in dietary sources used during ice-covered winter and open-water summer. Differences in isotope ratios of nitrogen between muscle and liver signify changes in the trophic level at which a sculpin is feeding, where an increase of one full trophic level is represented by an enrichment of $3.23 \%$ (Chapter III). Differences in isotope ratios of carbon between muscle and liver can signify a shift between three different dietary carbon sources. Ice algae is notably less depleted in $\delta^{13} \mathrm{C}$ signatures $(-15.7 \pm 0.5 \%$ ) than pelagic

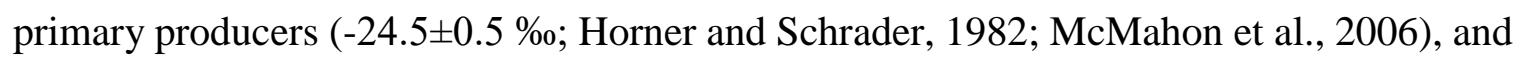
pelagic primary producers are significantly less depleted than terrestrial materials (-31 to 27 \%; Dunton et al., 2006). 


\section{Results}

Bulk stable carbon and nitrogen isotopes were analyzed from 62 sculpins (35 Arctic Sculpin, 7 Belligerent Sculpin [Megalocottus platycephalus], 9 Fourhorn Sculpin [Myoxocephalus quadricornis], 7 Plain Sculpin (Myoxocephalus jaok), 4 Shorthorn Sculpin [Myoxocephalus scorpius]). A Students T-test of the difference between isotopic ratios in muscle and liver tissues of all 62 sculpin was significant $(\mathrm{p}<0.001)$ for carbon and nitrogen. The mean difference from muscle to liver in $\delta^{13} \mathrm{C}$ was $-1.41 \%$ indicating that on average, dietary carbon was more depleted moving into the open-water season (Figure 4.2). The mean difference from muscle to liver in $\delta^{15} \mathrm{~N}$ was $-0.94 \%$, indicating that on average, dietary nitrogen became less enriched as the region transitioned from icecovered to open-water.

Carbon isotope ratios of muscle and liver varied between species (Figure 4.3, Table 4.1). For carbon isotopes, the differences between muscle and liver were all significant (p $<0.05)$, with the greatest mean difference in $\delta^{13} \mathrm{C}$ between muscle and liver tissues being in Plain Sculpin (1.92\%o), followed by Fourhorn Sculpin (1.71\%o), Belligerent Sculpin (1.36 \%o), Arctic Sculpin (1.28 \%o), and finally Shorthorn Sculpin (1.17\%o).

Nitrogen isotope ratios also varied by species (Figure 4.4, Table 4.1). For nitrogen isotopes, all species except Belligerent Sculpin had a significant difference between $\delta^{15} \mathrm{~N}$ in muscle and liver $(\mathrm{p}<0.05)$, with the greatest mean difference in $\delta^{15} \mathrm{~N}$ between tissues in Plain Sculpin (1.39\%o), followed by Shorthorn Sculpin (1.31 \%o), Fourhorn Sculpin (1.17 \%o), Arctic Sculpin (0.85 \%o), and finally Belligerent Sculpin (0.41 \%o). 


\section{Discussion}

The distinction in dietary carbon that make up muscle and liver tissues indicate that these sculpins actively shift their diets seasonally. Much research has shown that food webs under the ice are highly dependent on ice algae (Bradstreet and Cross, 1982; Budge et al., 2008; Gradinger and Bluhm, 2010; Ji et al., 2013) which are significantly less depleted in $\delta^{13} \mathrm{C}$ than other basal resources, such as pelagic primary producers and terrestrial organic material (Horner and Murphy, 1985; McMahon et al., 2006). If these sculpins were feeding in trophic pathways that depend on ice algae during ice-covered months, an isotopic shift between tissues would likely indicate a switch in the basal resource that supports the food web to either terrestrial materials or pelagic primary producers during summer seasons. Production during the summer is supported as rapid melting of ice, snow and permafrost transport not only terrestrial detritus but also labile nutrients into the lagoons that can support phytoplankton blooms (Dunton et al., 2006; Dutta et al., 2006; Strauss et al., 2011). Arctic lagoons hold high concentrations of detritus and phytoplankton in the water column (Dunton et al., 2005, 2006), and given the high dependence of nearshore food webs on nutrients concentrated in lagoons, it seems likely that sculpin in the nearshore take advantage of prolific prey resources associated with this increased production. Furthermore, sculpin were abundant immediately after ice breakup suggesting that they either remain in the nearshore during the ice-covered winter period, or are nearby so they can move in quickly to take advantage of available resources (Chapter II).

The magnitude of isotopic shifts (1.17 to $1.92 \%$ ) represented by the difference in isotopic values between muscle and liver in each species were relatively similar in $\delta^{13} \mathrm{C}$, even though the isotopic signature of muscle tissues varied. If all species were shifting 
dependence to the same basal resources, those with less depleted $\delta^{13} \mathrm{C}$ in muscle tissues would be expected to have a greater isotopic difference between muscle and liver tissues, as they would be shifting to a relatively more depleted carbon source. However, this is not the case; instead we observed the greatest isotopic carbon shift in species with more depleted $\delta^{13} \mathrm{C}$ in muscle (Plain Sculpin and Fourhorn Sculpin), and smaller shifts in those with less depleted $\delta^{13} \mathrm{C}$ in muscle (Belligerent, Arctic and Shorthorn Sculpins). This may be explained by the habitat that these species are associated with, and the amount of lagoonassociated carbon that is incorporated into their tissues. Fourhorn Sculpin and Plain Sculpin are predominantly found in the Elson Lagoon (Chapter II) where basal resources are expected to have depleted carbon isotope signatures (from pelagic primary producers and terrestrial material), therefore it would be expected that the shift in carbon isotopes between their muscle and liver tissues would be greater compared to species that spend more time outside of the lagoon. Belligerent and Arctic Sculpin are coastal nearshore species that were mostly caught in the Beaufort and Chukchi Sea stations (Chapter II; Figure 4.1) where lagoon associated carbon would be more diluted, and in turn the shift between their muscle and liver tissues was smaller. Shorthorn Sculpin were only caught in Chukchi Sea stations, where the influence of lagoon-associated carbon would be lowest due to being at the furthest distance from the Elson Lagoon (Figure 4.1), and they exhibited the smallest shift in carbon isotope ratios between muscle and liver (Gray et al., 2017). There is an apparent trend between the magnitude of the shift in carbon isotope ratios assimilated into muscle and liver tissues and the proximity to lagoon systems where more depleted carbon sources are concentrated, suggesting that sculpin are not changing prey but rather the basal resource that support their food web is changing. 
Changes in $\delta^{15} \mathrm{~N}$ are commonly used to indicate when a species is feeding at a different trophic level (DeNiro and Epstein, 1981; Hussey et al., 2014; McMeans et al., 2013), and in this study, we see nitrogen isotope ratios become depleted from muscle to liver, signifying a potential shift to lower trophic level prey items from ice-covered winter to open-water summer. However, the changes in basal resources that are suggested by the carbon isotope data also come with changes in baseline nitrogen isotopes values. Ice algae

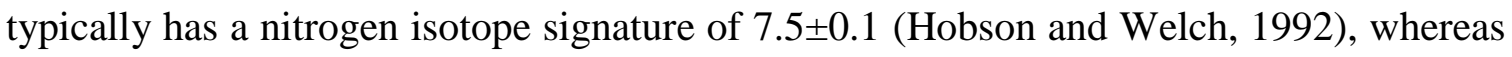
pelagic primary producers and terrestrial carbon range from 5 to $7 \%$ and 0 to $1.5 \%$, respectively (Dunton et al., 2006). If basal resources supporting these sculpins were to have shifted mostly to terrestrial carbon we would expect to see a much larger shift in $\delta^{15} \mathrm{~N}$ between muscle and liver, than if the shift was to pelagic primary producers. However, the difference between pelagic primary producers and ice algae is only 0.5 to $2.5 \%$ and is a viable explanation for the observed shift in $\delta^{15} \mathrm{~N}$ of 0.41 to $1.39 \%$. This suggests that the food webs supporting these sculpins were more dependent on pelagic primary producers than terrestrial materials, but that the differences between species-specific carbon signatures may be associated with influence of terrestrial carbon.

There are several caveats to consider while interpreting these results. The tissue turnover rates for both muscle and liver were determined at a single temperature $\left(8^{\circ} \mathrm{C}\right)$ to represent the warmer conditions of the Arctic nearshore in summer (Chapter III), and temperature is known to influence metabolic and growth rates, and isotopic tissue turnover (Bosley et al., 2002). Though the determined turnover rates are appropriate for the liver samples in this study because their isotopes were mostly assimilated during these warmer conditions, the same is not true for the muscle tissues. The muscle tissues represent winter 
conditions that are significantly colder and it is expected that metabolism and growth slow during these periods. Therefore, it is likely that muscle tissues may represent dietary resources consumed over a much longer period than the proposed 122 days (Chapter III). However, regardless of this uncertainty, the muscle tissues are still likely to represent winter conditions as they persist for 243 to 274 days per year, so the shift between muscle and liver should still represent a shift in resource dependence at the onset of open-water season.

Additionally, the low productivity of winter months is often associated with low prey abundance during which fish depend on fat stores to make it through these harsh conditions. As such, it is expected that these sculpins may be starving and catabolizing their own tissues for energy during winter, leading to enrichment in both nitrogen and carbon isotope values (Tamelander et al., 2006; Vander Zanden and Rasmussen, 2001). Since the muscle tissues represent the winter period, it is possible that this potential starvation could play a part in the enriched carbon and nitrogen signatures of muscle tissues relative to liver tissues. If starvation and catabolism of tissues plays a role in the enrichment of isotope values in muscle, then the shift in isotope signatures between muscle and liver may actually indicate an increase in prey abundance rather than a shift in basal resource dependence. However, little is known about feeding habits and prey availability during ice-covered months, so we cannot comment further on the potential effects of starvation on isotope values in muscle tissues.

It is important to consider that the 6 weeks in which these sculpins were sampled only cover $72 \%$ of the 58 days it takes for liver tissues to reach $90 \%$ turnover (Chapter III), and the magnitude of the differences between isotopic ratios of muscle and liver are likely 
to vary depending on how long after the start of open-water season that fish were collected as the rate of isotopic change differs across time for each tissue. Therefore, the differences observed in this study only suggest that a shift in basal resources is occurring from icecovered winter to open-water summer, but this study cannot pinpoint when exactly this shift occurs. However, if nearshore food webs shift their basal resource dependence to pelagic primary producers or terrestrial materials in the summer there may be broader implications to consider for the future as the availability, timing of influx, and concentrations of lagoon-associated resources change along with the morphology of lagoons.

Lagoon systems are especially productive because barrier islands partially enclose them, protecting them from strong currents and wave action, allowing organic material to deposit on the substrate (Dunton et al., 2012). These barrier islands are constantly being eroded by wave action and strong currents, and new sediments are deposited from riverine runoff to maintain the position and morphology of the islands and lagoons, which is largely driven by melt water in the summer (Jorgenson and Brown, 2005). With current warming trends, less ice will form in the future and glaciers in the Brooks Range will diminish, leading to a decrease in river discharge into Arctic lagoon systems (Nolan and Churchwell, 2011). Coupling a decrease in sediment transported by rivers with anticipated increases in coastal erosion due to increasing intensity of winter storms and decreasing sea ice coverage to buffer wave action (Fang et al., 2017), barrier island chains may disappear over time or become less prominent features. A decrease in magnitude of isotopic shifts between muscle and liver as climate change continues may suggest that nearshore fish communities have less lagoon-associated carbon resources available, which could follow a reduction in 
freshwater inflow and entrapment of associated nutrients in the lagoon. The isotopic shifts in basal resources documented in this data may be used as a baseline for future work to identify the loss of lagoon-associated carbon sources. Given the apparent dependence on lagoon-associated basal resources, the loss of barrier island chains may have catastrophic impacts on Arctic nearshore food webs.

\section{Conclusions}

Though a few caveats must be considered in interpreting tissue-dependent isotopes in sculpin, the distinct differences in carbon and nitrogen isotope ratios in muscle and liver clearly indicate that a shift in dietary sources occurs near the onset of open-water season, and confirms the potential utility of this method to monitor changes in resource availability through time. The relatively small depletion of carbon signatures (1.17 to $1.92 \%$ ) suggests that the difference in isotope signatures of muscle and liver tissues in nearshore sculpins is probably caused by a shift from ice algal dependence to pelagic primary producers. However, the differences between species of sculpin and the habitats with which those species are associated suggests that varying amounts of terrestrial carbon are also assimilated and may be responsible for the differences between species.

Nitrogen data supports the idea of a change in basal resources as the shift in nitrogen isotopes is too small to represent a change in prey selection. The change in nitrogen isotope ratios between muscle and liver could be caused by a shift in use of basal resources from ice algal dependence to pelagic primary producers, but it is unlikely that terrestrial materials makes large contributions as the stark difference between ice algae signatures 
and terrestrial nitrogen signatures would cause a much larger shift in tissue isotope composition.

There are concerns that the high dependence on nearshore production in Arctic coastal food webs may set these ecosystems up for a grim future as warming trends may limit sedimentation at barrier islands, and decreasing sea ice and increasing intensity of storms increase the rate of their erosion of the islands. This scenario would prevent nutrients from being trapped in high concentrations in lagoon systems, which is key in maintaining their high productivity. Isotope signatures of tissues such as muscle and liver with different turnover rates in indicator species can be used to identify changes in dependence on lagoon-associated resources, which can help track the progression of environmental changes.

\section{Bibliography}

Barton, M.B., Moran, J.R., Vollenweider, J.J., Heintz, R.A., Boswell, K.M., 2016. Latitudinal dependence of body condition, growth rate, and stable isotopes of juvenile capelin (Mallotus villosus) in the Bering and Chukchi Seas. Polar Biol. 1-13. https://doi.org/10.1007/s00300-016-2041-8

Bluhm, B., Gradinger, R., 2008. Regional variability in food availability for Arctic marine mammals. Ecol. Appl. 18, S77-S96. https://doi.org/http://dx.doi.org/10.1890/06-0562.1

Bosley, K., Witting, D., Chambers, R., Wainright, S., 2002. Estimating turnover rates of carbon and nitrogen in recently metamorphosed winter flounder Pseudopleuronectes americanus with stable isotopes. Mar. Ecol. Prog. Ser. 236, 233-240. https://doi.org/10.3354/meps 236233

Bradstreet, M.S.W., Cross, W.E., 1982. Trophic relationships at high Arctic ice edges. Arctic 35, 1-12. https://doi.org/10.1016/0266-9838(93)90013-8

Brewster, K., Program, O.H., Aiken, M., Brower, A., Itta, M., Itta, N., Leavitt, M. Lou, Leavitt, O., Matumeak, W., 2010. Iñupiat knowledge of selected subsistence fish near Barrow, Alaska Wildlife Management Barrow Elders. 
Budge, S.M., Wooller, M.J., Springer, A. M., Iverson, S.J., McRoy, C.P., Divoky, G.J., 2008. Tracing carbon flow in an arctic marine food web using fatty acid-stable isotope analysis. Oecologia 157, 117-129. https://doi.org/10.1007/s00442-008-1053-7

Carlisle, A.B., Kim, S.L., Semmens, B.X., Madigan, D.J., Jorgensen, S.J., Perle, C.R., Anderson, S.D., Chapple, T.K., Kanive, P.E., Block, B. a, 2012. Using stable isotope analysis to understand the migration and trophic ecology of northeastern Pacific white sharks (Carcharodon carcharias). PLoS One 7, e30492. https://doi.org/10.1371/journal.pone.0030492

Deegan, L. a., 1993. Nutrient and energy transport between estuaries and coastal marine ecosystems by fish migration. Can. J. Fish. Aquat. Sci. https://doi.org/10.1139/f93-009

DeNiro, M., Epstein, S., 1981. Influence of diet on the distribution of nitrogen isotopes in animals. Geochim. Cosmochim. Acta 45, 341-351.

Dunton, K.H., Goodall, J.L., Schonberg, S. V., Grebmeier, J.M., Maidment, D.R., 2005. Multi-decadal synthesis of benthic-pelagic coupling in the western Arctic: Role of crossshelf advective processes. Deep. Res. Part II Top. Stud. Oceanogr. 52, 3462-3477. https://doi.org/10.1016/j.dsr2.2005.09.007

Dunton, K.H., Schonberg, S. V., Cooper, L.W., 2012. Food web structure of the Alaskan nearshore shelf and estuarine lagoons of the Beaufort Sea. Estuaries and Coasts 35, 416435. https://doi.org/10.1007/s12237-012-9475-1

Dunton, K.H., Weingartner, T., Carmack, E.C., 2006. The nearshore western Beaufort Sea ecosystem: Circulation and importance of terrestrial carbon in arctic coastal food webs. Prog. Oceanogr. 71, 362-378. https://doi.org/10.1016/j.pocean.2006.09.011

Dutta, K., Schuur, E.A.G., Neff, J.C., Zimov, S.A., 2006. Potential carbon release from permafrost soils of Northeastern Siberia. Glob. Chang. Biol. 12, 2336-2351. https://doi.org/10.1111/j.1365-2486.2006.01259.x

Elliott, M., O’Reilly, M.G., Taylor, C.J.L., 1990. The forth estuary: a nursery and overwintering area for North Sea fishes. Hydrobiologia 195, 89-103. https://doi.org/10.1007/BF00026816

Fang, Z., Freeman, P., Field, C., Mach, K., 2017. Reduced sea-ice protection period increases storm exposure in Kivalina, Alaska 1-10.

Fry, B., Arnold, C., 1982. Rapid 13C / 12C Turnover During Growth of Brown Shrimp (Penaeus aztecus). Oecologia 54, 200-204. https://doi.org/10.1007/BF00378393

Gradinger, R., 2009. Sea-ice algae: Major contributors to primary production and algal biomass in the Chukchi and Beaufort Seas during May/June 2002. Deep. Res. Part II Top. Stud. Oceanogr. 56, 1201-1212. https://doi.org/10.1016/j.dsr2.2008.10.016 
Gradinger, R., Bluhm, B., 2010. Timing of ice algal grazing by the Arctic nearshore benthic amphipod Onisimus litoralis. Arctic 63, 355-358.

Gray, B.P., Norcross, B.L., Beaudreau, A.H., Blanchard, A.L., Seitz, A.C., 2017. Food habits of Arctic staghorn sculpin (Gymnocanthus tricuspis) and shorthorn sculpin (Myoxocephalus scorpius) in the northeastern Chukchi and western Beaufort Seas. Deep. Res. Part II Top. Stud. Oceanogr. 135, 111-123. https://doi.org/10.1016/j.dsr2.2016.05.013

Gray, M.A., Cunjak, R.A., Munkittrick, K.R., 2004. Site fidelity of slimy sculpin (Cottus cognatus): Insights from stable carbon and nitrogen analysis. Can. J. Fish. Aquat. Sci. 61, 1717-1722. https://doi.org/10.1139/f04-108

Hansen, T., Karlsen, Ø., Taranger, G.L., Hemre, G.I., Holm, J.C., Kjesbu, O.S., 2001. Growth, gonadal development and spawning time of Atlantic cod (Gadus morhua) reared under different photoperiods. Aquaculture 203, 51-67. https://doi.org/10.1016/S00448486(01)00610-X

Hobson, K., Welch, H., 1992. Determination of trophic relationships within a high arctic marine food web using Delta-13 C and Delta-15 N analysis. Mar. Ecol. Prog. Ser. 84, 918.

Horner, R., Murphy, D., 1985. Species composition and abundance of zooplankton in the nearshore Beaufort Sea in winter-spring. Arctic 38, 201-209.

Horner, R., Schrader, G.C., 1982. Relative contributions of ice algae, phytoplankton, and benthic microalgae to primary production in nearshore regions of the Beaufort Sea. 35, 485-503.

Hussey, N., MacNeil, M., McMeans, B., Olin, J., Dudley, S., Cliff, G., Wintner, S., Fennessy, S., Fisk, A., 2014. Rescaling the trophic structure of marine food webs. Ecol. Lett. 17, 239-250. https://doi.org/10.1111/ele.12226

Iken, K., Bluhm, B., Dunton, K., 2010. Benthic food-web structure under differing water mass properties in the southern Chukchi Sea. Deep. Res. Part II Top. Stud. Oceanogr. 57, 71-85. https://doi.org/10.1016/j.dsr2.2009.08.007

Ji, R., Jin, M., Varpe, Ø., 2013. Sea ice phenology and timing of primary production pulses in the Arctic Ocean. Glob. Chang. Biol. 19, 734-741. https://doi.org/10.1111/gcb.12074

Jorgenson, M.T., Brown, J., 2005. Classification of the Alaskan Beaufort Sea Coast and estimation of carbon and sediment inputs from coastal erosion. Geo-Marine Lett. 25, 6980. https://doi.org/10.1007/s00367-004-0188-8

Karlsen, Ø., Holm, J.C., Kjesbu, O.S., 1995. Effects of periodic starvation on reproductive investment in first-time spawning Atlantic cod (Gadus morhua). Aquaculture 133, 159170. https://doi.org/10.1016/0044-8486(94)00399-9 
Logan, J.M., Jardine, T.D., Miller, T.J., Bunn, S.E., Cunjak, R.A., Lutcavage, M.E., 2008. Lipid corrections in carbon and nitrogen stable isotope analyses: Comparison of chemical extraction and modelling methods. J. Anim. Ecol. 77, 838-846. https://doi.org/10.1111/j.1365-2656.2008.01394.x

Madigan, D.J., Litvin, S.Y., Popp, B.N., Carlisle, A.B., Farwell, C.J., Block, B.A., 2012. Tissue turnover rates and isotopic trophic discrimination factors in the endothermic teleost, Pacific Bluefin Tuna (Thunnus orientalis). PLoS One 7, e49220. https://doi.org/10.1371/journal.pone.0049220

McConnaughey, T., McRoy, C.P., 1979. Food-web structure and the fractionation of Carbon isotopes in the Bering Sea. Mar. Biol. 53, 257-262. https://doi.org/10.1007/BF00952434

McMahon, K.W., Ambrose, W.G., Johnson, B.J., Sun, M.Y., Lopez, G.R., Clough, L.M., Carroll, M.L., 2006. Benthic community response to ice algae and phytoplankton in Ny Ålesund, Svalbard. Mar. Ecol. Prog. Ser. 310, 1-14. https://doi.org/10.3354/meps310001

McMeans, B.C., Rooney, N., Arts, M.T., Fisk, A.T., 2013. Food web structure of a coastal Arctic marine ecosystem and implications for stability. Mar. Ecol. Prog. Ser. 482, 17-28. https://doi.org/10.3354/meps 10278

Nolan, M., Churchwell, R., 2011. Predicting the impact of glacier loss on fish, birds, floodplains, and estuaries in the Arctic National Wildlife Refuge. Proc. ....

Rijnsdorp, A., 1990. The mechanism of energy allocation over reproduction and somatic growth in female North Sea Plaice, Pleuronectes platessa. Netherlands J. Sea Res. 25, 279 290.

Strauss, J., Schirrmeister, L., Wetterich, S., Mangelsdorf, K., 2011. Old organic matter in Siberian permafrost deposits and it's degradation features. 571-572.

Sweeting, C.J., Polunin, N.V.C., Jennings, S., 2006. Effects of chemical lipid extraction and arithmetic lipid correction on stable isotope ratios of fish tissues. Rapid Commun. Mass Spectrom. 20, 595-601. https://doi.org/10.1002/rcm.2347

Tamelander, T., Søreide, J.E., Hop, H., Carroll, M.L., 2006. Fractionation of stable isotopes in the Arctic marine copepod Calanus glacialis: Effects on the isotopic composition of marine particulate organic matter. J. Exp. Mar. Bio. Ecol. 333, 231-240. https://doi.org/10.1016/j.jembe.2006.01.001

Tieszen, L.L., Boutton, T.W., Tesdahl, K.G., Slade, N.A., 1983. Fractionation and turnover of stable carbon isotopes in animal tissues: Implications for delta-13C analysis of diet. Oecologia 57, 32-37. 
Vander Zanden, M., Rasmussen, J., 2001. Variation in $\delta^{15} \mathrm{~N}$ and $\delta^{13} \mathrm{C}$ trophic fractionation: Implications for aquatic food web studies. Limnol. Oceanogr. 46, 2061-2066.

Vollenweider, J.J., Heintz, R.A., Schaufler, L., Bradshaw, R., 2011. Seasonal cycles in whole-body proximate composition and energy content of forage fish vary with water depth. Mar. Biol. 158, 413-427. https://doi.org/10.1007/s00227-010-1569-3 


\section{Tables}

Table 4.1 A summary of isotopic signatures in muscle and liver tissues of the five species of Arctic nearshore sculpin included in this study.

\begin{tabular}{llllll}
\hline Common Name & Species Name & $\mathrm{n}$ & $\begin{array}{l}\text { Isotope } \\
\text { Arctic Sculpin }\end{array}$ & $\begin{array}{l}\text { Muscle } \\
\text { Avg (SD) }\end{array}$ & $\begin{array}{l}\text { Liver } \\
\text { Avg (SD) }\end{array}$ \\
& $\begin{array}{llll}\text { Mcorpioides } \\
\text { Belligerent }\end{array}$ & \multirow{2}{*}{35} & $\delta^{13} \mathrm{C}$ & $-18.32(0.12)$ & $-19.60(0.24)$ \\
Sculpin & Megalocottus & 7 & $\delta^{15} \mathrm{~N}$ & $15.28(0.12)$ & $14.43(0.17)$ \\
Fourhorn & Myatycephalus & & $\delta^{15} \mathrm{~N}$ & $-18.90(0.15)$ & $-20.25(0.10)$ \\
Sculpin & quadricornis & & $\delta^{15} \mathrm{~N}$ & $15.05(0.34)$ & $14.64(0.19)$ \\
Plain Sculpin & Myoxocephalus & \multirow{2}{*}{7} & $\delta^{13} \mathrm{C}$ & $-20.08(0.32)$ & $-22.01(0.58)$ \\
& jaok & & $\delta^{15} \mathrm{~N}$ & $14.28(0.35)$ & $12.89(0.32)$ \\
Shorthorn & Myoxocephalus & 4 & $\delta^{13} \mathrm{C}$ & $-17.88(0.37)$ & $-18.32(0.12)$ \\
Sculpin & scorpius & & $\delta^{15} \mathrm{~N}$ & $15.19(0.22)$ & $13.89(0.33)$
\end{tabular}


Figures

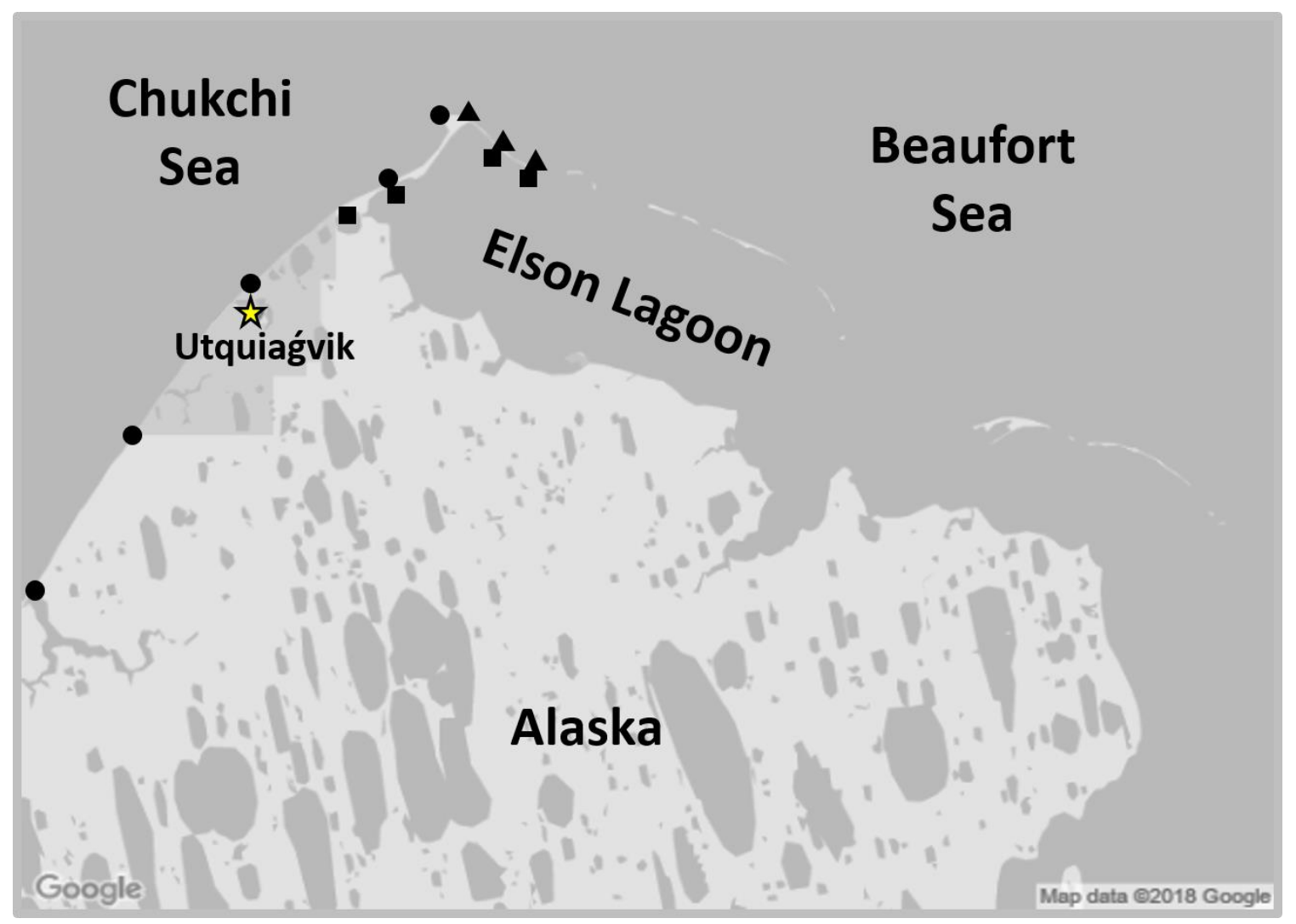

Figure 4.1 A map of Point Barrow showing the geography of the three waterbodies from which fish were collected. Stations marked by a circle $(\bullet)$ were those in the Chukchi Sea waterbody, triangles ( $\boldsymbol{\Delta})$ were those in the Beaufort Sea, and squares ( $\boldsymbol{\square})$ in the Elson Lagoon. 


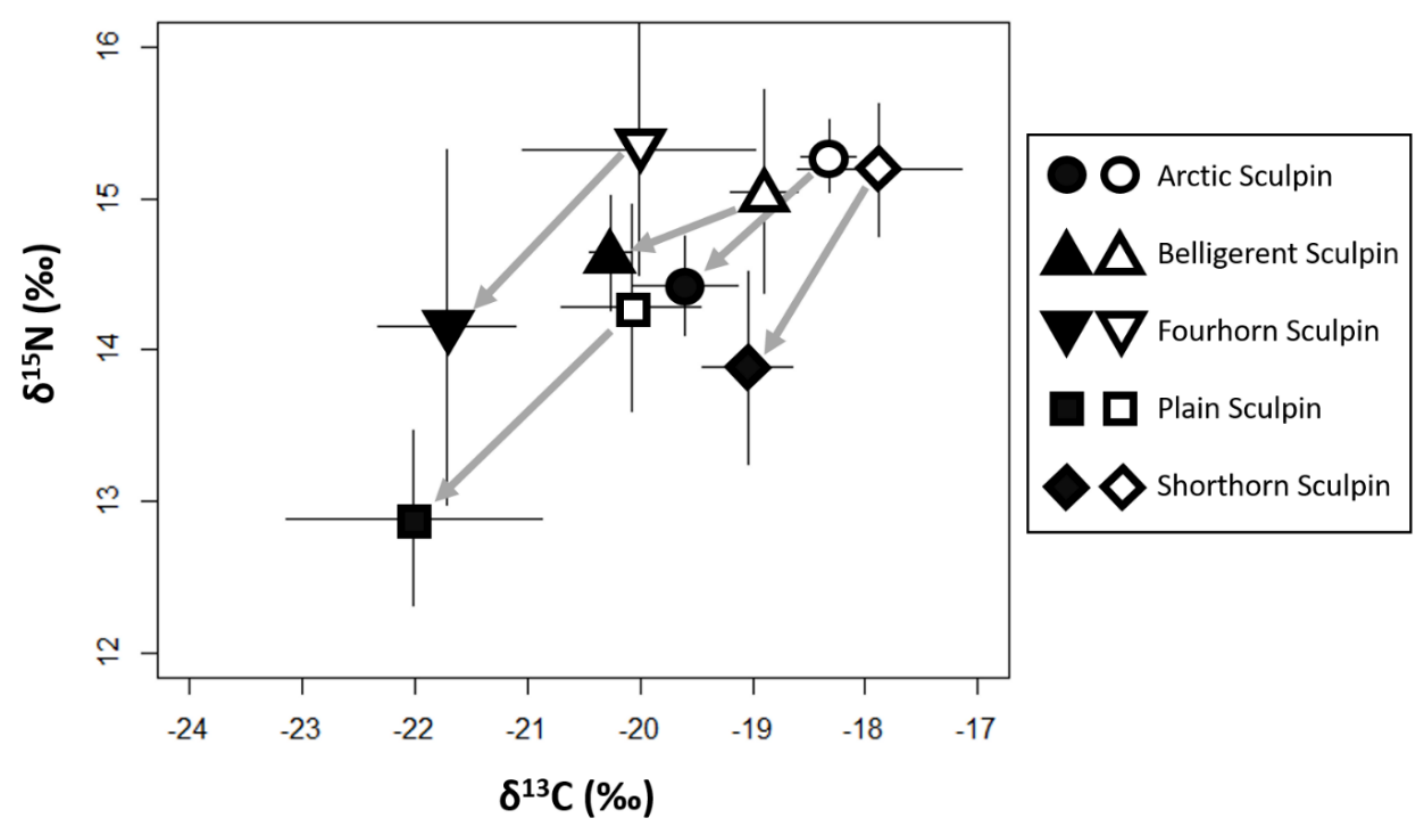

Figure 4.2 A biplot of average carbon and nitrogen isotope signatures in muscle (white) and liver (black). Error bars represent standard error. Averages and standard errors were calculated from muscle and liver tissues from 35 Arctic Sculpin (Myoxocephalus scorpioides), 7 Belligerent Sculpin (Megalocottus platycephalus), 9 Fourhorn Sculpin (Myoxocephalus quadricornis), 7 Plain Sculpin (Myoxocephalus jaok), 4 Shorthorn Sculpin (Myoxocephalus scorpius). The arrows show the isotopic shift from muscle to liver tissues, representing the shift in dietary carbon and nitrogen between ice-covered winter and open-water summer, respectively. 


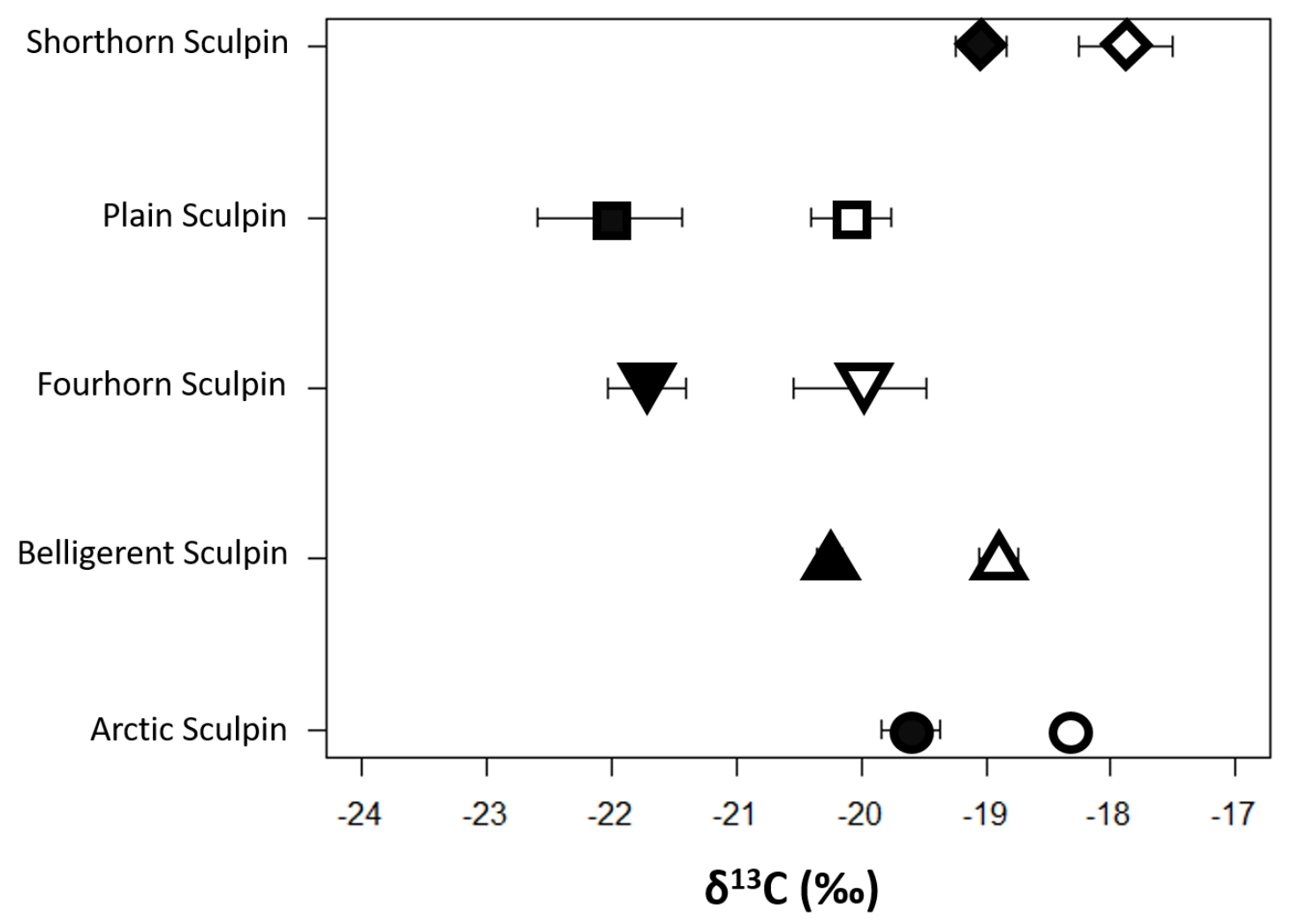

Figure 4.3 A scatter plot representing the difference in carbon isotope ratios in muscle (white) and liver (black) for each species. Error bars represent standard error. Averages and standard errors were calculated from muscle and liver tissues from 35 Arctic Sculpin (Myoxocephalus scorpioides), 7 Belligerent Sculpin (Megalocottus platycephalus), 9 Fourhorn Sculpin (Myoxocephalus quadricornis), 7 Plain Sculpin (Myoxocephalus jaok), 4 Shorthorn Sculpin (Myoxocephalus scorpius). The difference between the white and black points represent the isotopic shift $\left(\delta^{13} \mathrm{C}\right)$ from muscle to liver tissues, respectively, which represents the shift in dietary carbon between ice-covered winter and open-water summer. 


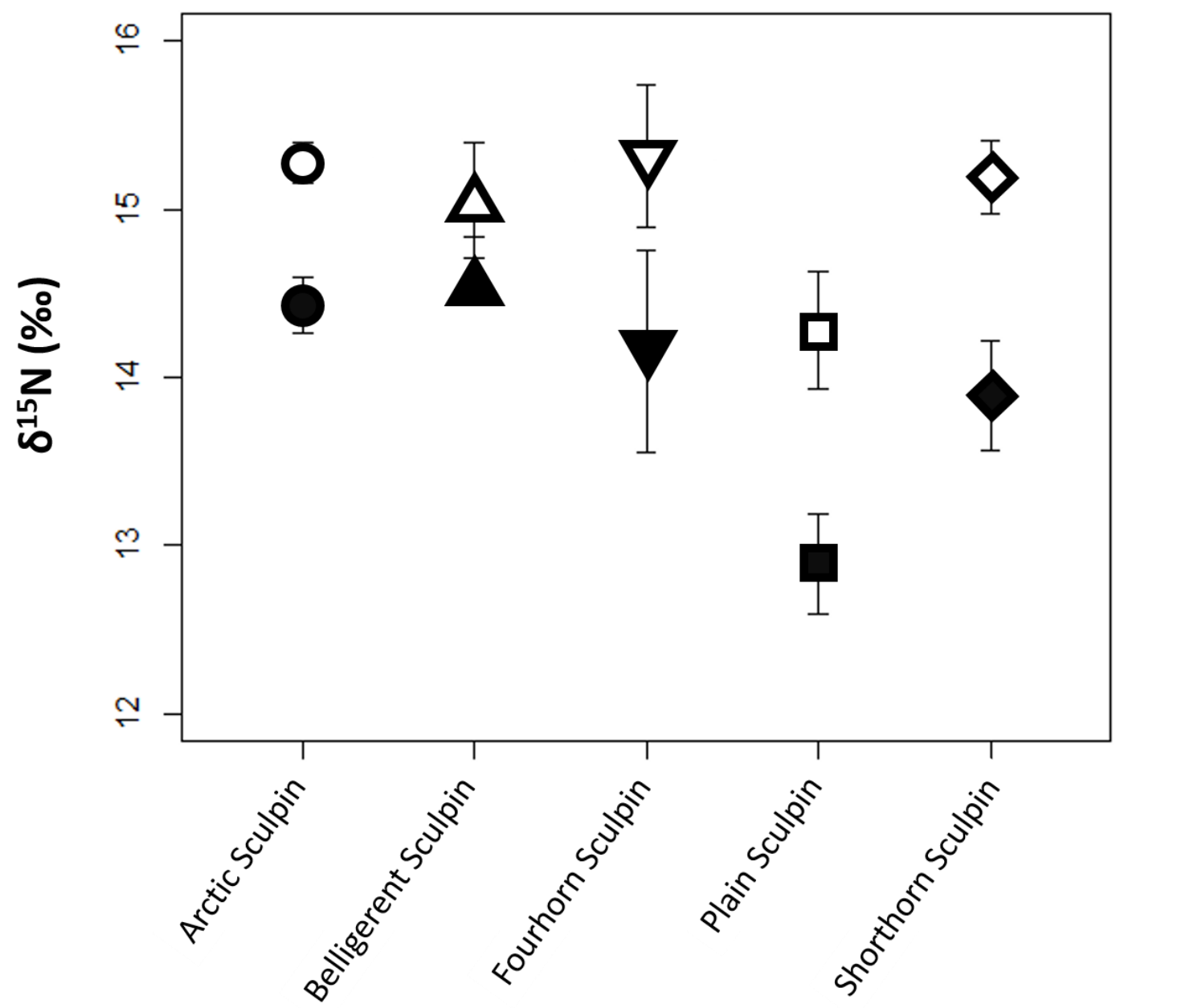

Figure 4.4 A scatter plot representing the difference in nitrogen isotope ratios in muscle (white) and liver (black) for each species. Error bars represent standard error. Averages and standard errors were calculated from muscle and liver tissues from 35 Arctic Sculpin (Myoxocephalus scorpioides), 7 Belligerent Sculpin (Megalocottus platycephalus), 9 Fourhorn Sculpin (Myoxocephalus quadricornis), 7 Plain Sculpin (Myoxocephalus jaok), 4 Shorthorn Sculpin (Myoxocephalus scorpius). The difference between the white and black points represent the isotopic shift $\left(\delta^{15} \mathrm{~N}\right)$ from muscle to liver tissues, respectively, which represents the shift in dietary nitrogen between ice-covered winter and open-water summer. 


\section{CHAPTER V}

LATITUDINAL DEPENDENCE OF BODY CONDITION, GROWTH RATE, AND STABLE ISOTOPES OF JUVENILE CAPELIN (MALLOTUS VILLOSUS) IN THE BERING AND CHUKCHI SEAS 


\begin{abstract}
Capelin occupy a key trophic role and have a broad latitudinal distribution in the northeastern Pacific and Arctic Oceans. Understanding their adaptation to a range of conditions is important to predicting how they will respond to climate change. To quantify the variation in body condition in different physical environments, we measured energy density, RNA/DNA ratios, carbon and nitrogen stable isotope ratios in 62 juvenile capelin along the Western Alaskan coast from Bristol Bay to Point Barrow ranging across approximately 14 degrees of latitude. Energy density correlated positively with latitude, whereas RNA/DNA (instantaneous growth index) was strongly correlated with sea surface temperature, indicating that optimal growth of capelin was achieved at $\sim 9^{\circ} \mathrm{C}$, followed by rapid decreases in RNA/DNA ratios at higher temperatures. $\delta^{13} \mathrm{C}$ and $\delta^{15} \mathrm{~N}$ had strong, inverse non-linear relationships with latitude. Depletion of $\delta^{13} \mathrm{C}$ seen in capelin North of Bristol Bay may be related to the incorporation of allochthonous basal resources into the diets of juvenile capelin from nearby riverine inputs. Observed enrichment of $\delta^{15} \mathrm{~N}$ North of Bristol Bay is likely to be related to incorporation of higher trophic level prey items. Given inverse relationship between $\delta^{13} \mathrm{C}$ and $\delta^{15} \mathrm{~N}$, these prey items are likely available due to the increased diversity of basal resources from increased inputs of riverine organic material.
\end{abstract}

\title{
Introduction
}

Latitudinal variation exists across seascapes and some species found across a wide range of climatic conditions have different feeding and life-history strategies according to the conditions they face (Conover, 1988; Post and Parkinson, 2014; Rypel, 2012; Shoji et al., 
2011). Life-history strategy is defined as the allocation of energy throughout a lifetime to optimize growth, survival, and reproduction (Noordwijk and Jong, 2014). Energy allocation in juvenile fish is particularly important, when there are concurrent energetic demands to grow (predator avoidance, increase accessibility to prey) and store energy to survive their first winter (Mogensen and Post, 2012). Fish condition is often used as a parameter to examine survival potential and recruitment processes (Heintz et al., 2013), and is often expressed as measures of energy density $(\mathrm{kJ} / \mathrm{g})$, which is driven by lipid content (Anthony et al., 2000). Stable isotopes have become a popular method for examining dietary sources and trophic structure within species and their ecosystems (DeNiro and Epstein 1978; DeNiro and Epstein 1981; Hobson and Welch 1992; Layman et al. 2007a; Peterson and Fry 2014). Many trophic studies focus on carbon and nitrogen isotopes but they rarely consider simultaneous measures of energetic condition and growth. These latter measures offer important information describing the quality of prey items and consequently diet implications for fish condition and optimality of habitats within a system (Sherwood et al., 2007). Thus, food web structures and carbon sources that maximize productivity can be identified by combining isotopic analysis with indices of growth and energetic condition. This is important in the Arctic and sub-Arctic where marine conditions are changing rapidly (Grebmeier et al., 2006), and those changes are likely to affect prey availability and quality.

As coastal waters in the Arctic become increasingly warmer and ice-free due to shifting climate conditions, it is likely that species will extend, restrict or shift their ranges as a function of changing tolerable conditions, eliciting change in coastal food web structures of northern oceans (Grebmeier et al. 2006; Moline et al. 2008; Eisner et al. 2013). 
These coastal food webs provide critical subsistence fisheries and serve as a food source for numerous endangered and protected marine mammals and sea birds (Hobson and Welch, 1992). With these changes occurring, high latitude species may see intrusions from lower latitude species; introducing new predators and competition for resources and space (Gilman et al. 2010; Sorte et al. 2010; Grebmeier 2012; Mueter and Litzow 2015). The lifehistory strategies of species that have wide tolerance of environmental conditions may serve as proxies to examine fish condition with changes in food web structure across extensive spatial domains, and offer insight in predicting how these important forage fish may fare in the Arctic as climatic conditions change.

The western coast of Alaska is bordered by the Bering Sea in the southwest, and the Chukchi Sea in the northwest. The high-nutrient, high-salinity Bering Shelf Water (BSW) and the freshwater runoff and wind driven Alaska Coastal Current (ACC) runs along the entire length of these coasts and the front between them typically occurs between 30-60 km from shore (Stabeno et al., 1995; Steele et al., 2010). The front between these two distinct water masses may generate optimal growth conditions to support an abundance of planktivorous fish in coastal waters (Coyle and Pinchuk 2005; Weingartner et al. 2005; Hopcroft et al. 2010; Eisner et al. 2013). Because of the extensive latitudinal range of this persistent front, it presents the opportunity to study the effects of latitude on trophic interactions and energy allocation strategies of coastal planktivorous fish. This water mass provides gradients of temperature and freshwater influx, two primary conditions that are expected to increase significantly with climate change (Chan et al., 2011; Dunton et al., 2014; Peterson et al., 2002). The proximity of this coastal current to land allows for the 
examination of fish trophodynamics and condition in response to freshwater/terrestrial influence.

Capelin (Mallotus villosus) are an abundant planktivorous forage fish found throughout western Alaskan waters and serve as an important link between lower and higher trophic levels (Gjøsæter and Båmstedt 1998; Johnson et al. 2010; Sherwood et al. 2007). Capelin's wide geographical distribution suggests plasticity in its life-history strategies. Because of capelin's trophic position and value as a prey resource, their ability to adapt to different conditions and prey resources will probably play an important role in the response of larger, economically important or endangered members of higher trophic levels, including fish, marine mammals and sea birds. Previous research has shown that great variability exists in planktonic assemblages throughout the ACC and BSW (Schell et al. 1998; Dunton et al. 2006; Eisner et al. 2013) and it is likely that distinct planktonic assemblages coincide and interact with distinct food webs. Capelin can be used as a model species for the adaptability of mid trophic levels (forage fish) to changing climatic conditions in the Arctic by examining their energy allocation patterns and trophodynamics across gradients in climate and latitudes in which they are abundant.

Past studies have examined the latitudinal dependence of energy allocation strategies of fish, but to date they have largely been restricted to smaller scales or closed freshwater and have not incorporated stable isotope analysis (SIA) to examine the effects of variations in diet (Shoji et al. 2011; Mogensen and Post 2012; Rypel 2012; Siddon et al. 2012). The use of a combination of energetics and stable isotope data may offer further insight into the adaptability and sensitivity of these coastal food webs to changing conditions throughout the Alaskan coastline. We aim to quantify energy density, growth 
rates and isotope ratios among juvenile capelin along the entire west coast of Alaska within a single water body, the ACC/BSW front, to examine how variation in condition and growth rate varies as a function of latitude, temperature, riverine influence, and trophic and dietary composition.

\section{Materials and Methods}

\section{Fish Collections}

Juvenile capelin $(n=62)$ were collected during the summer-fall of 2012 using three different vessels spanning $13.9^{\circ}$ of latitude $\left(57.5^{\circ}\right.$ N-71.4 $\mathrm{N}$; Fig. 5.1). Capelin were selectively subsampled from expansive fish surveys from stations between 25 and $75 \mathrm{~km}$ from the coastline (with exception of the stations in Bristol Bay that were approximately $100 \mathrm{~km}$ from the coast), and thus likely to be near the ACC/BSW front (Stabeno et al., 1995; Steele et al., 2010). Capelin analyzed for this project are also limited to those $<100$ mm length and are assumed to be juveniles based on their size (Hop and Gjøsæter, 2013; Vesin et al., 1981) and lack of adult pigmentation. Capelin were sampled using a 198 mlong surface trawl towed behind a 54.9 m chartered fishing vessel between August $8^{\text {th }}$ September $21^{\text {st }}, 2012$. The trawl had hexagonal mesh on the wings and body, a $1.2 \mathrm{~cm}$ mesh cod end liner, and a $50 \mathrm{~m}$ x $25 \mathrm{~m}$ mouth (horizontal x vertical). Each tow lasted for 30 minutes at approximately $8.3 \mathrm{~km} \mathrm{~h}^{-1}$ at stations within a $103 \mathrm{~km}^{2}$ grid along the western Alaskan coast between $60^{\circ} \mathrm{N}-71.4^{\circ} \mathrm{N}$. Four more sites were sampled using the same methods by the NOAA ship Oscar Dyson between $57.5^{\circ} \mathrm{N}-60^{\circ} \mathrm{N}$ (August $20^{\text {th }}-$ October $\left.9^{\text {th }}, 2012\right)$. Capelin along the nearshore were sampled with beach seines near Barrow, AK $\left(\sim 71^{\circ} \mathrm{N}\right)$ during August 7-20, 2012. The seine was $37 \mathrm{~m}$ long with variable mesh sizes (10 
$\mathrm{m}$ of $32 \mathrm{~mm}$ outer panels, $4 \mathrm{~m}$ of $6 \mathrm{~mm}$ middle panels, and $9 \mathrm{~m}$ of $3.2 \mathrm{~mm}$ blunt panel). Each set was round-haul style, paid out of a $7 \mathrm{~m}$ skiff following methods used by Johnson et al. (2010). All collections occurred during daylight hours. Physicochemical parameters from offshore stations were averaged from the top $20 \mathrm{~m}$ of the water column using a CTD at each sampling station at the time of collection. Water temperature and salinity from beach seine sites were measured from the top $0.5 \mathrm{~m}$ of water using a thermometer and refractometer. Fish were measured to fork length (FL) and kept frozen until analyzed in the laboratory.

Individual capelin were randomly sub-sampled within each site (Table 5.1). In the laboratory, individual fish wet weights were measured, stomach contents removed, and a sample of white muscle of $\sim 0.01 \mathrm{~g}$ was dissected and frozen $\left(-80{ }^{\circ} \mathrm{C}\right)$ for RNA/DNA analysis. Individual capelin were dried to a constant weight using a LECO Thermogravimetric Analyzer (TGA) 601/701 and homogenized using mortar and pestle until a uniform consistency was reached. Dry homogenates of individual juvenile capelin were stored in a desiccator prior to SIA and bomb calorimetry analyses.

\section{Bomb Calorimetry}

Energy density of juvenile capelin ( $\mathrm{kJ} \mathrm{g}^{-1}$ dry mass) was quantified using bomb calorimetry. A Parr Instrument 6725 Semi-micro Bomb Calorimeter was used to combust pellets of dry fish homogenate following standard instrument operating protocols from the manufacturer. Precision and accuracy of measurements were assessed by evaluating duplicate benzoic acid standards, replicate samples, and a tissue reference material of Pacific herring or walleye pollock homogenate. Error limits were set for the quality 
assurance samples, where precision from replicate benzoic acid standards was not allowed to vary by more than $1.5 \%$ coefficient of variation and must have been within $2.0 \%$ of the target value. Sample replicates were not allowed to vary by more than 1.5 standard deviations and tissue reference samples were not allowed to vary by more than $3.0 \%$ from target reference values.

\section{RNA/DNA Analysis}

Instantaneous growth rates were estimated from RNA/DNA ratios following methods outlined in Sreenivasan (2011). A 10 mg of frozen muscle sample was taken from each fish. RNA/DNA ratios were quantified fluorometrically using one dye and two enzymes (RNase and DNase; Caldarone et al. 2001). Nucleic acids were isolated from the smaller muscle samples and dyed using $75 \mu \mathrm{L}$ ethidium bromide $(5 \mu \mathrm{g} \mathrm{ml}-1)$ according to the protocol outlined by Caldarone et al. (2001). Total fluorescence at excitation and emission wavelengths of $355 \mathrm{~nm}$ and $600 \mathrm{~nm}$ respectively, was recorded and then the samples were sequentially treated with RNase and DNase, and the resulting reduced fluorescence was measured to obtain RNA and DNA fluorescence, respectively. Standard curves were constructed using serial dilutions of 18s-28s rRNA (Sigma R-0889) and calf thymus DNA (Sigma D-4764) standards. DNA concentrations in tissues are stable, but RNA concentrations vary greatly depending on the rate of protein synthesis where a high RNA/DNA ratio indicates a high growth rate (Weber et al., 2003). 


\section{Stable Isotopes Analysis}

SIA of carbon and nitrogen are used to examine the origins and type of dietary sources assimilated by fish (DeNiro and Epstein, 1981, 1978). All sub-samples of dried fish homogenate were weighed to $0.55 \mathrm{mg}+/-0.15 \mathrm{mg}$. In between every 4 samples, a standard or duplicate sample was analyzed to examine precision of measurements. Samples were analyzed at the Florida International University SERC Stable Isotope Lab using Elemental Analysis - Isotope Ratio Mass Spectrometry (EA-IRMS), with a NA1500 NC (EA) coupled to a Delta C (IRMS). Error based on internal glycine standards ranged 0.09$0.21 \%$ for $\delta^{15} \mathrm{~N}$ and $0.07-0.10 \%$ for $\delta^{13} \mathrm{C}$.

Lipid corrections were computed using $\mathrm{C} / \mathrm{N}$ ratios $(4.45 \pm 0.66)$ following "equation 1" outlined by Logan et al. (2008). This equation requires the assumption that the difference between bulk $\delta^{13} \mathrm{C}$ and lipid free $\delta^{13} \mathrm{C}$ approximates $6 \%$ as suggested by McConnaughey and McRoy (1979). Later work by Post et al. (2007) pointed out that these methods are suitable for organisms with $15 \%$ or less lipid content, and that caution should be used at higher lipid contents because they had insufficient samples with such high lipid content to adequately model the relationship. Thus, using the relationship presented by Post et al. (2007), we estimate that approximately $82 \%$ of our samples contain less than $15 \%$ lipids, $15 \%$ of our samples contain less than $17.5 \%$ lipid, and the remaining $3 \%$ contain less than $20 \%$ lipid. Based on this information we deemed this method of lipid correction appropriate for our samples. 


\section{Stomach Contents}

Prey from the stomach contents of juvenile capelin were identified to species and life history stage where possible using methods outlined by Sturdevant et al. (2012). Adult Calanus spp. were classified by size: small $\leq 2.4 \mathrm{~mm}$ in length, medium $=2.5-2.9 \mathrm{~mm}$, and large $\geq 3 \mathrm{~mm}$. Aggregate wet weights of separated prey groups were measured from each fish. Weights were converted into percent contributions to the total mass of prey found in each stomach to standardize against the unevenness in fullness. Percent contributions from individual capelin were averaged over regional groups (see Data Analysis section below) to standardize against unevenness in sample size.

\section{Data Analysis}

The 62 juvenile capelin from 17 sampling stations were separated into 7 regional groups (Table 5.1) based on latitude and distance from each other (Fig. 5.1). General Additive Models (GAMs) were used for qualitative assessment to identify patterns of dependent variables with latitude as the independent variables. Linear regressions were used to assess the relationship between dependent variables $\left(\delta^{15} \mathrm{~N}, \delta^{13} \mathrm{C}\right.$, energy density, RNA/DNA ratios, length, and weight) and to offer a quantitative approach to assessing the relationships of energetics and SIA with latitude.

\section{Results}

Energy Allocation

Across the sample set, energy density ranged from $20.77 \mathrm{~kJ} \mathrm{~g}^{-1}$ to $26.49 \mathrm{~kJ} \mathrm{~g}^{-1}$ $\left(\right.$ Mean $\left.\pm \mathrm{SD}=22.85 \pm 1.33 \mathrm{~kJ} \mathrm{~g}^{-1}\right)$. RNA/DNA ratios ranged from 13.10 to $31.61(22.89 \pm$ 
4.33). Linear regression indicated a weak positive correlation between energy density and RNA/DNA $\left(R^{2}=0.32, p<0.0001\right.$; Fig. 5.2A). Energy density increased significantly with latitude but RNA/DNA did not (energy density: Estimated Degrees Freedom [edf]=4, $R^{2}=0.34, p<0.0001$, Fig. 5.3A; RNA/DNA: $e d f=4, R^{2}=0.14, p=0.01$, Fig. 5.3B). The models for energy density and RNA/DNA suggest that the Point Barrow group may be an outlier relative to other samples, as the values rapidly decrease at this region group. In addition, capelin from Point Barrow were significantly smaller than all other groups (FL: $p=0.0002$; wet weight: $p<0.0001)$ and were the only fish collected by beach seines in the very near shore. When the Point Barrow group was removed from the analysis, energy density was linearly correlated with latitude $\left(R^{2}=0.36, p<0.0001\right.$, Fig. $\left.5.4 \mathrm{~A}\right)$; however, the linear model between RNA/DNA and latitude was not significant $\left(R^{2}=0.06, p=0.05\right.$, Fig. 5.4B). Furthermore, linear regressions indicated that energy density was strongly positively correlated with fish length (FL: $\left.R^{2}=0.47, p<0.0001\right)$ and full body wet weight $\left(R^{2}=0.63\right.$, $p<0.0001)$.

In contrast, GAM models using sea surface temperature as a predictor indicated that more variability in RNA/DNA ratios was explained by surface temperature than in energy density (RNA/DNA: $e d f=3, R^{2}=0.28, p<0.0001$; energy density: $e d f=4, R^{2}=0.15$, $p<0.0001$, Fig. 5.5A-B); however, both models suggest that these measures vary slightly with increasing temperature until a threshold of approximately $9^{\circ} \mathrm{C}$ is reached, at which point they both decreased rapidly. In turn, a GAM using surface temperature with latitude as the predictor indicates that these factors have a non-linear relationship $\left(e d f=4, R^{2}=0.29\right.$, $p<0.0001$, Fig. 5.6). 


\section{Stable Carbon and Nitrogen Isotopes}

Stable $\delta^{13} \mathrm{C}$ and $\delta^{15} \mathrm{~N}$ isotope ratios of juvenile capelin were analyzed to identify changes in the origins of dietary material and trophic position across latitudes. Across this range, $\delta^{13} \mathrm{C}$ ranged from $-22.47 \%$ to $-17.89 \%$ (Mean $\pm \mathrm{SD}=-20.33 \pm 1.10 \%$ ), and $\delta^{15} \mathrm{~N}$ ranged from $11.76 \%$ to $17.09 \% o(14.31 \pm 1.29 \%)$. The linear correlation between $\delta^{13} \mathrm{C}$ and $\delta^{15} \mathrm{~N}$ was strongly negative $\left(R^{2}=0.67, p<0.0001\right.$; Fig. 5.2B).

The relationships between $\delta^{13} \mathrm{C}$ and $\delta^{15} \mathrm{~N}$ with latitude were highly significant and much of the variability in both SIA measures could be explained by latitude $\left(\delta^{13} \mathrm{C}: e d f=3\right.$, $R^{2}=0.54, p<0.0001 ; \delta^{15} \mathrm{~N}: e d f=3, R^{2}=0.67, p<0.0001$; Fig. $\left.5.3 \mathrm{C}-\mathrm{D}\right)$. Linear regressions indicated that $\delta^{13} \mathrm{C}$ was positively correlated and $\delta^{15} \mathrm{~N}$ was negatively correlated with latitude $\left(R^{2}=0.55, p<0.0001 ; R^{2}=0.75, p<0.0001\right.$, respectively; Fig. 5.4C-D) when anomalies at the northern-most sampling stations (Point Barrow group) and the southernmost sampling stations (Bristol Bay group; Fig. 5.1) are removed. A similar pattern for each isotope was seen with temperature, suggesting that peak energy content and growth rate at the high latitudes coincide with feeding at higher trophic levels and incorporation of depleted $\delta^{13} \mathrm{C}$.

\section{Stomach Contents}

Juvenile capelin diets were dominated by Calanus spp. copepods, with the average proportion of copepods in non-empty stomachs being $79.8 \%$. Stomach contents in Bristol Bay consisted solely of large and medium sized Calanus spp. copepods, but stations near the Bering Strait had increased prey diversity, including important contributions from decapod larvae, and smaller contributions of small copepods, cladocerans, and 
chaetognaths. At the Point Barrow stations the diets consist completely of small copepods and Themisto libellula, a predatory hyperiid amphipod (Auel and Werner, 2003; Pinchuk et al., 2013). Of the capelin caught at Point Barrow, $56 \%$ of them had empty stomachs, while empty stomachs were not observed at any other station (Fig. 5.7).

\section{Discussion}

Energy Allocation

Given that capelin occupy a wide latitudinal range, it is expected that they exhibit plasticity not only in their diet but also the allocation of energy obtained to cope with differences in climatic conditions. When prey resources are limited, we expect to see a trade-off between energy storage and growth rate as energy availability is generally not great enough to allow for concurrent processes of high growth rates and energy storage in juvenile fish (Post and Parkinson 2001). We saw evidence for increased energy provisioning for more severe winters in juvenile capelin in higher latitudes, with a positive correlation between energy density and latitude. This phenomenon has been observed for other fish species where the longer high-Arctic winters require a larger store of energy to survive than shorter, low latitude winter locations (Biro et al., 2005).

It is also plausible that though the fish were sampled at approximately the same time of year, season could play a factor in the greater energy densities at higher latitudes. Many species of fish undergo seasonal changes in their energy content as a factor of ontogenetic changes and maturation, particularly pelagic species such as capelin (Vollenweider et al., 2011). In general, fish increase energy during summer periods of high productivity, peak in the fall, and decline overwinter when prey can be scarce and gametes 
start developing for later spawning. The onset of winter will come much sooner to the fish in the Arctic. Therefore, it could be that higher energy densities observed at higher latitudes are a factor of the accelerated onset of winter, while further to the south there is additional time to prepare.

Increased energy storage at high latitudes could be expected to impair growth rates relative to southern areas. Another reason to expect lower growth rates in the Arctic is that capelin, as are many species of fish, are smaller at age at higher latitudes (Chambers and Leggettt 1987; Chambers et al. 1989; Olsen et al. 2005). However, measurements of RNA/DNA remained relatively constant across latitudes. In concert, higher energy densities in the Arctic and equivalent RNA/DNA across latitudes imply that fish in higher latitudes have greater accessibility to energy resources that can be simultaneously allocated to growth and energy storage. An alternate explanation is that RNA/DNA ratios in juvenile capelin are driven more by sea surface temperature. Comparisons across a temperature range have been shown to require laboratory-based calibration studies (Caldarone 2001). Without these studies to validate the temperature effect on RNA/DNA and growth relationship, it is conceivable that temperature is confounding our use of RNA/DNA as an index to growth.

However, RNA/DNA ratios varied with temperature and were greatest just above $9{ }^{\circ} \mathrm{C}$, which occurred in the middle range of the Chukchi coast near Wainwright Inlet. This indicates that RNA production is maximized at this temperature. However, it is unclear if this translates to increased growth. It is possible increased RNA synthesis is a compensation for reduced efficiency in protein synthesis enzymes (Houlihan et al. 1995; Smith and Ottema 2006). Coincidently, this is also the location where energy density 
reached a maximum. This could suggest that growing conditions are maximized at $9{ }^{\circ} \mathrm{C}$. High growth rates near the end of the growing season have been associated with increased lipid reserves in high latitude perch and subsequent winter survival (Huss et al. 2008). A summer-long sampling effort of capelin in the Point Barrow region during ice-free periods in 2013 and 2014 show that capelin were more abundant at 8-9 ${ }^{\circ} \mathrm{C}$ (Barton et al. unpublished data). Capelin distribution, abundance and diet are impacted by water temperature. In cold years $\left(1-2^{\circ} \mathrm{C}\right.$ below average $)$, capelin are distributed across a much broader area in higher numbers in the Bering Sea, and energy-rich Calanus spp. are important diet items (Andrews et al. pers. comm.). In warm years $\left(1-1.5^{\circ} \mathrm{C}\right.$ above average), capelin distribution is relatively restricted to the cooler, northern reaches of the Bering Sea, and energy-poor Pseudocalanus spp. and Oikopleura spp. were more abundant in their diet. During August 2012, when these samples were collected, an average temperature anomaly near Point Barrow stations of 5 to $7.5^{\circ} \mathrm{C}$ above average was measured, suggesting that an abundance of energy-poor prey items were likely present (Parkinson and Comiso, 2013).

Similarly, capelin distribution in Glacier Bay in Southeast Alaska were highly correlated with water temperatures, but in contrast to our results, these capelin were most abundant in the colder $\left(6-7^{\circ} \mathrm{C}\right)$ glacial waters over warmer $\left(7-8^{\circ} \mathrm{C}\right)$ estuarine central bay waters (Arimitsu et al., 2008). In this case, the glacial waters must have offered an advantage over the central bay waters. Glacial runoff brings with it high concentrations of nutrients (Hood and Scott, 2008) and creates stratification by forming a freshwater lens, thus promoting plankton blooms to occur and providing an abundant food source for resident capelin. Additionally, Arimitsu et al. (2008) demonstrated that these waters were highly turbid, which may offer protection from sight-based predation, and increased 
feeding opportunities for capelin. Though we expect that temperature plays an important role in the life-history strategies of capelin, different temperature preferences in Southeast Alaska compared to the Western coast of Alaska in our study suggest that other factors such as predator abundance, prey availability, and turbidity may be more important drivers than temperature.

\section{Stable Carbon and Nitrogen Isotopes}

Relationships between $\delta^{13} \mathrm{C}$ and $\delta^{15} \mathrm{~N}$ can be used to identify a number of factors that describe the variation of assimilated materials obtained through capelin diets as a function of latitude. It is common to observe positive correlations between $\delta^{13} \mathrm{C}$ and $\delta^{15} \mathrm{~N}$ isotope ratios because both become enriched $\left(\delta^{13} \mathrm{C} \approx+1 \% ; \delta^{15} \mathrm{~N} \approx+3.8 \%\right.$ ) with increasing trophic level provided that the basal resources remain the same (Hobson and Welch 1992, Layman et al. 2007a). The negative correlation seen in our results may suggest that within a single species, carbon sources and trophic structure may differ spatially. In order to better understand these differences in dietary composition of juvenile capelin, $\delta^{13} \mathrm{C}$ and $\delta^{15} \mathrm{~N}$ ratios across the latitudinal range must be investigated individually.

\section{Stable Carbon Isotopes}

Basal resources in the BSW and Anadyr Water (AW) are mostly derived of pelagic production, but in the ACC basal resources consist mostly of terrestrial materials contributed by freshwater runoff (Grebmeier et al., 1988). This concept is consistent with the pattern of $\delta^{13} \mathrm{C}$ throughout our sampling stations, suggesting that the majority of the variation in $\delta^{13} \mathrm{C}$ may be explained by riverine inputs along the path of the ACC. It is 
expected that the ACC is less depleted in $\delta^{13} \mathrm{C}$ when entering Bristol Bay as it is derived from relatively marine waters from the Gulf of Alaska moving through Unimak Pass (Kline, 1999). As it travels north between $58-63{ }^{\circ} \mathrm{N}$, a number of rivers discharge a substantial amount of fresh water into the ACC, including the Kvichak, Nushagak, Kuskokwim, and Yukon which cumulatively average $310 \mathrm{~km}^{3} \mathrm{yr}^{-1}$ (40\% of the average annual freshwater runoff into the ACC; Figure 5.1) (Benke and Cushing, 2006; Weingartner et al., 2005). As these rivers discharge, $\delta^{13} \mathrm{C}$ depleted labile organic material accumulates and is incorporated into primary producers and eventually secondary consumers like capelin (Dunton et al., 2005b; Helfield and Naiman, 2016). As the ACC continues northward it converges and mixes with the benthic derived marine BSW and the AW (Grebmeier et al. 1988; Dunton et al. 2005), causing isotopic ratios to become less depleted again. The lack of major rivers that drain into the southern Chukchi coast of Alaska limits riverine inputs of terrestrial organic material north of the Bering Strait, and $\delta^{13} \mathrm{C}$ continues to become less depleted as the ACC travels further north.

The pattern described above might suggest that $\delta^{13} \mathrm{C}$ correlates with salinity, however, when this relationship was investigated we found no discernable patterns nor any significant correlation. This may be explained by the relative differences of salinity and isotopic content between riverine waters and ACC waters. We posit that the difference in salinity between riverine and coastal waters may be relatively small compared to the difference in abundance of materials that may be incorporated as basal resources, thus explaining why riverine discharge may elicit a change in $\delta^{13} \mathrm{C}$, but not in salinity. Given that the ACC is known to be driven by freshwater discharge, and has relatively low levels 
of in situ production (Grebmeier et al., 1988; Weingartner et al., 2005), this phenomenon may serve as a possible explanation for the observed trends.

Freshwater inputs support observations for $\delta^{13} \mathrm{C}$ between $58-70{ }^{\circ} \mathrm{N}$, but an anomaly exists at the northern-most regional groups (Wainwright Inlet and Point Barrow) of the data set where $\delta^{13} \mathrm{C}$ becomes more depleted again. It is possible that this could be attributed to the incorporation of high-lipid content in prey items that are depleting the carbon signature. However, if this were the case we would expect capelin in these regions to show an increase in energy density, which is not the case. A more likely explanation is that the series of small streams and rivers along the Chukchi coast of the North Slope of Alaska, as well as two substantial estuaries (Wainwright Inlet, and Peard Bay) that are likely to carry large loads of labile terrestrial carbon from permafrost meltwater runoff into coastal waters, and could be responsible for the depletion of $\delta^{13} \mathrm{C}$ ratios in capelin at the northern-most stations (Dutta et al., 2006; Schuur et al., 2008). Though this runoff is relatively small compared to major rivers in the Bering Sea, when combined, these terrestrial inputs may be large enough to cause a significant shift in dietary $\delta^{13} \mathrm{C}$ of capelin.

\section{Stable Nitrogen Isotope}

$\delta^{13} \mathrm{C}$ and $\delta^{15} \mathrm{~N}$ have inverse relationships with latitude, where $\delta^{15} \mathrm{~N}$ is less enriched in Bristol Bay, then rapidly becomes more enriched at Nunivak Island (17.1\%o). The ratios became gradually less enriched with latitude, reaching a minimum at Point Hope (11.8 \%o), at which point they become enriched again at the northern-most groups (Wainwright Inlet and Point Barrow). When investigating carbon isotope patterns, we found that our results resembled broad scale patterns described by Schell et al. (1998), however, the fluctuations 
we found in nitrogen isotopes do not. The difference between our maximum and minimum $\delta^{15} \mathrm{~N}$ surpasses the commonly accepted trophic enrichment value of $3.8 \%$ (Hansen et al., 2012; Hobson and Welch, 1992; D M Post, 2002) and suggests that capelin along this latitudinal gradient are feeding at different trophic levels. When this pattern is compared to that of $\delta^{13} \mathrm{C}$ it becomes clear that $\delta^{15} \mathrm{~N}$ is more enriched where terrestrial inputs are increased. This difference may be attributed to one or both of two scenarios: (1) the prey that capelin feed on are depending on different basal resources; (2) or capelin are feeding on different prey types in relation to latitude.

One possible explanation is that the basal resources vary with latitude and may elicit a cascading effect on the isotopic ratios of capelin. Fractionation of $\delta^{15} \mathrm{~N}$ differs depending on the type of nitrogen compounds used by primary producers. Atmospheric nitrogen $\left(\mathrm{N}_{2}\right)$ fixers such as phytoplankton generally have a small range of $\delta^{15} \mathrm{~N}$ (-2 to 2 $\%$ ), whereas nitrate, nitrite, ammonia, and ammonium fixers such as benthic marine plants and terrestrial plants have a much greater range (-8 to $3 \%$ ), leading to a wide range of possible values of coastal basal resources (Fry 2007). As mentioned previously, the relationship between $\delta^{13} \mathrm{C}$ and $\delta^{15} \mathrm{~N}$ suggests that $\delta^{15} \mathrm{~N}$ becomes more enriched where terrestrial inputs are highest. It is likely that the increased diversity in basal resources caused by the increased terrestrial inputs led to an increase in trophic level variation, thus supporting more trophic levels than areas with less terrestrial input (Layman et al. 2007b). This suggests that Arctic coastal food webs may gain complexity and productivity as Arctic warming continues to increase the magnitude of freshwater discharge (Peterson et al. 2002). 
This logic leads us to consider the types of prey items being consumed as an explanation for patterns in nitrogen isotopes. The majority of capelin analyzed may be classified into the lower half of the size class defined as juveniles (75-100 mm) by Vesin et al. (1981), a life-stage at which gape and stomach size limits consumable prey items and variability in their diet. Dietary composition of these small capelin was dominated by Calanus copepods, with the average proportion of copepods in non-empty stomachs being $79.8 \%$ (Fig. 5.7). Less common prey items included decapod larvae, cheatognaths, and the hyperiid amphipod T. libellula are only seen at the Point Barrow group. Isotopic ratios of different size copepods are not likely to differ greatly because of their low trophic position (Schell et al., 1998), but decapod larvae, chaetognaths and T. libellula feed on copepods, thus adding a trophic level between capelin and copepods (Auel and Werner, 2003; Saito and Kiørboe, 2001). The inclusion of these less common prey types may be responsible for the enrichment observed in $\delta^{15} \mathrm{~N}$. Feeding data suggests that at the latitudes where $\delta^{15} \mathrm{~N}$ became suddenly enriched (Nunivak Island and Point Barrow), capelin included less common prey items in their diet that would be expected to feed at higher trophic levels (chaetognaths and T. libellula, respectively; Fig 4.7). These results suggest that higher trophic level prey items are present where terrestrial nutrients are abundant and are at least partially responsible for variations in $\delta^{15} \mathrm{~N}$ with latitude.

Fish collected at Point Barrow were anomalous in all dependent variables $\left(\delta^{13} \mathrm{C}\right.$, $\delta^{15} \mathrm{~N}$, energy density and RNA/DNA). These fish were collected with beach seines, and thus are inhabitants of the very nearshore where conditions can be extremely variable in comparison to the coastal offshore waters where the other fish were collected with surface trawls. If these nearshore samples are comparable to the offshore samples in lower 
latitudes, we may expect that the energy density of sub-Arctic forage fish in the Arctic may increase as future high latitude conditions change to resemble current lower latitude conditions. This may offer an alternate high-quality prey source for Arctic piscivores as climate change continues.

However, it is also possible that these nearshore fish are not comparable to offshore samples, and thus were removed from most analyses as they were significantly smaller in size than all other samples. The Point Barrow fish were significantly lower in energy density $(p=0.0004)$ and RNA/DNA $(p=0.0004)$ than capelin examined from other areas. When examining the other regional groups, energy density increases from Bristol Bay to Wainwright Inlet, and RNA/DNA remains relatively constant; however, at Point Barrow both of these measures fell to some of the lowest values observed. Furthermore, diet data indicates that most of the nearshore fish had empty stomachs (61\%) suggesting that prey are sparsely distributed, and these fish may be undernourished or have difficulty locating prey. The anomalous enrichment of $\delta^{15} \mathrm{~N}$ in these fish may support this premise. During starvation, animals will metabolize their own fat and muscle tissue to survive; in essence they are eating themselves. This causes trophic fractionation and will make it appear as though they are feeding at a higher trophic level (Vander Zanden and Rasmussen, 2001). The combination of poor condition and growth, coupled with evidence of low food availability and potential starvation suggests that the Arctic nearshore habitats near Barrow may not be an optimal environment for juvenile capelin.

If these nearshore habitats are sub-optimal, why were capelin highly abundant? These had the highest surface temperatures $\left(11^{\circ} \mathrm{C}\right)$, and were much higher than the optimal growth temperatures $\left(\sim 9^{\circ} \mathrm{C}\right)$, which is not likely to motivate capelin to inhabit these waters. 
One explanation for their abundance is that these shallow and turbid nearshore waters offer an advantage over nearby habitats such as refuge from abundant local predators (belugas, seals and sea birds), which are commonly observed feeding in the nearshore. However, it is also possible that juvenile capelin are blown or advected into sub-optimal nearshore areas by strong wind and currents, and therefore their presence in the Arctic nearshore near Barrow is not by choice.

\section{Conclusions}

The combination of growth and condition indices with SIA is a useful method to understand how isotopic food sources contribute to fish production. We suggest that capelin may be an ideal species for such analysis and can provide insight into how the ecosystem may restructure under different climate scenarios, as they have a key trophic position in the ecosystem and a wide latitudinal range. A benefit of using a wide-ranging species such as capelin is that their response to different environmental conditions can be considered a natural experiment, however as we have pointed out, this also requires additional information to interpret at regional scales. The Chukchi Sea is a sink for biota advected from the Bering Sea and therefore communities associated with warm conditions in the Bering Sea may serve as proxies to examine Arctic community level dynamics in the face of warming conditions (Coyle et al., 2013; Walsh et al., 2004; Woodgate et al., 2012). Consequently, examining the response of capelin to a range of physiological conditions may offer a better understanding of how populations of these important forage fish, and the community in the Chukchi will respond to climate change. This study has 
revealed large scale variation in condition of capelin, but the mechanisms behind this variation need to be further explored.

Varying terrestrial inputs are one mechanism that likely affected capelin condition. Habitats with greater terrestrial inputs are likely to have higher trophic diversity and more basal resources based on ranges of isotopic ratios. This is an important premise as freshwater inputs are expected to increase with climate change, and thus we may expect to see more complex and more productive Arctic coastal food webs to develop in response. Two important questions arise from our results: (1) will climate change lead to higher energy density of sub-Arctic forage fish in the Arctic and offer alternate high-quality forage to nearshore piscivores? (2) Are capelin utilizing suboptimal nearshore habitats near Barrow to avoid predation or are they advected there through their ontogeny? We suggest that additional studies be developed to examine energetics and SIA of capelin in Arctic and sub-Arctic habitats to better elucidate the mechanisms that underlie these patterns.

\section{Acknowledgements}

We thank Franz Mueter and the rest of the Arctic EIS crew for providing samples, as well as the scientists and crewmen aboard the R/V Oscar Dyson. Special thanks to Craig George, Leandra de Sousa, Todd Sformo, Robert Suydam, and the North Slope Borough Division of Wildlife, who provided significant logistical support for collection of samples in Barrow. Additional thanks to those NOAA Affiliates who processed samples in the bioenergetics lab, including A Robertson, M Callahan, A Sreenivasan, E Fergusson, J Weems and H Findley. Funding was provided in part by the North Pacific Research Board to KM Boswell (Project 1229) and in part from BOEM Cooperative Agreement Contract 
Nos. M12PG00024 (ACES), and M12PG00018 (Arctic EIS) of the U.S. Department of the Interior, Bureau of Ocean Energy Management (BOEM), Alaska Outer Continental Shelf Region, Anchorage Alaska as part of the BOEM Environmental Studies Program. This report is funded in part with qualified outer continental shelf oil and gas revenues by the Coastal Impact Assistance Program, Fish and Wildlife Service, U.S. Department of the Interior under Agreement Number 10-CIAP-010, F12AF00188. This is contribution No. XX from the Marine Education and Research Center in the Institute for Water and the Environment at Florida International University.

\section{References}

Anthony JA, Roby DD, Turco KR (2000) Lipid content and energy density of forage fishes from the northern Gulf of Alaska. J Exp Mar Biol Ecol 248:53-78. doi: 10.1016/S00220981(00)00159-

Arimitsu ML, Piatt JF, Litzow MA, et al (2008) Distribution and spawning dynamics of capelin (Mallotus villosus) in Glacier Bay, Alaska: a cold water refugium. Fish Oceanogr 17:137-146. doi: 10.1111/j.1365-2419.2008.00470.x

Auel H, Werner I (2003) Feeding, respiration and life history of the hyperiid amphipod Themisto libellula in the Arctic marginal ice zone of the Greenland Sea. J Exp Mar Biol Ecol 296:183-197. doi: 10.1016/S0022-0981(03)00321-6

Benke A, Cushing C (2006) Rivers of North America, First Edition. Elsevier Academic Press, Burlington, MA

Biro PA, Post JR, Abrahams MV (2005) Ontogeny of energy allocation reveals selective pressure promoting risk-taking behaviour in young fish cohorts. P R Soc B 272:1443-1448. doi: $10.1098 /$ rspb.2005.3096

Caldarone EM, Wagner M, Onge-burns JS, Buckley LI (2001) Protocol and guide for estimating nucleic acids in larval fish using a fluorescence microplate reader. Northeast Fisheries Science Center Reference Document. 1:1-22. 
Chambers RC, Leggett WC (1987) Size and age at metamorphosis in marine fishes: an analysis of laboratory-reared winter flounder (Pseudopleuronectes americanus) with a review of variation in other species. Can J Fish Aquat Sci 44:1936-1947.

Chambers RC, Leggett WC, Brown JA (1989) Egg size, female effects, and the correlations between early life history traits of capelin, Mallotus villosus: an appraisal at the individual level. Fish Bull 87:515-523.

Chan P, Halfar J, Williams B, et al (2011) Freshening of the Alaska coastal current recorded by coralline algal $\mathrm{Ba} / \mathrm{Ca}$ ratios. J Geophys Res-Biogeo 116:1-8. doi: 10.1029/2010JG001548

Collatz GJ, Berry JA, Clark JS (1998) Effects of climate and atmospheric CO2 partial pressure on the global distribution of $\mathrm{C} 4$ grasses: present, past, and future. Oecologia 114:441-454. doi: 10.1007/s004420050468

Conover RJ (1988) Comparative life histories in the genera Calanus and Neocalanus in high latitudes of the northern hemisphere. Hydrobiologia 167:127-142. doi: 10.1007/BF00026299

Coyle KO, Gibson GA, Hedstrom K et al (2013) Zooplankton biomass, advection and production on the northern Gulf of Alaska shelf from simulations and field observations. J Marine Syst 128:185-207. doi: 10.1016/j.jmarsys.2013.04.018

Coyle KO, Pinchuk AI (2005) Seasonal cross-shelf distribution of major zooplankton taxa on the northern Gulf of Alaska shelf relative to water mass properties, species depth preferences and vertical migration behavior. Deep-Sea Res Pt II 52:217-245. doi: 10.1016/j.dsr2.2004.09.025

DeNiro M, Epstein S (1978) Influence of diet on the distribution of carbon isotopes in animals. Geochim Cosmochim Ac 42:495-506.

DeNiro M, Epstein S (1981) Influence of diet on the distribution of nitrogen isotopes in animals. Geochim Cosmochim Ac 45:341-

Dunton KH, Goodall JL, Schonberg SV et al (2005) Multi-decadal synthesis of benthicpelagic coupling in the western arctic: role of cross-shelf advective processes. Deep-Sea Res Pt II 52:3462-3477. doi: 10.1016/j.dsr2.2005.09.007

Dunton KH, Grebmeier JM, Trefry JH (2014) The benthic ecosystem of the northeastern Chukchi Sea: An overview of its unique biogeochemical and biological characteristics. Deep-Sea Res Pt II 102:1-8. doi: 10.1016/j.dsr2.2014.01.001

Dunton KH, Weingartner T, Carmack EC (2006) The nearshore western Beaufort Sea ecosystem: Circulation and importance of terrestrial carbon in arctic coastal food webs. Prog Oceanogr 71:362-378. doi: 10.1016/j.pocean.2006.09.011 
Dutta K, Schuur EAG, Neff JC, Zimov SA (2006) Potential carbon release from permafrost soils of northeastern Siberia. Glob Change Biol 12:2336-2351. doi: 10.1111/j.13652486.2006.01259.x

Eisner L, Hillgruber N, Martinson E, Maselko J (2013) Pelagic fish and zooplankton species assemblages in relation to water mass characteristics in the northern Bering and southeast Chukchi seas. Polar Biol 36:87-113. doi: 10.1007/s00300-012-1241-0

Fry B (2007) Stable Isotope Ecology. Springer Science and Business Media.

Gilman SE, Urban MC, Tewksbury J et al (2010) A framework for community interactions under climate change. Trends Ecol Evol 25:325-31. doi: 10.1016/j.tree.2010.03.002

Gjøsæter H, Båmstedt U (1998) The population biology and exploitation of capelin (Mallotus villosus) in the Barents Sea. Sarsia 83:453-496.

Grebmeier JM (2012) Shifting patterns of life in the Pacific Arctic and sub-Arctic seas. Ann Rev Mar Sci 4:63-78. doi: 10.1146/annurev-marine-120710-100926

Grebmeier JM, Mcroy CP, Feder HM (1988) Pelagic-benthic coupling on the shelf of the northern Bering and Chukchi Seas. I. Food supply source and benthic biomass. Mar Ecol Prog Ser 48:57-67

Grebmeier JM, Overland JE, Moore SE et al (2006) A major ecosystem shift in the northern Bering Sea. Science 311:1461-4. doi: 10.1126/science.1121365

Hansen J, Hedeholm R, Sünksen K et al (2012) Spatial variability of carbon $\left(\delta^{13} C\right)$ and nitrogen $\left(\delta^{15} \mathrm{~N}\right)$ stable isotope ratios in an Arctic marine food web. Mar Ecol Prog Ser 467:47-59. doi: 10.3354/meps09945

Heintz RA, Siddon EC, Farley EV, Napp JM (2013) Correlation between recruitment and fall condition of age-0 pollock (Theragra chalcogramma) from the eastern Bering Sea under varying climate conditions. Deep-Sea Res Pt II 94:150-156. doi: 10.1016/j.dsr2.2013.04.006

Helfield J, Naiman R (2016) Salmon and alder as nitrogen sources to riparian forests in a boreal Alaskan watershed. Oecologia 133:573-582

Hobson K, Welch H (1992) Determination of trophic relationships within a high arctic marine food web using Delta-13C and Delta-15N analysis. Mar Ecol Prog Ser 84:9-18

Hood E, Scott D (2008) Riverine organic matter and nutrients in southeast Alaska affected by glacial coverage. Nat Geosci 1:583-587. doi: 10.1038/ngeo280

Hop H, Gjøsæter H (2013) Polar cod (Boreogadus saida) and capelin (Mallotus villosus) as key species in marine food webs of the Arctic and the Barents Sea. Mar Biol Res 9:878894. doi: 10.1080/17451000.2013.775458 
Hopcroft RR, Kosobokova KN, Pinchuk AI (2010) Zooplankton patterns in the Chukchi Sea during summer 2004. Deep-Sea Res Pt II 57:27-39. doi: 10.1016/j.dsr2.2009.08.003

Houlihan DF, Pedersen BH, Steffensen JF, Brechin J (1995) Protein synthesis, growth, and energetics in larval herring (Clupea harengus) at different feeding regimes. Fish Physiol Biochem 14: 195-208.

Huss M, Byström B, Strand A, Eriksson L, Persson L (2008) Influence of growth history on the accumulation of energy reserves and winter mortality in young fish. Canadian journal of fisheries and aquatic sciences 65:2149-2156.

Johnson SW, Thedinga JF, Neff AD, Hoffman CA (2010) Fish fauna in nearshore waters of a barrier island in the western Beaufort Sea, Alaska. US Dep Commer, NOAA Tech Memo NMFSAFSC 210: 1-28.

Kline TC (1999) Temporal and spatial variability of ${ }^{13} \mathrm{C} /{ }^{12} \mathrm{C}$ and ${ }^{15} \mathrm{~N} /{ }^{14} \mathrm{~N}$ in pelagic biota of Prince William Sound, Alaska. Can J Fish Aquat Sci 56:94-117.

Layman CA, Arrington DA, Montaña CG et al (2007a) Can stable isotope ratios provide for community-wide measures of trophic structure. Ecology 88:42-48.

Layman CA, Quattrochi JP, Peyer CM, Allgeier JE (2007b) Niche width collapse in a resilient top predator following ecosystem fragmentation. Ecol Lett 10:937-44. doi: 10.1111/j.1461-0248.2007.01087.x

Loecher M, Ropkins K (2015) R googlemaps and loa: Unleashing R Graphics Power on Map Tiles. J Stat Softw 63:1-18

Logan JM, Jardine TD, Miller TJ et al (2008) Lipid corrections in carbon and nitrogen stable isotope analyses: comparison of chemical extraction and modelling methods. J Anim Ecol 77:838-846. doi: 10.1111/j.1365-2656.2008.01394.x

McConnaughey T, McRoy CP (1979) Food-Web structure and the fractionation of carbon isotopes in the Bering sea. Mar Biol 53:257-262. doi: 10.1007/BF00952434

Mogensen S, Post JR (2012) Energy allocation strategy modifies growth-survival tradeoffs in juvenile fish across ecological and environmental gradients. Oecologia 168:92333. doi: 10.1007/s00442-011-2164-0

Moline M a, Karnovsky NJ, Brown Z et al (2008) High latitude changes in ice dynamics and their impact on polar marine ecosystems. Ann NY Acad Sci 1134:267-319. doi: 10.1196/annals.1439.010

Mueter FJ, Litzow MA (2008) Sea ice retreat alters the biogeography of the Bering Sea continental shelf. Ecol Appl 18:309-320. 
Noordwijk AJ Van, Jong G De (2014) Acquisition and allocation of resources: their influence on variation in life history tactics. Am Nat 128:137-142.

Olsen EM, Lilly GR, Heino M et al (2005) Assessing changes in age and size at maturation in collapsing populations of Atlantic cod (Gadus morhua). Can J Fish Aquat Sci 62:811823. doi: 10.1139/f05-065

Parkinson CL, Comiso JC (2013) On the 2012 record low Arctic sea ice cover: combined impact of preconditioning and an August storm. Geophys Res Lett 40:1356-1361. doi: $10.1002 /$ grl.50349

Peterson BJ, Fry B (2014) Stable isotopes in ecosystem studies. Annu Rev Ecol Syst 18:293-320.

Peterson BJ, Holmes RM, McClelland JW, et al (2002) Increasing river discharge to the Arctic ocean. Science 298:2171-2173. doi: 10.1126/science.1077445

Pinchuk AI, Coyle KO, Farley EV, Renner HM (2013) Emergence of the Arctic Themisto libellula (Amphipoda: Hyperiidae) on the southeastern Bering Sea shelf as a result of the recent cooling, and its potential impact on the pelagic food web. ICES J Mar Sci 70:12441254.

Post DM (2002) Using stable isotopes to estimate trophic position: models, methods, and assumptions. Ecology 83:703-718. doi: 10.2307/3071875

Post DM, Layman CA, et al (2007) Getting to the fat of the matter: models, methods and assumptions for dealing with lipids in stable isotope analyses. Oecologia 152:179-189 doi: $10.1007 / \mathrm{s} 00442-006-0630-\mathrm{x}$

Post JR, Parkinson EA (2001) Energy allocation strategy in young fish: allometry and survival. Ecology 82:1040-1051.

Rypel AL (2012) Meta-analysis of growth rates for a circumpolar fish, the northern pike (Esox lucius), with emphasis on effects of continent, climate and latitude. Ecol Freshw Fish 21:521-532. doi: 10.1111/j.1600-0633.2012.00570.x

Saito H, Kiørboe T (2001) Feeding rates in the chaetognath Sagitta elegans: effects of prey size, prey swimming behaviour and small-scale turbulence. J Plankton Res 23:1385-1398. doi: 10.1093/plankt/23.12.1385

Schell D, Barnett B, Vinette K (1998) Carbon and nitrogen isotope ratios in zooplankton of the Bering, Chukchi and Beaufort seas. Mar Ecol Prog Ser 162:11-23. doi: 10.3354/meps162011

Schuur EAG, Bockheim J, Canadell JG et al (2008) Vulnerability of permafrost carbon to climate change: Implications for the global carbon cycle. Bioscience 58:701-714. doi: $10.1641 / \mathrm{B} 580807$ 
Sherwood GD, Rideout RM, Fudge SB, Rose GA. (2007) Influence of diet on growth, condition and reproductive capacity in Newfoundland and Labrador cod (Gadus morhua): insights from stable carbon isotopes (813C). Deep-Sea Res Pt II 54:2794-2809. doi: 10.1016/j.dsr2.2007.08.007

Shoji J, Toshito SI, Mizuno KI et al (2011) Possible effects of global warming on fish recruitment: shifts in spawning season and latitudinal distribution can alter growth of fish early life stages through changes in day length. ICES J Mar Sci 68:1165-1169. doi: 10.1093/icesjms/fsr059

Siddon EC, Heintz RA, Mueter FJ (2013) Conceptual model of energy allocation in walleye pollock (Theragra chalcogramma) from age-0 to age-1 in the southeastern Bering Sea. Deep-Sea Res Pt II 94:140-149. doi: 10.1016/j.dsr2.2012.12.007

Smith RW, Ottema C (2006) Growth, oxygen consumption, and protein and RNA synthesis rates in the yolk sac larvae of the African catfish (Clarias gariepinus). Comp Biochem Physiol A 143: 315-325.

Sorte CJB, Williams SL, Carlton JT (2010) Marine range shifts and species introductions: comparative spread rates and community impacts. Glob Ecol Biogeogr 19:303-316. doi: 10.1111/j.1466-8238.2009.00519.x

Sreenivasan A (2011) Nucleic acid ratios as an index of growth and nutritional ecology in Pacific cod (Gadus macrocephalus), walleye pollock (Theragra chalcogramma), and Pacific herring (Clupea pallasii). University of Alaska Fairbanks

Stabeno PJ, Reed RK, Schumacher JD (1995) The Alaska coastal current: continuity of transport and forcing. J Geophys Res 100:2477-2485

Steele J, Thorpe S, Turekian K (2010) Ocean currents: a derivative of the encyclopedia of ocean sciences. Academic Press, London, UK

Sturdevant MV, Orsi JA, Fergusson EA. (2012) Diets and trophic linkages of epipelagic fish predators in coastal southeast Alaska during a period of warm and cold climate years, 1997-2011. Mar Coast Fish 4:526-545. doi: 10.1080/19425120.2012.694838

Team R, Core (2013) R: A language and environment for statistical computing.

Vander Zanden M, Rasmussen J (2001) Variation in 15N and 13C trophic fractionation: implications for aquatic food web studies. Limnol Oceanogr 46:2061-2066.

Vesin J, Legget W, Able K (1981) Feeding ecology of capelin (Mallotus villosus) in the estuary and Western Gulf of St. Lawrance and its multispecies implications. Can J Fish Aquat Sci 38:257-267. 
Vollenweider JJ, Heintz RA, Schaufler L, Bradshaw R (2011) Seasonal cycles in wholebody proximate composition and energy content of forage fish vary with water depth. Mar Biol 158:413-427. doi: 10.1007/s00227-010-1569-3

Walsh JJ, Dieterle DA, Maslowski W, Whitledge TE (2004) Decadal shifts in biophysical forcing of Arctic marine food webs: numerical consequences. J Geophys Res C Ocean 109:1-30. doi: 10.1029/2003JC001945

Weber LP, Higgins PS, Carlson RI, Janz DM (2003) Development and validation of methods for measuring multiple biochemical indices of condition in juvenile fishes. J Fish Biol 63:637-658. doi: 10.1046/j.1095-8649.2003.00178.x

Weingartner TJ, Danielson SL, Royer TC (2005) Freshwater variability and predictability in the Alaska coastal current. Deep-Sea Res Pt II 52:169-191. doi: 10.1016/j.dsr2.2004.09.030

Woodgate RA, Weingartner TJ, Lindsay R (2012) Observed increases in Bering Strait oceanic fluxes from the Pacific to the Arctic from 2001 to 2011 and their impacts on the Arctic Ocean water column. Geophys Res Lett 39:2-7. doi: 10.1029/2012GL054092 


\section{Tables}

Table 5.1. Details of sample sizes and regional group differentiation. Throughout this paper, "regional group" refers to the 7 groups differentiated by symbols.

\begin{tabular}{|c|c|c|c|c|c|c|c|c|}
\hline $\begin{array}{l}\text { Group } \\
\text { Name }\end{array}$ & Symbol & $\begin{array}{l}\text { Sample } \\
\text { Date }\end{array}$ & $\begin{array}{l}\text { Sample } \\
\text { Gear }\end{array}$ & $\begin{array}{c}\text { Latitude } \\
\text { Range }\left({ }^{\circ} \mathrm{N}\right)\end{array}$ & $\begin{array}{c}\mathrm{N} \\
\text { Fish }\end{array}$ & $\begin{array}{c}\mathrm{N} \\
\text { Stations }\end{array}$ & $\begin{array}{c}\text { Fish Length } \\
(\mathrm{mm}) \text { Mean (SD) }\end{array}$ & $\begin{array}{r}\text { SST }\left({ }^{\circ} \mathrm{C}\right) \\
\text { Mean (SD) }\end{array}$ \\
\hline Pt. Barrow & 口n & Aug 18-19 & $\begin{array}{l}\text { Beach } \\
\text { Seine }\end{array}$ & $\begin{array}{c}71.09- \\
71.39\end{array}$ & 11 & 5 & $72.8(8.1)$ & $11.2(0.2)$ \\
\hline $\begin{array}{l}\text { Wainwright } \\
\text { Inlet }\end{array}$ & $\bullet \bullet$ & Aug 19-20 & $\begin{array}{c}\text { Surface } \\
\text { Trawl }\end{array}$ & $\begin{array}{c}70.50- \\
70.52\end{array}$ & 11 & 3 & $88.4(7.3)$ & $7.3(0.6)$ \\
\hline Point Hope & $\boldsymbol{\Delta} \mathbf{\Delta}$ & Aug 13-14 & $\begin{array}{c}\text { Surface } \\
\text { Trawl }\end{array}$ & 68.54 & 7 & 1 & $89.7(6.0)$ & $9.9(-)$ \\
\hline $\begin{array}{l}\text { Kotzebue } \\
\text { Sound }\end{array}$ & $\diamond$ & Aug 8-10 & $\begin{array}{c}\text { Surface } \\
\text { Trawl }\end{array}$ & $\begin{array}{c}66.57- \\
67.04\end{array}$ & 11 & 2 & $89.5(8.0)$ & $9.5(0.5)$ \\
\hline $\begin{array}{l}\text { Norton } \\
\text { Sound }\end{array}$ & $\nabla \nabla$ & Sept 12-14 & $\begin{array}{c}\text { Surface } \\
\text { Trawl }\end{array}$ & $\begin{array}{c}63.97- \\
64.51\end{array}$ & 8 & 2 & 85.4 (10.9) & $5.95(0.0)$ \\
\hline $\begin{array}{l}\text { Nunivak } \\
\text { Island }\end{array}$ & $\square \square$ & Sept $10-20$ & $\begin{array}{c}\text { Surface } \\
\text { Trawl }\end{array}$ & $\begin{array}{c}60.01- \\
61.98\end{array}$ & 11 & 2 & $82.2(7.9)$ & $7.1(0.1)$ \\
\hline Bristol Bay & $\diamond \diamond$ & Aug 21-26 & $\begin{array}{c}\text { Surface } \\
\text { Trawl }\end{array}$ & $\begin{array}{c}57.52- \\
58.49\end{array}$ & 3 & 2 & $81.3(7.8)$ & $8.7(0.9)$ \\
\hline
\end{tabular}




\section{Figures}

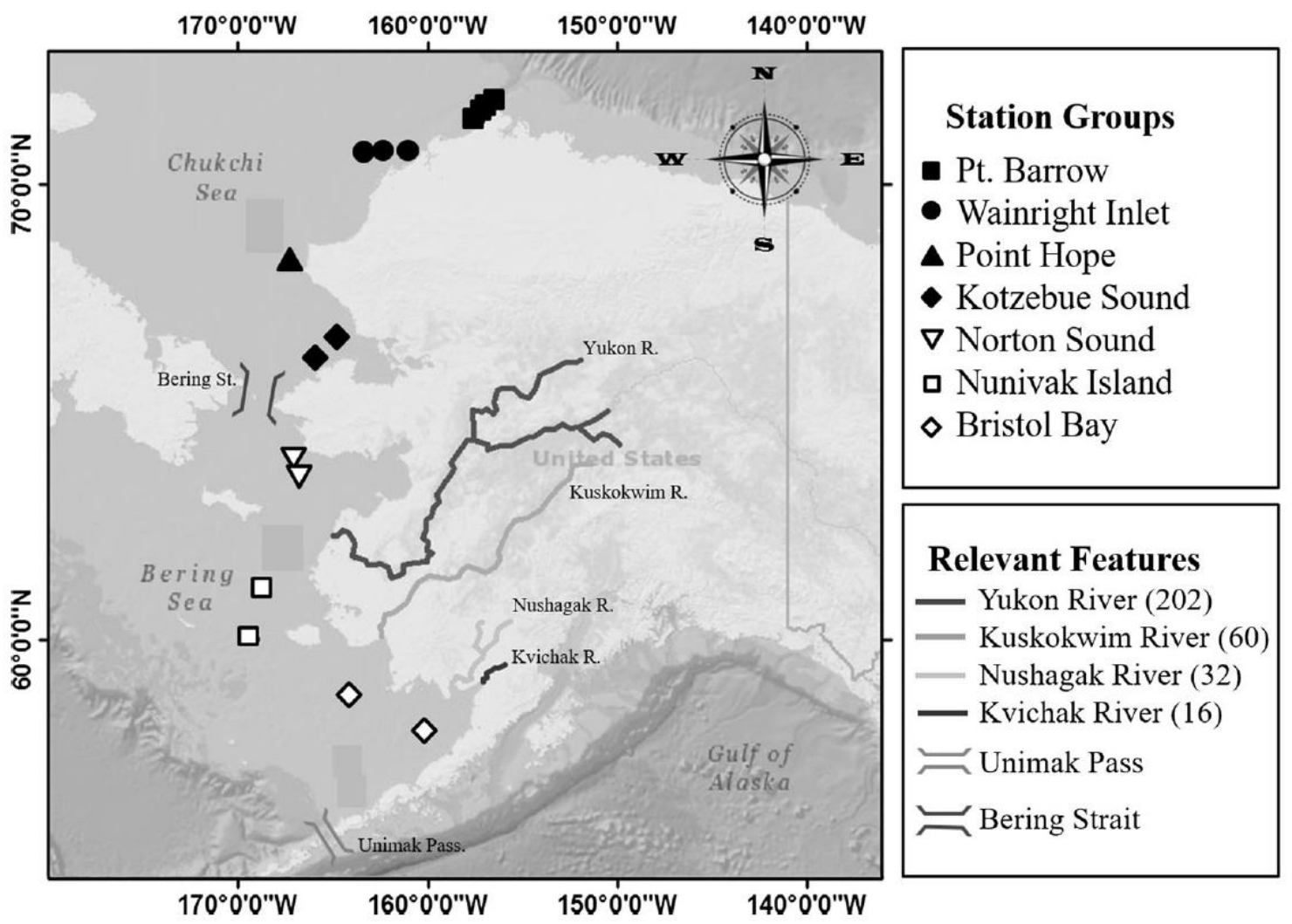

Figure 5.1 Map of Alaskan waters showing sampling locations of juvenile capelin collected. Filled shapes represent the Chukchi Sea stations, open shapes represent Bering Sea stations. Like symbols represent regional groups of fish at similar latitudes. The numbers in parentheses after each river represent the individual annual discharge $\left(\mathrm{km}^{3} \mathrm{yr}^{-}\right.$ ${ }^{1}$ ) of each river (Benke and Cushing, 2006; Nemeth et al., 2014). This map was produced with the CRAN-R package "Rgooglemaps" (Loecher and Ropkins, 2015). 

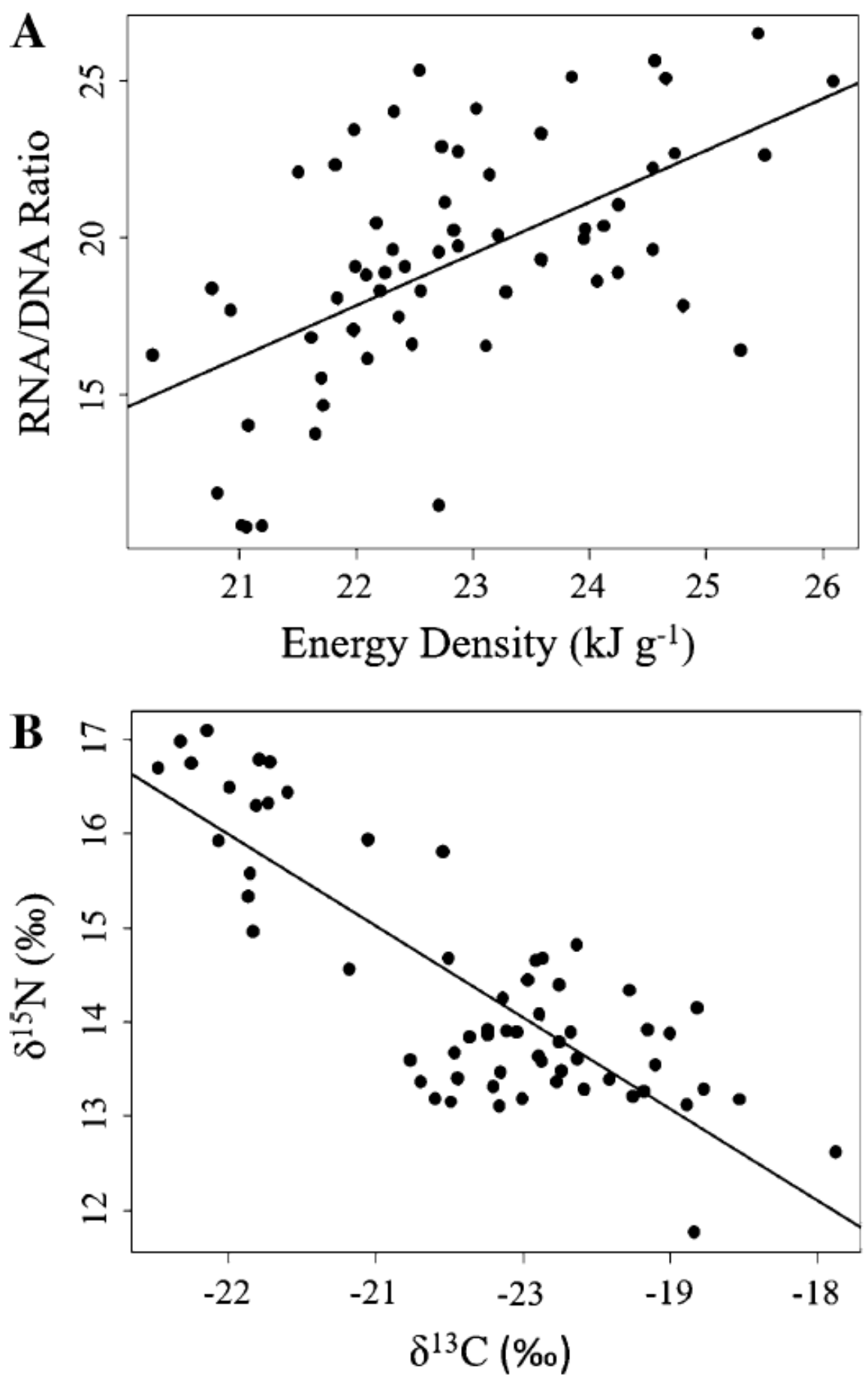

Figure 5.2 Linear regression between energy density and RNA/DNA ratios were strongly correlated $\left(\mathrm{A} ; R^{2}=0.3163, p<0.0001\right)$. A linear regression between $\delta^{13} \mathrm{C}$ and $\delta^{15} \mathrm{~N}$ shows a strong negative correlation $\left(\mathrm{B} ; R^{2}=0.6747, p<0.0001\right)$. 

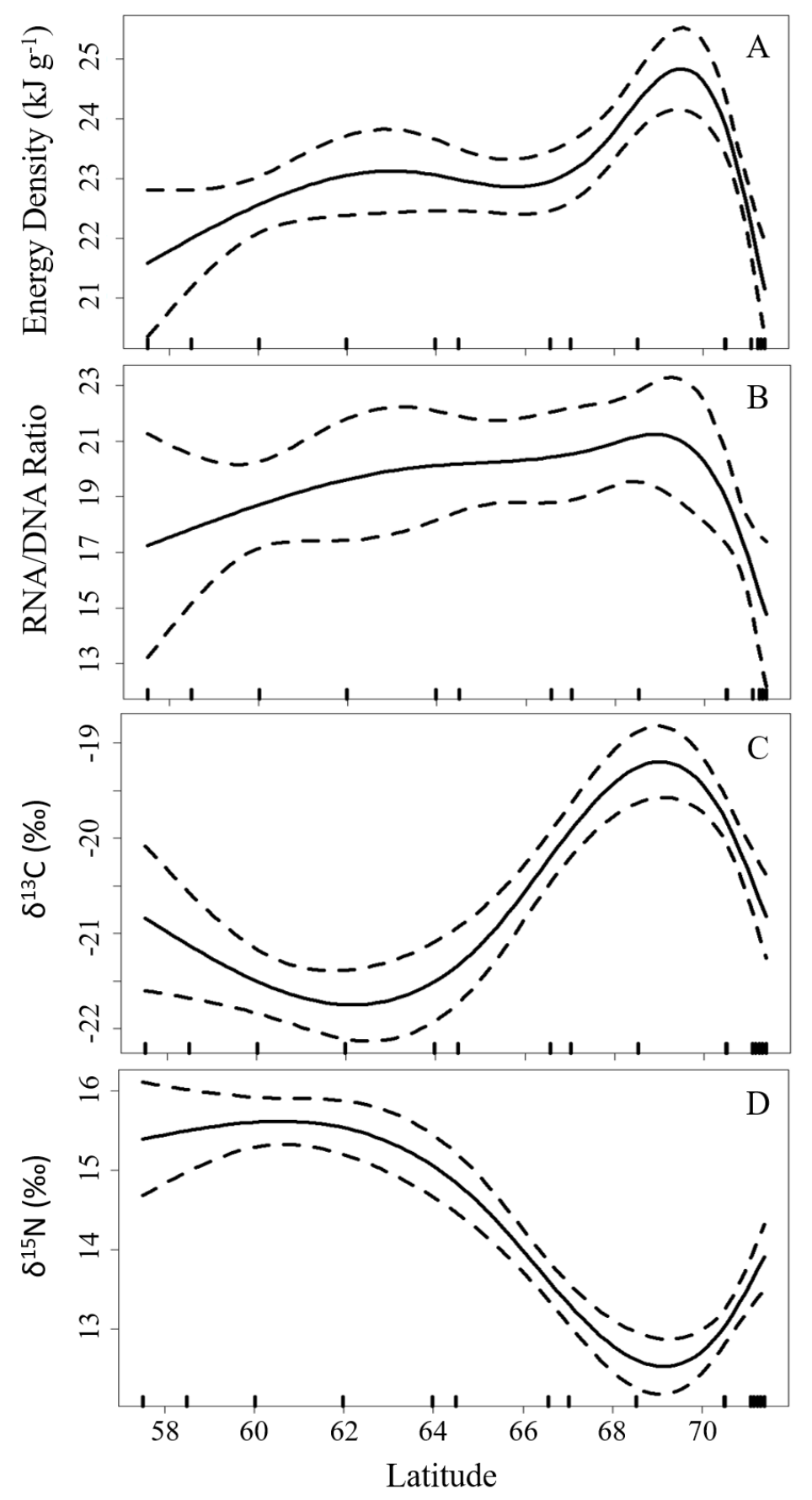

Figure 5.3 General Additive Models for energy density (A), RNA/DNA Ratios (B), $\delta^{13} \mathrm{C}$ (C) and $\delta^{15} \mathrm{~N}$ (D) for all juvenile capelin with a smoothing function on latitude. All models were created using cubic splines were used with 5 knots $(\mathrm{edf}=4)$ for Energy Density and RNA/DNA ratios, and 4 knots (edf $=3$ ) for $\delta^{13} \mathrm{C}$ and $\delta^{15} \mathrm{~N}$. The dashed lines represent the $95 \%$ confidence interval. Each model was significant with varying levels of deviance explained (A: $R^{2}=0.34, p<0.0001 ; \mathrm{B}: R^{2}=0.14, p=0.01 ; \mathrm{C}: R^{2}=0.54, p<0.0001 ; \mathrm{D}: R^{2}$ $=0.67, p<0.0001)$. The bold tick marks above the $\mathrm{x}$-axis represent latitudes at which fish samples were collected. 


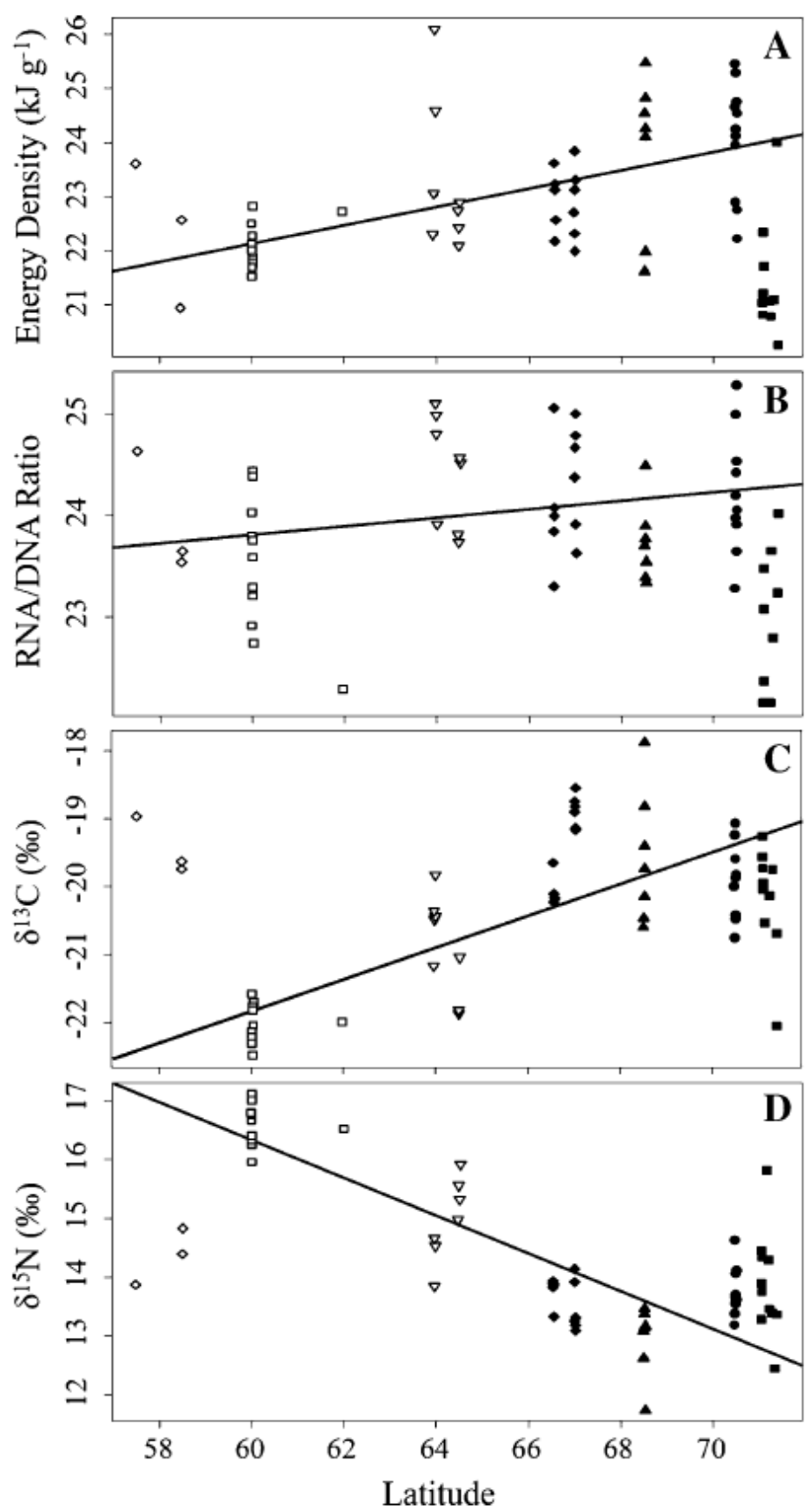

Figure 5.4 Linear regressions of energy density (A), RNA/DNA Ratios (B), $\delta^{13} \mathrm{C}(\mathrm{C})$ and $\delta^{15} \mathrm{~N}$ (D) with latitude. The northern-most sampling stations (Point Barrow group: $\mathbf{\square}$ ) and the southern-most sampling stations (Bristol Bay group: $\diamond$ ) were removed as outliers for the analysis. Energy density was strongly correlated $\left(R^{2}=0.36, p<0.0001\right)$ with latitude, but RNA/DNA ratios were not $\left(R^{2}=0.06, p=0.05\right) . \delta^{13} \mathrm{C}$ is negatively correlated and $\delta^{15} \mathrm{~N}$ is positively correlated with latitude $\left(R^{2}=0.55, \quad p<0.0001 ; R^{2}=0.75, \quad p<0.0001\right.$; respectively). Station symbology: Wainwright inlet $(\bullet)$, Point Hope $(\boldsymbol{\Delta})$, Kotzebue Sound $(\diamond)$, Norton Sound $(\nabla)$, and Nunivak Island $(\square)$. 


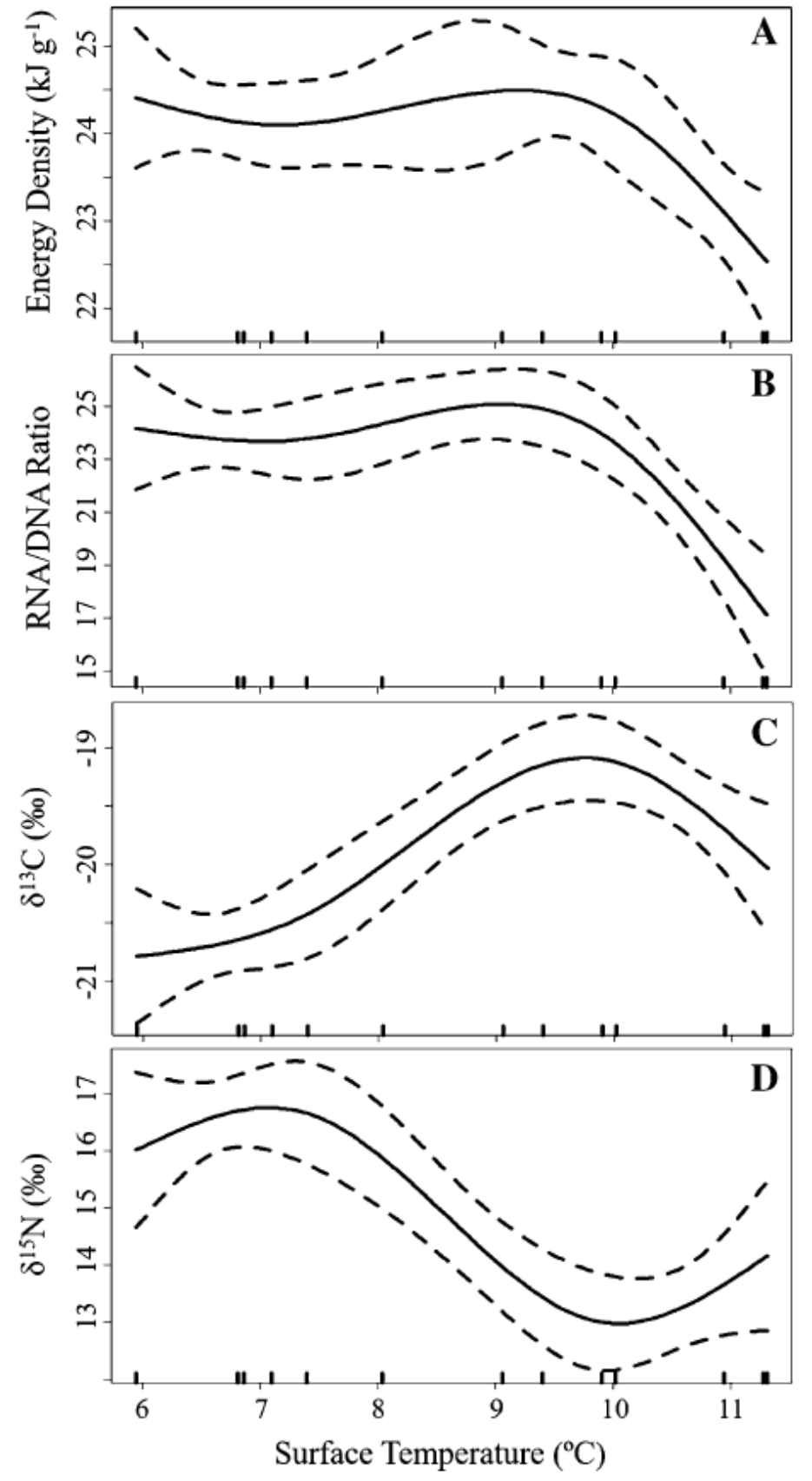

Figure 5.5 General Additive Models for energy density (A), RNA/DNA Ratios (B), $\delta^{13} \mathrm{C}$ (C) and $\delta^{15} \mathrm{~N}$ (D) for all juvenile capelin with a smoothing function on temperature. All models were created using cubic splines were used with 5 knots (edf $=4$ ) for Energy Density, and 4 knots (edf $=3$ ) for RNA/DNA ratios, $\delta^{13} \mathrm{C}$ and $\delta^{15} \mathrm{~N}$. The dashed lines represent the $95 \%$ confidence interval. All models were significant with varying levels of deviance explained (A: $R^{2}=0.15, p<0.0001 ; \mathrm{B}: R^{2}=0.28, p<0.0001 ; \mathrm{C}: R^{2}=0.31$, $p<0.0001$; D: $\left.R^{2}=0.30, p<0.0001\right)$. The bold tick marks above the x-axis represent latitudes at which fish samples were collected. 


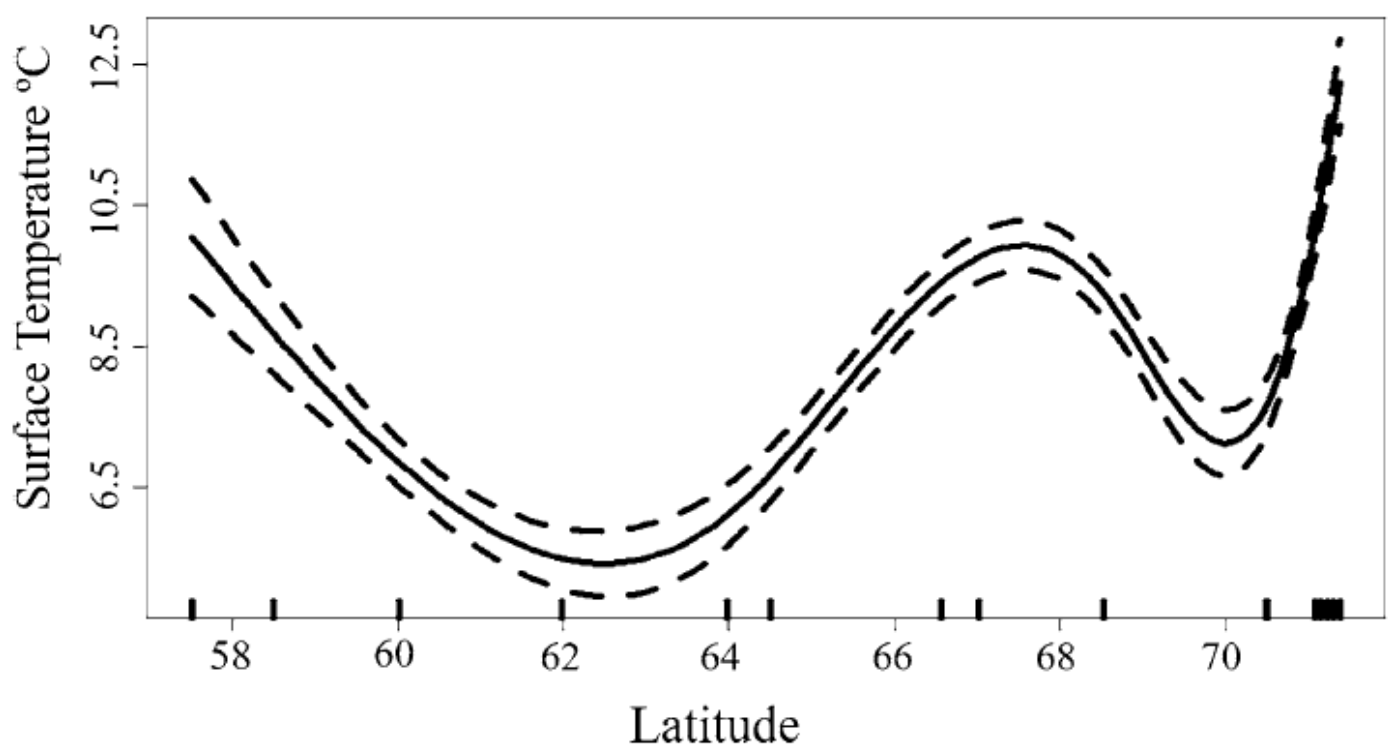

Figure 5.6 GAM of surface temperature with a smoothing function on latitude. The nonlinear relationship shows that there is no discernable trend between surface temperature and latitude. The dashed lines represent the $95 \%$ confidence intervals. Cubic splines were used with 5 knots $(e d f=4)$, the GAM explains $28.8 \%$ of the deviance and the relationship was found to be significant $(p<0.0001)$. The bold tick marks above the $\mathrm{x}$-axis represent latitudes at which fish samples were collected. 


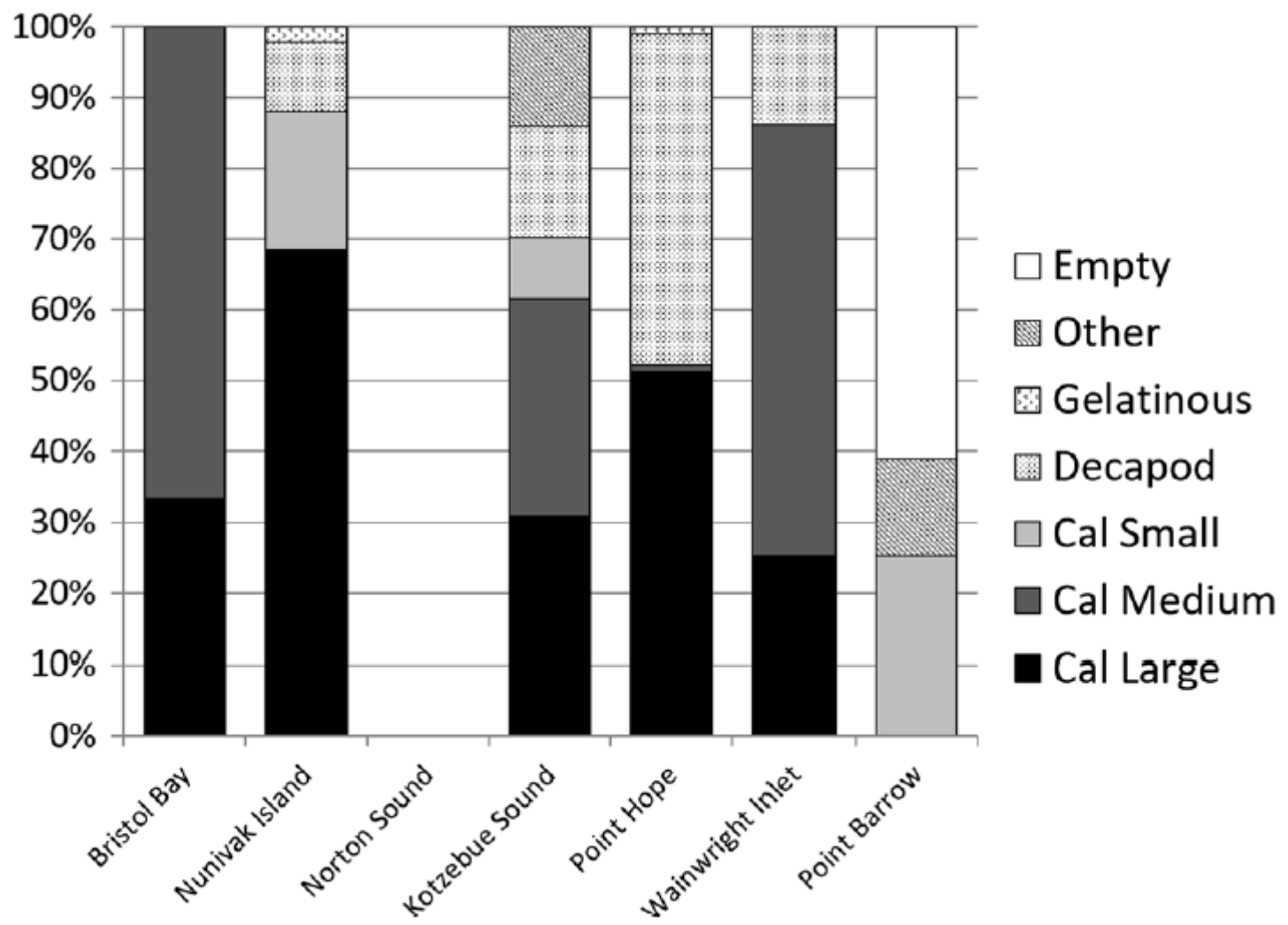

Figure 5.7 Average contributions by weight of prey type in the stomach contents of the analyzed capelin for 6 of the 7 regional groups identified in Table 1. Cal = Calanus spp. copepod. No stomach contents data was available for the Norton Sound Group. 
CHAPTER VI

IMPLICATIONS OF TROPHIC DISCRIMINATION FACTOR SELECTION FOR STABLE ISOTOPE FOOD WEB MODELS OF LOW TROPHIC LEVELS IN THE ARCTIC NEARSHORE 


\section{$\underline{\text { Abstract }}$}

Stable isotope analysis has become a useful tool to investigate food web structures in Arctic marine ecosystems. This method requires assumptions about how isotopes are assimilated from food into tissues. Few controlled lab experiments have determined the appropriate trophic discrimination factors (TDFs) for Arctic marine species, thus many studies have resorted to using global averages or values determined from species in different habitats or taxa. We examine the trophic niche space for prey resources predicted from the isotopic ratios of fish collected in coastal Beaufort and Chukchi Seas using several published Arctic marine TDFs. The different predictions are compared to highlight the implications of selecting appropriate TDFs in Arctic marine food web models. Predicted trophic niche space of prey resources differed greatly depending on the TDFs that were used, and the most appropriate TDFs from those that are currently available were identified for modeling Arctic nearshore lower trophic levels.

\section{Introduction}

As climate change and anthropogenic activities continue to increase in Arctic marine ecosystems, it is likely that species' ranges will expand, contract, or shift in response to new conditions, and as a result species assemblages in the Arctic are expected to change (Poloczanska et al. 2008; Grebmeier 2012; Barton et al. 2016). These changes in community composition are expected to shift food web structure and available resources (Dunton et al. 2012; McTigue \& Dunton 2014). In response, there has been great effort to better understand the current structure of Arctic food webs and basal resource dependence 
to gain insight to how they will be affected in the future as lower latitude species compete for resources.

Past works have suggested that the use of stable isotope analysis would allow for food web-wide comparisons of different trophic structures, and that the difference in these structures offers insight to the resilience and functionality of an ecosystem (Lindeman 1942; Post 2002). Stable isotope analysis (SIA) of animal and plant tissues has become a useful method to investigate trophic structures in food webs at many spatial and temporal scales (Hobson \& Welch 1992; Dunton et al. 2012; Fry 2013). Furthermore, SIA can be used in mixing models to estimate proportions of prey types that make up the diets of consumers based on known trophic pathways (Phillips et al. 2014). These methods rely on the assumption that an organism's tissues are comprised of the materials that they ingested and assimilated at the time that the tissues were synthesized, and therefore the stable isotope ratios in consumers and prey tissues should resemble each other.

Two decades ago Gannes et al. (1997) called for more experimental isotope studies after recognizing the rapid increase in the use of stable isotope ecology and a paucity of experimental studies to support and further develop these methods. These experiments aim to understand how the assimilation of isotopes into tissues is affected by the physiochemical processes that break down and rebuild macromolecules after ingestion. Through the processes of digestion and synthesis of new tissues, metabolic processes preferentially use lighter isotopes, leaving behind heavier isotope to be assimilated into new tissues, resulting in isotopically heavier or more enriched tissues than the material that was consumed (Vander Zanden \& Rasmussen 2001). This process, known as trophic fractionation, causes a difference between prey and consumer (Trophic Discrimination 
Factor: TDF), which is used to predict the trophic niche space of an individual's prey or predator, and thus plays a crucial role in reconstructing food webs using stable isotope analysis.

For practical reasons, most isotope studies assume that TDFs are constant through a food web. Commonly cited averages derived from early works have shown that fish muscle tissues often have TDFs of $3.4 \%$ for ${ }^{15} \mathrm{~N}$ and $1 \%$ for ${ }^{13} \mathrm{C}$ (Post, 2002), but more recent works have shown that TDFs are more variable than was once believed (Vander Zanden \& Rasmussen 2001). TDFs not only vary among taxa, tissue types and trophic levels, but are also affected significantly by nutrition and dietary quality (Mohan et al. 2016, Chapter III), excretion (Tamelander et al. 2006), temperature (Barnes et al. 2007), and metabolic rate (Gaye-siessegger et al. 2004). It is highly possible that these factors affect the isotopic fractionation in Arctic fish species and thus it is important to gain a more comprehensive database of TDFs.

The call for more isotope experiments (Gannes et al. 1997) has largely been answered with lower latitude species (Logan et al. 2006; Madigan et al. 2012; Rosenblatt \& Heithaus 2013; Mohan et al. 2016), but experiments focused on Arctic species are still lacking, and until recently there were no published isotopic lab-based experiments for Arctic marine fish species (Chapter III). Consequently, studies focused on fish have relied on TDFs derived from experiments on species from vastly different ecosystems or taxonomic groups (Hobson \& Welch 1992; Hobson et al. 1996; Dunton et al. 2012; McTigue \& Dunton 2014). Given the key role of fish in the transfer of energy from lower to higher trophic levels in Arctic food webs, it is imperative to use appropriate TDFs when modelling trophodynamics in these systems. 
If TDFs of Arctic fish are different from those that have been used in past studies, there could be important implications for interpreting SIA data in the context of food web structure. We tested the hypothesis that the use of different TDFs in food web reconstructions affects estimates of prey resource dependence. Our objectives were to summarize all published TDFs that have been cited for use with Arctic marine fish and apply them to SIA data of fish collected in the Arctic nearshore to determine the possible implications of variability in TDF values on estimating trophic niche space of the resources on which these fish depend.

\section{$\underline{\text { Methods }}$}

Published experimentally-derived trophic discrimination factors for muscle tissues of Arctic marine species were compiled from published literature (Table 6.1). Exhaustive literature searches in Google Scholar ${ }^{\odot}$ and Research Gate ${ }^{\odot}$ were performed to find experimental isotope studies focused on Arctic marine species, including fish. Searches were performed using combinations of the following keywords: nitrogen, carbon, isotope(s), trophic, discrimination, enrichment, fractionation, factor, Arctic, experiment, experimental, turnover rate, and incorporation rate.

\section{Study Area}

In order to understand the potential impact of TDFs on predicted food web structure we applied the published values to a nearshore food web near Point Barrow, AK. This is a unique area where multiple Arctic nearshore habitat types are found in close proximity to each other. Point Barrow is bordered on the west by the Chukchi Sea (CHS) and to the east by the Beaufort Sea (BFS), with the large estuarine Elson Lagoon (ESL) opening into the 
Beaufort Sea just $5 \mathrm{~km}$ Southeast of Point Barrow (Figure 6.1). These water bodies have distinct conditions that support different species assemblages and thus the sampled fish community here is representative of a variety of Arctic nearshore habitats (Vollenweider et al. 2016).

\section{Sample Collection}

Fish communities were sampled using a beach seine at 12 stations ( 5 CHS, 3 BFS, and 4 ESL) at weekly intervals from July 14 - August 25 (Week 1-6) for two consecutive years (2013-14). The seine was $37 \mathrm{~m}$ long with variable mesh sizes (10 m of $32 \mathrm{~mm}$ outer panels, $4 \mathrm{~m}$ of $6 \mathrm{~mm}$ middle panels, and $9 \mathrm{~m}$ of $3.2 \mathrm{~mm}$ blunt panel). Each set was roundhaul style, paid out of a $3 \mathrm{~m}$ inflatable Zodiac following methods used by Barton et al. (2016). Fish were sorted by species, enumerated and a maximum of 5 individuals of each species per haul were stored in a $-80^{\circ} \mathrm{C}$ freezer for stable isotope analysis.

Zooplankton samples were collected intermittently during the 2014 beach seine surveys. A $50 \mathrm{~cm}$ diameter, $333 \mu \mathrm{m}$ plankton net was towed behind a $3 \mathrm{~m}$ rigid hull inflatable at 3 knots for approximately 3 minutes. Samples were reduced volumetrically to approximately $50 \mathrm{~mL}$ using a Folsom Splitter. Plankton were then sorted by major taxa and enumerated. Larger taxa (krill, amphipods, ichthyoplankton, etc.) were sorted first, and then smaller taxa (copepods, small larvae) were sorted under a dissecting microscope.

\section{Stable Isotope Analysis}

For all fish specimens larger than $25 \mathrm{~mm}$ TL, a muscle sample was collected on the left dorsal side and all skin and bones were removed. Fish that were smaller than $25 \mathrm{~mm}$ TL and zooplankton samples were processed whole, in composite samples of at least 5 individuals. Tissues were dried to a consistent weight at $50^{\circ} \mathrm{C}$ for at least 7 days, and 
homogenized to a uniform consistency using a mortar and pestle. Subsamples of dried fish homogenate were weighed (0.4-0.7 mg), and sent to the Florida International University Southeast Environmental Research Center Stable Isotope Laboratory. The samples were analyzed using Elemental Analysis - Isotope Ratio Mass Spectrometry (EA-IRMS), with a Delta C Finnagen (Thermo Fisher Scientific) and Conflo II dilution interface (Thermo Fisher Scientific) coupled to a NA-1500 NC Carlo ERBA elemental analyzer (Fisons Instruments). Precision and accuracy of the instruments were controlled with NIST standard IAEA-CH-6 for $\delta^{13} \mathrm{C}$, and IAEA-N1 for $\delta^{15} \mathrm{~N}$. Three in-house standards were also used: Bovine Liver, Citrus Leaves, and Glycine. Error based on standard deviations of internal glycine standards ranged $0.09-0.21 \%$ for $\delta^{15} \mathrm{~N}$ and $0.07-0.10 \%$ for $\delta^{13} \mathrm{C}$. Isotope ratios are expressed in delta-notation $(\delta)$ as per mil (\%o) relative to the standard Vienna Peedee Belemnite (VPDB; $\left.{ }^{13} \mathrm{C}\right)$ and atmospheric nitrogen $\left({ }^{15} \mathrm{~N}\right)$ as shown below:

$$
\delta^{q} X=\left(\frac{R_{\text {sample }}}{R_{\text {standard }}}-1\right) \times 1000
$$

where $q$ is the number of neutrons in the isotope, $X$ is the element of the isotope, and $R$ represents the ratio of heavy to light isotopes within the sample or the standards PDB and AN $\left({ }^{13} \mathrm{C} /{ }^{12} \mathrm{C}\right.$ for carbon; ${ }^{15} \mathrm{~N} /{ }^{14} \mathrm{~N}$ for nitrogen). Carbon isotope ratios were corrected for the effects of lipid content in sample tissues using $\mathrm{C} / \mathrm{N}$ ratios as a proxy for lipid content (Equation 1: Logan et al. 2008). 


\section{Data Analysis}

First, the trophic niche space of the sampled Arctic nearshore fish community was determined as the two-dimensional area taken up by the isotope signatures of species in bivariate space $\left(\delta^{13} \mathrm{C}-\delta^{15} \mathrm{~N}\right)$. This trophic niche space was represented as the $90 \%$ confidence ellipse of the carbon and nitrogen isotope ratios of all fish, centered at the average $\delta^{13} \mathrm{C}-\delta^{15} \mathrm{~N}$ values.

Next, we generate the predicted trophic niche spaces of prey and basal resources on which those fish depend by displacing the center of the ellipse by whole trophic steps by subtracting TDF values (in delta-notation: $\Delta^{13} \mathrm{C}$ and $\Delta^{15} \mathrm{~N}$ ) from the average $\delta^{13} \mathrm{C}$ and $\delta^{15} \mathrm{~N}$ values for the fish community. This displacement of the ellipse occurs along a straight line with the slope $\left(\Delta^{15} \mathrm{~N} / \Delta^{13} \mathrm{C}\right)$, and models the trophic fractionation between each trophic level based on the nitrogen and carbon TDFs that are used, and thus will be referred to as the Trophic Discrimination Slope (TDS). The TDS was used to generate the predicted trophic niche space 1,2, and 3 trophic levels below that of the fish community using the published TDFs of four Arctic marine species and recently published TDFs for Arctic Sculpin.

Finally, the predicted trophic niche spaces of lower trophic levels generated using the five different sets of TDFs were compared to the actual isotope values of lower trophic level species from the Arctic nearshore to assess the accuracy of predictions and the differences between predicted niche space. 


\section{$\underline{\text { Results }}$}

\section{Trophic Niche Space of Samples}

The average isotope signatures of all fish species collected from the Arctic nearshore ranged from -22.08 to $-17.58 \%$ for $\delta^{13} \mathrm{C}(\mu \pm \mathrm{SD}=-19.89 \pm 1.59 \%$ ), and 13.41 to $15.27 \%$ for $\delta^{15} \mathrm{~N}(14.46 \pm 0.58 \%$ o. Isotope values for Near-Surface Sediment Particulate Organic Matter (SPOM), Near-Bottom SPOM, Phytoplankton, and Sediment bulk organic matter were used from McTigue \& Dunton (2014) to represent basal resources in Arctic nearshore habitats, and averages ranged from -24.70 to $-21.60 \%$ for $\delta^{13} \mathrm{C}(-23.95$ $\pm 0.50 \%$, and 4.6 to $7.7 \%$ for $\delta^{15} \mathrm{~N}(6.48 \pm 1.22)$. Isotope values for Calanoid Copepods (McTigue \& Dunton 2014), Pteropods, and Krill were used to represent direct prey for the community of zooplanktotrophic fish, and range from -21.91 to $-19.97 \%$ for $\delta^{13} \mathrm{C}(-21.16$ $\pm 0.85 \%$, and 11.10 to $12.03 \%$ for $\delta^{15} \mathrm{~N}(11.51 \pm 0.39 \%$ ).

\section{Trophic Discrimination Factors}

Extensive literature searches in Google Scholar@ and Research Gate $\bigcirc$ yielded only 5 published carbon and nitrogen TDFs for Arctic marine species (Table 1). TDFs for nitrogen ranged from $2.4 \%$ for Pagophilus groenlandicus (Harp Seals; Hobson et al. 1996) to 3.8 \%o for Ursus maritimus (Polar Bears; $3.8 \pm 0.5$ \%o; Hobson \& Welch 1992), and for carbon from $0.4 \%$ for Ampelisca macrocephala (an Arctic amphipod; McTigue \& Dunton 2014) to $1.8 \%$ for Myoxocephalus scorpioides (Arctic Sculpin; $1.8 \pm 0.5 \%$; Chapter III). The TDSs ranged from 1.7 for Arctic Sculpin to 8.5 for A. macrocephala. 


\section{Predictions of Trophic Niche Space}

For the TDSs derived from TDFs for all 5 Arctic species, estimated trophic niche space of zooplankton was one trophic level below the trophic niche space of fishes, however the estimated trophic niche space of basal resources differed greatly depending on the set of TDFs used. Using TDFs from Harp Seals (Figure 6.2A) and chaetognaths (Figure 6.2B), the predicted trophic niche space of basal resources was 3 trophic levels below that of the fish. TDFs from Polar Bears (Figure 6.2C) and A. macrocephala (Figure 6.2D) estimated the trophic niche space of basal resources at 2 and 3 trophic levels below fish, but carbon ranges of the predicted space were too enriched compared to actual values from McTigue \& Dunton (2014). Only the TDFs from Arctic Sculpin (Figure 6.3) both estimated the trophic niche space of basal resources at 2 and 3 trophic levels below fish and predicted the correct range of $\delta^{13} \mathrm{C}$ values.

\section{Discussion}

The predictions of trophic niche space of basal resources using TDSs derived from TDFs of the five different Arctic marine species had varying implications of food web structure. Though any of these sets of TDFs could probably be used to predict the niche space of direct prey sources (zooplankton in this case), the variability in predictions of basal resource niche space exemplify that predictions that extend beyond one trophic level require appropriate TDFs to be used.

The Arctic fish that were collected in the nearshore habitats around Point Barrow were mostly juvenile fishes with relatively small gape sizes that are expected to be zooplanktivores feeding at the $3^{\text {rd }}$ or sometimes $4^{\text {th }}$ trophic level (Hussey et al. 2014; Barton 
et al. 2016). The appropriate set of TDFs for nitrogen and carbon should not only estimate the appropriate $\delta^{15} \mathrm{~N}$ ranges for known trophic levels, but also estimate the position of trophic niche spaces of the organisms within the habitat in question.

All five of the food web models represented in Figures 6.2 and 6.3 suggest that these Arctic nearshore fish are dependent on the trophic niche space occupied by calanoid copepods, krill (Thysanoessa spp.), pteropods and similar plankton. However, the difference between these models is amplified and becomes evident as they are extrapolated to further trophic levels; leading to contrasting predictions about the basal resource dependence of Arctic nearshore fish and zooplankton. The calculated $\Delta^{15} \mathrm{~N}$ values for Harp Seals or Chaetognaths are relatively low (2.4 and 2.5, respectively), and their TDSs predict that there is a trophic level in between the basal resources and zooplankton, and that these zooplankton are feeding on the $3^{\text {rd }}$ trophic level. Though it is possible that these zooplankton are feeding on microzooplankton and thus would have more enriched $\delta^{15} \mathrm{~N}$ values, this seems unlikely as copepods, krill and pteropods are more commonly known as primary consumers at the $2^{\text {nd }}$ trophic level (Hobson \& Schell 1998; Eisner et al. 2013), and suggests that these TDFs may be inappropriate to model the structure of lower trophic levels in Arctic nearshore food webs. Alternatively, it is possible that the basal resources represented (McTigue \& Dunton 2014) have different isotopic ratios than those that the collected zooplankton and fish were actually dependent on. However, this is unlikely because the values for basal resources presented in this analysis are consistently similar in a variety of Arctic isotope studies (Hobson \& Welch 1992; Iken et al. 2010; Dunton et al. 2012). 
The remaining three models (TDFs from Polar Bears, A. macrocephala, and Arctic Sculpin) are derived of $\Delta{ }^{15} \mathrm{~N}$ values between 3 and 3.8 and thus the predicted trophic levels of fish and plankton fit known values; however, there is much variation in the $\Delta^{13} \mathrm{C}$ values causing the TDSs to differ greatly. Due to the low $\Delta{ }^{13} \mathrm{C}$ derived from the Polar Bear and A. macrocephala studies, models using their TDFs suggest that fish and zooplankton are mostly dependent on basal resources that have less depleted carbon isotope ratios than the basal resources found in this region of the Arctic nearshore (Dunton et al. 2012; McTigue \& Dunton 2014). However, when the TDFs for Arctic Sculpin are used, the model predicts that these juvenile Arctic nearshore fish are feeding at the $3^{\text {rd }}$ or $4^{\text {th }}$ trophic levels as expected and demonstrates the appropriate isotopic niche space for the lower trophic level resources in this food web.

In this example the use of inappropriate TDFs could lead to erroneous food web models. Inappropriate $\Delta^{15} \mathrm{~N}$ (TDFs from Harp Seals and Chaetognaths) would have led to the conclusion that an entire trophic level was missing from our community samples, whereas incorrect $\Delta^{13} \mathrm{C}$ (TDFs from Polar Bears and A. macrocephala) would have led to the conclusion that the community is dependent on an unknown or unsampled basal resource or primary producer. As rapid climate change occurs in the Arctic, it is important that the baseline stable isotope food web models are accurate so that changes in food web structure can be quantified in the future.

\section{Conclusion}

These results exemplify that the use of inappropriate TDFs can lead to erroneous conclusions regarding food web structure from stable isotope food web models, and 
therefore it is important to select the most appropriate TDFs. Using this example, the TDFs for Arctic Sculpin are different from the TDFs of the 4 other Arctic species previously examined, and it is likely that the same is true for other species of Arctic fish. Due to this apparent variability in TDFs in Arctic marine species, it is imperative that a more comprehensive database of TDFs is created so that stable isotope food web models can be used accurately to investigate the trophodynamics of Arctic fish in the future.

Though the TDFs for Arctic Sculpin may be the best values currently available to represent trophodynamics between Arctic fish and their prey, they should not be regarded as the correct values for all isotope models of lower trophic levels in the Arctic. On the contrary, this analysis should function as a call for more experimental determination of TDFs for Arctic marine species at all trophic levels as the current database of TDFs is greatly lacking.

\section{Acknowledgments}

Special thanks to Craig George, Leandra Sousa, Todd Sformo, Robert Suydam, and the North Slope Borough for providing significant logistical support during the collection of Arctic nearshore fish. Additional thanks to laboratory and field technicians at Florida International University (FIU), NOAA Auke Bay Labs, and University of Alaska Fairbanks who processed the isotope samples or contributed to field collection efforts, including Robert Darcy, Mark Kleese, Katrina Abel, Alexandra Brownstein, Matthew Callahan, Samuel George, and Ann Robertson. We also thank the FIU Southeast Environmental Research Center Stable Isotope Laboratory for analyzing the fish tissues. Finally, thanks to our sponsors for providing materials and gear including Columbia $\odot$, Engel Coolers $\odot$, and Smith Optics@ $\odot$. This is contribution No. XX from the Marine Education and Research Center in the Institute for Water and the Environment at Florida International University. We also thank our funding sources: this work was supported by the North Pacific Research 
Board (grant number 1229, 2012); Bureau of Ocean Energy Management (BOEM), Cooperative Agreement Contract Nos. M12PG00024 (ACES), and M12PG00018 (Arctic EIS) of the U.S. Department of the Interior (Cooperative Agreement Contract \#M12PG00024, \#M12PG00018).

\section{References}

Barnes, C., Sweeting, C.J., Jennings, S., Barry, J.T. \& Polunin, N.V.C. (2007). Effect of temperature and ration size on carbon and nitrogen stable isotope trophic fractionation. Funct. Ecol., 21, 356-362.

Barton, M.B., Moran, J.R., Vollenweider, J.J., Heintz, R.A. \& Boswell, K.M. (2016). Latitudinal dependence of body condition, growth rate, and stable isotopes of juvenile capelin (Mallotus villosus) in the Bering and Chukchi Seas. Polar Biol., 1-13.

Dunton, K.H., Schonberg, S. V. \& Cooper, L.W. (2012). Food web structure of the Alaskan nearshore shelf and estuarine lagoons of the Beaufort Sea. Estuaries and Coasts, 35, 416435 .

Eisner, L., Hillgruber, N., Martinson, E. \& Maselko, J. (2013). Pelagic fish and zooplankton species assemblages in relation to water mass characteristics in the northern Bering and southeast Chukchi seas. Polar Biol., 36, 87-113.

Fry, B. (2013). Alternative approaches for solving underdetermined isotope mixing problems. Mar. Ecol. Prog. Ser., 472, 1-13.

Gannes, L.Z., Brien, D.M.O., Martínez, C. \& Jun, N. (1997). Stable isotopes in animal ecology: Assumptions, caveats, and a call for more laboratory experiments. Ecology, 78, 1271-1276.

Gaye-siessegger, J., Focken, U., Muetzel, S., Abel, H. \& Becker, K. (2004). Feeding level and individual metabolic rate affect $\delta^{13} \mathrm{C}$ and $\delta^{15} \mathrm{~N}$ values in carp: implications for food web studies. Oecologia, 138, 175-183.

Grebmeier, J.M. (2012). Shifting patterns of life in the Pacific Arctic and sub-Arctic seas. Ann. Rev. Mar. Sci., 4, 63-78.

Hobson, K.A., Schell, D.M., Renouf, D. \& Noseworthy, E. (1996). Stable carbon and nitrogen isotopic fractionation between diet and tissues of captive seals: Implications for dietary reconstructions involving marine mammals. Can. J. Fish. Aquat. Sci., 53, 528-533.

Hobson, K. a \& Schell, D.M. (1998). Stable carbon and nitrogen isotope patterns in baleen from eastern Arctic bowhead whales (Balaena mysticetus). Can. J. Fish. Aquat. Sci., 55, 2601-2607. 
Hobson, K. \& Welch, H. (1992). Determination of trophic relationships within a high arctic marine food web using Delta-13 C and Delta-15 N analysis. Mar. Ecol. Prog. Ser., 84, 918.

Hussey, N., MacNeil, M., McMeans, B., Olin, J., Dudley, S., Cliff, G., et al. (2014). Rescaling the trophic structure of marine food webs. Ecol. Lett., 17, 239-250.

Iken, K., Bluhm, B. \& Dunton, K. (2010). Benthic food-web structure under differing water mass properties in the southern Chukchi Sea. Deep. Res. Part II Top. Stud. Oceanogr., 57, $71-85$.

Lindeman, R. (1942). The trophic-dynamic aspect of ecology.pdf. Ecology, 23, 399-417.

Logan, J., Haas, H., Deegan, L. \& Gaines, E. (2006). Turnover rates of nitrogen stable isotopes in the salt marsh mummichog, Fundulus heteroclitus, following a laboratory diet switch. Oecologia, 147, 391-5.

Logan, J.M., Jardine, T.D., Miller, T.J., Bunn, S.E., Cunjak, R.A. \& Lutcavage, M.E. (2008). Lipid corrections in carbon and nitrogen stable isotope analyses: Comparison of chemical extraction and modelling methods. J. Anim. Ecol., 77, 838-846.

Madigan, D.J., Litvin, S.Y., Popp, B.N., Carlisle, A.B., Farwell, C.J. \& Block, B.A. (2012). Tissue turnover rates and isotopic trophic discrimination factors in the endothermic teleost, Pacific Bluefin Tuna (Thunnus orientalis). PLoS One, 7, e49220.

McTigue, N.D. \& Dunton, K.H. (2014). Trophodynamics and organic matter assimilation pathways in the northeast Chukchi Sea, Alaska. Deep Sea Res. Part II Top. Stud. Oceanogr., 102, 84-96.

Mohan, J.A., Smith, S.D., Connelly, T.L., Attwood, E.T., McClelland, J.W., Herzka, S.Z., et al. (2016). Tissue-specific isotope turnover and discrimination factors are affected by diet quality and lipid content in an omnivorous consumer. J. Exp. Mar. Bio. Ecol., 479, 3545.

Phillips, D.L., Inger, R., Bearhop, S., Jackson, A.L., Moore, J.W., Parnell, A.C., et al. (2014). Best practices for use of stable isotope mixing models in food-web studies, 835, $823-835$.

Poloczanska, E.S., Hwakins, S.J., Southward, A.J. \& Burrows, M.T. (2008). Modeling the response of populations of competing species to climate change. Ecology, 89, 3138-49.

Post, D.M. (2002). Using stable isotopes to estimate trophic position: Models, methods, and assumptions. Ecology, 83, 703-718.

Rosenblatt, A.E. \& Heithaus, M.R. (2013). Slow isotope turnover rates and low discrimination values in the American Alligator: implications for interpretation of ectotherm stable isotope data. Physiol. Biochem. Zool., 86, 137-48. 
Tamelander, T., Søreide, J.E., Hop, H. \& Carroll, M.L. (2006). Fractionation of stable isotopes in the Arctic marine copepod Calanus glacialis: Effects on the isotopic composition of marine particulate organic matter. J. Exp. Mar. Bio. Ecol., 333, 231-240.

Vollenweider, J.J., Heintz, R.A., Boswell, K.M., Norcross, B.L., Li, C., Barton, M.B., et al. (2016). Distribution and habitat use of fish in the nearshore ecosystem in the Beaufort and Chukchi Seas.

Vander Zanden, M. \& Rasmussen, J. (2001). Variation in $\delta^{15} \mathrm{~N}$ and $\delta^{13} \mathrm{C}$ trophic fractionation: Implications for aquatic food web studies. Limnol. Oceanogr., 46, 20612066. 


\section{Tables}

Table 6.1 Results from the literature searches on Google Scholar $\odot$ and Research Gate $\odot$. "Field Isotopes" experiment type refers to the deduction of TDFs from isotope ratios of species collected in a field study. These deductions require the assumption that the consumer species is a specialist feeding only on the prey species. "Lab based" experiment type refers to controlled experiments where the isotopic ratio of food was known and controlled. $\Delta^{15} \mathrm{~N}$ and $\Delta^{13} \mathrm{C}$ are the differences in $\delta^{15} \mathrm{~N}$ and $\delta^{13} \mathrm{C}$ between prey and consumer. TDS is the Trophic Discrimination Slope, calculated from the TDFs from each study $\left(\Delta^{15} \mathrm{~N} / \Delta^{13} \mathrm{C}\right)$.

\begin{tabular}{|c|c|c|c|c|c|c|c|}
\hline $\begin{array}{l}\text { Species } \\
\text { (common) }\end{array}$ & $\begin{array}{l}\text { Species } \\
\text { (scientific) }\end{array}$ & $\begin{array}{c}\text { Experiment } \\
\text { Type }\end{array}$ & $\mathrm{N}$ & $\begin{array}{l}\Delta^{15} N \\
(\% o)\end{array}$ & $\begin{array}{l}\Delta^{13} \mathrm{C} \\
(\% 0)\end{array}$ & TDS & Source \\
\hline Arctic & Myoxocephalus & & & & & & \\
\hline Sculpin & scorpioides & Lab Based & 78 & 3.2 & 1.8 & 1.7 & Chapter III \\
\hline Harp Seal & $\begin{array}{l}\text { Pagophilus } \\
\text { groenlandicus }\end{array}$ & Lab Based & 2 & 2.4 & 1.3 & 1.8 & $\begin{array}{l}\text { Hobson et } \\
\text { al. } 1996\end{array}$ \\
\hline Polar Bear & $\begin{array}{l}\text { Ursus } \\
\text { maritimus }\end{array}$ & $\begin{array}{l}\text { Field } \\
\text { Isotopes }\end{array}$ & 3 & 3.8 & 0.7 & 5.4 & $\begin{array}{l}\text { Hobson et } \\
\text { al. } 1992\end{array}$ \\
\hline Amphipod & $\begin{array}{l}\text { Ampelisca } \\
\text { macrocephala }\end{array}$ & $\begin{array}{l}\text { Field } \\
\text { Isotopes }\end{array}$ & 8 & 3.4 & 0.4 & 8.5 & $\begin{array}{l}\text { McTigue et } \\
\text { al. } 2013\end{array}$ \\
\hline Chaetognaths & $\begin{array}{l}\text { Parasagitta } \\
\text { elegans }\end{array}$ & $\begin{array}{c}\text { Field } \\
\text { Isotopes }\end{array}$ & 36 & 2.5 & 1.3 & 1.9 & $\begin{array}{l}\text { Dunton et } \\
\text { al. } 2012\end{array}$ \\
\hline
\end{tabular}




\section{Figures}

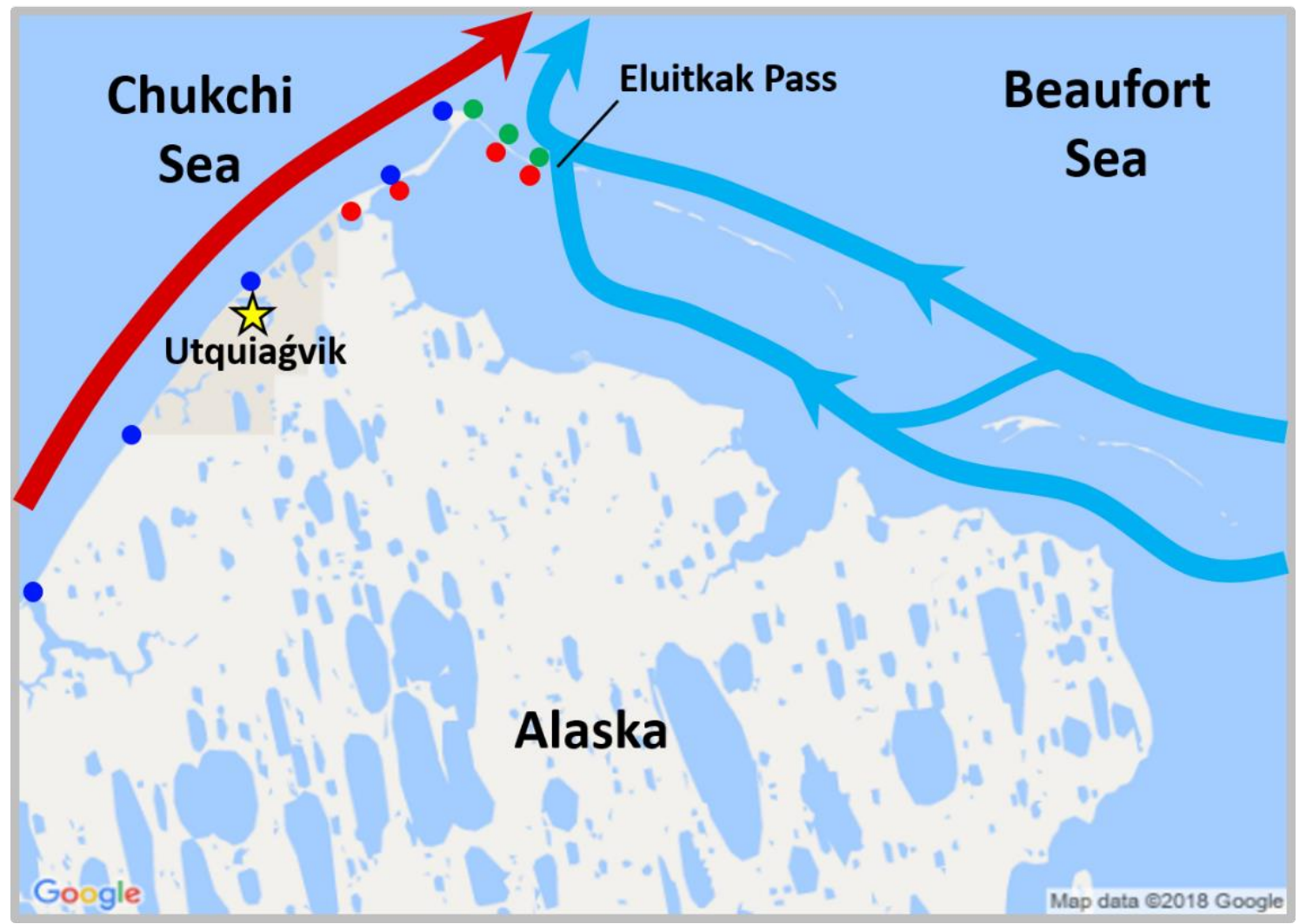

Figure 6.1 A map of the study area and relevant geographic and oceanographic features. Sampling stations are depicted by circles: blue (Chukchi Sea), green (Beaufort Sea), and red (Elson Lagoon). The prevalent flow of the Alaska Coastal Current (ACC) is depicted by red arrows traveling along the Alaskan coast north past Point Barrow through the Barrow Canyon. The prevalent wind driven flow along the Beaufort coast and through the Elson Lagoon out Eluitkak Pass is depicted by blue arrows. 

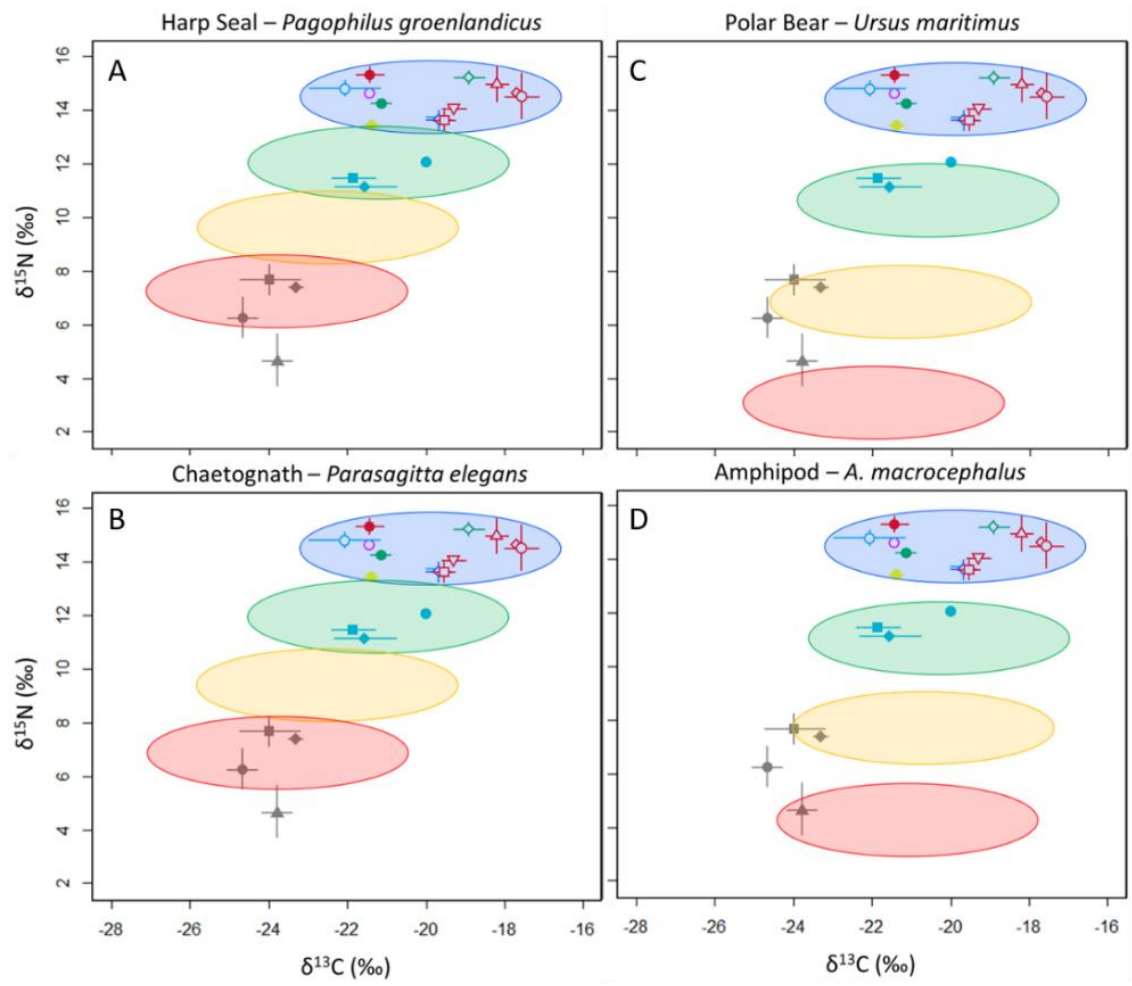

$$
\begin{array}{|ll}
\hline & \text { Arctic Shanny } \\
\diamond & \text { Capelin } \\
& \text { Gelatinous Seasnail } \\
& \text { Least Cisco } \\
& \text { Pacific Sand Lance } \\
& \text { Pterapods } \\
& \text { Calanoid Copepods } \\
& \text { Krill } \\
\Delta & \text { Mysis Shrimp } \\
\diamond & \text { Arctic cod } \\
\triangle & \text { Sculpin, Arctic } \\
\nabla & \text { Sculpin, Belligerent } \\
\square & \text { Sculpin, Fourhorn } \\
\diamond & \text { Sculpin, Larvae } \\
O & \text { Sculpin, Shorthorn } \\
\text { Slender Eel Blenny } \\
\text { Near Surface SPOM } \\
\Delta \text { Near-Seafloor SPOM } \\
\text { Phytoplankton } \\
\text { Sediment Bulk Organic Matter }
\end{array}
$$

Figure 6.2 Graphical representations of trophic level niche spaces estimated from published trophic discrimination factors (TDF) of four Arctic species; Polar Bears (Ursus maritimus; A), Harp Seals (Pagophilus groenlandicus; B), Amphipods (Ampelisca macrocephala; C), Chaetognaths (Parasagitta elegans; D). The data points are measured carbon and nitrogen isotope values of fish and zooplankton collected from the Arctic nearshore in 2013 and 2014. The blue ellipses represent the measured trophic niche space of all fish, and the green, yellow, and red ellipses represent the estimated trophic niche space of their prey resources at 1,2, and 3 trophic levels below the fish, respectively. 


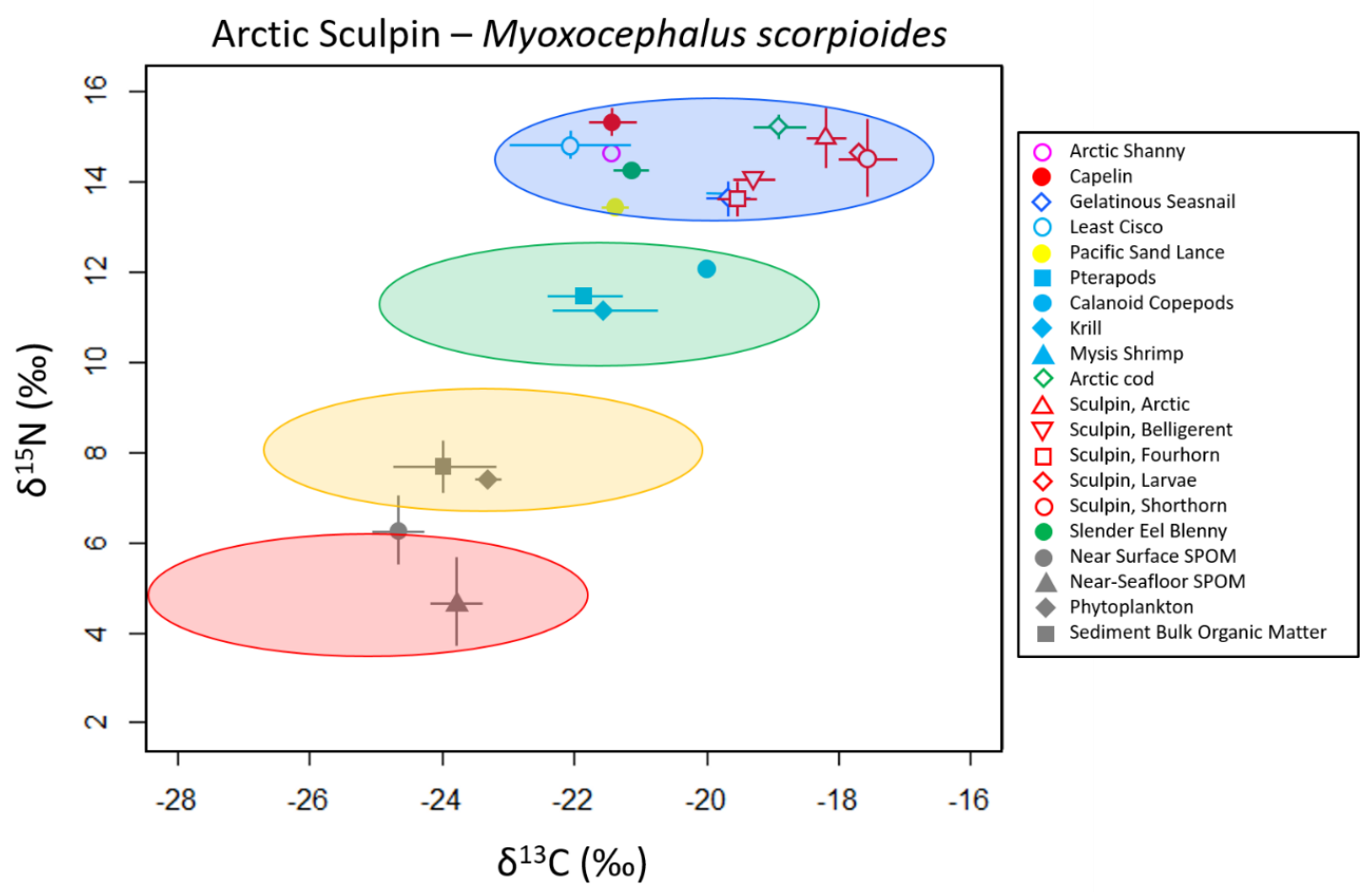

Figure 6.3 Graphical representations of trophic level niche spaces estimated from the trophic discrimination factors (TDF) of Arctic Sculpin (Myoxocephalus scorpioides; Chapter III). The data points are measured carbon and nitrogen isotope values of fish and zooplankton collected from the Arctic nearshore in 2013 and 2014. The blue ellipse represents the measured trophic niche space of all fish, and the green, yellow, and red ellipses represent the estimated trophic niche space of their prey resources at 1,2 , and 3 trophic levels below the fish, respectively. 


\section{CHAPTER VII}

FOOD WEB DYNAMICS OF TROPHIC NICHE SPACE AND BASAL RESOURCE DEPENDENCE IN ARCTIC NEARSHORE FISH COMMUNITIES 


\begin{abstract}
Changing environmental conditions in Arctic marine habitats are expected to shift abundances and distributions of warm and cold water-associated fish species. The increasing abundances of warm-water species are expected to modify trophodynamics and competition for available prey resources within Arctic nearshore fish communities. A thorough understanding of Arctic food web structures and the prey resources on which nearshore fish communities depend must be gained to assess the impacts that these changes will have in the future. We used stable isotope analysis of carbon and nitrogen on 649 samples of common nearshore species of fish and invertebrates to investigate the trophic niche space that they occupy within Arctic nearshore food webs. The fish community occupied several trophic levels, and depended on basal resources comprised of terrestrial materials, pelagic primary producers, and ice algae. Most Arctic cold-water fish species were found to have small trophic niche spaces, and may suggest poor adaptability to future changes in trophodynamics, whereas warm-water species either occupied unexploited niche space or showed high variance in carbon isotope values suggesting the ability to take advantage of multiple dietary resources. During warm years, when warm-water species were more abundant, cold-water species' niche spaces were smaller than in years with fewer warm-water species, potentially suggesting that competition for resources may already be occurring.
\end{abstract}

\title{
Introduction
}

The Arctic Ocean has become of increasing interest due to the rapid rate of climate change in these extreme environments (Johannesson et al. 2004; Moline et al. 2008; 
McMahon et al. 2009). The rapid decrease in sea ice cover has drawn the attention of oil and gas, shipping, and tourism industries looking to capitalize on previously unavailable resources (AMAP 2008; Jones 2012), which has both potential to benefit the world economy and to harm marine ecosystems. As climate change continues, lower-latitude species will continue to become abundant in the Arctic, introducing new competition for resources and space for the well-established Arctic forage species (Grebmeier et al. 2006; Grebmeier 2012; Hollowed et al. 2013). In the past few decades, a considerable amount of research has focused on food webs of the Arctic Ocean to establish baselines before these potential threats are realized. However, despite this effort, only a small portion of this research has been focused on coastal or continental shelf regions (Bluhm \& Gradinger 2008; Iken et al. 2010; Norcross et al. 2012), and an even smaller portion of that has focused on the very nearshore shallower than $15 \mathrm{~m}$ (Craig et al. 1985; Dunton et al. 2006, 2012; McTigue \& Dunton 2014). Due to the lack of studies of nearshore fish communities in the Arctic, it is hard to determine the relative abundance or distribution of all nearshore species. Instead of referring to species in this study as lower-latitude or higher-latitude they will be categorized as Arctic warm-water and cold-water species as defined by Barton et al. (Chapter II); warm-water species are expected to increase in abundance as Arctic warming continues, and this shift in abundance is expected to change competition for resources with well-established forage fish species that were favored by historic colder temperatures.

A large portion of biomass in the Arctic Ocean is found at the benthos, and the productivity of these benthic food webs is highly dependent on benthic-pelagic coupling to transfer organic material from pelagic primary production to the benthos (Gradinger \& 
Bluhm 2010; Iken et al. 2010; Griffiths et al. 2017; Stasko et al. 2018). However, benthicpelagic coupling may be less important in structuring food webs in nearshore habitats where influence of terrestrial runoff can play a much larger role than it does further offshore (Dunton et al. 2012). The Arctic nearshore is largely comprised of estuarine lagoon and barrier island systems, where allochthonous nutrients are concentrated due to riverine discharge and permafrost melt water (Dunton et al. 2006; Dutta et al. 2006; Strauss et al. 2011). Based on knowledge of well-studied lower-latitude systems, these estuaries have the potential to be highly productive and important habitats for the rearing of juvenile fish, foraging grounds for a multitude of protected and endangered marine mammals and seabirds (Fry \& Arnold 1982; Elliott et al. 1990; Beck et al. 2001; Dunton et al. 2012), as well as a valuable resource for nearby subsistence villages. Though we presume that Arctic estuaries are characterized by many of the same ecological processes as their low-latitude counterparts, the scales and patterns of these processes need to be analyzed to understand similarities or differences in the way that Arctic nearshore habitats function.

The study of food webs can offer insight to the functionality of an ecosystem and identify important pathways for energy transfer through the community. Several studies have investigated trophic pathways to high level predators such as seals, seabirds, whales and Polar Bears (Ursus maritimus; Hobson \& Welch 1992; Dehn et al. 2006, 2007), and low trophic levels (Iken et al. 2010; Dunton et al. 2012; McTigue \& Dunton 2014) but to date the Arctic nearshore fish communities have not been the focus of study. These fish communities are an essential vector to transfer energy from low-trophic level primary producers (e.g., phytoplankton and algae) to higher trophic levels such as seals, seabirds, whales, and Polar Bears (Hobson \& Welch 1992; Welch et al. 1993; Benoit-Bird et al. 
2008). Given the importance of fish in the food web of the Arctic Ocean (Hobson \& Welch 1992; Benoit-Bird et al. 2008, 2010), it is important to elucidate the trophic relationships under current conditions to understand how food webs may be restructured in response to climate change and expected shifts in the abundances and geographic ranges of dominant species.

The paucity of information describing Arctic nearshore food webs is in part due to the inherent logistical constraints in acquiring adequate samples during ice covered periods of the year (Dunton et al. 2005, 2012). Traditional methods to assess trophic connectivity rely on stomach content analyses; however, using this method to determine food web structure based on summer-collected fish m(Layman et al. 2007)ay result in a biased food web model that only represents summer prey selection or availability (Wiens 1989; Hobson \& Welch 1992; Gray et al. 2017). Stable isotope analysis (SIA) of carbon and nitrogen is a better-suited approach as the isotope ratios within the tissues of fish represent prey resources across an extended temporal scale, thus incorporating part of the year when ice cover prevents sample collection (Hobson \& Clark 1992; Fry 2006; Dunton et al. 2012). Furthermore, the ability to use linear models of stable isotope ratios to represent trophic pathways allows for the estimation of trophic position, prey and basal resource dependence (Vander Zanden et al. 1998; Dunton et al. 2012).

SIA of carbon and nitrogen in a community of fish offer insight to the diversity of trophic structure and resource dependence, which can help predict how resilient species within a food web may be to change (Layman et al. 2007). Past SIA works have used community-wide metrics of isotopic niche space to describe trophic diversity and redundancy within food webs (Layman et al. 2007; McTigue \& Dunton 2014). However, 
the metric proposed to describe trophic niches by Layman et al. (2007) are predicated on all species in a community depending on similar baseline $\delta^{15} \mathrm{~N}$ values, so that vertical isotopic position (on the $\delta^{15} \mathrm{~N}$ axis) reflects the range of trophic levels in the community. Since baseline $\delta^{15} \mathrm{~N}$ between terrestrial materials, primary producers, and ice algae may differ by approximately 8 \% (Hobson \& Welch 1992; Dunton et al. 2006), and different species may depend on different basal resources, it is more appropriate in this case to represent vertical trophic structure by the estimated range of trophic position occupied within the fish community. Furthermore, these metrics also depend on the assumption that there is little to no trophic discrimination of carbon isotopes so that ranges of $\delta^{13} \mathrm{C}$ represent changes in basal resource dependence. Given that Arctic fish species may have high rates of trophic fractionation in carbon isotopes (Chapter III), ranges of $\delta^{13} \mathrm{C}$ are likely to be exaggerated.

Another way to assess trophodynamics is through isotope mixing models (Phillips et al. 2014; Solomon et al. 2014), but again these are not appropriate to assess basal resource dependence in Arctic nearshore habitats. Mixing models are used to identify the most probable dietary contribution of prey or resources of a species or group of species based on a priori knowledge of prey included in their diet. Though diet data exists for a few of the species of fish included in this analysis, we do not have adequate samples to determine the isotopic signatures of all prey included in their diet. Furthermore, it is not possible to use mixing models to estimate contributions of different basal resources because these basal resources have such variable baseline isotope values.

We examine the relationship between carbon and nitrogen stable isotope ratios to investigate food web structure and basal resource dependence in the Arctic nearshore 
surrounding Point Barrow, AK using model parameters determined by Barton et al. (Chapter III). We discuss the diversity of trophic niche space of fish species in Arctic nearshore habitats, and the potential competition that may arise as the Arctic climate continues to change.

\section{Methods}

\section{Study Area}

Point Barrow, AK is a unique area where multiple Arctic nearshore habitat types are found in close proximity to each other. Point Barrow is uniquely positioned at the confluence of the Chukchi and Beaufort Seas. It is bordered on the west by the Chukchi Sea (CHS) and to the east by the Beaufort Sea (BFS), with the large estuarine Elson Lagoon (ESL) opening into the Beaufort Sea just $5 \mathrm{~km}$ southeast of Point Barrow (Figure 7.1). These water bodies have distinct conditions (Chapter II), thus sampling in this region represents a broad array of Arctic nearshore habitats.

\section{Sample Collection}

Nekton communities were sampled using a beach seine at 12 stations ( 5 CHS, 3 BFS, and 4 ESL; Figure 7.1) at weekly intervals from July $14^{\text {th }}-$ August $25^{\text {th }}$ for three consecutive years (2013-15). The seine was $37 \mathrm{~m}$ long with variable mesh sizes (10 $\mathrm{m}$ of $32 \mathrm{~mm}$ outer panels, $4 \mathrm{~m}$ of $6 \mathrm{~mm}$ middle panels, and $9 \mathrm{~m}$ of $3.2 \mathrm{~mm}$ blunt panel). Each set was round-haul style, paid out of a $3 \mathrm{~m}$ inflatable zodiac following methods used by Johnson et al. (2010). All collections occurred during daylight hours. When sufficient samples were available three or more individuals of each fish species from each waterbody 
collected within each sampling week were retained for SIA to ensure that estimated trophic niche space within the fish community combined multiple temporal and spatial scales. All salmon samples included in this study were collected in gill nets and donated by local subsistence fishermen.

Zooplankton samples were collected opportunistically during the 2014 and 2015 beach seine surveys, but not in 2013. A $50 \mathrm{~cm}$ diameter, $333 \mu \mathrm{m}$ plankton net was towed behind a $3 \mathrm{~m}$ rigid hull inflatable at 3 knots for approximately 3 minutes. Samples were reduced volumetrically to approximately $50 \mathrm{~mL}$ using a Folsom Splitter. Plankton were sorted by major taxa and enumerated. Larger taxa (krill, mysids, amphipods, ichthyoplankton, etc.) were removed and smaller taxa (copepods, small planktonic larvae) were sorted under a dissecting microscope.

\section{Stable Isotope Analysis}

For all fish specimens larger than $25 \mathrm{~mm}$ TL, a muscle sample was collected on the left dorsal side and all skin and bones were removed. Fish that were smaller than $25 \mathrm{~mm}$ TL and zooplankton samples were processed whole, in composite samples of at least 5 individuals. Tissues were dried at $50^{\circ} \mathrm{C}$ for at least 7 days, weighing the vial every 2 days until a consistent weight was obtained, indicating that all moisture was removed. Samples were then homogenized to a uniform consistency using a mortar and pestle. Samples were weighed (0.4-0.7 mg of dry homogenate), rolled into a tin capsule, and analyzed at the Florida International University Southeast Environmental Research Center Stable Isotope Laboratory. The samples were analyzed using an Elemental Analysis - Isotope Ratio Mass Spectrometry (EA-IRMS), with a Delta C Finnagen (Thermo Fisher Scientific) and Conflo 
II dilution interface (Thermo Fisher Scientific) coupled to a NA-1500 NC Carlo ERBA elemental analyzer (Fisons Instruments). Precision and accuracy of the instruments were controlled with NIST standard IAEA-CH- 6 for $\delta^{13} \mathrm{C}$, and IAEA-N1 for $\delta^{15} \mathrm{~N}$. Three inhouse standards were also used: Bovine Liver, Citrus Leaves, and Glycine. Isotope ratios are expressed in delta-notation $(\delta)$ as per mil (\%) relative to the standard Vienna Peedee Belemnite (VPDB; $\left.{ }^{13} \mathrm{C}\right)$ and atmospheric nitrogen $\left({ }^{15} \mathrm{~N}\right)$ as shown below:

$$
\delta^{q} X=\left(\frac{R_{\text {sample }}}{R_{\text {standard }}}-1\right) \times 1000
$$

where $q$ is the mass number of the isotope, $X$ is the element of the isotope, and $R$ represents the ratio of heavy to light stable isotopes for carbon $\left({ }^{13} \mathrm{C} /{ }^{12} \mathrm{C}\right)$ and nitrogen $\left({ }^{15} \mathrm{~N} /{ }^{14} \mathrm{~N}\right)$ within the sample and standards.

Carbon isotope ratios were corrected for the effects of lipid content in sample tissues (Sweeting et al. 2006).

$$
\delta^{13} C_{\text {protein }}=\delta^{13} C_{\text {sample }}+\left(6 \% \times\left(\frac{\% \text { lipid }}{100}\right)\right)
$$

where $\delta^{13} C_{\text {protein }}$ is the isotope ratio of lipid-free sample tissue, and $\delta^{13} C_{\text {sample }}$ is the isotope ratio of bulk sample tissue (Sweeting et al. 2006). This method makes two assumptions: (1) lipid $\delta^{13} \mathrm{C}$ is $6 \%$ depleted compared to protein, and (2) the lipid-extracted tissue and pure protein are isotopically identical (McConnaughey \& McRoy 1979; Sweeting et al. 
2006; Logan et al. 2008). Percent lipid was estimated from C/N ratios using a linear model created in Chapter III:

$$
\text { Percent lipid }=\frac{C}{N} * 2.04-3.01,
$$

\section{Analytical Approach}

Stable isotopes differ between trophic positions as metabolic processes preferentially use lighter isotopes, leaving behind heavier isotopes to be assimilated into tissues. The discrimination of light and heavy isotopes causes enrichment between trophic positions, and is represented by trophic discrimination factors (Chapter III; Hussey et al. 2014). Using linear models of stable isotope ratios, one can estimate trophic positions and prey/basal resource dependence.

Trophic discrimination is significantly higher in nitrogen isotope ratios than in carbon, and thus nitrogen isotopes are used to estimate trophic position (Logan et al. 2006; Hussey et al. 2014). A trophic discrimination factor of $\Delta^{15} \mathrm{~N} 3.23 \pm 0.53 \%$, derived from a lab experiment on Arctic Sculpin (Myoxocephalus scorpioides; Chapter III), was used to estimate trophic position for all species, as it is the only discrimination factor available for Arctic marine fish species currently available. Trophic discrimination is relatively low in carbon isotopes compared to nitrogen, however carbon isotope values are greatly affected by different dietary sources, and for this reason it is used to gain insight to the types of basal resources on which a food web depends (Vander Zanden \& Rasmussen 2001; von Biela et al. 2013). In Chapter III, I computed a trophic discrimination factor for carbon of 
$\Delta{ }^{13} \mathrm{C} 1.87 \pm 0.24 \%$. These two trophic discrimination factors were used to investigate differences in basal resource dependence of fish in different habitat types.

The trophic discrimination slope represents the per-unit change of carbon and nitrogen isotope values between trophic levels $\left(\Delta^{15} \mathrm{~N} / \Delta^{13} \mathrm{C}\right)$, and can be used to identify the possible isotopic ranges of prey or basal resources on which organisms depend in bivariate space $\left(\delta^{13} \mathrm{C}\right.$ versus $\delta^{15} \mathrm{~N}$; Chapter III; McTigue and Dunton, 2014). Bivariate $\delta^{13} \mathrm{C}$ $\delta^{15} \mathrm{~N}$ space will hereafter be referred to as 'isotopic space'. Isotopic space differs from 'trophic niche space' as the latter accounts for difference in baseline carbon and nitrogen isotope values by representing vertical food web structure as trophic position. Fish species were assigned to trophic groups based on differences in isotopic space. Benthic crustaceans and zooplankton were assigned to their own groups (BCRU and ZOOP, respectively). The different groups were assigned to eliminate clutter in visual assessment of isotopic and trophic niche space, and should not be regarded as different trophic guilds.

Baseline $\delta^{13} \mathrm{C}$ and $\delta^{15} \mathrm{~N}$ values from the Beaufort and Chukchi Seas were obtained from literature: terrestrial materials $\left(\delta^{13} \mathrm{C}=0.75 \pm 0.38 \%, \delta^{15} \mathrm{~N}=-29.00 \pm 1.00 \% 0\right)$ and pelagic primary producers $\left(\delta^{13} \mathrm{C}=6.00 \pm 0.50 \%, \delta^{15} \mathrm{~N}=-23.50 \pm 1.00\right.$; Dunton et al., 2006), ice algae $\left(\delta^{13} \mathrm{C}=-20.7 \pm 0.64 \%, \delta^{15} \mathrm{~N}=7.5 \pm 0.07 \%\right.$; Hobson and Welch, 1992). The trophic discrimination slopes were calculated from the average $\Delta{ }^{15} \mathrm{~N}$ and $\Delta{ }^{13} \mathrm{C} \pm \mathrm{SE}$ determined in Chapter III:

$$
\begin{aligned}
& T D S=\frac{\Delta^{15} N+S E}{\Delta^{13} C-S E}, \\
& T D S=\frac{\Delta^{15} N-S E}{\Delta^{13} C+S E},
\end{aligned}
$$


The potential isotopic space that could be supported by each basal resource were represented by the region in between a trophic discrimination slope of 2.02 and 1.47 that originate from two standard errors below and above the average $\delta^{13} \mathrm{C}$ value of each basal resource (McTigue and Dunton, 2014; Figure 7.3).

\section{Results}

Stable carbon and nitrogen isotope ratios of 649 samples representing 18 common species of nearshore fish and 7 species of benthic or planktonic invertebrates (Table 1) were analyzed to identify nearshore Arctic food web structures across three water bodies surrounding Point Barrow, Alaska. Across all species of fish and invertebrates, $\delta^{13} \mathrm{C}$ ranged from $-26.07 \%$ to $-16.83 \%$ (Mean $\pm \mathrm{SD}=-20.23 \pm 1.74 \%$ ), and $\delta^{15} \mathrm{~N}$ from $9.08 \%$ to $16.80 \%$ (13.91 $\pm 1.08 \%$ \%). Predicted trophic pathways indicate that Arctic nearshore fish, zooplankton, and benthic crustacean communities are dependent on terrestrial resources (TERA), pelagic primary producers (PRIM), and ice algae (ICEA) or a combination of these three during early open-water season (Figure 7.3).

Isotopic space of TG-1 ranges from $\delta^{13} \mathrm{C}-26.07$ to $-20.28 \%$ (range $=5.79 \%$ ), and $\delta^{15} \mathrm{~N} 13.80$ to $16.69 \%$ (2.90\%o). All three species (Arctic Smelt, Least Cisco, and Pacific Capelin) exhibited a similar range of $\delta^{15} \mathrm{~N}$, however Pacific Capelin had less depleted $\delta^{13} \mathrm{C}$ values (Figure 7.3). The isotopic space of TG-1 suggests that it feeds mostly in a trophic pathway that depends on TERA, but Pacific Capelin may have some influence of PRIM. Given that the isotopic space of all species in TG-1 was within the TERA trophic pathway, trophic positions for TG- 1 were calculated using $\delta^{15} \mathrm{~N}$ of TERA as a baseline $(0.75 \%$ ) and 
the average $\Delta^{15} \mathrm{~N}$ of 3.23 determined in Chapter III: $4.56 \pm 0.03$ (mean $\pm \mathrm{SE}$; Arctic Smelt), $4.34 \pm 0.06$ (Least Cisco), and 4.48 0.06 (Pacific Capelin; Table 7.1).

Isotopic space of TG-2 ranged from $\delta^{13} \mathrm{C}-24.22$ to $-21.65 \%$ (2.57\%o), and $\delta^{15} \mathrm{~N}$ 13.80 to $16.69 \%$ (2.89 \%o). Both Saffron Cod and Arctic Sand Lance exhibited a similar range of $\delta^{13} \mathrm{C}$, however Saffron Cod had a larger range of $\delta^{15} \mathrm{~N}$ values, though on average, $\delta^{15} \mathrm{~N}$ was less enriched than Arctic Sand Lance (Figure 7.3). The isotopic space of TG-2 suggested that group may feed within trophic pathways that depend on TERA as well as PRIM. For this reason, trophic positions for TG-2 are calculated using baseline $\delta^{15} \mathrm{~N}$ values from TERA and PRIM (6 \%o). TERA: $3.93 \pm 0.04$ (Arctic Sand Lance) and $3.74 \pm 0.18$ (Saffron Cod). PRIM: $2.31 \pm 0.04$ and $2.12 \pm 0.18$, respectively (Table 7.1).

isotopic space of TG-3 ranged from $\delta^{13} \mathrm{C}-24.43$ to $-19.65 \%$ (4.78\%o), and $\delta^{15} \mathrm{~N}$ 9.21 to $14.24 \%$ (5.03\%). Chum Salmon exhibited a wider range of $\delta^{13} \mathrm{C}$, and Pink Salmon a wider range of $\delta^{15} \mathrm{~N}$ (Figure 7.3), however the average isotopic space of both species was similar (Figure 7.2), indicating that the group may feed within trophic pathways that are dependent on TERA and PRIM, therefore trophic positions for TG-3 are calculated using baseline $\delta^{15} \mathrm{~N}$ values from both. TERA: $3.19 \pm 0.21$ (Chum Salmon) and $3.25 \pm 0.51$ (Pink Salmon). PRIM: $1.57 \pm 0.21$ and $1.62 \pm 0.51$, respectively (Table 7.1).

Isotopic space of TG-4 ranged from $\delta^{13} \mathrm{C}-25.73$ to $-16.60 \%$ (9.13\%o), and $\delta^{15} \mathrm{~N}$ 9.55 to $16.87 \%$ ( $7.32 \%$ ). This group covered the largest isotopic space and includes the majority of the fish species examined (11 species). Fourhorn Sculpin had the widest range in both $\delta^{13} \mathrm{C}$ and $\delta^{15} \mathrm{~N}$, but an exponential model fit to the data $\left(\mathrm{p}<0.001, \mathrm{R}^{2}=0.59\right)$ indicated that much of this variation is due to size of the sculpin, and Fourhorn Sculpin have similar isotopic space to the other species in TG-4 at similar sizes. Belligerent, Arctic, 
and Ribbed Sculpins shared a similar isotopic space, and Shorthorn Sculpin had similar $\delta^{13} \mathrm{C}$ range to these sculpins but their $\delta^{15} \mathrm{~N}$ range was less enriched. Gelatinous Snailfish and Larval Sculpin shared a similar isotopic space and were less enriched in $\delta^{15} \mathrm{~N}$ and more depleted in $\delta^{13} \mathrm{C}$ values than Belligerent, Arctic, Ribbed, and Shorthorn Sculpins. Larval Sculpin had a wider range in $\delta^{13} \mathrm{C}$ than Gelatinous Snailfish. Both flatfishes (Arctic Flounder and Longhead Dab) occupied a similar isotopic space, and were similar in $\delta^{15} \mathrm{~N}$ as Belligerent, Arctic, Ribbed, and Shorthorn Sculpin, but are more depleted in $\delta^{13} \mathrm{C}$ values. Only three samples of each Slender Eelblenny and Arctic Shanny were available for SIA, and consequently, their isotopic space had similar ranges of $\delta^{15} \mathrm{~N}$ values, but was fragmented into two clusters by $\delta^{13} \mathrm{C}$ values (Figure 7.3). For all species in TG-4, the occupied isotopic space indicated that they may utilize all three trophic pathways (TERA, PRIM and ICEA), therefore trophic positions for TG-4 are calculated using all three baseline $\delta^{15} \mathrm{~N}$ values (Table 7.1).

Isotopic space of BCRU ranges from $\delta^{13} \mathrm{C}-22.23$ to $-16.17 \%(6.06 \%)$, and $\delta^{15} \mathrm{~N}$ 10.78 to $14.79 \%$ ( $4.01 \%$ ). All four species of benthic crustaceans occupy a similar range of $\delta^{15} \mathrm{~N}$, though are separated by variation in $\delta^{13} \mathrm{C}$. G. wilkitzkii has the widest range in $\delta^{13} \mathrm{C}$, suggesting it depends on both all three basal resources (Figure 7.3). S. entomon is less depleted in $\delta^{13} \mathrm{C}$, suggesting that it primarily depends on ICEA. Miscellaneous Amphipods and T. libellula are most depleted in $\delta^{13} \mathrm{C}$, suggesting dependence on PRIM and TERA. Trophic positions were calculated for BCRU using baseline $\delta^{15} \mathrm{~N}$ values for each species based on the above observations on niche space.

Trophic niche space of ZOOP ranged from $\delta^{13} \mathrm{C}-23.63$ to $-20.13 \%$ ( $3.5 \%$ ), and $\delta^{15} \mathrm{~N} 10.08$ to $14.13 \%$ (4.05\%). All three species of zooplankton occupied separated 
isotopic spaces. Pteropods (L. helicina) were the most depleted in both $\delta^{13} \mathrm{C}$ and $\delta^{15} \mathrm{~N}$, and Mysis were most enriched; the single sample of Krill occupied an isotopic space in between the other two groups (Figure 7.3). The isotopic space of ZOOP suggests that it may feed along trophic pathways that utilize on TERA and PRIM; however, given that Pteropods are grazers that generally feed at the $1^{\text {st }}$ trophic level (Gilmer \& Harbison 1991), trophic positions for ZOOP are calculated using baseline $\delta^{15} \mathrm{~N}$ values from PRIM: $1.46 \pm 0.17$ (Pteropods), $2.39 \pm 0.08$ (Mysis), 1.87 (Krill).

The difference in isotopic space occupied by each species in different years was tested using MANOVA of $\delta^{13} \mathrm{C}-\delta^{15} \mathrm{~N}$. In several cases, samples were only available for one year; however, in those cases where multiple years were available (Arctic Shanny, Slender Eelblenny, Arctic Sculpin, Shorthorn Sculpin, Fourhorn Sculpin, Arctic Smelt, and Arctic Sand Lance), only Arctic Sculpin and Shorthorn Sculpin showed significant difference between years $(\mathrm{p}<0.05)$. In both instances, isotopic space in 2014 was wider and more enriched in $\delta^{15} \mathrm{~N}$ than 2013 and 2015 (Figure 7.4, Table 7.2).

\section{Discussion}

Trophodynamics in the Arctic nearshore are complex and difficult to understand due to overlapping estimated trophic pathways because of highly variable $\delta^{15} \mathrm{~N}$ baselines among the expected predominant basal resources. For a few species, basal resource dependence was clear (Arctic Smelt, Least Cisco, S. entomon); however, for most species isotopic space potentially depended on several trophic pathways, making it difficult to determine which baseline $\delta^{15} \mathrm{~N}$ was most appropriate to compute trophic position. Fortunately, ecomorphological traits, dietary preference, and gape limitation can validate 
estimated trophic position and help elucidate the basal resources on which fish and invertebrates are most likely to depend upon (Albouy et al. 2011). In this paper, we assumed that the above referenced traits were indicative of prey selection and these factors were interpreted to validate or refute the different trophic positions that were estimated using the baseline values of the suggested trophic pathways on which each species may rely.

Our data suggest that Arctic nearshore fish were feeding between the $1^{\text {st }}$ and $4^{\text {th }}$ trophic level. TG-1 included Arctic Smelt and Cisco that fed at the highest $\left(4^{\text {th }}\right)$ trophic level (Table 1), suggesting that these fish are secondary piscivores (Hussey et al. 2014). Both species are relatively large (137 $\pm 64 \mathrm{~mm}$ TL, and $229 \pm 34 \mathrm{~mm}$ TL, respectively), with gapes large enough to eat small fish. Analyses of stomach contents have shown small fish in their diet (Norcross et al. 2012). It was unexpected that Pacific Capelin occupied the same trophic niche space as these larger piscivores as the capelin collected were much smaller (54 $\pm 19 \mathrm{~mm} \mathrm{TL}$ ), and Pacific Capelin of this size are limited by gape to small zooplankton, and small calanoid copepods generally make up the bulk of their diet (Vesin et al. 1981). Therefore, it is expected that Pacific Capelin would feed at the $2^{\text {nd }}$ trophic level. Pacific Capelin in the Arctic nearshore had more enriched $\delta^{15} \mathrm{~N}$ signatures than other Pacific Capelin throughout their latitudinal range, and the poor nutritional condition and prevalence of empty stomachs suggests it is the result of catabolism due to starvation (Barton et al. 2016). Pacific Capelin in this study also show more enriched $\delta^{15} \mathrm{~N}$ values than expected, and if this is more evidence of potential starvation, it could support the hypothesis that the Arctic nearshore is not optimal habitat for this species (Barton et al. 2016). If $\delta^{15} \mathrm{~N}$ of Pacific Capelin in this habitat is enriched due to starvation, it is likely that 
their true trophic niche space is not well represented by these data. However, it is unclear how much trophic fractionation of nitrogen isotopes is occurring in Pacific Capelin due to catabolism and metabolism in the process of starvation, and thus we cannot correctly estimate trophic position for this species.

Arctic Sand Lance and Saffron Cod (TG-2) occupied isotopic space within the TERA and PRIM trophic pathways, leading to estimations of trophic position between the $2^{\text {nd }}$ and $3^{\text {rd }}$ trophic level. Given the small sizes $(71 \pm 27 \mathrm{~mm}$ and $23 \pm 7 \mathrm{~mm}$ TL, respectively) and gapes of these species, it is expected that they feed on zooplankton and thus are likely to occupy the $2^{\text {nd }}$ trophic level (Norcross et al. 2012). This coincides with estimates of trophic position based on feeding in the PRIM trophic pathway, thus we infer that these fish are most likely dependent on PRIM basal resources.

Chum Salmon and Pink Salmon (TG-3) also occupied isotopic space in the TERA and PRIM trophic pathways, and estimates of trophic position from each of these baselines suggest that they feed at the $1^{\text {st }}$ or $3^{\text {rd }}$ trophic level. Feeding habits of Pacific salmon are well understood, and there is extensive evidence to suggest they do not graze on primary producers (Groot \& Margolis 1995). Age 1+ Pink Salmon are known to be more generalist in prey selection than Chum Salmon, though there is much overlap in both species feeding on fish, cephalopods, krill, and other zooplankton (Groot and Margolis, 1995). Thus, the estimated trophic positions on the $3^{\text {rd }}$ trophic level using TERA baseline $\delta^{15} \mathrm{~N}$ values is more appropriate for these species than the estimates using PRIM baseline values, and indicating that they are dependent on TERA.

All of the fish species in TG4 were relatively small $(37.53 \pm 21 \mathrm{~mm}$ TL) and it is unexpected that any of these fish are piscivores feeding at the $4^{\text {th }}$ trophic level as 
estimations from a TERA baseline $\delta^{15} \mathrm{~N}$ would suggest. For all species, estimates of trophic position from PRIM and ICEA $\delta^{15} \mathrm{~N}$ indicate that these fish are feeding at the $2^{\text {nd }}$ trophic level as planktivores. It is difficult to differentiate between dependence on the PRIM and ICEA trophic pathways, but it is likely that these species depend on resources derived of both.

Estimates of trophic position for amphipods range from the $1^{\text {st }}$ trophic level using ICEA $\delta^{15} \mathrm{~N}, 2^{\text {nd }}$ trophic level using PRIM baselines, and $3^{\text {rd }}$ using TERA baselines. It is hard to differentiate which estimate is best suited for amphipods as they are highly abundant in the Arctic nearshore and can scavenge on carrion (Sainte-Marie 1984) on the benthos (resulting in relatively higher trophic position) and prey on zooplankton in the water column (relatively lower trophic position). Thus, it seems reasonable to assume that given the isotopic space occupied by amphipods, they may occupy multiple trophic levels in the Arctic nearshore. Using the above discussion of basal resource dependence and best baseline $\delta^{15} \mathrm{~N}$ values to calculate trophic position, an overview of all species trophic positions is presented in Figure 7.5 and Table 7.1.

There is clear separation in basal resource dependence among Arctic nearshore fish species, however there is also a great deal of overlap in trophic niche space. This suggests that there may be a diverse prey base in these habitats on which fish can forage, but during early open-water season, most species are competing for prey that depend on pelagic primary producers (von Biela et al. 2013). Wide ranges of $\delta^{13} \mathrm{C}$ and $\delta^{15} \mathrm{~N}$ values may suggest that a species is dependent on multiple basal resources and feeding at different trophic positions, and thus may be more adaptable to changes in available prey abundance (Cohen 1977; Flaherty \& Ben-David 1992; Layman et al. 2007). By this logic, species with 
smaller niche spaces may be less adaptable and more likely to be affected by changing food web dynamics.

As warm-water species increase abundance and expand distribution in the Arctic with warming conditions, there is some concern that these newcomers may increase competition for resources with well-established cold-water species that have been more abundant in the past (Grebmeier et al. 2006; Grebmeier 2012; Laurel et al. 2016). In addition, some have suggested that shifts in production cycles to more pelagic production will favor a greater fish biomass, while reducing benthic biomass as less ice algae sinks to the benthos and is available to support benthic production (Bluhm \& Gradinger 2008; Iken et al. 2010). Our results suggest that the more abundant warm-water species found in our survey (Arctic Sand Lance, Pacific Capelin, and Saffron Cod) may be occupying trophic niche space that is not being occupied by cold-water species, and is relatively unexploited and thus the increased abundance of warm-water species may not change competition for resources with cold-water species. The potential lack of competition within those trophic niches may explain why these species are often encountered in extremely high abundance (beach seine catches containing thousands of individuals) in the Arctic nearshore (Chapter II). However, Arctic Shanny and Slender Eelblennies were found in the same trophic niche space as several cold-water species, and may present new competition as they increase in abundance (Cohen 1977; Flaherty \& Ben-David 1992). Though these two species were not strongly represented in the SIA samples, their wide range of $\delta^{13} \mathrm{C}$ values suggest that they may be adaptable to multiple prey types and can feed within several trophic pathways which will play a vital role in their ability to survive and flourish in the Arctic nearshore. The cold-water species (Belligerent, Arctic, Shorthorn Sculpins, and Gelatinous Snailfish) 
have relatively small trophic niche spaces and thus may not be as adaptable as to changing trophodynamics as conditions continue to change in the Arctic nearshore.

The three years that were sampled showed markedly different environmental conditions, with 2013 and 2015 being significantly warmer than 2014 (Chapter II). Multivariate analysis of community composition indicated that warm-water species are less abundant during colder years (2014). Only Arctic and Shorthorn Sculpin exhibited significant differences in occupied niche space between years. Both Arctic and Shorthorn Sculpin occupied a larger niche space in the colder year (2014), but smaller niche spaces for both warmer years (2013 and 2015). Though the differences were not significant for Fourhorn Sculpin, the same pattern was present. Perhaps this is a reflection of the competition for resources that warm-water species present, where less competition in cold years allowed cold-water species to feed on a variety of prey resources, and more competition in warmer years forced them to feed on less exploited prey resources. If warmwater species are to continue increasing in abundance in Arctic nearshore habitats (Grebmeier et al. 2006), and pelagic primary production is to increase (Gradinger \& Bluhm 2010), then species which occupy a trophic niche that is unexploited by cold-water species may form a robust prey base for Arctic piscivores. However, the species which compete with Arctic fish for the same resources may cause a restructuring of fish community composition, the trophic niche space occupied by each species, and thus the entire nearshore food web. 


\section{References}

Albouy, C., Guilhaumon, F., Villéger, S., Mouchet, M., Mercier, L., Culioli, J.M., et al. (2011). Predicting trophic guild and diet overlap from functional traits: Statistics, opportunities and limitations for marine ecology. Mar. Ecol. Prog. Ser., 436, 17-28.

AMAP. (2008). Arctic Oil and Gas. Arctic Monitoring and Assessment Programme, Oslo, Norway.

Barton, M.B., Moran, J.R., Vollenweider, J.J., Heintz, R.A. \& Boswell, K.M. (2016). Latitudinal dependence of body condition, growth rate, and stable isotopes of juvenile capelin (Mallotus villosus) in the Bering and Chukchi Seas. Polar Biol., 1-13.

Beck, M., Jr, K.H. \& Able, K. (2001). The identification, conservation, and management of estuarine and marine nurseries for fish and invertebrates. Bioscience, 51, 633-641.

Benoit-Bird, D., Simard, Y. \& Fortier, L. (2008). Hydroacoustic detection of large winter aggregations of Arctic Cod (Boreogadus saida) at depth in ice-covered Franklin Bay (Beaufort Sea). J. Geophys. Res., 113, 1-9.

Benoit-Bird, D., Simard, Y., Gagné, J., Geoffroy, M. \& Fortier, L. (2010). From polar night to midnight sun: photoperiod, seal predation, and the diel vertical migrations of Polar Cod (Boreogadus saida) under landfast ice in the Arctic Ocean. Polar Biol., 33, 1505-1520.

von Biela, V.R., Zimmerman, C.E., Cohn, B.R. \& Welker, J.M. (2013). Terrestrial and marine trophic pathways support young-of-year growth in a nearshore Arctic fish. Polar Biol., 36, 137-146.

Bluhm, B. \& Gradinger, R. (2008). Regional variability in food availability for Arctic marine mammals. Ecol. Appl., 18, S77-S96.

Cohen, J.E. (1977). Food webs and the dimensionality of trophic niche space. Proc. Natl. Acad. Sci. U. S. A., 74, 4533-4536.

Craig, P., Griffiths, W., Haldorson, L. \& McElderry, H. (1985). Distributional patterns of fishes in an Alaskan arctic lagoon. Polar Biol., 4, 9-18.

Dehn, L., Follmann, E., Thomas, D., Sheffield, G., Rosa, C., Duffy, L., et al. (2006). Trophic relationships in an Arctic food web and implications for trace metal transfer. Sci. Total Environ., 362, 103-123. 
Dehn, L., Sheffield, G., Follmann, E., Duffy, L.K., Thomas, D. \& O’Hara, T. (2007). Feeding ecology of phocid seals and some walrus in the Alaskan and Canadian Arctic as determined by stomach contents and stable isotope analysis and stable isotope analysis. Polar Biol., 30, 167-181.

Dunton, K.H., Goodall, J.L., Schonberg, S. V., Grebmeier, J.M. \& Maidment, D.R. (2005). Multi-decadal synthesis of benthic-pelagic coupling in the western arctic: Role of crossshelf advective processes. Deep Sea Res. Part II Top. Stud. Oceanogr., 52, 3462-3477.

Dunton, K.H., Schonberg, S. V. \& Cooper, L.W. (2012). Food Web Structure of the Alaskan Nearshore Shelf and Estuarine Lagoons of the Beaufort Sea. Estuaries and Coasts, $35,416-435$.

Dunton, K.H., Weingartner, T. \& Carmack, E.C. (2006). The nearshore western Beaufort Sea ecosystem: Circulation and importance of terrestrial carbon in arctic coastal food webs. Prog. Oceanogr., 71, 362-378.

Dutta, K., Schuur, E.A.G., Neff, J.C. \& Zimov, S.A. (2006). Potential carbon release from permafrost soils of Northeastern Siberia. Glob. Chang. Biol., 12, 2336-2351.

Elliott, M., O’Reilly, M.G. \& Taylor, C.J.L. (1990). The forth estuary: a nursery and overwintering area for North Sea fishes. Hydrobiologia, 195, 89-103.

Flaherty, E.A. \& Ben-David, M. (1992). Overlap and partitioning of the ecological and isotopic niches. Agriculture, 4235, 44 ST-Guidelines and sample protocol for sampling.

Fry, B. (2006). Stable Isotope Ecology. Third. Springer, Baton Rouge, LA.

Fry, B. \& Arnold, C. (1982). Rapid ${ }^{13} \mathrm{C} /{ }^{12} \mathrm{C}$ Turnover during growth of brown shrimp (Penaeus aztecus). Oecologia, 54, 200-204.

Gilmer, R.W. \& Harbison, G.R. (1991). Diet of Limacina helicina (Gastropoda: Thecosomata) in Arctic waters in midsummer. Mar. Ecol. Prog. Ser., 77, 125-134.

Gradinger, R. \& Bluhm, B. (2010). Timing of ice algal grazing by the Arctic nearshore benthic amphipod Onisimus litoralis. Arctic, 63, 355-358.

Gray, B.P., Norcross, B.L., Beaudreau, A.H., Blanchard, A.L. \& Seitz, A.C. (2017). Food habits of Arctic staghorn sculpin (Gymnocanthus tricuspis) and shorthorn sculpin (Myoxocephalus scorpius) in the northeastern Chukchi and western Beaufort Seas. Deep. Res. Part II Top. Stud. Oceanogr., 135, 111-123.

Grebmeier, J.M. (2012). Shifting patterns of life in the Pacific Arctic and sub-Arctic seas. Ann. Rev. Mar. Sci., 4, 63-78.

Grebmeier, J.M., Overland, J.E., Moore, S.E., Farley, E. V, Carmack, E.C., Cooper, L.W., et al. (2006). A major ecosystem shift in the northern Bering Sea. Science (80)., 311, 14614. 
Griffiths, J.R., Kadin, M., Nascimento, F.J.A., Tamelander, T., Törnroos, A., Bonaglia, S., et al. (2017). The importance of benthic-pelagic coupling for marine ecosystem functioning in a changing world. Glob. Chang. Biol., 23, 2179-2196.

Groot, C. \& Margolis, L. (1995). Pacific Salmon Life Histories. UBC Press.

Hobson, K. \& Clark, R. (1992). Assessing avian diets using stable isotopes I: turnover of $13 \mathrm{C}$ in tissues. Condor, 94, 181-188.

Hobson, K. \& Welch, H. (1992). Determination of trophic relationships within a high arctic marine food web using Delta-13 C and Delta-15 N analysis. Mar. Ecol. Prog. Ser., 84, 918.

Hollowed, A.B., Planque, B. \& Loeng, H. (2013). Potential movement of fish and shellfish stocks from the sub-Arctic to the Arctic Ocean. Fish. Oceanogr., 22, 355-370.

Hussey, N., MacNeil, M., McMeans, B., Olin, J., Dudley, S., Cliff, G., et al. (2014). Rescaling the trophic structure of marine food webs. Ecol. Lett., 17, 239-250.

Iken, K., Bluhm, B. \& Dunton, K. (2010). Benthic food-web structure under differing water mass properties in the southern Chukchi Sea. Deep. Res. Part II Top. Stud. Oceanogr., 57, $71-85$.

Johannesson, O.M., Bengtsson, L., Miles, M.W., Kuzmina, S.I., Semenov, V.A., Alekseev, G. V, et al. (2004). Arctic climate change: observed and modelled temperature and sea-ice variability. Tellus, 56, 328-341.

Johnson, S.W., Thedinga, J.F., Neff, A.D. \& Hoffman, C.A. (2010). Fish Fauna in Nearshore Waters of a Barrier Island in the Western Beaufort Sea, Alaska.

Jones, N. (2012). Oil exploration ramps up in US Arctic.

Laurel, B.J., Spencer, M., Iseri, P. \& Copeman, L.A. (2016). Temperature-dependent growth and behavior of juvenile Arctic cod (Boreogadus saida) and co-occurring North Pacific gadids. Polar Biol., 39, 1127-1135.

Layman, C.A., Arrington, D.A., Montaña, C.G., Post, D.M. \& Monta, G. (2007). Can Stable Isotope Ratios Provide for Community-Wide Measures of Trophic Structure. Ecology, 88, 42-48.

Logan, J., Haas, H., Deegan, L. \& Gaines, E. (2006). Turnover rates of nitrogen stable isotopes in the salt marsh mummichog, Fundulus heteroclitus, following a laboratory diet switch. Oecologia, 147, 391-5.

Logan, J.M., Jardine, T.D., Miller, T.J., Bunn, S.E., Cunjak, R.A. \& Lutcavage, M.E. (2008). Lipid corrections in carbon and nitrogen stable isotope analyses: Comparison of chemical extraction and modelling methods. J. Anim. Ecol., 77, 838-846. 
McConnaughey, T. \& McRoy, C.P. (1979). Food-Web structure and the fractionation of carbon isotopes in the Bering Sea. Mar. Biol., 53, 257-262.

McMahon, C.R., Bester, M.N., Hindell, M. A., Brook, B.W. \& Bradshaw, C.J. A. (2009). Shifting trends: Detecting environmentally mediated regulation in long-lived marine vertebrates using time-series data. Oecologia, 159, 69-82.

McTigue, N.D. \& Dunton, K.H. (2014). Trophodynamics and organic matter assimilation pathways in the northeast Chukchi Sea, Alaska. Deep Sea Res. Part II Top. Stud. Oceanogr., 102, 84-96.

Moline, M. A, Karnovsky, N.J., Brown, Z., Divoky, G.J., Frazer, T.K., Jacoby, C.A., et al. (2008). High latitude changes in ice dynamics and their impact on polar marine ecosystems. Ann. N. Y. Acad. Sci., 1134, 267-319.

Norcross, B.L., Aspens, S.J., Bell, L.E., Bluhm, B.A., Dissen, J.N., Edenfield, L.E., et al. (2012). US-Canada transboundary fish and lower trophic communities: Abundance, distribution, habitat and community analysis.

Phillips, D.L., Inger, R., Bearhop, S., Jackson, A.L., Moore, J.W., Parnell, A.C., et al. (2014). Best practices for use of stable isotope mixing models in food-web studies. NRC Res. Press, 835, 823-835.

Sainte-Marie, B. (1984). Morphological adaptations for carrion feeding in four species of littoral or circalittoral lysianassid amphipods. Can. J. Zool., 62.

Solomon, C.T., Carpenter, S.R., Clayton, M.K., Jonathan, J., Coloso, J.J., Pace, M.L., et al. (2014). mixing model use in lakes: and pelagic resource terrestrial, model results from a three-isotope Bayesian mixing model. Ecology, 92, 1115-1125.

Stasko, A.D., Bluhm, B.A., Michel, C., Archambault, P., Majewski, A., Reist, J.D., et al. (2018). Benthic-pelagic trophic coupling in an Arctic marine food web along vertical water mass and organic matter gradients. Mar. Ecol. Prog. Ser., 594, 1-19.

Strauss, J., Schirrmeister, L., Wetterich, S. \& Mangelsdorf, K. (2011). Old organic matter in Siberian permafrost deposits and it's degradation features, 571-572.

Sweeting, C.J., Polunin, N.V.C. \& Jennings, S. (2006). Effects of chemical lipid extraction and arithmetic lipid correction on stable isotope ratios of fish tissues. Rapid Commun. Mass Spectrom., 20, 595-601.

Vesin, J., Legget, W. \& Able, K. (1981). Feeding ecology of capelin (Mallotus villosus) in the estuary and Western Gulf of St. Lawrance and its multispecies implications. Can. J. Fish. Aquat. Sci., 38, 257-267. 
Welch, H.E., Crawford, R.E. \& Hop, H. (1993). Occurence of Arctic cod (Boreogadus saida) schools and their vulnerability to predation in the Canadian High Arctic. Arctic, 46, 331-339.

Wiens, J. (1989). Spatial scaling in ecology. Society, 3, 385-397.

Vander Zanden, M., Hulshof, M., Ridgway, M. \& Rasmussen, J. (1998). Application of Stable Isotope Techniques to Trophic Studies of Age-0 Smallmouth Bass. Trans. Am. Fish. Soc., 127, 729-739.

Vander Zanden, M. \& Rasmussen, J. (2001). Variation in d $15 \mathrm{~N}$ and d $13 \mathrm{C}$ trophic fractionation: Implications for aquatic food web studies. Limnol. Oceanogr., 46, 20612066. 


\section{Tables}

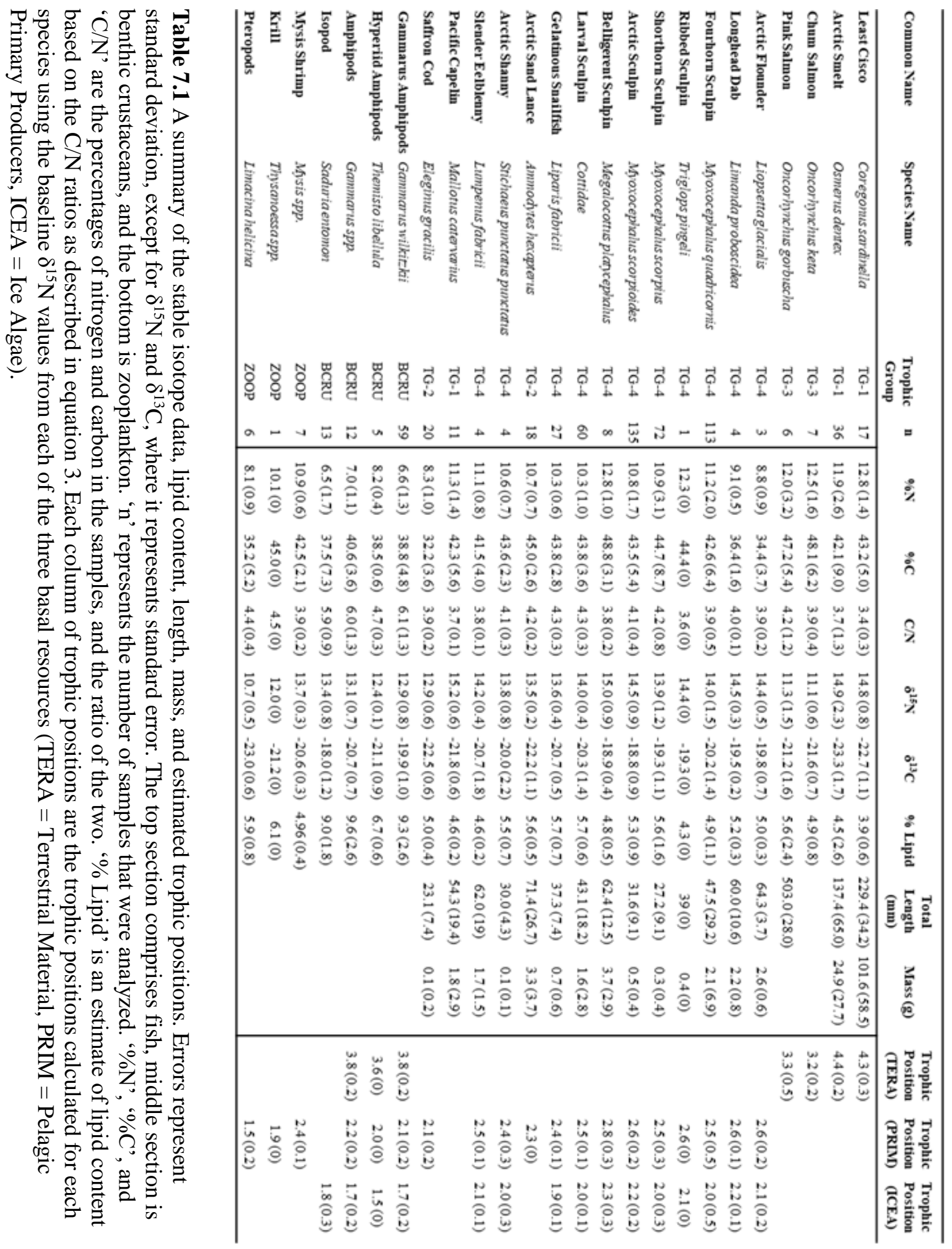


Table 7.2 A summary of isotopic signatures by year for the six species for which samples were available from all three sampling years. Values in parentheses represent standard deviations.

\begin{tabular}{l|ccc|ccc|ccc}
\hline & \multicolumn{3}{|c|}{$\mathbf{2 0 1 3}$} & \multicolumn{3}{c|}{$\mathbf{2 0 1 4}$} & \multicolumn{3}{c}{$\mathbf{2 0 1 5}$} \\
Common Name & $\mathbf{n}$ & $\boldsymbol{\delta}^{\mathbf{1 5}} \mathbf{N}$ & $\boldsymbol{\delta}^{\mathbf{1 3}} \mathbf{C}$ & $\mathbf{n}$ & $\boldsymbol{\delta}^{\mathbf{1 5}} \mathbf{N}$ & $\boldsymbol{\delta}^{\mathbf{1 3}} \mathbf{C}$ & $\mathbf{n}$ & $\boldsymbol{\delta}^{\mathbf{1 5}} \mathbf{N}$ & $\boldsymbol{\delta}^{\mathbf{1 3}} \mathbf{C}$ \\
\hline Arctic Sand Lance & 1 & 13.73 & -17.98 & 10 & 13.43 & -22.43 & 2 & 13.48 & -22.25 \\
& & & & & $(0.06)$ & $(0.14)$ & & $(0.17)$ & $(0.22)$ \\
Arctic Sculpin & 54 & 13.87 & -18.71 & 50 & 15.25 & -18.47 & 21 & 13.98 & -20.11 \\
& & $(0.08)$ & $(0.08)$ & & $(0.08)$ & $(0.12)$ & & $(0.08)$ & $(0.09)$ \\
Arctic Shanny & 2 & 13.82 & -17.88 & 1 & 14.64 & -22.14 & 1 & 12.91 & -22.24 \\
& & $(0.45)$ & $(0.11)$ & & & & & & \\
Fourhorn Sculpin & \multirow{2}{*}{37} & 14.09 & -19.88 & 32 & 13.71 & -20.42 & 31 & 14.2 & -20.39 \\
& & $(0.20)$ & $(0.22)$ & & $(0.33)$ & $(0.27)$ & & $(0.22)$ & $(0.2)$ \\
Pacific Capelin & 2 & 15.88 & -21.41 & 1 & 15.27 & -22.04 & 3 & 14.75 & -21.5 \\
& & $(0.15)$ & $(0.44)$ & & $(0.36)$ & $(0.47)$ & & $(0.45)$ & $(0.36)$ \\
Shorthorn Sculpin & 23 & 13.57 & -18.69 & 7 & 14.95 & -19.09 & 32 & 13.68 & -19.85 \\
& & $(0.28)$ & $(0.21)$ & & $(0.49)$ & $(0.4)$ & & $(0.11)$ & $(0.13)$ \\
\hline
\end{tabular}


Figures

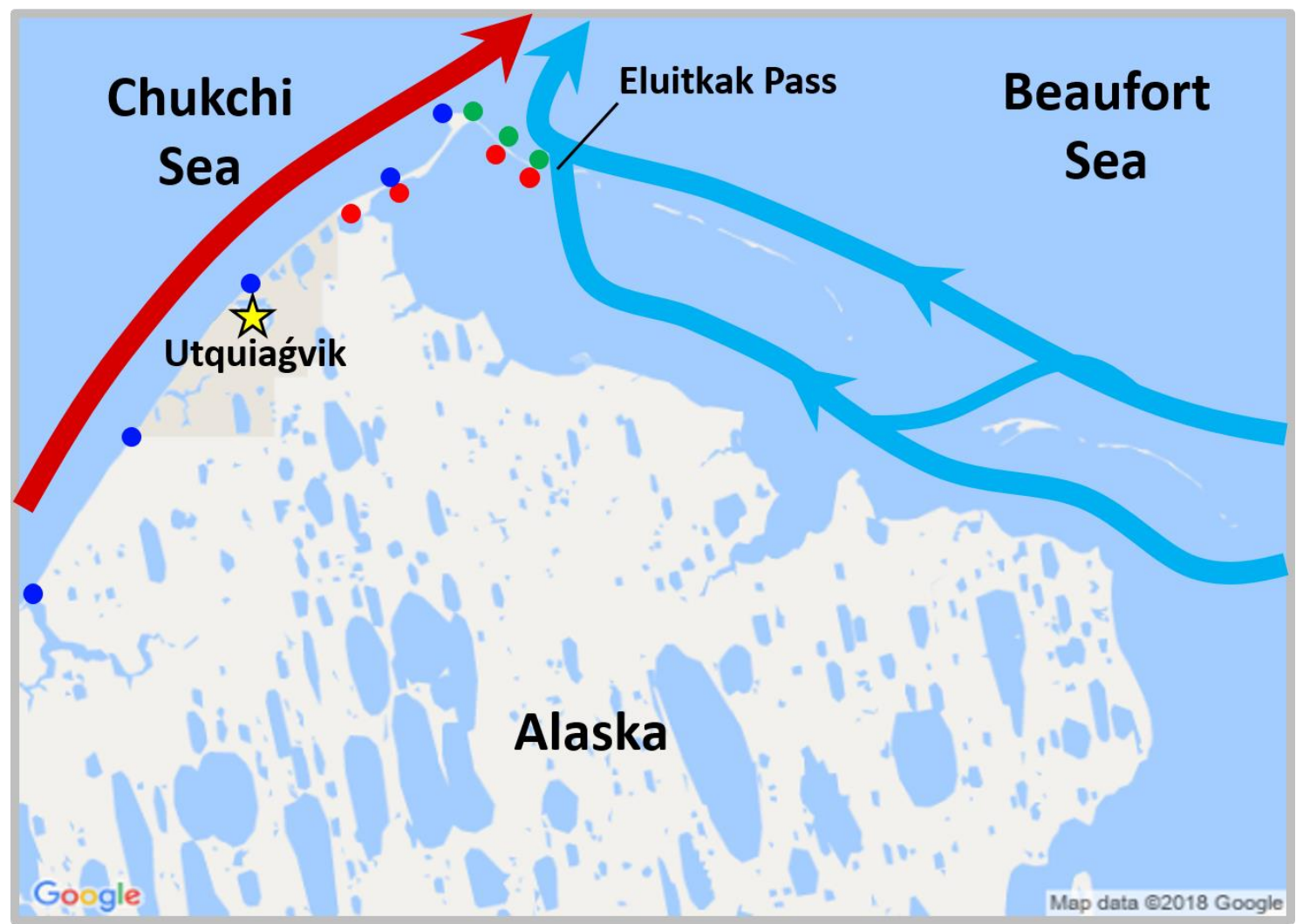

Figure 7.1 A map of the study area and relevant geographic and oceanographic features. Sampling stations are depicted by circles: blue (Chukchi Sea), green (Beaufort Sea), and red (Elson Lagoon). The prevalent flow of the Alaska Coastal Current (ACC) is depicted by red arrows traveling along the Alaskan coast north past Point Barrow through the Barrow Canyon. The prevalent wind driven flow along the Beaufort coast and through the Elson Lagoon out Eluitkak Pass is depicted by blue arrows. 


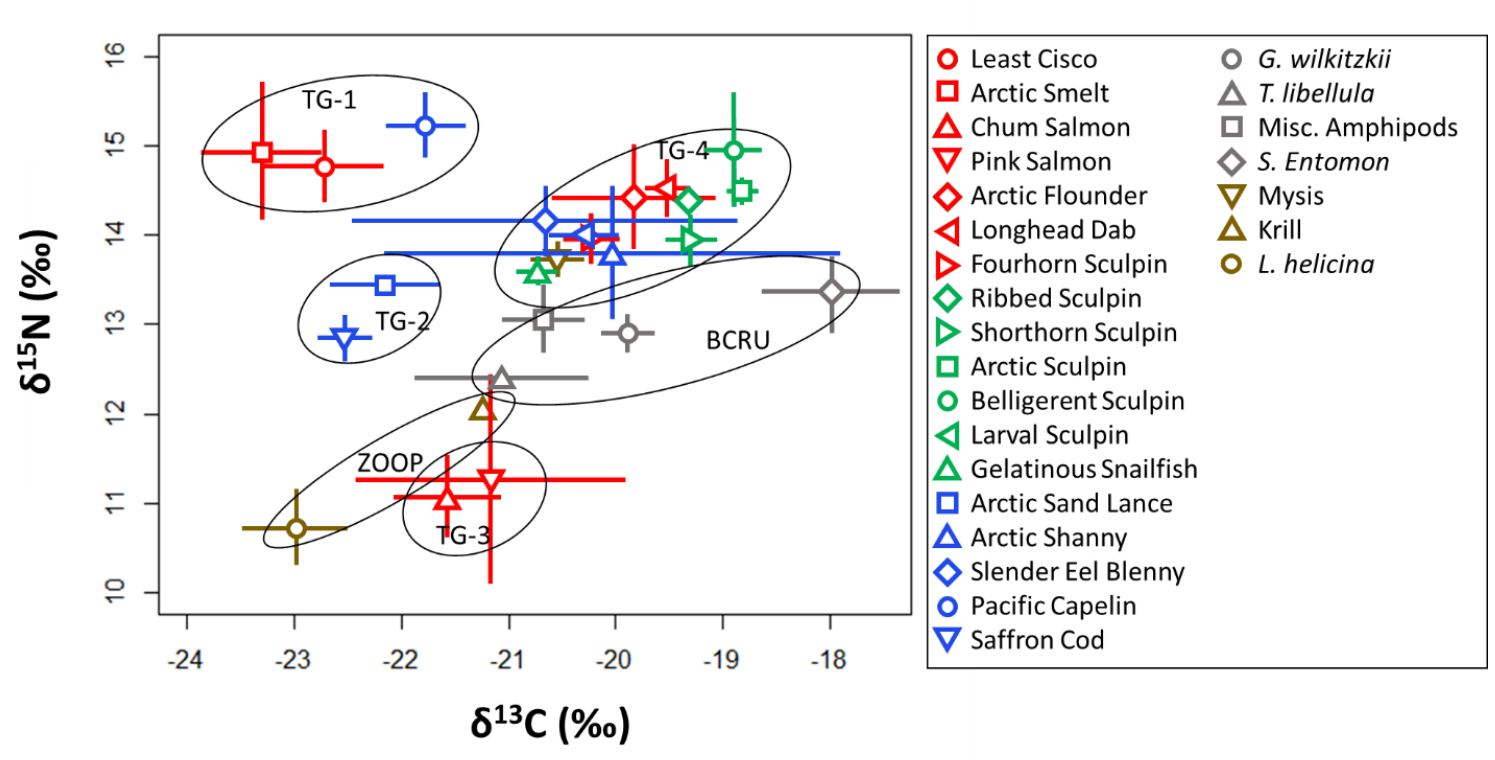

Figure 7.2 The average trophic niche spaces occupied by each species. Error bars represent standard error. Colors are grouped by groups functional species groups identified in Chapter II: Red (anadromous and estuarine fish), green (Arctic cold-water fish), blue (Arctic warm-water fish), gray (benthic crustaceans), brown (zooplankton). Ellipses represent the trophic groups for which niche space was investigated separately. 

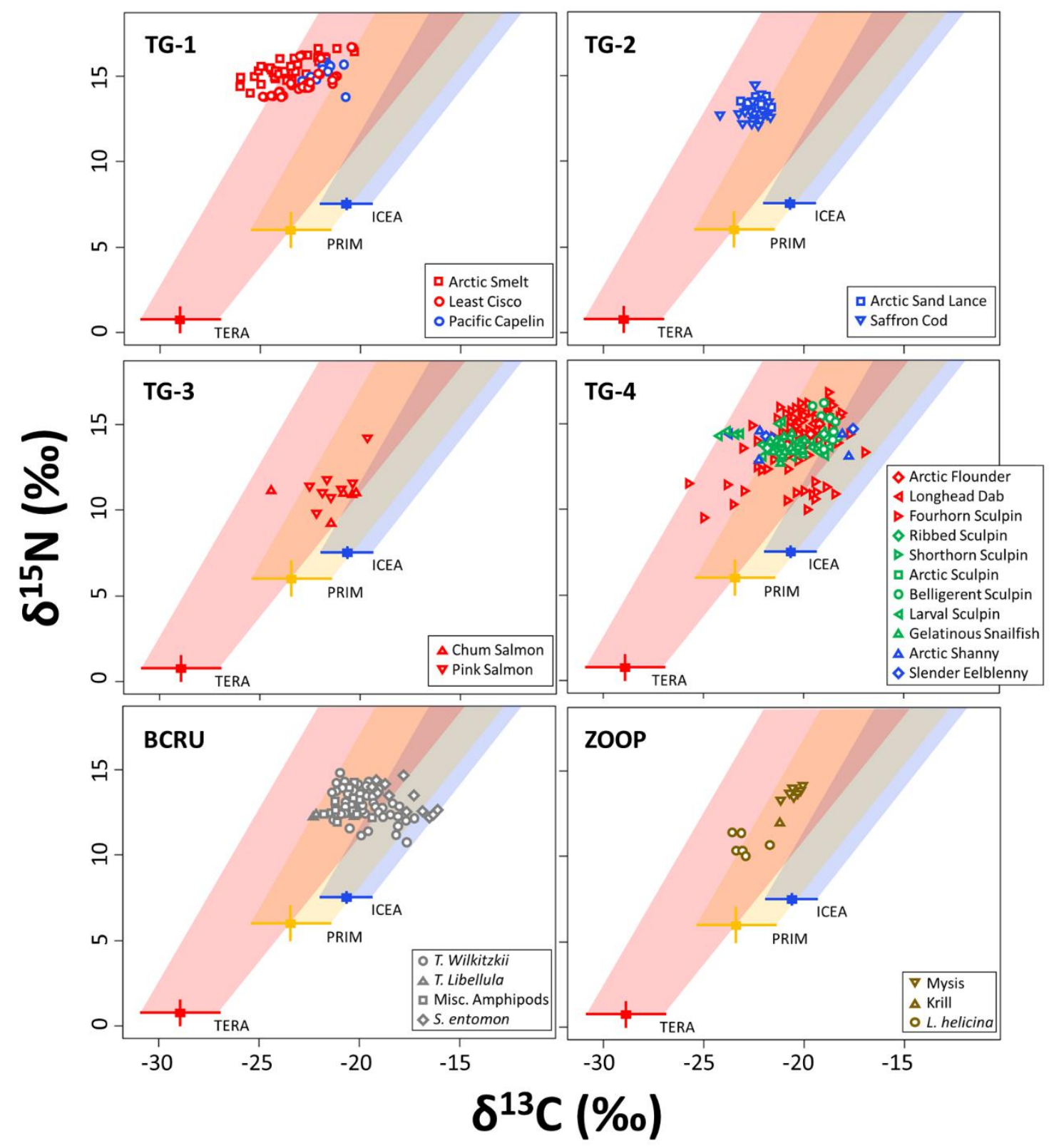

Figure 7.3 Isotope ratios for all individuals in Trophic Group 1-4, BCRU, and ZOOP in $\delta^{13} \mathrm{C}-\delta^{15} \mathrm{~N}$ space in relation to estimated trophic niche space of trophic pathways that depend on Terrestrial Materials (TERA), Pelagic Primary Producers (PRIM), and Ice Algae (ICEA). Data point shape and color match throughout Figures 7.2, 7.3, and 7.5. Color represents functional species groups derived in Chapter II: red (anadromous and estuarine fish), green (Arctic cold-water fish), blue (Arctic warm-water fish), gray (benthic crustaceans), brown (zooplankton). 


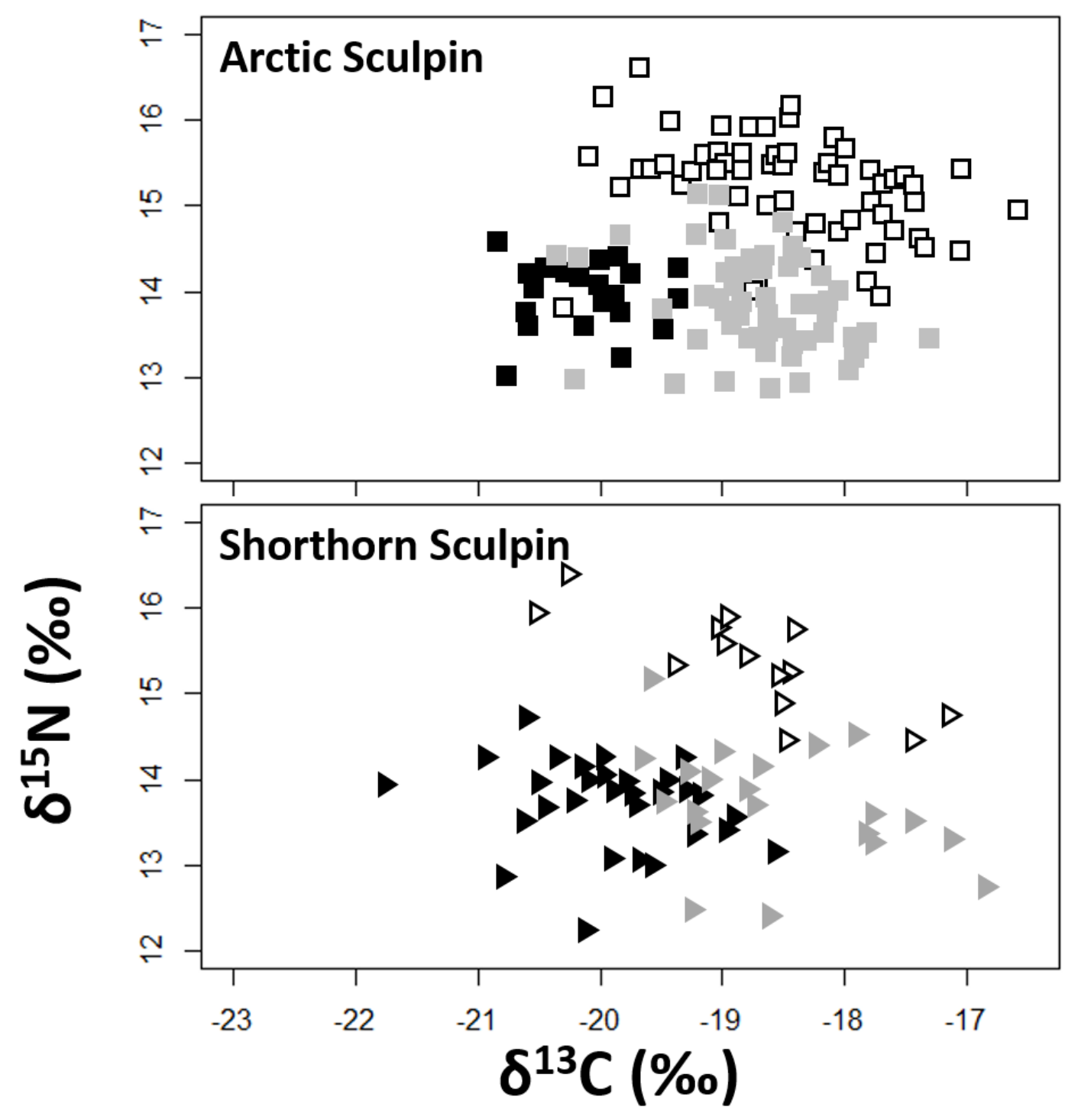

Figure 7.4 Isotope ratios for all individuals in $\delta^{13} \mathrm{C}-\delta^{15} \mathrm{~N}$ of the two species that exhibit significant difference between trophic niche space between 2013, 2014, and 2015 samples. Color represents different sampling years: gray (2013), white (2014), black (2015). 


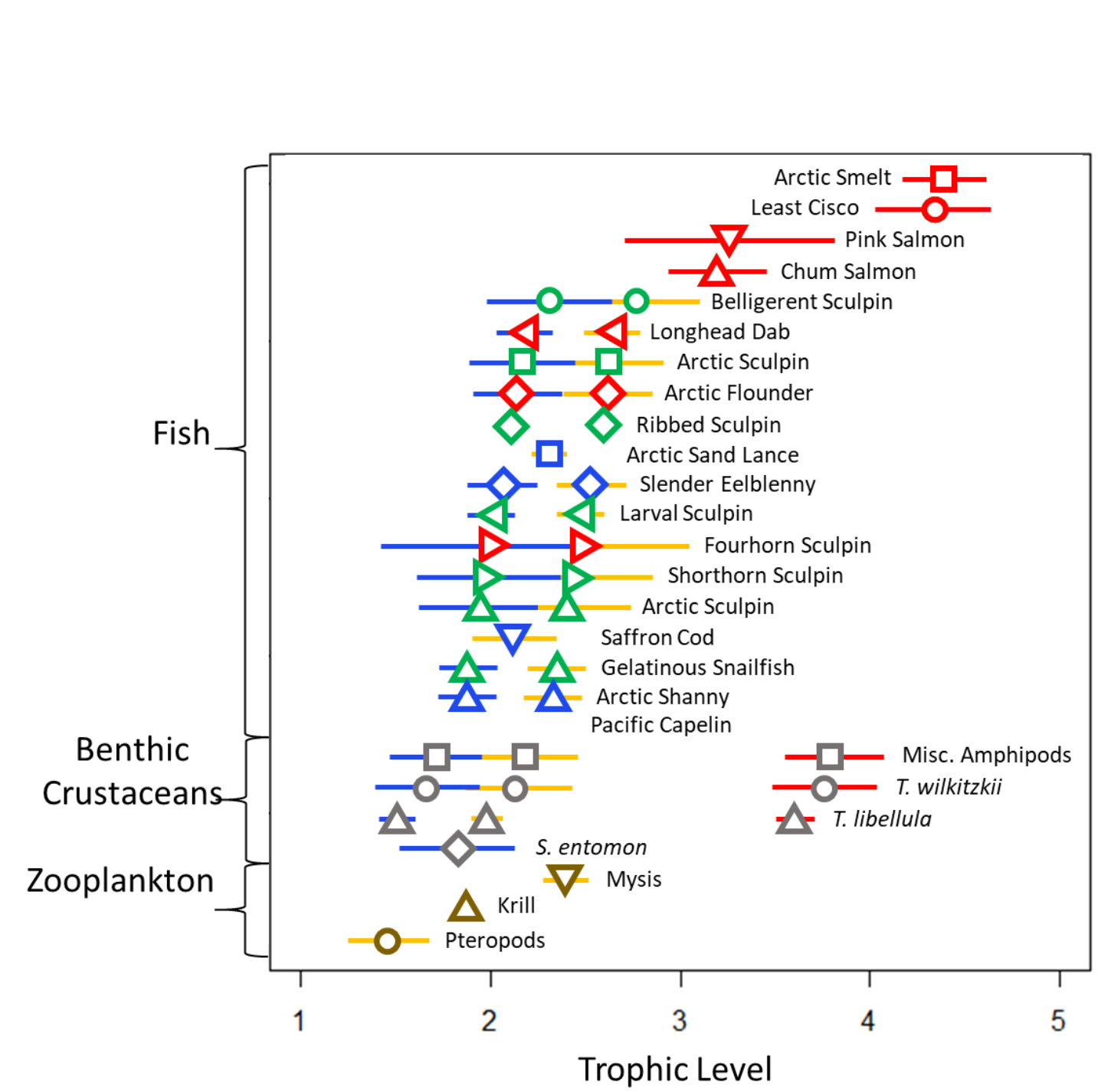

Figure 7.5 A summary of estimated trophic positions for each species. Points represent average trophic position; error bars represent standard deviation. The color of points represents functional species groups derived in Chapter II: red (anadromous and estuarine fish), green (Arctic cold-water fish), blue (Arctic warm-water fish). The colors of the error bars indicate the baseline $\delta^{15} \mathrm{~N}$ values used to estimate the average trophic position that they originate from: red (TERA), yellow (PRIM), blue (ICEA). 
CHAPTER VIII

CONCLUSIONS 
Understanding spatiotemporal patterns in Arctic fish communities is a complex and relatively daunting task as each species may respond to different types of variables or respond differently to the same variables. The majority of fish encountered in the Arctic nearshore are juveniles, and suggests that much like lower-latitude estuaries, Arctic estuaries function as a nursery habitat for young fish (Elliott et al., 1990; Nuraini et al., 2007). Canonical Correspondence Analysis offered insight to the variables that are most important in driving changes in community composition. Using a forward selection method, I identified that salinity, dissolved oxygen, and the easterly component of wind were important environmental drivers of beta diversity. Furthermore, distance in space and time between sampling events were also important drivers, specifically between waterbodies and between years.

The dominant species caught in the Beaufort Sea are species that generally prefer colder conditions (Arctic Sculpin, Belligerent Sculpin, Arctic Cod, Shorthorn Sculpin, Snailfishes; Mecklenburg et al., 2010), whereas the dominant species caught in the Chukchi Sea were warm-water species (Arctic Sand Lance, Pacific Capelin, Arctic Shanny, Saffron Cod, and Tubenose Poachers). Given that most of these fish were post-larval juveniles, these patterns may reflect the area where these fish were advected from. The predominant wind driven flow along the Beaufort coast would advect individuals from the Arctic Ocean, where as the dominant flow of the Alaska Coastal Current (ACC) would advect individuals from the Bering Sea. This pattern supports the idea that warm-water species are being advected from the Bering Sea into the Arctic along the Chukchi coast where they are most abundant. 
Much of the changes in community structure explained by these parameters is also explained by zooplankton abundances and suggests that prey resources play an important role in Arctic nearshore fish communities. Most species increase their abundance along with copepod abundance, and this gradient occurs with increasing proximity to the Elson Lagoon, suggesting that the Elson Lagoon, like other Beaufort Sea lagoons, is highly productive in comparison to surrounding waters. Coupling this with patterns of species increasing in abundance in the nearshore with time after ice break-up may indicate that species move into these nearshore habitats to forage on the abundance of primary producers and zooplankton that follow the onset of open-water conditions (Bluhm and Gradinger, 2008; Gradinger and Bluhm, 2010). Anadromous and lagoon-associated species (Ciscos, Arctic Smelt, and Flatfishes) were most abundant in the Elson Lagoon soon after ice breakup when salinity is decreasing due to rapid ice-melt and increased river discharge into the lagoon (Dunton et al., 2012; Peterson et al., 2002). In addition, warm-water species were most abundant later in the season, and are also more abundant in warm years, this may suggest that these anadromous, lagoon associated, and warm-water species are excluded from these Arctic nearshore habitats with elevated levels of production until water temperatures or salinities are more tolerable.

The shift in production sources following the onset of open-water season is supported by tissue-dependent stable isotopes from five species of sculpin in the Arctic Nearshore. Sculpin generally have high site-fidelity, are generalists, and are abundant in the nearshore, and thus isotope ratios in their tissues represent the prey resources that are available in the habitat from which they were collected (Gray et al., 2017b, 2004). Based on the isotope experiment on Arctic Sculpin (Chapter III), the isotopic difference between 
liver and muscle tissues of sculpins represents food ingested for 58 days and 122 days before collection. In the case of the nearshore surrounding Point Barrow, all five species of sculpins collected in the first 6 weeks of open-water season exhibited a significant enrichment of $\delta^{13} \mathrm{C}$ and $\delta^{15} \mathrm{~N}$ from muscle to liver tissues indicating that the available basal resources in these habitats shifted from ice algal production to pelagic primary production during the shift from ice-covered to open-water conditions (Dunton et al., 2006b; Hobson and Welch, 1992).

Shifts in $\delta^{13} \mathrm{C}$ and $\delta^{15} \mathrm{~N}$ were also present in Pacific Capelin from Alaskan coastal waters along a latitudinal gradient extending from the Bering Sea to Point Barrow, AK. These fish were sampled in surface trawls within the Alaska Coastal Current, and their isotopic signatures indicate that the food webs along the Alaska coast are dependent on different basal resources, where $\delta^{13} \mathrm{C}$ became more depleted where discharge into the ACC from major rivers (Kvichak, Nushagak, Kuskokwim and Yukon Rivers) was expected to increase indicating a shift to dependence on terrestrial resources (Benke and Cushing, 2006). Isotopes in Pacific Capelin tissues also showed enrichment in $\delta^{15} \mathrm{~N}$ values, indicative of increased vertical trophic structure (Layman et al., 2007). This increased trophic structure was corroborated with diet information that suggested that Pacific Capelin were feeding on higher trophic level prey items where these terrestrial resources were present. Food webs with more trophic levels require an increase in biomass at the basal resource level (Layman et al., 2007), again supporting that estuaries in the Arctic are highly productive like analogous lower-latitude habitats.

The Arctic has a diverse prey base for juvenile fish to feed on, and prey dependence differs depending on environmental conditions. Therefore, it is likely that species in Arctic 
habitats occupy different trophic niche spaces to take advantage of the prey resources that they favor. Analysis of $\delta^{13} \mathrm{C}-\delta^{15} \mathrm{~N}$ signatures of nearshore fish species indicated that these communities are dependent on either terrestrial resources, pelagic primary producers, ice algae, or a combination of two or all three (Dunton et al., 2006b; Hobson and Welch, 1992). Some niche spaces were occupied by only a few species, suggesting less competition for resources (Layman et al., 2007), however the majority of species were dependent on pelagic primary producers. This could either mean that there exists high competition for these resources, or that these resources are highly abundant in the Arctic summer making it possible for many species to take advantage. Given Bluhm and Gradinger's (2008) prediction for increased pelagic primary production as warming continues, and the evidence provided that a shift to dependence on pelagic primary producers occurs following ice break-up, it is likely that the latter is the case. However, several of the warmwater species occupy the same trophic niche space and depend on the same basal resource as cold-water species; and if numbers of warm-water species continue to increase in the Arctic these resources may be in higher demand thus increasing competition for the coldwater species. Furthermore, the wide $\delta^{13} \mathrm{C}$ ranges of warm-water species that share the same trophic niche space as cold-water species indicates that they may be more adaptable, and thus will fare better as trophic structures change. On a more positive note, the warmwater species that are often found in high numbers (Pacific Capelin, Arctic Sand Lance, and Slender Eelblennies, and Saffron Cod) are high quality prey items and may offer a new and plentiful prey base for Arctic piscivores that are struggling due to the loss of sea ice and other climate change related environmental changes. 
The evidence provided in this dissertation supports Arctic nearshore habitats are an important nursery and foraging ground for juvenile fish much like they are in lowerlatitudes. Abundance of species in response to environmental conditions indicates that warm-water species will continue to become more abundant as the current Arctic warming trend continues. This restructuring of fish communities and food webs may lead to higher competition for available resources, but predictions of increasing fish biomass in the Arctic may provide enough resources for both warm-water and cold-water fish to coexist causing the prey base for higher trophic level piscivores to become more diverse and abundant.

\section{References}

Benke, A., Cushing, C., 2006. Rivers of North America, First Edit. ed. Elsevier Academic Press, Burlington, MA.

Bluhm, B., Gradinger, R., 2008. Regional variability in food availability for Arctic marine mammals. Ecol. Appl. 18, S77-S96. https://doi.org/http://dx.doi.org/10.1890/06-0562.1

Dunton, K.H., Schonberg, S. V., Cooper, L.W., 2012. Food web structure of the Alaskan nearshore shelf and estuarine lagoons of the Beaufort Sea. Estuaries and Coasts 35, 416435. https://doi.org/10.1007/s12237-012-9475-1

Dunton, K.H., Weingartner, T., Carmack, E.C., 2006. The nearshore western Beaufort Sea ecosystem: Circulation and importance of terrestrial carbon in arctic coastal food webs. Prog. Oceanogr. 71, 362-378. https://doi.org/10.1016/j.pocean.2006.09.011

Elliott, M., O'Reilly, M.G., Taylor, C.J.L., 1990. The forth estuary: a nursery and overwintering area for North Sea fishes. Hydrobiologia 195, 89-103. https://doi.org/10.1007/BF00026816

Gradinger, R., Bluhm, B., 2010. Timing of ice algal grazing by the Arctic nearshore benthic amphipod Onisimus litoralis. Arctic 63, 355-358.

Gray, B.P., Norcross, B.L., Beaudreau, A.H., Blanchard, A.L., Seitz, A.C., 2017. Food habits of Arctic staghorn sculpin (Gymnocanthus tricuspis) and shorthorn sculpin (Myoxocephalus scorpius) in the northeastern Chukchi and western Beaufort Seas. Deep. Res. Part II Top. Stud. Oceanogr. 135, 111-123. https://doi.org/10.1016/j.dsr2.2016.05.013 
Gray, M.A., Cunjak, R.A., Munkittrick, K.R., 2004. Site fidelity of slimy sculpin (Cottus cognatus): Insights from stable carbon and nitrogen analysis. Can. J. Fish. Aquat. Sci. 61, 1717-1722. https://doi.org/10.1139/f04-108

Hobson, K., Welch, H., 1992. Determination of trophic relationships within a high arctic marine food web using Delta-13 C and Delta-15 N analysis. Mar. Ecol. Prog. Ser. 84, 918.

Layman, C.A., Arrington, D.A., Montaña, C.G., Post, D.M., Monta, G., 2007. Can Stable Isotope Ratios Provide for Community-Wide Measures of Trophic Structure. Ecology 88, $42-48$.

Mecklenburg, C.W., Møller, P.R., Steinke, D., 2010. Biodiversity of Arctic marine fishes: taxonomy and zoogeography. Mar. Biodivers. 41, 109-140. https://doi.org/10.1007/s12526-010-0070-z

Nuraini, S., Carballo, E.C., Van Densen, W.L.T., Machiels, M.A.M., Lindeboom, H.J., Nagelkerke, L.A.J., 2007. Utilization of seagrass habitats by juvenile groupers and snappers in Banten Bay, Banten Province, Indonesia. Hydrobiologia 591, 85-98. https://doi.org/10.1007/s10750-007-0786-3

Peterson, B.J., Holmes, R.M., Mcclelland, J.W., Vo, C.J., Lammers, R.B., Shiklomanov, A.I., Shiklomanov, I.A., Rahmstorf, S., 2002. Increasing River Discharge to the Arctic Ocean. Science (80). 298, 2171-2173. https://doi.org/10.1126/science.1077445 
VITA

\section{MARK B. BARTON}

Born, Baton Rouge, Louisiana

2009-2012

B.S., Marine Science

Florida Gulf Coast University

Fort Myers, Florida

$2012-2018$

Doctoral Candidate

Florida International University

Miami, Florida

\section{PUBLICATIONS AND PRESENTATIONS}

Barton MB, KM Boswell, JJ Vollenweider, RA Heintz, JR Moran. Erratum to: Latitudinal dependence of body condition, growth rate, and stable isotopes of juvenile capelin (Mallotus villosus) in the Bering and Chukchi Seas. Polar Biology; April 2017. doi:10.1007/s00300-016-2041-8

Catano LB, MB Barton, KM Boswell, DE Burkepile. Predator identity and time of day interact to shape the risk-reward trade-off for herbivorous coral reef fishes. Oecologia December 2016. 10.1007/s00442-016-3794-z

Barton MB, KM Boswell, JJ Vollenweider, RA Heintz, JR Moran. Latitudinal dependence of body condition, growth rate, and stable isotopes of juvenile capelin (Mallotus villosus) in the Bering and Chukchi Seas. Polar Biology October 2016. doi:10.1007/s00300-0162041-8

Barton MB, KM Boswell, S Litvin, RA Heintz, JJ Vollenweider, BL Norcross. Assimilation of carbon and nitrogen isotopes in a common Arctic nearshore fish. Alaska Marine Science Symposium, Anchorage, AK. Jan 22, 2018.

Nodal A, Barton MB, KM Boswell, S Litvin, RA Heintz, JJ Vollenweider, BL Norcross, L Sousa. A first look at weekly variability in relative abundance of plankton in Arctic nearshore habitats near Barrow, AK. Alaska Marine Science Symposium, Anchorage, AK. Jan 22, 2018.

Barton MB, KM Boswell, S Litvin, RA Heintz, JJ Vollenweider, BL Norcross. Tissue turnover rates and trophic enrichment of carbon and nitrogen isotopes in a common Arctic nearshore fish. ESSAS Open Science Meeting, Tromso, Norway. June 14, 2017.

Barton MB, KM Boswell, N Lemoine, RA Heintz, JJ Vollenweider, LD Sousa. Environmental drivers of spatio-temporal changes in Arctic nearshore fish communities. Alaska Marine Science Symposium, Anchorage, AK. Jan 23, 2017. 
Barton MB, KM Boswell, JJ Vollenweider, RA Heintz, B Norcross. Interconnectivity and structure in Arctic nearshore food webs around Barrow, AK. Alaska Marine Science Symposium, Anchorage, AK. Jan 23, 2017.

Barton MB, KM Boswell, JJ Vollenweider, RA Heintz, JR Moran. Latitudinal dependence of body condition, growth rate, and stable isotopes of juvenile capelin (Mallotus villosus) in the Bering and Chukchi Seas. Alaska Marine Science Symposium, Anchorage, AK. Jan $23,2017$.

Heintz RA, JJ Vollenweider, KM Boswell, C Li, B Norcross, MB Barton, A Frothingham, B Gray. Arctic coastal ecosystems: Evaluating the functional role and connectivity of lagoon and nearshore habitats. Alaska Marine Science Symposium, Anchorage, AK. Jan $27,2017$.

KA Abel, MB Barton, KM Boswell. Composition of suspended particulate matter in Arctic nearshore habitats. Alaska Marine Science Symposium, Anchorage, AK. Jan 27, 2017.

Barton MB, KM Boswell, N Lemoine, RA Heintz, JJ Vollenweider, LD Sousa. Partitioning variance in environmental drivers of Arctic nearshore fish community composition. Alaska Marine Science Symposium, Anchorage, AK. Jan 20, 2016. Ocean Sciences Meeting, New Orleans, LA. Feb 23, 2016.

Barton MB, KM Boswell, RA Heintz, JJ Vollenweider. Arctic sculpin (Myoxocephalus scorpioides): A biomonitor for environmental change. Alaska Marine Science Symposium, Anchorage, AK. Jan 20, 2016. FIU Biology Research Symposium, North Miami, FL, Feb 2016. Ocean Sciences Meeting, New Orleans, LA. Feb 23, 2016.

Kleese MC, MB Barton, KM Boswell, G Divoky. Identifying timing and magnitude of dietary shifts in black guillemots (Cephus grylles) using stable isotope analysis on flight feathers: A proof of concept. Ocean Sciences Meeting, New Orleans, LA. Feb 23, 2016.

George S, MB Barton, S Mosher, R Heintz, J Vollenweider, L Sousa, A Zenone. Growth rates of abundant Arctic nearshore fish species with respect to environmental conditions. Alaska Marine Science Symposium, Anchorage, AK. Jan 20, 2016.

Brownstein A, MB Barton, KM Boswell, J Straley, J Moran. Stable isotope analysis of humpback whales (Megaptera noveangliae) to confirm diet during winter foraging. Alaska Marine Science Symposium, Anchorage, AK. Jan 20, 2016. FIU Biology Research Symposium, North Miami, FL, Feb 2016.

Barton MB, KM Boswell, RA Heintz, JR Moran, JJ Vollenweider. Temporal scales of Arctic nearshore fish community restructuring. Alaska Marine Science Symposium, Anchorage, AK. Jan 19, 2015. FIU Biology Research Symposium, North Miami, FL. Jan 31,2015 